\title{
Public health aspects of bacterial resistance in food animals
}

Citation for published version (APA):

van den Bogaard, A. E. J. M. (2000). Public health aspects of bacterial resistance in food animals. [Doctoral Thesis, Maastricht University]. Datawyse / Universitaire Pers Maastricht.

https://doi.org/10.26481/dis.20001222ab

Document status and date:

Published: 01/01/2000

DOI:

10.26481/dis.20001222ab

Document Version:

Publisher's PDF, also known as Version of record

\section{Please check the document version of this publication:}

- A submitted manuscript is the version of the article upon submission and before peer-review. There can be important differences between the submitted version and the official published version of record.

People interested in the research are advised to contact the author for the final version of the publication, or visit the DOI to the publisher's website.

- The final author version and the galley proof are versions of the publication after peer review.

- The final published version features the final layout of the paper including the volume, issue and page numbers.

Link to publication

\footnotetext{
General rights rights.

- You may freely distribute the URL identifying the publication in the public portal. please follow below link for the End User Agreement:

www.umlib.nl/taverne-license

Take down policy

If you believe that this document breaches copyright please contact us at:

repository@maastrichtuniversity.nl

providing details and we will investigate your claim.
}

Copyright and moral rights for the publications made accessible in the public portal are retained by the authors and/or other copyright owners and it is a condition of accessing publications that users recognise and abide by the legal requirements associated with these

- Users may download and print one copy of any publication from the public portal for the purpose of private study or research.

- You may not further distribute the material or use it for any profit-making activity or commercial gain

If the publication is distributed under the terms of Article $25 \mathrm{fa}$ of the Dutch Copyright Act, indicated by the "Taverne" license above, 
Public health aspects of bacterial resistance in food animals

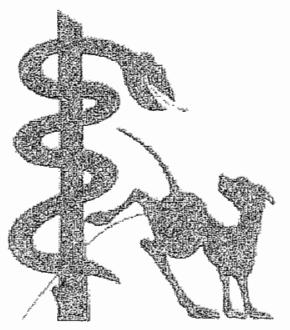


Vormgeving en druk:

Datawyse | Universitaire Pers Maastricht

Ontwerp omslag:

Chris Voskamp

ISBN 9052782938

Q2000, A.E.J.M. van den Bogaard. All rights reserved.

All chapters previously published are reprinted with the permission of the original copyright holders.

The studies presented in this thesis were performed with the financial support of the University Maastricht, The Dutch Veterinary Health Inspectorate. The Dutch Ministry for Agriculture, Nature Management and Fisheries, The Dutch Prevention Fund and Intervel-International. 


\section{Public health aspects of bacterial resistance in food animals}

Volksgezondheidsaspecten van bacteriële resistentie bij nutsdieren

\section{PROEFSCHRIFT}

ter verkrijging van de graad van doctor aan de Universiteit Maastricht,

op gezag van de Rector Magnificus,

Prof. dr. A.C. Nieuwenhuijzen Kruseman, volgens het besluit van het College van Decanen, in het openbaar te verdedigen op vrijdag 22 december 2000 om 16.00 uur door

Antonius Eugenius Johannes Maria van den Bogaard

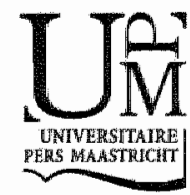




\section{Promotores}

Prof. dr. C.A. Bruggeman

Prof. dr. A. Pijpers (Universiteit Utrecht)

\section{Co-promotor}

Dr. E.E. Stobberingh

\section{Beoordelingscommissie}

Prof. dr. J.F.M. Smits (voorzitter)

Prof. dr. J.E. Degener (Rijksuniversiteit Groningen)

Prof. dr. F. van Knapen (Unversiteit Utrecht)

Prof. dr. P.G. Knipschild

Prof. dr. J.A. Knottnerus

Prof. dr. K.M.L. Leunissen 
"Vanitas est praesentem vitam solum attendere, et quae futura sunt non praevidere"

"IJdelheid is alleen acht slaan op het beden en niet aan de toekomst denken"

Thomas à Kempis, De imitatione Christi 1.1.4 



\section{Contents}

Introduction

Outline of the thesis

Chapter I Antibiotic usage in animals: impact on bacterial resistance and public health (a review of the literature). A.E. van den Bogaard and E.E. Stobberingh. Drugs 1999; 58: $589-607$.

Chapter II A veterinary antibiotic policy: a personal view on the perspectives in the Netherlands. A.E. van den Bogaard. Veterinary Microbiology 1993; 35: 303-312.

Chapter III Antimicrobial resistance in pig faecal samples from five abattoirs in the Netherlands and from Sweden.

Adapted from:

The prevalence of antimicrobial resistance of indicator bacteria: Escherichia coli and enterococcii, in pig faecal samples collected at 5 Dutch abattoirs. A.E. van den Bogaard, N. London and E. E. Stobberingh. Report Dutch Ministry of Agriculture, Nature Management and Fisheries, August 1998.

and

Antimicrobial resistance in pig faecal samples from the Netherlands (five abattoirs) and Sweden. A.E. van den Bogaard, N. London and $\mathbb{E}$.E. Stobberingh Journal of Antimicrobial Chemotherapy 2000; 45: 663 671 .

Chapter IV Vancomycin resistant enterococci in turkeys and farmers. A.E. van den Bogaard and E.E. Srobberingh. The New England Journal of Medicine 1997; 337: $1558-1559$.

and

Enterococci with glycopeptide resistance in turkeys, turkey farmers, turkey slaughterers, and (sub)urban residents in the south of the Netherlands: evidence for transmission of vancomycin resistance from animals to humans? E.E. Stobberingh, A.E. van den Bogaard, N. London, C. Driessen, J. Top and R. Willems. Antimicrobial Agents and Chemorherapy 1999; 43: 2215-2211.

Chapter $V$ Faecal carriage of antibiotic resistant enterococci by poultry, poultry farmers and poultry slaughterers in the Netherlands. A.E. van den Bogaard, R. Willems, N. London, J. Top and E.E. Stobberingh (submitred for publication). 
Chapter VI Antibiotic Resistance of faecal Escherichia coli from poultry, poultry farmers and poultry slaughterers in the Netherlands. A.E. van den Bogaard, N. London, C. Driessen and E.E. Stobberingh (submitted for publication).

Chapter VII The effect of flavophospholipol on the prevalence and degree of resistance of the endogenous flora, using faecal Escherichia coli and enterococci as indicator microorganisms, of fattening pigs under farm conditions. A.E. van den Bogaard, M. Hazen, M. Hoyer, P. Oostenbach and E.E. Stobberingh (submitted for publication).

Chapter VIII The effect of banning avoparcin on VRE carriage in the Netherlands. A.E. van den Bogaard, N. Bruinsma and E.E. Stobberingh. Joumal of Antimicrobial Chemotherapy 2000, 46: 146-148.

Discussion

Summary

Samenvatting

Dankwoord

Curriculum vitae 


\title{
Introduction
}

\author{
"Predicting things is hard, especially about the future" \\ attributed to Yogi Berra
}

Over the last 60 years, antibiorics have largely changed the prognosis of many bacterial diseases. Their success originates in the combination of their high antimicrobial activity, low toxicity for the host and the ease with which they can be administered. This explains the huge quantities that are used for therapy and control of bacterial diseases in humans and animals, for growth promotion in animal husbandry, for crop protection in agriculture and even for conservation of food and wood $^{20}$. This high efficacy and low toxicity, however, might also have provoked lavish use and even abuse. These life-saving drugs have been and are still being used with unrestrained enthusiasm far surpassing the needs of the management and control of bacterial infections and often only for mere economic reasons. The other side of the coin is that resistance is an inevitable sequel of antibiotic use, which endangers the efficacy of these drugs. Immediately after the introduction of the furst antibiotics emergence of resistance has been described ${ }^{1,18}$, but, because of the euphoria and the regular introduction of new drugs at that time, this warning was neglected. In recent years, however, antibiotic resistance has been increasing at an alarming rate world-wide. Some authorities are referring to an approaching "post-antimicrobial era" in which bacterial infections will again be a common cause of death like before the introduction of antibiotics in clinical medicine ${ }^{4}$.

Are things really so bad? At present, no. Indeed sixcy years of antibiotic usage have provided an unfortunate example of a massive experiment in microbial evolution under intense selection. The bacteria found in many hospitals today are very different from those of the pre-antibiotic era, as increasingly antibiotic resistant strains of the perennially important pathogens have replaced their antibiotic-susceptible forebears ${ }^{21}$.
However, despite the increased resistance in bacteria all over the world, most infections requiring antimicrobial therapy remain amenable to the common antibiotics that have become the mainstay of the formularies for treatment of bacterial infections in humans and animals. Indeed we have now in some countries reached the unacceptable situation that many hospital isolates of Gram-negative enteric bacteria, staphylococci and enterococci are now resistant to most, formerly very effective, antibiotics ${ }^{2}$. This hampers empirical therapy, which causes therapy failures resulting in increased morbidity and even mortality. In addirion it requires, apart from necessary extra laboratory tests, regular use of, always more expensive and often more toxic new antibacterial agents. Similar problems with anvibiotic resistance are increasingly found with many of the communicy-acquired parhogens 7,24 and with bacteria pathogenic for animals $23,29,37$. Until recently, such new antibiotics have always appeared just in the nick of time, before resistance problems got out of hand. However, now the increasingly rapid pace at which bacteria develop or acquire new drug resistance profiles seems to outpace the rate at which the pharmaceutical industry is able to develop and market new antibiotics. In the near future few really new antibiotics, that are noc analogues of existing drugs, might be expected to become available for clinical use.

With any new antibiotic becoming available it is not a question of whether resistance to the new drug will emerge (it will!), but how fast and how exrensive. Moreover newly developed antibiotics will be mainly used against multiple resistant parhogens. This practise will virtually ensure that eventually resistance will appear in the currently multiple resistant species. Also other new strategies for infection intervention which might arise from the rapidly increasing knowledge of 
bacterial genomics are not likely to become available to us fast ${ }^{3}$.

Despite the massive usage of antibiotics the microbial ecosystems seem not to have been much affected, at least quantitatively. Bacteria are still present in high numbers in the human and animal environment. For instance, the intestinal tract of humans and animals are still populated by huge numbers of bacteria - roughly ten times more bacterial cells than the eukaryoric cells of which the body of the host consists i.e. $10^{12}$ bacteria and $10^{11}$ body cells per $\mathrm{kg}$ bodyweight - just as it was before the introduction of antibiotics into clinical medicine ${ }^{\Perp}$. Resistance, however, is very common among the bacteria that populate the intestinal tract of humans and animals living today and, although historical comparisons are missing, it is very likely that the endogenous flora is now more resistant to antibiotics than previously. Results from studies of bacteria collections from before the introduction of antibiotics 8,15 and in populations of humans and animals, who had not been exposed to modern medical and veterinary practices 25 seem to confirm this hypothesis. Also nowadays large differences in the prevalence and degree of resistance berween human and animal populations with a high respectively low antibiotic usage are observed. The intestinal flora of populations with a high antibiotic consumption harbours significantly more resistant bacteria than that of populations exposed to less antibiotics 19. 39. It has been shown that these resistant bacteria in the intestinal flora of man and other animals form a reservoir of resistance genes for pathogenic bacteria ${ }^{19}$. From this point of view the prevalence of resistance in pathogenic bacteria could be considered as only the top of the resistance iceberg.

\section{ANTIMICROBIAL RESISTANCE}

Antimicrobial resistance in bacteria may emerge by several pathways. A bacrerium of a normally susceptible species might become resistant by mutation or acquisition of new genes.

\section{Genetic mutations}

Changes in only a few base pairs causing substirution of one or a few amino-acids in a crucial target (enzyme, cell structure or function, or the cell wall) can affect chromosomal structural or control genes leading to new resistant strains, that might be able to inactivate a whole class of antibiotics, such as the penicillins. Subtle mutations in an existing resistance gene can have major effects on an organisms resistance profile. So the change of a single amino-acid in the protein sequence of the TEM or SHV $\beta$-lactamases can extend their spectrum of activity from mainly inactivation of aminopenicillins to almost all existing $\beta$-lactam antibiotics $^{14,16,35}$.

\section{Acquisition of genetic material}

Resistance can be acquired by a susceptible strain from other bacteria by transfer of genetic bacterial i.e. DNA from one bacterium to another via transformation, transduction or conjugation. Many of the resistance genes are on transposons that can jump between the bacterial chromosome and plasmids present in the bacterial cell. These plasmids can, and do, transfer themsellves to other bacteria belonging to the same or a different species or genus?. Even exchange of genes between Gram positive and Gram negative bacterial species has been reported ${ }^{6}$. An example of clinical importance is the movement of genes encoding for $\beta$-lactamase and high level gentamicin resistance from staphylococci to enterococci which leaves only vancomycin or another glycopeptide available for therapy of serious enterococcal infections ${ }^{31}$. Of greatest concern presently is the risk that transfer of vancomycin resistance genes from enterococci to staphylococci will occur in vivo, as already has happened under laboratory conditions ${ }^{33}$. This could make methicillin resistant Staphylococcus aurews strains, which are usually multiresistant, virtually impossible to treat with antibiotics clinically available at this moment.

Mutations and acquisition of new resistance genes occur spontaneously and at random in bacteria and are in most cases not influenced by the presence of antibiotics. Resistant bacteria have been found in soil bacteria, bacteria of the intestinal flora and clinical isolates before antibiorics became clinically available, but in very low numbers 8,15 . 


\section{Introduction of resistant bacteria into a previously susceptible population}

Apart from mutations or gene acquisition resistant strains can be introduced in a population from the outside. Examples are vancomycin resistant enterococci brought into a hospital by a new patient who carries it in his intestinal flora or a fluoroquinolone resistant Escherichia coli strain from food animals which might reach the human intestinal tract via meat(products).

\section{SELECTION OF RESISTANCE}

Due to mutations, acquisition of resistance genes or introduction of a single or a few resistant strains a minority of strains resistant to a certain antibiotic may be present in a population.

Whether these resistant strains survive and replicate depends in large degree on the selective pressure placed on them. Mostly they will disappear as spontaneously as they emerged, but in a niche characterised by large quantities of antibiotics they might proliferate because the majority of susceptible bacteria are killed by the use of that antibiotic or a related one allowing the resistant subset of resistant strains to grow at expense of susceptible organisms. Within a short time all susceptible bacteria will be eradicated and replaced by resistant bacteria; a typical example of the Darwinian principle of survival of the firtest. Moreover the large numbers and the high diversity of bacterial species present in the intestinal tract further facilitate the transfer of resistance among bacteria. After discontinuation of antibiotic use the susceptible bacteria might be gradually reintroduced, but certainly after repeated exposure to antibiotics a certain percentage will stay resistant. After prolonged or continuous use of antibiotics in a popularion even the majority of bacteria present may stay resistant. This effectively means that the use of antibiotics, both in people and in animals, will "amplify" the numbers of resistant bacteria present, which also increases the chance of transfer of their resistance genes to bacteria of other species e.g. (opportunistic) pathogens.

\section{DISSEMINATION OF RESISTANCE}

The increase in numbers of resistant bacteria by selecrion under antibiotic pressure means also that they are excreted in much larger numbers into the environment enhancing the chance of colonisation and/or infecrion of other individuals. This can be either by direct contact between individuals or indirectly among patients via health care workers or medical equipment in hospitals or via foods of animal origin from animals to huw mans.

\section{RESERVOIRS OF RESISTANCE}

The extend of antibiotic resistance in a population is strongly correlated with the level of antibiotic usage and the ease with which bacteria can disseminate: crowding and poor sanitary levels. Hospitals are tradicionally the major breeding grounds and reservoirs of resistant bacteria $13,26,28$, however other important reservoirs are for the same reasons day care centres and nursing homes 30,32 . Moreover, as fortunately many more people live outside than inside hospitals, more than $80 \%$ of all antibiotics consuned by humans are used in the open population. "Therefore carriage of resistant bacteria by healthy persons is another source of resistance 22,24 . Outside the human population intensive farming units in which large numbers of animals are closely housed together with no restrictions to oral faecal contact and where, in addition to the high antibiotic use for treatment and control of bacterial infections, antibiotics are continuously fed to these animals for growth promotion are an ideal place for selection and dissemination of resistant bacterial strains. This might not only endanger the efficacy of antibiotics in veterinary medicine, but also affect public health. As we now begin to appreciate more fully the interrelatedness of resistance in bacteria of animal origin: zoonotic bacteria and faecal flora, and resistance encountered in bacteria isolated from humans, measures to curb bacterial resistance in the human populations must extend beyond human medicine, and also include antibiotic usage in animals.

\section{CONTROL OF RESISTANCE}

Prevention of dissemination of resistant strains population by hygienic measures in populations is an important way in the control of bacterial resistance. Infection control, strict hygiene and barrier isolation of patients 
infected with resistant organisms have been very successful in preventing acquisition of resistant microorganisms from exogenous sources in hospitals 27. However, for prevention of infections by resistant bacteria, which are endogenous to the patient i.e. originating from the patient's own intestinal flora, strict adherence to these procedures is not very successful. As it is obvious that the selective pressure of antibiotic usage is a factor of major importance, - according to Gaynes "amplification of resistance by antibiotic use is the major factor" 12 , decreasing antibiotic use is a cornerstone in dealing with antimicrobial resistance.

\section{CONCLUSIONS}

Antibiotic resistance in pathogenic bacteria is only the tip of the iceberg and resistant bacteria and resistance genes are to be found in the intestinal flora of man and other animals.

Antibiotic resistance in the intestinal flora is high in populations where antibiotic consumpion is large. It is not only a source of resistance genes for pathogens, but can also spill over to other populations. Hence food animals might be a source of resistant bacteria and resistance genes for the human intestinal flora and for (human) pathogenic bacteria. To prevent the emergence of resistance in human pathogenic bacteria it has been suggested that a low degree of resistance in the intestinal flora of humans should be considered a public health goal like low cholesterol levels and normal blood pressure ${ }^{19}$. In food animals this should be considered as a safery and quality bench mark, as this will not only safeguard the future efficacy of antibiotics in vererinary medicine, but also decreases public health risks ${ }^{40}$. In food animals where prevention of dissemination of bacteria among animals is impossible this can only be achieved by using less antibiotics. This means that these agents should only be used, if indicared, for treatment and control of bacterial infections and not for economic reasons as growth promoters. The structural dependence on antibiotics in intensive farming should be reduced by infection control measures and improving animal husbandry.

\section{AIMS OF THE STUDY}

The risk of transfer of resistant bacteria other than zoonotic pathogens, or resistance genes from food animals to humans is now generally acrepted, but the extend to what this contributes to resistance problems encountered in human medicine is still much debated.

Therefore the literature on transfer of resistant bacteria and resistance genes from animals to humans is reviewed. As antibiotic use in animals is the major factor for resistance encountered in bacteria of animal origin the phasing out of the usage of antibiotic for mere economic reasons as growth promoters has been suggested $5,10,17,36$, but a ban on the veterinary use of antibiorics is out of the question. We are as humans responsible for the welfare of animals under our care. Therefore a proposal was made for a veterinary antibiotic policy. This is a set of rulles and guidelines for veterinary surgeons to optimise the treatment of bacterial infections in animals ensuring at the same time an adequate veterinary therapy and minimising resistance development. Surveillance of resistance is an essential part of a veterinary antibiotic policy. Therapy advice and eventual interventions have to be based on recent susceptibility data.

A feasibility study was performed whether it was possible to detect differences in antibiotic consump tion in pig populations based on the basis of the prevalence and degree of resistance of bacteria in faecal samples of pigs collected in slaughterhouses, using $E$. coli and enterococci as indicator bacteria.

To detect if and to what extent, antibiotic resistance bacteria and resistance genes from animal bacteria can be transferred to the intestinal flora of humans we studied the resistance in bacteria from faecal samples of poultry, poultry farmers and poultry slaughterers. The use of antibiotics in poultry is in the Netherllands higher than in other animal species and in man. This is mainly due to the use in broilers and turkeys. In laying hens producing eggs for human consumption, antibiotic use is, at least during their productive life, low. The prevalence and degree of resistance was determined in indicator bacteria $E$. coli and enterococci from faecal samples of animals with a high exposure to antibiotics: broilers and turkeys, and with a relatiwely low exposure: laying hens. 
In addition we compared five populations with a different inrensity and frequency of contact with poultry or poultry products:

a. broiler farmers and turkey farmers, who have daily intensive contact with these animals, that are continuously fed antimicrobial growth promorers and in which therapeutic antibiotics are regularly used for control of bacterial infecrions

b. laying hen farmers, who have daily intensive contact with chickens with a low antibiotic consumption.

c. broiler and turkey slaughterers, who have daily contact with carcasses or meat from poultry that have been heavily exposed to antibiotics.

The effect of addition of an in vitro "plasmid curing" antibiotic to food animal feeds on the prevalence and degree of resistance in the faecal flora of exposed animals was studied on a commercial pig farm as an additional possibility to control antimicrobial resistance in the faecall flora of food animals.

Finally to evaluate the public health effect of an intervention measure: the suspension by the European commission in 1997 of the use of avoparcin as antimicrobial growth promoter in food animal feeds, in 1999 the prevalence and degree of resistance of enterococci was determined in faecal samples of broilers and pigs, collected after slaughtering, and of healthy human volunteers.

\section{REFERENCES}

1. Abraham, E. P., and E. Chain. 1940. An enzyme from bacteria able to destroy penicillir. Nature. 146837.

2. Amabile-Cuevas, C. F., M. Cardenas Garcia, and M. Ludgar. 1995. Antibiotic Resistance: mechanisms preventing antibiotis from killing bacteria are appearing much faster than ways to control resistance. Americat Scientist. 83:320-329.

3. Burler, D. 2000. New fronts in an old war Nature. 406:770672.

4. Cohen, M. L. 1992. Epidemiology of drug resistance: implications for a post-antimicrobial era. Srience. 257:1050-1055.

5. Commintee on Antimicrobial Growth Promoters. 1998. Antimicrobial growth promoters $15 / \mathrm{E}$. Health Council of the Netherlands. 1-108.

6. Courvalin, P. 1994. Transfer of antubiotic resistance genes beween gram-positive and gram-negative bacterian Antmicrobial Agends and Chemotberapy. 38:1447-1451.
7. Cullmann, W. 1996. Comparative evaluation of ofshlly active antibiotics aguinst communicy-acquired parthogens: Results of eight European counries. Chemotherapy 42:11-20.

8. Datra, N., and V. M. Hughes 1983. Pasmids of the same Inc groups in Enterobacteria before and after the medical usage of antibiorics. Namure. $306: 616-617$.

9. Deftaun, N. F., and S. B. Lewy 1991. Genes and their waried hoses, p. 1-32. In S. B. Levy, and M. R. Y. (eds), Gene transfer in the environment. McGraw Hill Publishng New York.

10. Europan Commission. 1999. Opinion of the scientific steering commitce on antimicrobial resistance. Directorate general XXIV: consumer policy and consumer health protection. $1-122$.

11. Finegold, S. M., V. L. Surter, and G. E. Marhisen 1983. Normal indigenous intestinal flora. Academic press. New York.

12. Gaynes, $R_{n}$ 1995. Antibiotic resistance in $1 C U$. $A$ multifaceted problem requiting a multifaceded solution. Infenion Control and Hosptial spidewology. 1.6:328-330.

13. Gerberding I. L., J. E. McGowan, and F. C. Tenover 1999. Emerging nosocomial infections and antimicrobial resistance Current Clinical Topics in Irfections Diseases 19:83-98.

14. Heritage, J., M. Z FH, D. Gascoyne Binzi, and P. M. Hawkey 1999. Evolution and spread of SHV extended-specrum beta-lactamases in Gram-negative bacteria. Joumal of Amtimicrobial Cbematherapy. 44:309-318.

15. Hughes, V. M., and N. Datta 1983. Conjugative plasmids in bacteria of the "pre-antibiotic"ena. Nanue. 302:725-726.

16. Jacoby, G. A. 1994. Genetics of extended-spectrum betalactamases. European Jounal of Clinical Microbiology of Infertious Diseases. 13:2-11.

17. Joint Expere Adwisomy Commirtec of Ancibiotic Resienance (JETACAR) 1999. "The use of antibiorics in food producing animals: antibiotic resistant bacteria in animals and humans. Commonwealth deparment of health and aged care, 1-224. Commonwealth deparment of agriculture, fischeries and forestry.

18. Kirby, W. M. M. 1944. Extraction of a highly potent penicillin inactivator from penicillin resistant staphylococci. Scienc. 99:452-455.

19. Lester, S. C. M. del Pilar, F. Wang, I. Perez-Schael, H. Jiang, and T. F.O'Brier. 1990. The carriage of Escherichia coli resistant to antimocrobial agents by healtry children in Boston, in Caracas, Venezuela, and in Qin Pu, China, The Netu England Joumal of Medicin. 323:285-289.

20. Levy, S. B. 1992. The antibiotic paradox: thow micacle drugs are destroying the miracle. Mlenum Press, New Yotk

21. Levy, S. B. 1992. Balancing the drug resistance equation. Trends in Microbiology. 2:341-342.

22. Linton, K. B. M. H. Richmond, R. Bevally, and W.A. Gillespie. 1974. Antbiotic resistance and R Gactors in coliform bacill isolated from hospial and domestic sewage foum of Medical Microbiolog. 7:91-103.

23. Lothanmer, K. H., and D. Klamann. 1999. Problems of antimicrobial resistance in weterinary medicine-investigation in 
an initensive livestock region. Theratrzthobe Unschat. 54: $183-188$

24. Magee, J. T., E. L. Pritchard, K. A. Fitzgerald, F. D. I. Dunstan, and A. J. Howard. 1999. Antibiotic prescribing and antibiotic resistance in community practice. etrospective study, 1996-8. British Medical Joumal 319:1239-1240.

25. Mare, 1. 1968. Incidence of R-factors among Gram-negative bacteria in drug free human and animal communities. Nature. 220:1046-1047.

26. McGowan, J. E. 1983. Antimicrobial resistance in hospital organisms and its relation to antibiotic use. Revieus of Infectrous Diseasex. 5;1033-1048.

27. MoGowan, J. E. 1999. Drug resistance and nosocomial infections: epidemiology and prevention straregies. Clinical Infecwow Diserases. 5:177-192.

28. McGowan, J. E., E. C. Hall, and P. L. Parrott. 1989. Antimicrobial susceptibility in Gram-Negative Bacteremia: are Nosocomial isolates really more resistant? Antimucrobial Agents and Chemotherapy. 33:1855-1859.

29. Mevius, D. J., and E. G. Harman. 2000. In vitro activicy of twelwe veterinary antibacterial drugs against Mannheimia thaenolytica and Pasteurella multocida isolated from Dutch calves. Tijolschrift Voor Diergemeeskunde. 125:147-152.

30. Murray, 13. E. 1997. Antibiotic Resistance. Aduances in Internal Medicine. 42:339-367.

31. Murray, B. E. 1998. Diversity among Multidrug-resistant Enterococci. Energing Infectiow Diseases. 4:37-47.

32. Murray, B.E. 1992. Problems and dilemmas of antimicrobial resistance. Pharmacotherapy. 12:86S-935.
33. Noble, W. C., Z. Virani, and R. G. Cree. 1992. Comransfer of varicomycin and other tesistance genes from Enterococcus faecalis NCTC 12201 to Staphylococcus aurems. FEMS Microbiological Lethers.72:195-8.

34. Parry, M. F. 1989. Epidemiology and mechanisms of antimicrobial resistance. American Jourral of Infection Control. $17: 286-94$

35. Philippon, A. G. Arlet, and P. H. Lagrange. 1994. Origin and impact of plasmid-mediated extended-spectrum beta-lactamases. European Joumal of Clinical Microbiology of Infectious Diseates. 13:17-29.

36. SOU 1997. Commission on antimicrobial feed additives. Antimicrobial feed additives. 1-132. Ministery of Agriculture.

37. Trolldenier, H. 1980. Development of drug resistance among pathogenic bacteria obtained from veterinary examinations berween 1971 and 1977 [Die Resistenzentwicklung pathogener Keime aus veterinarmedizinischem Untersuchungsmaterial in den Jahren 1971 bis 1977.] Monatshefte fir Veterinämedizin. $35: 460-467$

38. van den Bogaard, A. E. 1997. Antimicrobial Resistance-Relation to Human and Animal Exposure to Antibiotics Journal of Antimicrobial Chemotherapy. 40:453-45.4.

39. wan den Bogaard, A. E., N. London, and E. E. Stobberingh. 2000. Antimicrobial resistance in pig faecal samples from the Nerherlands (five abattoirs) and Sweden. fownd of Antimicrobial Chemotherapy. 45:663-671.

40. wan den Bogaard, A. E., and E. E. Stobberingh. 1996. Is it time to ban all antibiotics as animal growth-promoting agents? + reply and author' reply. The Lancet 1996; 348: 619 and 14541456 


\section{OUTLINE OF THE THESIS}

This thesis attends to several aspects of antimicrobial use in animals, the consequences for public health and possible intervention methods.

In chapter I, entirled "Antibiotic Usage in Animals; Impact on bacterial resistance and public health" the literature on usage of antibiotics in and the consequences for public health of antimicrobial resistance in food animals is reviewed with special emphasis on antimicrobial growth promoters.

In chapter II, entitled "A veterinary antibiotic policy; a personal view on the perspectives in the Netherlands" ways to minimise selection and dissemination of bacterial resistance against antibiorics by enhancing optimal use and selection of antibiotics for the treatment and control of bacterial infections in animals are discussed. A policy and the development of therapeutic guidelines for use and selection of antibiotics in veterinary medicine is proposed.

In Chapter III, entitled "Antimicrobial resistance in pig faccal samples from five abattoirs in the Netherlands and from Sweden" the feasibility of monitoring resistance in faecal indicator bacteria: $E$. coli and entrecocci, in faecal samples of pigs collected at abattoirs is examined. As no antibiotic consumption data could be obtained from the different Dutch pig popu lations studied the results are compared with those from Swedish pig samples.

In Chapter IV, entitled "Enterococci with glycopeptide resistance in turkeys, turkey farmers, turkey slaughterers, and (sub)urban residents in the South of the Netherlands: evidence for transmission of vancomycin resistance from animals to humans?" the public health risk of addition of alycopeptide antibiotic: avoparcin, as growth promoter to turkey feeds was studied.

In Chapter Ventitled "Faecal carriage of antibiotic resistant enterococci by poultry, poultry farmers and poultry slaughterers in the Netherlands" the prevalence and degree of resistance of faecal enterococci of broilers and laying hens, and of broiler farmers, laying hen farmers and poultry slaughterers are compared and analysed.

In Chapter VI, entitled "Prevalence of resistance in faecal E. coli of poultry, poultry farmers and poultry slaughterers in the Netherlands" the prevalence and degree of resistance of faecal $E$. coli of poultry: turkeys, broilers and laying hens, and of poultry farmers and poultry slaughterers are compared and analysed with special emphasis on fuoroquinolone resistance.

In Chapter VII, entitled "The effect of flavophospholipol on the prevalence and degree of resistance of indicator bacteria; $E$. coli and enterococci, in the intestinal flora of fattening pigs under field conditions" the effect of adding flavophospholipol, a "plasmid curing" antibiotic, to the finisher feed of fattening pigs on the prevalence and degree of resistance of faecal E. coli and enterococci from pigs is scudied.

In Chapter VII, entitled "Results of decreasing antibiotic usage in animals on resistance in the intestinal flora of food animals and healthy humans", the effect is shown of the suspension of the use of growth promoters on the prevalence and degree of resistance of indicator bacteria: E. coli and enterococci, in faecal samples of pigs and poultry and healthy humans with special emphasis on vancomycin resistant enterococci. 
Chapter I

Antibiotic usage in animals 


\title{
Antibiotic Usage in Animals Impact on Bacterial Resistance and Public Health
}

\author{
Anthony E. van den Bogaard and Ellen E. Stobberingh \\ Department of Medical Microbiology, University Maastricht, Maastricht, The Netherlands
}

\section{Abstract}

Since the 1970 s many reports have been published about multiresistant bacteria, but it has only been recently reported that organisms resistant to all clinically available antibiotics have emerged. ${ }^{[1,2]}$ Despite the fact that hospitals are considered to be major breeding grounds of resistant bacteria, it is becoming accepted that the much larger populations of healthy people living outside hospitals might be an important reservoir of resistant genes as well. Most antibiotics are used outside hospitals, and not only in humans but also in animals. ${ }^{[3]}$ Antibiotic use in animals, as in humans inevitably selects for resistant bacteria. The proliferation of antibiotic resistance genes on transposons and plasmids in animal populations is a direct result of the widespread use of antibiotics in animals and is increased by the ease of dissemination of resistant strains between animals via faecal contact, espe- 
cially among animals housed together in large groups, as with intensive farming units. ${ }^{[4.5]}$

In domestic animals antimicrobial agents are used for 3 major purposes: therapy to treat an identified bacterial infection, prevention of bacterial infections in animals at risk, or as feed additives to enhance performance. Veterinary antibiotic therapy involves treatment of an individual animal or a group of sick animals with one or more antibiotics during a defined period of time and, in most Western countries, only upon prescription from a veterinarian. Similarly, antibiotics can be prescribed by a veterinarian for a defined period of time to prevent bacterial infections in a group of animals at risk or to prevent the spread of an existing infection in a herd. In the situations when antimicrobials are used as therapy or for prevention of disease in a group of animals, antibiotics are mostly dissolved in the drinking water or milk, or mixed in the feed. This is called group or mass medication.

Despite the fact that much attention is being paid to hygiene and prevention of infectious diseases, intensive animal production depends heavily on the usage of antimicrobial agents for veterinary purposes. Apart from veterinary use, antibiotics are added continuously to the feed of animals used as a food source (i.e. 'food animals') for humans (e.g pigs, poultry and nonruminating veal calves), to enhance their performance and increase growth. In this situation they are called antimicrobial growth promoters (AGP). The term growth promoter is used for feed additives, other than dietary nutrients, which increase growth rate and/or improve feed efficiency in heal thy animals fed a balanced diet. ${ }^{|6|}$ AGP are more effective in young than in older animals and the general opinion is that the observed growth and feed efficiency responses to the use of AGP are lower under optimal hygienic and animal husbandry conditions compared with poorer environments. ${ }^{[7]}$ However, even under optimal conditions, the positive effects on growth rate and feed efficiency are between $2 \%$ and $4 \%\left[{ }^{[8]}\right.$ As a consequence of the improved feed efficiency, the amounts of waste products excreted in faeces and urine by the animals are lowered in proportion to the decreased amount of feed consumed by the animals, that is, by approximately 3 to $4 \%$. ${ }^{\text {[1 }}$

From an economic point of view, responses in feed efficiency are of greater importance than growth improvement or decreased waste production. The mode of action of AGP has been the subject of numerous scientific papers, but most of these deal with effects rather than modes of action. An early and fundamental finding was that germfree animals, that grow approximately $20 \%$ faster than conventionally-reared animals, do not respond to dietary inclusion of AGP. ${ }^{[10]}$ Therefore, the growth promoting activity of AGP seems to be related in one way or another to effects on or mediated by modulation of the intestinal flora of the exposed animals. Recently, several reviews on the possible modes of action of AGP have been published. ${ }^{[7,11,12]}$ Other names for AGP are antimicrobial performance enhancers, antimicrobial feed additives, feed savers, digestion enhancers or intestinal flora modulators.

The use of antibiotics for veterinary purposes is strictly regulated in most countries in a similar way to pharmaceuticals for humans. AGP, however, are regulated separately and differently, even if exactly the same drug is also registered for therapeutic use. Despite the fact that $\mathrm{APG}$ are not intended for and not registered for prevention of bacterial diseases, a part of their positive effect is most likely caused by prevention or suppression of bacterial infections as was claimed already by the discoverer of the growth promoting effect of antibiotics. ${ }^{[13]}$ This might be an explanation of why they are more ef fective in young animals and. when used under suboptimal conditions. As many people are not very familiar with the use of antibiotics as growth promoters and with the special agents used for this purpose, special attention will be paid in this review to the use of antibiotics as AGP, that is, the compounds used and their antibacterial activity, the effect of their use on the resistance of bacterial flora of animals, and the risk of transfer of resistant bacteria or their genes from animals to humans. 


\section{Antimicrobial Growth Promoters}

Originally, therapeutic antibiotics like tetracyclines and penicillins were used as AGP, but in lower doses than those required for therapeutic use. ${ }^{\left[1^{4}\right]}$ In the US, oxytetracycline is still used, but for therapeutic applications it is mixed in pig feeds in concentrations between 200 to $800 \mathrm{mg} / \mathrm{kg}$. For AGP use, it is administered in concentrations between 50 to $200 \mathrm{mg} / \mathrm{kg}$. The quinoxaline antibiotics, carbadox and olaquindox, are used in the US in pig feeds at doses of 50 to $55 \mathrm{mg}$ per $\mathrm{kg}$ for therapy, and at doses of 10 to $25 \mathrm{mg}$ per $\mathrm{kg}$ as AGP. ${ }^{[15]}$ Therefore, the use of antibiotics as AGP is sometimes referred to as the 'subtherapeutic use of antibiotics'. In contrast, in the European Union (EU) and many other countries, drugs that have been registered for therapeutic use in humans and/or animals are not allowed to be used as AGP. However, many of the compounds used as AGP are analogues of, and show cross resistance with, therapeutic antibiotics. Table I shows the most important compounds authorised as AGP in the EU, together with the concentrations in which they are added to animal feeds and the minimum inhibitory concentration (MIC) range of susceptible indicator bacteria, namely, Enterococcus spp., Clostridium perfringens and Escherichia coli. ${ }^{\mid 15-18]}$
For AGP that are not used for therapy, no official breakpoints to differentiate between resistant and susceptible strains have been established. As cross resistance to therapeutically used antibiotics occurs, the break-points of the therapeutic counterpart have been used. Adsorption from the intestinal tract of most of these drugs is very limited or nonexistent, therefore, the concentrations used are high enough to ensure that the levels of AGP reached in the intestinal tract of exposed animals are inhibitory to susceptible bacteria, as shown in table I. This inhibitory effect is confirmed by the preventive effect of $\mathrm{AGP}$ against certain intestinal diseases in animals such as necrotic enteritis in poultry (which is caused by Clostridium perfringens), swine dysentery (a contagious diarrhoea in pigs caused by Serpulina hyodysenteriae), and weaning diarrhoea in swine caused by $E$. coli. ${ }^{[15,19]}$

In Sweden, which prohibited the use of AGP in 1986, a higher incidence of bacterial infections in poultry and pigs was observed immediately after the ban, with a resulting increase in the veterinary use of antibiotics by approximately $20 \%{ }^{[20]}$ However, improvement of hygiene and animal husbandry systems, and reformulation and modification of feeds has solved nearly all of these problems. Consequently, the incidence of clostridia enteritis in poultry in Sweden is now much

Table 1. Authorised antibacteral performance enthancers

\begin{tabular}{|c|c|c|c|c|}
\hline \multicolumn{3}{|l|}{ Compound } & \multicolumn{2}{|c|}{ Minimum inhibltory concentration range (mg/L) } \\
\hline Name & Chemical group & Dose in animal leeds (mg/kg) & Clostridia & Einterococol \\
\hline Avilamycin & Everninomycins & $18=40$ & $<0.25-0.5$ & $0.06-0.075$ \\
\hline Avoparcin & Glycopeptide & $5-100$ & $0.5-2$ & $1-2$ \\
\hline Bacitracin & Polypeptides & $5-100$ & $<1-4$ & $<0.5+16$ \\
\hline Flavomycin & Bambermycins & $1-25$ & $<1-8^{b}$ & $0.25-4$ \\
\hline Monensin & lonophore & $10-40$ & $0.5-4$ & $1+2$ \\
\hline Spiramycin & Macrolide & $5-80$ & $0.25-8$ & $0.5 \cdot 4$ \\
\hline Tylosin & Macrolde & $4 \cdot 40$ & $\ll$ & $1-4$ \\
\hline Veginiamycin & Streptogramins & $5-80$ & $0.25-1$ & 0.25 .8 \\
\hline \multirow[t]{2}{*}{ Salinomycin } & lonophore & $15 \cdot 60$ & No data & 0.5 \\
\hline & & & & Escherichia colf \\
\hline Carbadox & Quinoxaline & $20-50$ & 50.25 & $\leq 2$ \\
\hline Oiaquindox & Quinoxaline & $15-50$ & No data & $\leq 16$ \\
\hline a Registra & ly suspended. & & & \\
\hline b Clostridiur & xs is naturally res & & & \\
\hline
\end{tabular}


lower than before the ban on AGP. On pig farms, mainly those with a suboptimal management, there are still problems with bacterial infections in recently weaned pigs. Zincoxide is now added routinely to the feed of young pigs for a short period after weaning for the control of these infections. As a result, the total amount of antibiotics used in animals is now (10 years after the ban on AGP), 55\% lower than that before the ban. Furthermore, the total amount of antibiotics used for veterinary prescriptions decreased by $33 \%$, despite an increase in the total number of animals. ${ }^{[20]}$ This decrease in antibiotic use was reflected in a recent study in which faecal samples of Swedish pigs were compared with samples of Dutch pigs for the prevalence and degree of resistance of faecal indicator bacteria: enterococci and $E$. colli. The prevalence and degree of resistance was not only significantly lower for AGP, but also for veterinary administered antibiotics. ${ }^{21 \mid}$

Despite their undisputed economic value in animal husbandry, there is much concern about the effect of AGP on the selection of resistant bacteria and resistance genes, not only in zoonotic pathogens, but also in the endogenous microflora of animals, as these bacteria might reach humans either directly or via foods of animal origin. ${ }^{[22]} \mathrm{Ac}$ cording to the advice of the Swann committee in 1968 ${ }^{\text {223| }}$ (adopted by most European countries at that time), no antibiotics should be used as AGP which are also (or closely related to) therapeutically used antibiotics. In the EU, this is only true for monensin, salinomycin, flavomycin and quinoxalines. Other compounds such as spiramycin and bacitracin are used in human medicine, and avoparcin, tylosin and virginiamycin are closely related analogues of valuable human therapeutic antibiotics: vancomycin, erythromycin and pristinamycin, respectively.

Moreover, older agents, rejected for therapy and presently used as AGP, are being used as templates for the development of new antibiotics for the treatment of infections with multiresistant bacteria. ${ }^{24]}$ For example, everninomycin ( $\mathrm{SCH}-27899$ ) is a new antibiotic being developed for treatment of multiresistant cocci, derived from avilamycin by chemical modification of the molecule. ${ }^{[25,26]}$ The mode of action of these new human therapeutics is similar to the AGP ancestor molecules and they show complete cross resistance. As mentioned before, the concentrations in which AGP are used, are high enough to reach levels well above their MIC in the gut. Therefore, the use of AGP results in bacterial subclones or subpopulations resistant against these AGP and related therapeutic compounds.

\section{Amount of Antibiotics Used in Animals}

Accurate figures on the antibiotic use in humans or animals are hard to obtain. Most data on antimicrobial use in humans and animals are based on the monetary value of sales of antibiotics per annum and show that use in humans is considerably higher. ${ }^{[27]}$ However, as antibiotic use in humans is more expensive per gram of active compound than veterinary antibiotics and certainly than AGP; this might be very misleading. ${ }^{[28]}$ It has also been speculated that the overall use in humans is at least 4 times that in animal husbandry and veterinary medicine. This assumption is based on figures that, in

Table II. Veterinary use of antibiotics in the Netherlands in 1990 (300 $000 \mathrm{~kg} / \mathrm{year})$

\begin{tabular}{|c|c|c|c|c|}
\hline Animals & $\%$ of total & $\begin{array}{l}\text { No. of animais } \\
\left(\times 10^{6}\right)\end{array}$ & $\begin{array}{l}\text { Total weight of animals } \\
\left(\mathrm{kg} \times 10^{6}\right)\end{array}$ & $\begin{array}{l}\text { Total amount of antibiotics } \\
\text { used (mg/kg/year) }\end{array}$ \\
\hline Pigs: & 42 & 15 & 1000 & 125 \\
\hline Poultry & 26 & 100 & 180 & 430 \\
\hline Cattle & 30 & 5 & 1800 & 55 \\
\hline Averageb & & & & 100 \\
\hline Other domestic species & 2 & No datta presented & No data presented & No data presented \\
\hline \multicolumn{5}{|l|}{ a Active substance. } \\
\hline b Average of antibiotic & food anin & & & \\
\hline
\end{tabular}


humans, most antibiotics are used in individuals below the age of 15 years and above 65 years, ${ }^{[29]}$ and that the older age group does not exist in food animals but is only limited to pet animals. Therefore, it was thought likely that antibiotic use in humans contributes more to resistance in the bacterial population than does nonhuman or veterinary use. ${ }^{\left[{ }^{[0]}\right]}$ However, compared on a body weight basis the antibiotic consumption by animals might be as high or higher, because the lifespan of food animals is short, for example, for broilers approximately 7 weeks, and for fattening pigs 6 months. This means that most of the animals present in a population belong to the young age group that is more susceptible to bacterial infections, similar to humans below the age of 15 years. Moreover, in small animals like poultry, the dosage per $\mathrm{kg}$ bodyweight is much higher than that in humans.

According to the European Federation of Animal Health Industries (FEDESA), ${ }^{1}$ the World Animal Health Product Market was, at manufacturers prices, 11 billion Euro in 1995, of which $44 \%$ were therapeutic pharmaceutical products and $41 \%$ feed additives. The European market was 3.3 billion Euro of which $48 \%$ were therapeutics and $37 \%$ feed additives. In 1993, it was estimated that $42 \%$ of all pharmaceuticals used in animals worldwide were AGP and $18 \%$ therapeutic antibiotics. [3]] Prescott ${ }^{[32]}$ considered that some $40 \%$ of the total antibiotic production in the US was for animal production, and even 55 to $60 \%$ of the production of benzylpenicillin (penicillin $\mathrm{G}$ ) and tetracyclines was used in food animal feeds. Levyl33] agreed with the figure of $40 \%$ of total production, which he considered to be 23 million $\mathrm{kg}$. He also reported that more than $80 \%$ of all tetracycline and benzylpenicillin use were in subtherapeutic doses mixed in animal feeds as AGP.

In the EU and Switzerland in $1997,{ }^{2} 10493$ tons of antibiotics (active ingredient at 100\% purity) were used and of this amount nearly $50 \%$ was used

1 Fedesa Animal Heath Dossier 14. Facts and figures about the European Animal Health Industry 1997.

2 Pres. release FEFANA at the invitational EU-conference 'The Microbial Threat' Copenhagen, Denmark, 1998. in animals: 3474 tons $(33 \%)$ were used in animals for therapy and prevention, and 1590 tons (15\%) as AGP. However, large differences in antibiotic use exist between countries. In Belgium, Denmark, France, Ireland and the Netherlands (countries with a large intensive animal farming industry), the use of AGP was of the same size of order as the veterinary use of antibiotics. In Austria, AGP use was 3 times higher than the therapeutic use in animals. In Sweden and Finland, no $\mathrm{AGP}(<1 \%)$ were used, and in Germany, Greece, Italy, Portugal, Spain and the UK, AGP use was considerably lower ( 15 to $50 \%$ ) than veterinary use.

These figures are not stable, but tend to change over time. In Finland in 1995 for example, 14 tons of antibiotics were used as AGP and 14 tons for therapeutic reasons in animalls (approximately $30 \%$ of the human use). In Denmark in 1995, these figures were 94 and 50 tons, respectively. ${ }^{[34]}$ In Norway, figures were $25000 \mathrm{~kg}$ in humans and $50000 \mathrm{~kg}$ in animals. In 1990 in the Netherlands, $80000 \mathrm{~kg}$ of antibiotics were used on medical prescription for a population of approximately $15 \mathrm{mil}$ lion people. This is equivalent to 60 million defined daily doses or $100 \mathrm{mg}$ active substance $\mathrm{kg}$ bodyweight/year. ${ }^{[28]}$ The veterinary usage was $300000 \mathrm{~kg}$, which also equated to $100 \mathrm{mg}$ active substance/kg bodyweight/year, as presented in table II. The additional use of antibiotics as AGP in animal feeds was estimated (no official figures could be obtained) to be approximately $300000 \mathrm{~kg} .128$ These figures show that the selection pressure exerted by the veterinary use of antibiotics on the animal bacterial population in the Netherlands is of the same order as medical usage. However, this selection pressure is more than doubled in intensively reared animals because of the use of antibiotics as AGP.

The literature on resistance against $A G P$ is very limited as most of these compounds are not used for therapy, susceptibility testing is not regularly performed, and no recognised breakpoints to differentiate between susceptible and resistant microorganisms exist. Therefore, AGP that are not com- 
monly used in human or veterinary medicine will be discussed briefly.

\section{Antimicrobial Growth Promoters}

\subsection{Avoparcin and Ardacin}

Avoparcin and ardacin are glycopeptides and closely related to vancomycin and teicoplanin. Avoparcin has been widely used as AGP in the EU, but has never been registered in the US. However, the EU has suspended the use of avoparcin and ardacin, which was just being introduced, in 1997. Both agents are active against most aerobic and anaerobic Gram-positive bacterial species, but not against most Gram-negatives as these drugs are unable to pass through the outer membrane of these bacteria. $^{[39]}$

Glycopeptides are compounds of 2 or more substances with similar mollecular structures, produced by a variety of soil bacteria. Lactobacilli are intrinsically resistant to glycopeptides. The use of avoparcin selects for an acquired high level resistance in enterococci, that is mostly mediated by the VamA-gene cluster located on a transposon Tn 1546 or a self transferable plasmid. ${ }^{[35-37]}$ Transfer of the VanA-gene cluster has been shown in vitro from Enterococcus faecium to Listeria monocylogenes, Staphylococcus aureus and several Streptococcus spp. with frequencies ranging from $10^{-6}$ to $10^{-9}$. Transfer from $E$. faecium to $E$. faecium was more efficient with a frequency of $1: 10^{-4} \cdot .^{381}$ The $\operatorname{Van} B$ gene cluster is transferable either via Tn 1547 or via plasmids at a low frequency, ${ }^{[39-41]}$ and is induced by vancomycin, but not by teicoplanin or avoparcin, ${ }^{[42]}$ which is consistent with the fact that there are no reports that avoparcin use selects for VanB resistance genes. Transfer in vivo of glycopeptide, erythromycin and chloramphenicol resistance on the skin of nude mice from Enterococcus faecalis to $S$. aureus has been described by Noble et al. ${ }^{[42]}$

Use of avoparcin results in a wide spread prevalence of enterococci with high level VanA-mediated resistance to vancomycin (VRE) and other glycopeptides in the enterococcal flora of exposed animals and their environment ${ }^{[43-45]}$ However, the lack of earlier data precludes conclusions on whether the resistance trait was present in animal populations before or at the time of introduction of avoparcin in animal husbandry ${ }_{*}[19]$ but in countries where avoparcin has never been used, such as the US, or where its use has been suspended for several years as in Sweden, no VRE have been found in the intestinal flora of food animals or healthy people outside the hospital environment. ${ }^{[46,47]}$ The presence of VanC, conferring low level resistance is species-specific for $E$. gallinarum and $E$. casseliflavus. ${ }^{[48]}$ More recently, the VanD gene which confers low level transferable resistance to vancomycin has been described in enterococci. ${ }^{[49]}$

\subsection{Tylosin, Spiramycin and Virginiamycin}

Tylosin and spiramycin, are macrolide antibiotics, while virginiamycin belongs to the streptogramins. Both groups of antibiotics are produced by Streptomyces spp. Macrolides and streptogramins are not chemically related, but are often grouped together because of similar antibacterial spectra and mode of action. The lincosamides (linco- and clindamycin) are often included for the same reason, leading to the acronym MLS antibiotics (macrolides, lincosamides and streptogramins $\rangle$. They all inhibit protein synthesis by binding to the $50 \mathrm{~S}$ subunit of the bacterial ribosome and are active against a wide range of aerobic Gram positive bacteria and obligately anaerobic bacteria. ${ }^{[15]}$ Most aerobic Gram-negative bacteria are not susceptible because their outer membrane is not permeable for MLS antibiotics.

Lincosamides are not used as AGP. Tylosin and spiramycin, are commonly used as therapeutic agents in veterinary medicine, and as AGP. They are in contrast to most other AGP readily absorbed from the gut. Virginiamycin is not absorbed and in most countries only used as AGP, but in a few countries it is utilised for therapy in animalls or humans. An analogue compound, however, quinupristindalfopristin has recently been introduced as an alternative for treatment of multiresistant and/or glycopeptide-resistant E. faecium. E. faecalis is in- 
trinsically resistant to streptogramins, ${ }^{1501}$ and another new streptogramin efepristin (RPR 106972) is currently being evaluated for oral medication in humans. ${ }^{[51]}$ Virginiamycin is effective for therapy or prevention of clostridial infections in animals. ${ }^{[15]}$ All streptogramins (also called pristinamycins) are a mixture of 2 different groups of molecules: $A$ and $B$, which are both bacteriostatic, but act synergistically to express bactericidal activity. Acquired resistance to MLS antibiotics is due to alteration of the ribosomal target, enzymatic inactivation and active efflux. ${ }^{[52,53]}$ Two genes SatA and $v g b$ encoding streptogramin resistance in $E$. faecium have been detected in streptogramin resistant clinical isolates of E. faecium ${ }^{[54]}$ and in faecal isolates from healthy individuals and food animals. ${ }^{[55]}$ SatA encodes for resistance to the streptogramin A components while $v g b$ confers resistance against the streptogramin B components. Erm-genes not only confer resistance to streptogramin B but also to all MLS antibiotics. ${ }^{[56,57]}$

Transfer of pIP811, a self transmissible plasmid carrying the ermB-gene, and also resistance to chloramphenicol, tetracycline and streptomycin from $L$ monocytogenes to $E$. faecalis and vice versa has been observed. ${ }^{[58]}$ Moreover, transfer of Tn 1545, a chromosomally located transposon carrying resistant determinants to macrolides, lincosomides, streptogramin B (ermB), kanamycin (aphA3') and tetracycline (tetM) from E. faecalis to $L$. monocytogenes has been described both in vitro and in vivo in mice. ${ }^{[59]}$

\subsection{Avilamycin}

Avilanycin, a mixture of oligosaccharides of the orthosomycin group produced by Strepromyces viridochromogenes, is mainly active against Grampositive bacteria by binding to the $30 \mathrm{~S}$ subunit of the bacteriall ribosomes. ${ }^{[60]}$ Other members of this group include curamycin and the everninomycins. Avilamycin has never been used for therapeutic purposes, but a related compound everninomycin (Ziracin ${ }^{3}$ ) is being developed for therapeutic use in humans. ${ }^{(25.26)}$ No data have been published on resistance mechanisms against everninomycins, but increased MICs for avilamycin and bacteria resistant to everninomycin have been shown. 1611

\subsection{Bacitracin}

A mixture of cyclic polypeptides produced by Bacillus subtilis and Bacillus licheniformis, bacitracin is bactericidal against Gram-positive bacteria and shows limited activity against Gram-negatives. ${ }^{[15]}$ Bacitracin interferes with the formation of bacterial cell wall peptidoglycans. As AGP it is mostly used in complex with zinc which stabilises the molecule. Bacitracin, in concentrations used as AGP, also showed preventive and therapeutic effects on necrotic enteritis in poultry. ${ }^{162,631}$ In humans, bacitracin is mainly used topically and for intestinal decontamination in elective colorectal surgery. ${ }^{[64]}$ It is expected that future bacitracin use in humans will increase because of its effectiveness against VRE. ${ }^{[65,66]}$ No information about cross resistance with other antibiotics exists, but several resistance mechanisms of which at least one is plasmid mediated, have been described. ${ }^{[67]}$

Bacitacin has been shown to induce the expression of the VamA-gene in enterococci ${ }^{168,691}$ It has been claimed that bacitracin as AGP 'cures' resistance against other antibiotics ${ }^{|70.73|}$ but because of weaknesses in study design this claim cannot be considered to be substantiated.

\subsection{Flavophosphalipol}

Flavophospholipol, a complex of very similar phosphorus-containing glycolipids, produced by a group of Streptomyces spp. is also known as flavomycin, bambermycins or moenomycin. It is used for growth promotion only and is effective against Gram-positive organisms, by inhibiting bacterial cell wall synthesis. However, it is not active against Gram-negative bacteria as it cannot penetrate the lipid membrane of these organisms. ${ }^{174 \mid}$ Nevertheless, some activity against enterobacteriaceae has been observed. ${ }^{[22,75-77]}$ In some studies a plasmid clearing effect and a decrease in transfer frequency of some R-plasmids has been described, but an increase in frequency transfer of other plasmids has also been observed. ${ }^{178-82 !}$ No reports on resistance 
mechanisms against flavophospholipol have been found. Flavophospholipol has been shown to induce VanA resistance in enterococci. ${ }^{[68]}$ Currently, insufficient data are available to assess the risk of flavomycin use as AGP on the prevalence and spread of resistance of this compound and related substances in humans.

\subsection{Monensin and Salinomycin}

Monensin, like salinomycin, is a carboxylic ionophore antibiotic produced by Streptomyces cinnamonensis. Both drugs are bactericidal by altering the membrane permeability which causes passive transport of potassium ions out of the bacterial cell. The drop in intracellular $\mathrm{pH}$ as a result of their replacement by hydrogen ions kills the bacterial cells. They are active against Gram positive bacteria, Campylobacter spp., Serpulina spp., coccidia and Toxoplasma. These drugs are used in poultry feeds for the prevention of clinical coccidiosis in chickens. ${ }^{115]}$

In contrast to other AGP that are only used in pigs, poultry and nonruminating veal calves, monensin and salinomycin are also used to enhance leed conversion in ruminants by modulation of the rumen flora. Both are toxic (at the recommended dosages for pigs and poultry) for several other mammalian species such as horses and dogs. Even in poultry and pigs, it has a small tolerability margin and its toxicity is increased by a number of other drugs. ${ }^{[15]}$ No information could be found on resistance mechanisms, transfer and prevalence of resistance in bacteria.

\subsection{Carbadox and Olaquindox}

Carbadox and olaquindox are quinoxalines. which are synthetically produced compounds with activity against obligately anaerobic bacteria such as Clostridium spp., and Enterobacteriaceae and staphylococci. ${ }^{[15,83]}$ In contrast to most other AGP they are readily absorbed from the intestinal tract. Quinoxalines are not used in human medicine. Despite their toxicity they are used therapeutically in some countries against Salmonella, E. coli and Serpulina infections in pigs. Quinoxalines inhibit
DNA synthesis and denature preexisting DNA. Resistance to quinoxalines is caused by target alterations, cell wall impermeability or increased efflux of the drug. Plasmid mediated resistance has been described. $[84,85]$

\section{Resistance in Animals}

\subsection{Animal Pathogens}

Many retrospective and prospective studies have been performed concerning the emergence and selection of resistance in bacteria from animals following antibiotic use. Despite large differences in methodology, most results show that after the introduction of an antibiotic in veterinary practice the resistance in pathogenic bacteria and/or the commensal intestinal microflora increases, as in human medicine. However, some bacteria, such as most Enterobacteriaceae, staphylococci and Pasteurella spp. become more readily resistant to certain antibiotics than other bacteria such as Clostridium spp. and streptococci, of which animal isolates are still fully susceptible to benzylpenicillin.

In veterinary medicine the problem of resistant bacteria is less severe than in human medicine. Broad-spectrum $\beta$-lactamases or bacteria that are multiresistant, because of a broad spectrum efflux pump mechanism, ${ }^{186,87]}$ coded for by a single gene and conferring resistance to several unrelated antibiotics, have never been found in veterinary pathogens. This difference is most likely due to the fact that immunocompromised patients and the accumulation of these patients in special wards in hospitals are uncommon in veterinary medicine. Recently, however, for the first time the first well documented cases of methicillin-resistant $S$. aureus infection in animals have been published, namely, postoperative wound infections in a horse and in dogs. ${ }^{[88.89]}$

\subsection{Faecal Flora}

Antibiotic use not only selects for resistance in the target pathogenic bacteria, but also causes the emergence of resistant populations of bacteria in the endogenous flora of exposed individuals and 
populations. Resistance genes are mostly associated with plasmids or transposons located on plasmids or on the chromosome and can easily be transferred to susceptible micro-organisms. The high density of bacteria in the gut facilitates this transfer between bacteria.

Transfer of resistance has been described between bacteria belonging to the same species, and the gene pool of Gram-positive cocci has extended to Gram-negative bacteria as well. ${ }^{190,91]}$ Under antibiotic pressure, resistance genes tend to accumulate in multiresistant plasmids. However, not only does clonal spread of bacteria occur but also resistant bacteria from animal origin may transfer these resistance genes either to bacteria pathogenic for humans or to the endogenous flora of humans. Conjugal transfer of plasmid pAT 191 DNA which confers resistance against kanamycin, from $E$. faealis to $E$. coli in the digestive tracts of gnotobiotic mice have been found with a frequency of $3 \times$ $10^{-9} \cdot{ }^{[92]}$ Furthermore, in vitro conjugative transfer of VanA vancomycin resistance between Enterococci and listeriae of different species have been found. . $^{93 !}$

Co-transfer or linked transfer, that is, the simultaneous transfer of different genes located on the same mobile element, has been described for genes encoding for different antimicrobial agents and for genes encoding for antibiotic resistance and virulence genes. The $E$. coli plasmid pNV 13 encodes for resistance to carbadox, streptomycin, spectinomycin and ampicillin. ${ }^{[84.85]}$ The transposon Tn 1545 carries resistance genes to kanamycin, macrolides and tetracyclines. ${ }^{[59]}$ Furthermore, cotransfer of antibiotic resistance and virulence genes has been described for enteropathogens. ${ }^{[94]}$ Macrolide resistance and toxin A production, encoded by Tn 5398 can be transferred from Clostridium difficile to B. subtilus. ${ }^{[95]}$ The greater the number of resistant intestinal micro-organisms in the intestinal flora the greater the chance of transfer of their resistance genes to pathogenic bacteria and dissemination in the environment.

Comparing the populations of 3 cities in 3 different countries, Lester found that the prevalence of resistance in the intestinal flora of each population was not only strongly correlated with the amount and types of antibiotics used, but also indicative of resistances observed in pathogenic bacteria isolated from infections in that particular population. ${ }^{[96]}$ This clearly demonstrates that the endogenous flora is a reservoir for resistance genes and that resistance in pathogenic bacteria is only the 'tip of the resistance iceberg'. Because intensively reared food animals are mostly treated as a group, continuously with AGP and temporarily (but regularly) for therapeutic reasons or for prevention, the endogenous flora of these animals contains a relatively high proportion of resistant bacteria. Furthermore, since hygienic measures in intensive farming are only directed against the introduction of pathogenic micro-organisms from outside the stable or farm, and not against the prevention of spread within a stable, newly introduced resistant bacteria or emerged resistance genes will spread very fast through the whole herd by faecal contact. These resistant micro-organisms can reach humans either directly through direct contact or indirectly via meat products.

As bacteria of the endogenous flora of food animals contaminate foods of animal origins, they might either colonise humans or transfer resistance genes to human endogenous flora and so superimpose an additional load to the reservoir of resistance genes alreadly present in humans. Therefore, it has been proposed that a low level of resistance in the intestinal flora of food animals should be considered as a safety and quality mark for these animals. ${ }^{[24,28]}$ Several studies have shown a correlation between the amount of antibiotics used and the prevalence of resistance in the faecal flora of animals.

In the Netherlands, enrofloxacin, a methylester of ciprofloxacin, is extensively used for therapy in turkeys, but its use in pigs is very limited. In a point prevalence study the prevalence of ciprofloxacin resistant raecal $E$. coli in turkey flocks was $49 \%$ and in pig herds $2 \%{ }^{[97]}$ For tetracycline, ampicillin and furazolidone, which are used regularly for therapy in both animal species, the prevalence of 
resistance was, for both animal populations, in the same order of approximately $98 \%, 98 \%$ and $16 \%$, respectively. The literature on resistance against AGP is very limited as most of these compounds are not used for therapy and therefore susceptibility testing is not regularly performed.

In a surveillance study on the resistance against AGP of C. perfringens from various animal sources conducted from 1979 until 1992 no increase in resistance to AGP was observed. 1161 However, Linton et all. ${ }^{[98 \mid}$ found a significant increase in the prevalence of resistance against tylosin and bacitracin in faecal enterocacci of pigs and poultry fed these compounds. Virginiamycin use did not result in an increase in resistance. Thal et al. ${ }^{[99]}$ found an increase over time in resistance against quinupristin/ dalfopristin in faecal $E$. faecium in turkey flocks given virginiamycin as AGP. After the introduction of olaquindox in 1982 on farms using olaquindox as AGP the prevalence of resistance in faecal $E$. coli in pigs increased from $0.004 \%$ to $6 \%$ in 3 years, whereas on farms not using olaquindox the prevalence of resistance increased by a significantly lesser degree, suggesting dissemination of resistant clones. "100]

Ohmae ot al. ${ }^{[84,85 !}$ noticed an increase of resistance against carbadox in faecal $E$. coli isolates in pigs after its introduction as AGP. All resistant isolates from 6 farms that fed carbadox continuously to pigs either as AGP or for prevention of swine dysentery, carried the same transferable plasmid conferring carbadox resistance. Carbadox is not used in poultry and cattle, and no carbadox resistance was found in $E$. coli isolates from these animal species in the same region. Mills and Kelly[101] also reported an increase in resistance of Salmonella isolates from $37 \%$ to $61 \%$ after the introduction of carbadox. Carbadox, however, was not only used as an $A G P$, but also for the prevention of swine dysentery and therapy of salmonellosis. Hedges and Linton ${ }^{[102]}$ showed that not only the prevalence but also the degree of resistance increased by olaquindox use. In herds not exposed to the AGP, the degree of resistance varied from 0 to $0.02 \%$. while in herds given olaquindox it varied from 1.3 to $6.5 \%$

\subsubsection{Vancomycin-Resistant Enteracocci}

Interest in the selection of resistance by $\mathrm{AGP}$ increased after the emergence of vancomycin resistant enterococci (VRE) in human infections. It was soon recognised that avoparcin, a glycopeptide like vancomycin and until recently commonly used as AGP in most EU-member states, selects for VRE in the intestinal flora of animals ${ }^{[44,103]}$ In countries where avoparcin was used as AGP, VRE were not only found in food animals fed avoparcin, but also in the faecal flora of healthy humans and pet animals. ${ }^{[43,103-106]}$ Furthermore, resistance against MLS antibiotics such as erythromycin and the streptogramins is common in enterococci from animals fed related antibiotics as AGP, such as tylosin (a macrolide) or virginiamycin (a streptogramin). [106] Similar figures have been found in other European countries like Denmark, ${ }^{[34]}$ where in 1995 the prevalence of resistance in enterococci isolated from faecal samples of pigs and poultry was $21 \%$ and $56 \%$ against vancomycin, $91 \%$ and $59 \%$ against erythromycin, and $53 \%$ and $37 \%$ against pristinamycin, respectively. In Finland, however, where tylosin is not used as AGP and only limited to veterinary purposes, the prevalence of erythromycin resistance in enterococci is significantly lower, being $18 \%$ and $9 \%$, respectivelly. ${ }^{107]}$

Since 1986, Sweden has banned the use of AGP in animal feeds. The prevalence of resistance against AGP or related compounds in faecal samples of Swedish pigs was significantly lower than that in Dutch pigs in 1997. In Sweden and the US, where avoparcin has never been used, no high level VRE (VanA resistance) have been found in faecal samples of food animals or healthy humans outside hospitals. ${ }^{[46]}$ Following the suspension of the use of avoparcin in Denmark in 1995 the prevalence of vancomycin-resistant $E$. faecium in broilers decreased from $5.2 \%$ in 1995 to $1.2 \%$ in $1997 .[34]$

In the Netherlands, a significantly higher percentage of VRE per gram of faeces (10 to 100\%) was observed in veal calves from farms using avoparcin as an AGP than in faecal samples of calves 
fed bacitracin as $\mathrm{AGP}(\leq 1$ to $10 \%){ }^{[108]}$ The prevalence of VRE in turkey flocks fed avoparcin was $60 \%$ in contrast to $8 \%$ in flocks not exposed to avoparcin, ${ }^{[109]}$ and the relative odds ratio was 7.5 . In Denmark, Bager et al. ${ }^{[10]}$ found a high correlation between the use of avoparcin on a farm and the prevalence of VRE in the intestinal flora of animals. The likelihood of isolation of VRE from faecal samples of animals (pigs and poultry) was 3 times higher in animals fed avoparcin than in other animals. The relative odds ratio for the use of avoparcin on the presence of VRE in the faecal flora of these animals was 2.9 for poultry and 3.3 for pigs.

It can be concluded that the use of antibiotics for growth promotion in animals, as with veterinary antibiotic use, selects for resistance among susceptible micro-organisms, not only in pathogens but also in bacteria belonging to the commensal intestinal microflora of animals, such as enterococci and $E$. coli. This has been shown for avoparcin, bacitracin, tylosin, virginiamycin, carbadox and olaquindox.

\section{Transfer of Resistant Bacteria from Animals to Humans}

\subsection{Zoonotic Bacteria}

Most investigations on the transfer of resistant bacteria from animals to humans concern Gramnegative food infections caused by bacteria like Salmonella spp., Campylobacter spp. and Yersinia spp. Transfer of resistant Salmonellae from animals to humans has been described by several authors. ${ }^{[11-114]}$ Because the resistance of salmonella isolates from humans and animals has been monitored for many years, the emergence and dissemination of resistance in this species is very well documented. Before the introduction of antibiotics, salmonella isolates and other Enterobacteriaceae were susceptible to most antibiotics despite the prevallence of plasmids. ${ }^{[1] 5]}$ Humans become infected with salmonella isolates from animals by direct contact with infected animals or animal fae- ces, but the most important source of human infections are food products of animal origin.

Asymptomatic salmonellat infections and carriers are common in food animals in intensive animal husbandry. The salmonellae in the intestinal tract of these animals contaminate during slaughtering and processing of the carcasses, and meat and meat products. Humans can then become infected via the meat and meat products, and also via eggs etc. Humans do not always become ill after a salmonella infection. Deleener and Haebaert ${ }^{[16]}$ showed that the frequency and variation of the different isolated salmonella-serotypes from asymptomatic carriers in a meat packing plant corresponded with the serotypes isolated from the supplied meat and from the produced meat products.

Despite the fact that since the introduction of antibiotics in clinical medicine resistance in human and animal isolates increased in general, the majority of clinical salmonella isolates are still susceptible to most antibiotics. ${ }^{[177]}$ In the Netherlands, the prevalence of tetracycline resistance in human and animal salmonella isolates increased clearly until the ban on tetracycline as $\mathrm{AGP}_{4}[118]$ when it started to gradually decline..$^{119-122 /}$ In Great Britain, after the ban on tetracycline as $A G P$, tetra cycline-resistant Salmonella typhimurium isolates from calves fell from $60 \%$ in 1970 to $8 \%$ in 1977. [123] However, the spontaneous ending of epidemics by virulent tetracycline resistant $S$. typhimurium clones might have contributed to this decrease as well. ${ }^{[124\rfloor}$ In most EU member states Salmonella enteritidis is the most commonly isolated serotype from human infections, as a result of its extensive dissemination among poultry since 1980. Because this serotype does not, in most cases, cause clinical symptoms in affected flocks, the animals are not treated with antibiotics. Therefore, the selection pressure is low and generally isolates are still susceptible to most antibiotics.

Sporadically however, epidemics of salmonella clones with an enhanced virulence and pathogenicity for animals occur, such as S. typhimurium phage type 29 from 1963 to 1969 , definitive type (DT) 
204 in 1977, and DT 204 and DT 193 in 1980..$^{1231}$ The primary reservoir of S. typhimurium is calves, but sheep, goats, pigs, poultry and horses can also become infected. During all these epidemics the same phage type with identical resistance profiles was isolated from animal and human infections. Because these strains cause serious disease in affected animals, these animals are treated with antibiotics and as a result of the selection pressure these strains tend to become (multi)resistant. Since 1994, S. typhimurium DT 104 has caused an epidemic. This strain was, from the start, resistant to most of the antibiotics normally used to treat enteric infections in animals, but it has acquired additional resistance against trimethoprim and fluoroquinolones, ${ }^{[177,125,126]}$ most likely because affected groups of animals could only be treated with these antibiotics.

The most important reservoir for human campylobacter infections is poultry. Endtz et al. ${ }^{[127]} \mathrm{ob}-$ served that the emergence of fluoroquinoloneresistant $C$. jejuni infections in humans in the Netherlands coincided with the introduction of enrofloxacin for poultry therapy in spring 1987. Enrofloxacin and ciprofloxacin (the latter was introduced in October 1988 for human therapy in the Netherlands), are fully cross-resistant. In 1989 , $1.4 \%$ of poultry and $11 \%$ of human isolates of $C$. jejuni were resistant to ciprofloxacin. Experimentally, it was shown that in flocks only colonised with ciprofloxacin-susceptible $C$. jejuni, after therapy with enrofloxacin mutants resistant to ciprofloxacin emerged. ${ }^{(128)}$ In Great Britain, enrofloxacin was registered for veterinary use in 1993, and in that year $14 \%$ of $C$. jejun isolated from poultry carcasses imported from the Netherlands were fluoroquinolone resistant compared with $1 \%$ from locally raised broilers. ${ }^{129}$ In 1997 , the percentage of fluoroquinolone resistant $C$. jejuni from English broilers had approached a continental level of about $10 \%$. Transfer of chloramphenicol resistant Yersinia enterocolitica strains from animals to humans has been described by Perez Trallero. ${ }^{[130]}$

\section{Disturbance of Colonisation}

Another aspect of the use of antibiotics in animals is disturbance of the colonisation resistance of the intestinal flora of animals exposed to certain antibiotics. ${ }^{[131.332]}$ In cases of reduced colonisation resistance not only are the minimal infectious or colonisation doses of pathogenic or resistant bacteria considerably lower, but animals also excrete these bacteria in higher numbers and over a longer period of time compared with animals with an intact colonisation resistance. This enhances not only dissemination of salmonellae or resistant bacteria within a group of animals, but also increases the contamination of carcasses with these bacteria during slaughter. This effect has been clearly demonstrated for most broad-spectrum antibiotics ${ }^{[33]}$ and for certain AGP: avoparcin ${ }^{[134-136]}$ and to a lesser extent, virginiamycin and tylosin. Avilamycin and bacitracin do not appear to disturb the colonisation resistance in the dosages used for growth promotion. ${ }^{[137-141]}$ Furthermore, flavomycin has been shown to provide a certain degree of protection against salmonella infections. "142]

\subsection{Indicator Bacteria}

As a result of exposure to antibiotics, the level of resistance against antibiotics among bacteria belonging to the normal intestinal flora of humans and animals increases. These bacteria constitute an enormous reservoir of resistance genes for (potentially) pathogenic bacteria. ${ }^{[4]}$ Moreover, the level of resistance in the endogenous flora is considered a good indicator for the selection pressure exerted by antibiotic use in that population and for resistance problems to be expected in pathogens. ${ }^{[96]} \mathrm{Re}$ sistant bacteria from the intestinal flora of food animals contaminate, like zoonotic bacteria, the carcasses of slaughtered animals and reach the intestinal tract of humans via the food chain.

Investigation of the prevalence of resistance of certain indicator bacteria like $E$. coli and enterococci in the intestinal tract of different populations of animals and humans makes it feasible to compare the prevalence of resistance in different pop- 
ulations and to detect a possible transfer of resistant bacteria from animals to humans and vice versa. Because of the inevitable high use of antibiotics in hospitals, selection and dissemination of resistant clones and resistance genes is high in this environment. The emergence of new resistances due to the acquirement of new genes or gene clusters like the VanA-gene cluster are not likely to occur in hospitals but must have been introduced from somewhere outside into the hospital setting. Therefore, healthy individuals in the community are a source of resistant bacteria and resistance genes, and can be considered to be a suitable population to study with regard to the possibility of transfer of resistance from animals to humans.

Corpet ${ }^{[143]}$ showed that the prevalence and degree of resistance in faecal $E$. coli flora in humans who used only sterilised food decreased significantly. Furthermore, Nijsten found significantly more resistant $E$. coli in the faecal flora of pig farmers than in faecal (sub)urban residents. ${ }^{[144,145]}$ However, the personal antibiotic use of the farmers was much higher than that of the (sub)urban residents.

Comparison of the prevalence of ciprofloxacin resistant $E$. coli in faecal samples of turkeys and turkey farmers with pig and pig farmers clearly indicated transfer of ciprofloxacin-resistant $E$. coli strains from turkeys to turkey farmers. ${ }^{197 !}$ In the Netherlands, enrofloxacin is commonly used in turkeys but not in pigs because no oral formulation for pigs was available at the time of study. Tetracyclines are extensively used in both animal species, similar to the use of furazolidone in the past. The prevalence of ciprofloxacin resistant $E$. coli was not only significantly higher in turkey farmers and turkeys than in pig farmers and pigs, but also E. coli strains were isolated from farmers and turkeys which were completely identical in pulsed field gel electrophoresis (PFGE) after XbaI digestion. None of the turkey farmers and urban residents in this study had used antibiotics in the 3 months prior to the study. For the turkey slaughterers the infection risk seemed much lower, despite the fact that ciprofloxacin-resistant $E$. coli strains had been isolated from the lurkey carcasses after slaughtering. $\left.{ }^{\text {[ }} 109\right]$

In contrast, there was no difference between the prevalence of furazolidone or tetracycline resistant $E$. coli between the 2 animal populations and between the 2 groups of farmers. For furazolidone, as with the fluoroquinolones, horizontal transfer of resistance via plasmids or transposons is not inportant for dissemination of resistance, but only clonal spread of resistant strains. These results therefore suggest transfer of resistant strains from animals to humans. The extent of transfer seems to be correlated with the prevalence of resistance in the animal population, which is positively correlated with the amounts of antibiotics to which the animal population is exposed. In the same study, VRE were isolated from a turkey farmer and his turkeys which were not only identical using PFGE after SmaI digestion, but also had a VanA-gene with a unique mutation. ${ }^{[105]}$ This again strongly indicates transfer of resistant strains from animals to humans.

In Sweden, no VRE were found in the faecal flora of healthy humans and animals, and no VRE could be detected in stool samples of healthy volunteers after taking a course of oral vancomycin. [146] However, in Belgium in a similar experiment, all volunteers in which no VRE were found in their stool samples before the study, became positive. ${ }^{[14]]}$ This is in concordance with the results of Quednau et al.. ${ }^{[148]}$ who were able to isolate VRE from Danish but not Swedish meat products, and a Dutch study in which VRE could only be isolated from faecal samples of carnivorous humans but not from vegetarians. ${ }^{\text {|149] }}$

\section{Transfer of Resistance Genes from Animals to Humans}

In 1976 in a prospective study, Levy observed transfer of tetracycline resistance genes between chicken $E$. coli-strains, from chicken to chicken and from chicken to humans, in chickens fed tetracycline. ${ }^{1150,151]} \mathrm{A}$ wide dissemination of a tetracycline resistance gene (tet $Q$ ) was observed by Nikolich et al. ${ }^{[152]}$ They found identical tet $Q$ genes 
in host-specific intestinal flora bacteria; Bacteroides spp. and Prevotella intermedius from humans, and $P$. ruminicola from bovines. ${ }^{[152,153]}$ The relationship between the use of an antibiotic and the dissemination of bacterial resistance from animals to humans has been described in detail by Hummel et al. ${ }^{[154]}$

In 1982 in the former German Democratic Republic (DDR) nourseotricin, a streptotricin antibiotic, was introduced as an AGP for pigs. Streptotricin antibiotics have not been used in human medicine and do not show cross-resistance with other antibiotics. Resistance to nourseotricin became, within 1 year after its introduction, common in faecal $E$. coli from pigs fed this antibiotic. The resistance genes were located on transposon $\mathrm{Tn}$ 1825 and within 2 years this transposon was found in faecal isolates from pig farmers and their family members, in urban residents, and in $E$. coli isolated from urinary tract infections in humans. A few years later it was also found in pathogenic bacteria, not only in zoonotic bacteria like Salmonella spp. but also in Shigella spp., which only affect humans and do not have an animal reservoir. Outside the DDR, nourseotricin resistance has never been found.

Other examples of the dissemination of resistance genes from animals to humans are the dissemination of the aac 4 -gene (apramycin resistance) and $h p h B$-gene (hygromycin resistance) from animals to human bacteria. These genes are cotransferred. Despite the fact that apramycin is only used in animals, these genes have been found in animall isolates or zoonotic bacteria isolated from humans, in Enterobacteriaceae in the environment, the intestinal flora of farmers, and in hospital isolates. ${ }^{[155.158]}$ A high degree of similarity between plasmids encoding for $a a c C 4$ and $h p h B$ from these sources has been demonstrated. ${ }^{[15 \%, 100]}$ A question regarding the similarity of the VanA-gene cluster from animals and humans has been addressed in several studies. In a study from Norway, horizontal transfer of the gene cluster was strongly suggested, that is, 9 out of 12 human and 7 out of 10 poultry isolates were identical. ${ }^{[161]}$ In the Netherlands, sim- ilarity between a VRE isolated from a turkey and a turkey farmer was demonstrated . ${ }^{\text {(105]) }}$ Furthermore, in a study from the $\mathrm{UK}$, the novel insertion sequences in the VanA genes from VRE isolated from poultry were not found in hospital isolates. ${ }^{[162]}$

\section{Conclusions}

In animals, as with humans, the use of antibiotics causes an increase of resistance both in pathogenic bacteria, and in the endogenous flora of these animals. Resistant bacteria from animals, that is, zoonotic bacteria or intestinal flora, can infect or reach the human population by direct contact, and also via food products of animal origin. These resistant bacteria can colonise humans and/or transfer their resistance genes to other bacteria belonging to the endogenous flora of humans. Moreover, the greater the number of resistant bacteria in the intestinal flora, the greater the likelihood that genes encoding resistance will be transferred to (potentially) pathogenic bacteria, and disseminated into the environment from animals to foods of animal origin. In this respect, one might consider the resistance observed in zoonotic and nosocomial pathogens to be just the tip of the iceberg.

As bacteria from the human flora cause not only infections in immunocompromised hosts, but are also considered an important reservoir of resistance genes for human pathogens, it has been proposed that a low level of carriage of resistant strains by humans should be a public health goal in much the same way as a normal blood pressure and a low serum cholesterol level are public health goals. ${ }^{[96]}$ Despite the fact that it is not yet clear to what extent the use of antibiotics in animals contributes to the resistance problems in human medicine, it cannot be disputed that there is a definite link. Because we are now encountering multiresistant micro-organisms in the clinical setting which are difficult to combat with currently available antibiotics, every source of resistance must be controlled as efficiently as is feasible. Consequently, a low level of resistance in the intestinal flora of food animals should be thought of as a distinguishing safety and quality mark for food animals. $[24,28]$ 
Moreover, this will not only protect public health, but also safeguard the future efficacy of antibiotics in veterinary medicine.

This goal can only be achieved by reducing the amounts of antibiotics used in animals. The requirement for antibiotics in veterinary therapy and bacterial infection prevention should be minimised by improving methods of animal husbandry, disease eradication, optimal use of existing vaccines and the development of new vaccines. If antibiotics have to be used, the use of agents with a narrow spectrum of activity should be preferred and this use should be according to a sensible veterinary antibiotic policy. ${ }^{[163]}$ Discontinuing the practice of routinely adding AGP to animal feeds would reduce the amount of antibiotics used for animals in the EU by a minimum of $30 \%$ and in some countries by up to $50 \%$. In this case, the public health risks should be weighted against the economic profits. The Swedish have shown that modern and profitable animal husbandry without AGP is feasible. ${ }^{[20]} \mathrm{A}$ ban on the use of AGP would encourage research into alternatives like pre- and probiotics.

\section{References}

1. Murray BE. New aspects of antimicrobial resistance and the resulting therapelitic dilemmas. J Infect Dis 199! $163(6)$ $1184-94$

2. New HC. The crisis in antibiatic resistance. Science $1992 ; 257$ $(5073): 1664-73$

3. Whe R, Hart T, Cars O, et al. Antimicrobial resistance is a major threat to public health. BMU 1998: 317:609-10

4. Murray BE. Problems and dilemmas of antimicrobial resisfunce. Pharmacotherapy $1992: 12: 865 \mathrm{~s}-93 \mathrm{~s}$

5. Murray BE Cam antibiotic resistance be controlled? $N$ Engl J Med 1994:330(17):1229-30

6. De Craene A, Viaene 1. Economics effects of technology in agriculture. Do perfomance enhancers for animals benefit consiumers? Report University of Gent. Belgium "Faculty of Agriculiural Sciences. Department of Agro-Marketing 1992; 162

7. Rosen GD. Antibacterials in poultry and pig nutuition. In: Wallace $\mathrm{RJ}$, Chessoli $\mathrm{A}_{\text {; }}$ editors. Biotechnology in animal feeds and feeding. Weinheim: VCH Verlagsgesel Ischaft mbH, 1995:47:143.72

8. CEAS. The impact of animal husbardry in the European Community of the wse of growth promoters in arimal Feeds. Brussels E.C. 1991 Feb; 1, 2: 319

9. Thomke S, Elwinger $K$. Growth promotants in feeding pies and poultry. Il. Mode of action of antibiotic growth promotants. Ann Zootech 1998:47 (3): 153-67

10. Forbes M, Park JY'. Growth of germmfree and conventional chicks: effect of diet, dietary penicillin and bacterial environ. ment. J Nutr $1959 ; 69 ; 78-84$
11. Frost AJ. In: Woolcock JB, editor. Microbiology of animats and animal protucts. Antibiotics and avimal production. Amsterdam: Eksevier, 1997: 181-94

12. Thomke $S$. Elwinger $K$. Growth promoters in feeding pigs and poultry. III. Alternatises to antibiotic gow th promotes. Ant Zooted 1998; $47(4): 245-71$

13. Jukes TH. The history of the "antibionte growth effect". Fed Proc $1977: 36(11): 2514-8$

14. Jukes "TH. The present status and background of antibiotics in the fereding of domestic aminals. Ann $\mathrm{N}$ Acad Soi 197: 182:362-79

15. Prescot JF, Baggot JD. Antimicrobial therapy in veterinary medicine. Ames, Lowa State University Press: 1993

16. Dewriese $\mathrm{L} A$, Daube $\mathrm{G}$, Hommez J, al Ir viro susceptibility of Clostridim perfringens isolated from farm aninals to growth-enhancing antibiotics. J Appl Bacteriol 1993: 75 (1): $5.5 \% 7$

17. Dutta GN, Devriese L.A. Susceptibility of fecal streptococoi of poulty origin to nine growth-promoting agents. Appl Envi. ron Microbiol 1982;44 (4): $832-7$

18. SOU. Antimicrobial Feed Addives. Repott trom the commission on antumicrobual feed additives. Stockhol ru, 1997: 132

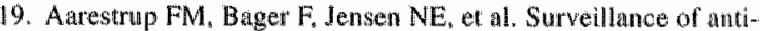
microbial resistance in bacteria isolated from food animals to antimicrobial growth promoters and related therapentic agents in Denmark. APMIS 1998; 106:606-22

20. Wherup M. Preventive methods replace antiblotic growth prow moters: ten years axpenience from Siweden. APUA Newsletter 1998: $16: 1-4$

21. van den Bogand $A E$, London $N$, Driessen $C$, el al. The effect of antimicrobial giow th promoters on the resistance tu faecal Indicator bacteria of pigs [abstract]. Proceedings of the 38 th Interscionce Conference on Antimicrobial Agents and Che motherapy: 1998 Sep 24: 7; San Ditgo: 1998; C077

22. Witte W. Impact of antibiotic une in animal ficeding on resiso

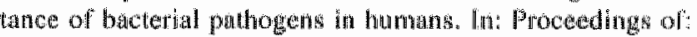

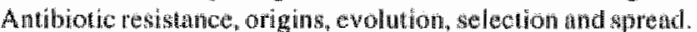
Ciba Fourd Symp 1997:207:61-71

23. Swann MM Joint Committee on the use al antibiotics in animal husbandry and veterinary medicine. London: Her Wajesty"s Stationary Office, 1969

24. van den Bogard $\mathrm{AE}_{\text {s }}$ Stobberingh $\mathrm{EE}$. Thne to ban anll antibiotics as animal growith-promoting agents? [letter]. Lancer $1996: 348,(9027): 619.1454 \times 6$

25. Chopra 1, Hodgson $j$, Metcall B, et at The semoh for antimicrobial agents effective against bacteria restent to multhple antibiotics. Antinicrob Agents Chemolner 1997; 41 (3): 497.503

26. Jones $R$ N Marihall SA, Erwin ME. Antimicrobual activity and spectrum of SCH27899 (2aracing tested engand Gram positive species including recommendations for routhe susceptibility testing methods and quality control. Diagn Microbiol Infeat Dis 1999:34:103\%10

27. Cook $\mathbb{R}_{\mathrm{k}}$. Antimicrobial resistance-use in veterinary and human medicine. I Antimicrob Chemother $1997 ; 39(3): 435$

28. van den Bogaard $\mathrm{AE}$, Antimicrobial resistance - relation to human and animal exposure to antibiotics [letter]. I Antimicrob Chemother 1997:40 (3): 453-4

29. de Neeling Al, van Klingeren B, Harteloh PPM. Het gebruitk yan antibiotica ber hetreden wan resilstentiv. Volksgezondheid Toekomst Verkenning, 1995-2010. RIVM 1993: $658-62$ 
30. Emersen AM. Control of the spread of resistance. In: Greenwood, D, editor. Antimucrobial chemotherapy. Oxford: Oxford University Press, 1995

31. Miller DJS. Present statle and heads in the wse of veterinary drugs. In: Proceedings of Euroresidue II: conference, Veldhoven, The Netherlands; 1993 May $3-5$

32. Prescott JF. Antibiotics: Miracle drugs or pigg food? Can Vet J $1997: 38(12): 763-6$

33. Levy SB. Multidrug resistance - a sign of the times. N Engl J Med 1998; $338(19): 1376-8$

34. DANMAP, 1995. Consumption of antimicrobial agents and occurence of antimicrobial resistance in bacteria from food animals, food and humans in Denmark. 1997" DANMAP No.

35. Reynolds P. Glycopeptide antibiotics: phamacokinetics, spectrum of activity, resistance patterns. Hosp Formulary 1990 $25: 537-44$

36. Arthur M, Courvalin P. Genetics and mechanisms of glycopeptide resistance in enterococci. Antimicrob Agents Chemother 1993: 37 (8): $1563-71$

37. Arthur M, Reynolds P. Couryalin P. Glycopeptide resistance in enterococci. Trends Microbial 1996; 4 (10): 401-7

38. Leclercq $R$, Derlot $\mathrm{E}$, Weber M, et al. Transferable vancomycin and teicoplanin resistance in Enterosoccus faecium. Antimicrob Agents Chemother $\| 989 ; 33(1): 10-5$

39. Quintiliani Jr R, Courvalin P. Conjugal transfer of the wancomycin resistance determinant wan $B$ between enterococci involves the movement of large genetic elenents from chro. mosome to chromosome. FEMS Microbiol Lett 1994; 119 (3) $359-63$

40. Quintiliani $J_{n} R$, Courvalin P. Characterization of Tn 1547, a composite transposon flanked by the IS16 and IS256-like elements, that confers vancomycin resistance in Enterococcas faecatis BM4281. Gene $1996 ; 172$ (1):1.8

41. Woodford $\mathrm{N}_{n}$ Jones BL, Baccus $\mathrm{Z}$, et al. Linkage of Wancomycin and high-Hevel gentamicin resistance genes on the same plas. mid in alnical isolate of Enterococcus faecalis. J Antimicrob Chemother 1995; 35 (1): 179-84

42. Noble WC, Virani Z. Cree RG. Co-transfer of vancomycin and other resistance grenes from Enteracoccus faccalis NCTC 12201 to Stophylococos aurets. FEMS Microbiol Let 1992; $72(2): 195-8$

43. Devriese LA, Ieven M, Grossens $H$, et all Presence of vancomycin-resistant enterococi in farm and pet animals. Antimicrob Agents Chemother 1996:40 (10):2285.7

44. Bates J, Jorders 22 , Griftiths DT. Farm animals as a putative reservoit for wancomycin-resistant elaterococcal infection in math. J Antimicrob Chemother 1994; 34 (4): 507-14

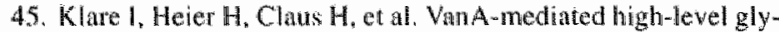
copeptide resistance in Enerococcus foccium from animal husbandry. FEMS Microbiol Lett 1995; 125 (2-3): 165-71

46. Coque TM, Tomako JF, Ricke SC, et al. Vancomycin-resistant enterococi from nosocomial community, and animal sources in the United States. Antimicrob Agents Chemother 1996: 40 (11): $2605-9$

47. Greko C. Lindbad J. Vancomycin sensitivity of enterococci from Swedish poultry and pigs. Proceedings of Symposium Food Associated Pathogens; 1996 May 6-8; Department of Food Hygiene, SLU, Uppsala, Sweden

48. Patel R. Uhil $\mathbb{R}$, Kohner $P$, et al. Multiplex PCR detection of wand, vanB, vanC-1, and vanC $2 / 3$ genes in enterococoi. J Clin Microbiol 1997:35 (3): 703-7

49. Woodford N. Glycopeptide-resistant enterococal a decade of experience. J Med Microbiol 1998; 47:849-62
50. Cormican MG, Johnson DM. Jones RN. Activity of the quinupristin-dalfopristin combination (RP-59500; Synercid) tested against vancomycin-resistant Enterococcus species. Diagn Microbiol Infect Dis 1996; 24 (1): $59-60$

51. Putnam $\mathrm{SD}$, Jones $\mathrm{RN}$, Johnson $\mathrm{DM}$, el al. In witro antimicrobial activity and MIC quality control guidelines of RPR 106972 (RPR 112808/RPR 106950): a nowel orally administered streptogramin combination. Diagn Microbiol Infect Dis 1997: $28(3): 139-47$

52. Leclercq $R$, Courvalin $P$. Bacterial resistance to macrolide, lincosamide, and streptogramin antibiotics by target modification. Antimicrob Agents Chemother 1991; $35(7): 1267-72$

53. Leclereq $R$, Courvalin $P$. Intrinsic and unusual resistance to macrolide, lincosamide, and streptogramin antibiotics in bacteria. Antimicrob Agents Chemother 1991; $35(7): 1273-6$

54. Rende Fournier R, Leclercq $\mathbb{R}$, Galimand $M$, et al. Identification of the sat $A$ gene encoding a sireptogramin $A$ acetyltuanserase in Enteracoccus faecium BM4145. Antimicrob Agents Chemother 1993:37 (10): $2119-5$

55. Jensen $L$, Hammerum AM, Aarestrup FM, et al. Occurence of sat $A$ and rgb genes in streptogramin-resistant Enterococow faeciam isolates of animal and louman origins in the Nether lands. Antimicrob Agents Chemother 1998: $42: 3330-1$

56. Weisblum B. Erythromycin resistance by ribosome modification. Antimicrob Agents Chemother 1995; 39:577-608

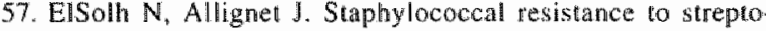
gramins and related antibiotics. Drug Resist Update 1998: 1 (3): $169-75$

58. Poyart-Salmeron C. Carlier C, Trieu-Cuot P, et al Transferable plasmid-mediated antibiotic resistance in Listeria monocytogenes. Lancet 1990; $335(8703)$ : 1422-6

59. Doucet-Populaire F. Trieu-Cuot P, Dosbaa $I$, et al. Inducitble transfer of conjugative transposon Tw1545 from Enterococ. cus facentis to Listeria monocytogenes in the digestive tracts of gnotobiotic mice. Antimicrob Agents Chemother 1991; 35 (1): 185.7

60. Wolf $\mathrm{H}$. Avilamycin, an inhibitor of the 30 S ribosomal subunits function. FEBS Lett 1973; $36(2): 181-6$

6!. Aarestop FM. Association between decreased susceptibility to a new antibiotic for treatment of human diseases, ever ninomycin (SCH 27899), and resistance to an antibiotic used for growth promotion in animals, avilamycin. Microb Drug Resist Mech Epidemiol Dis 1998; 4: 137.41

62. Prescott JF, Sivendra $\mathbb{R}_{4}$ Barnum DA. The use of bacitracin in the prevention and treatment of experimentally-induced ne crotic enteritis in the chicken. Can Vet J 1978;19(7): 181-3

63. Wicker DL, Isgrigg WN, Trammel JH. The control and preven tion for necrotic enteritis in broilers with zinc bacitracin. Poultry Sci 1977; $56: \mid 229-31$

64. Weidema WF, van den Bogaard AE. Whole gut irrigation and antimicrobial prophylax is in elective colorectal surgery. Neth J Surg 1984; 5: 1-108

65. O'Donovan CA, Fan-Havard P, Tecson-Tumang FT, et al. Enteric eradication of vancomycin-resistant Enterococcus faecium with oral bacitacin. Diagn Microbiol Infect Dis 1994; 18 (2): $105 \times 9$

66. Chia JK, Nakata MM, Park SS, et al. Use of bacitracin therapy for infection due to vancomycin-resistant Enterococcts faecUum. Clin Infect Dis 1995; 21 (6): 1520

67. Cain BD, Norton PJ, Eubanks W, et al. Amplification of the bacA gene confers bacitracin resistance to Excherichio coli. J Bacteriol 1993: 175 (12): 3784.9 
68. Allen NE, Hobbs Ir IN. Induction of vancomycin resistance in Enterococos foccium by ron-glycopeptide antibiontics. FEMS Microbiol Let 1995: $132(1.2): 107.4$

69. Lai MH. Kirsch DR. Induction signals for vancomycin resisLance encoded by the wan gene cltster in Enterococcus fore ium. Artimicrob Agents Chemother 1996 : 40 , 7 : 1645-8

70. Walton JR. The effect of zinc bacitacin on the suceptibitity of selected Grammegative and Grampositive bacteria to thera peutic antibiotics. Zentralbl Veterinar Med B 1978; 25 (4): $329-1$

71. Walton JR, Whe Jer JE Loss of resistance to the tetracyclines from porcine Eschericha coli in contact with dietary bacitracin methylene disalicylate. Zentralbl Veterinarmed $\mathrm{B} 1987$; $34(3): 161.4$

72. Walton JR. The effect of dietary zinc bactuacin on the resistance status of intestinal Escherichio colt and enterococci from broiler chickens. Zentralbl Vekrimat Med B 1984; 31 (1): 1.8

73. Gedek B. Factors influencing multiple rexistance in entertic bactheria in animals. Proceedings of ten years on from Swamm; London: 1981 Oct $5-6: 1111-26$

74. Huber G. Monomycin and related phospons contaming antibiotics In: Hahn FE, editor. Antibiotics. New York: Springer Verlag, 1979: 135-53

75. Dealy 1. Moeller MW. lnfluence of bambermycins on Salmo nella infection and antibiotic resistance in swine. I Anim Sei 1976; $42(5): 1331-6$

76. Dealy J, Moeller MW. Effect of bambermycins on Escherichia coli and antibiotic resistance in calves. J Anim Sci 1977; 45 (6): $1239-42$

77. Dealy $\mathrm{J}$, Moeller MW. InTuence of bambermycins on Salmonella infection and antibiotic resistance in calves. J Anim Sci $1977 ; 44(5): 734-8$

78. Corpet DE. The effect of bambermycin, carbadox chlortetra cycline and olaquindox on antibiotic asestance in intestinal coliforms: a new animal model. Ann Microbiol Paris 1984. 135in (2): 329.9

79. Sepulche M. Flawomycine: inhibition de l'antibioresistance chez les enterobacteries. Bulletin Mensuel de la Soctete Véterinaire Practique de France 1979; 63, 199.225

80. George BA. Fagerberg DA, Quarles CL, at al Effect of bambermycins on quantiry prevalence, dumion, and antimi. crobial resistance of Solmonella syphomarim in experimentally infected broiler chackens. Am J Vet Res 1982; 43 : $299-303$

81. George BA. Fangerberg DJ. Effec of bambermycins, in wirn, on plassmid-mediatted antimictobial resistance. Am J Vet Res $1984: 45: 2336-41$

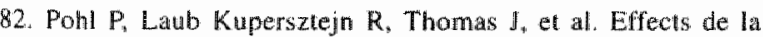
Aavomycine et de quelques agents antiparasilaires sur une souche colbacillaire hébergeant divers facteurs-R. Ann Med Vet $1975 ; 119: 51 \%$ ?

83. Devriese LA. Sensitivity of staphylococci from farm animal 10 antibacterial agenis used for growth promotion and therapy: a ten year study. Ann tes Vet 1980: 11 (4): $399-408$

84. Onmae $K$, Yonezawa $S$, Terakado $N$. R plasmid with cabadox resistance from Escherichia coll of porcine origin. Anti. microb Agents Chemother 1981:19 (1):86.90

85. Ohmae K Yonezawa S. Terakado N. Epizootiological studieg on R plasmid with carbadox resistance. Nippon Juigaku Zasshi $1983 ; 45(2): 165-79$

86. Quelete M, Nicas $M$, Kundig C Antimicrobial multidrug resistance. Int J Antimicrob Agents 1997;8 (3): 179-87
87. Cohen SP, Hachler H, Levy SB. Gemetio and hunchonat andysis of the nulliple ancibion restance (mar) locus in Esclues. ichacoli. I Buctertol 1993; 17\$ (5): $1484-92$

88. Hartmain FA. Trostle SS, Klohnen AA. Isolation of methicil. lin-resistant Strophlococous aurew from a postoperative wound infection in a horse; $f$ An Vet Med Assoc 1997; 21 (5): $590-2$

89. Tombin J, Pead MJ Lloyd DH, et methicillin-mesistant SraphWococurs anpeus infactions in 11 dogs. Vet Rec 1999; 144: $60-4$

90. Courvalin P. Transfer of antibiotic resistance gene between Gram-positive and Gram-negative bucteria. Antimichob Agents Chemother 1994:38(7): 1447-51

91. Brisson-Nioel A. Arthur M, Couryatin P. Evidence of notural gene transfer from Gram positive coci to Endherichia coli. I Bacterio $1988 ; 170: 1739-45$

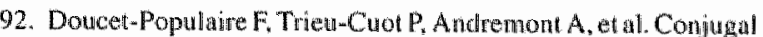
transfer of plasmid DNA from Enerococos faecals to Esch. erichia colt in digestive tracts of gnotobiotic mice. Antimicrob Agents Chemother 1992; 36 (2):502-4

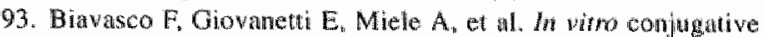
transfer of VanA vancomycin resistance between Enterococci and Listerime of differenl species. Eur J Clin Microbiol Infed Dis $1996 ; 15(1): 50.9$

94. Fintalitin A, Mollby R. Concurtent transfer and recombination between plasmids encoding for heat-stable enterotoxin and drug resistance in porcine enterotoxigenic Escherichio coli. Med Microbiol Immunol Berl 1983; 172 (3): 137.4\%

95. Mullany P. Wilks M. Taba of challi S. Transter of mactolidem lincosamide streptogramin B (MLS) resistance in Chomrid. inm diffichle is linked to a gene homologous with toxin A and is mediated by a conjungative tansposon, Tn 5398 . I Antinicrobial Chemother 1995; 35:305: 15

96. Lester $\mathrm{SC}$, del Pilar-Pla M, Watg F, et al, The carriage of Esch. wrichia coli reshstant to antimicrobial agents by thealthy chi dren in Boston, in Cabacas, Venoznela, and in Oin Pu China, N Engl Med 1990:323(5):285-9

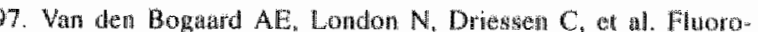

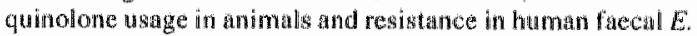
coll labstact 37 th Intemational Conference on Antimionom bial Agents and Chemothertpy: 1997 Sep 24-7; Torono. $\mathrm{C}-137$

98. Linton $A H_{3}$ Hinton $M H$, Al Chalaby $2 A$. Monitoring for antibiotic resistance in enteracocci consequent upon feeding growth promoters aldive against grami-positive bacteria. I Vet Pharmacol Then 1985; 8 (1): 62.70

99. That LA, Welton LA, Perti MB, et all. Antimicrobial resistance in enterococci isolated from turkeys fed virginamycin labstract. Proceedings of 36 th tritermational Conference on Antimicrobial Agents and Chemotherapy; 1996 Sep 15.18; New Orleans

100. Linton AH, Hedges A. Benner PM. Moniloring for the development of minichobal resistance during the wat of oldquindox as a feed additive on commercial pir farms. I Appl Bacteriol 1988: 64:3)1-27

101. Mills KW, Kelly BL. Antibiotic susceptibilities of swine Sal monella isolates from 1979:0 1983. Am J Ver Res 1986:47 (11): 2349.50

102. Hedges AJ. Lintor AH. Ofaquindox resistance in the colliform flora of pigs and their enviromment: an ecological study. J Appl Bacteriol 1988; 64 (5):429-3

103. McDonald LC, Kuehnert MJ. Tenover $\mathrm{FC}$, et al. Vancomycin. resistant entacocei outside the health-care setting: prewa 
Ience, sources and public health implications. Emerg Irfect Dis 1997; $3(3): 311 \%$

104, van den Brak N, van Belkum A, wan Keullen M, et al. Molecular characterizalon of wancomycinu resistur enterococei from hospinatized patients and poultry products in the Nethrelands. JChin Microbiol $1998 ; 36 ; 1927-32$

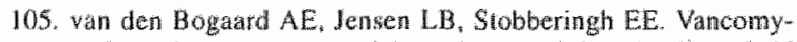
cin-reststant anterococo in turkeys and farmers [letter]. No Engl I Med $1997 ; 337$ (21): 1558-9

106. van den Bogard AE, Merten P. London NH, et al. High prevatence of colonization with vancomycin- and pristinarrycinresistant enterococes in healthy humans and pigs un The Netherlands: is the addion of antibiotics to animal feeds to blame? [leter). J Antimicrob Chemother 1997:49)(3):454\%

107. Tast E, Honkanen Buzalski $T$, Mannerkorp $P$. Tylosin and spiramycin as feed additives: influence on the efficacy of therapeutic macrolides. Report of the Ministry of Agriculure and Fonestuy of Finland, Julkaisuja, May 1997

108. Antmicrobial Growth Promoters. Commuttee on Antimictobial Corowth Promoters. Halth Council of the Netherlands, 1998 : No. 1998/15E, Rijswijk, The Nethertands

109. Van den Bogand A, London N, Driessen $C_{\text {i }}$ e all. Prevaldace of resistant faecal backeria in turkeys, turkey farmers and turkey slatghterers Iabstract. 36th International Conference on Antimicrobial Agents and Chemotherapy: 1996 Sep 15-8; New Onleans: $\mathrm{C}-163$

110. Bager F, Madsen M. Christensen J, at al. Avoparcin used as a growth promoter is alssocithed wh the oceurrence of vanco-

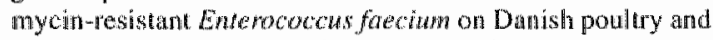
pig farms. Prev Vet Med 1997; $31(1-2): 95-112$

H11. Bezanson GS, Khakhria R, Bollegraf E Nosocomial outbreak caused by antibiote-nesistant strain of Salwonella typhmu ium acquired from day catle. Can Med Assoc J 1983; 128 $(4): 426-7$

112. Hohmberg SD. Oskrholm MT: Senger KA, ot al. Drug-resistant Salmondu from anmals fed antimicrobials. N Engl J Med $1984: 311(10): 617.22$

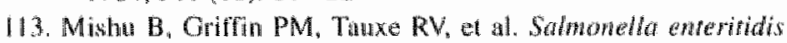

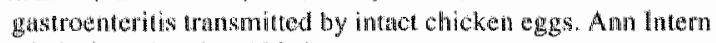
Med 1991:115(3):190-4

14. Splka 1S. Wateman SH, HoO OW, al. Chloramphenteol.

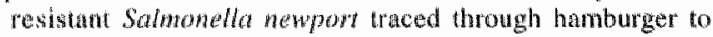
dary farros an mor persisting source of human salmonellosis in Califonia. Engl J Med 1987; 316 (10):565-70

115. Datua $N_{1}$ Maghes VM. Plasmids of the swame Ine groups in Enterobacteris before and atter the medical wse of antibiotics. Nature $1983 ; 306(5943): 6: 16-7$

116. Delener J. Hacebart K. Enquête sur la role joué dans propagation de Samonalla ol Shigella par les porteurs de germes datns lindustrie de la viande. Med Mal lnfect 1980: 10:394-8

117. Wray C. Medical impact of antimicrobiall use in food anjmat production: soencrios and risk assessment Salmonella and $\mathbb{E}$. colf in England and Wales. Proceedings of the WHO Meeting on the Usage of Qunolones in Animals. $19970 \mathrm{ct} 13-7$; Bentin

118. Manten A, Guines PA, Kanpelmacher EH, et al. Arueven year study of drug resistance in Salmonella in the Netherlands. Buil Word Heall Organ 1971:45 (1):85-93

119. Voogd $C E$, Guinee PA. Manten $A$, et al. Incidence of resistance to tetracychine, chloramphenicol and ampicillin anong Sallmonella species isolated in The Netherlands in 1965 and 1966. Antonie van Leeuwenhoek 1968; 34(3):357-64

120. Voogd $C E$, Oumee PA, Manten $A_{4}$, et al. Incidence of resistance to letracycine, chloramphenicol and ampicillin arnong Sal- monella species isolated in the Nethertands in 1967 and 1968. Antonile vat Leewwenhoek 1970; 36 (2): 297-304

121. Voogd CE, wain Leeuwer WJ, Guiree PA, el all Incidence of ressistance to ampicillin, chloramphenicol, kamanycin and hetracyclne among Salmonelta species isolated wn the Netherlands in 1972,1973 and 1974. Antonic var lueeunenhok $1977,43(3-4), 269-81$

122. van Leewwen WJ, Hoogd C. Guinee PA, et al. Incidence of reatsance to ampicitin, choramphenicot, kanamycin. vetracycline and trimethoprim of Samonella strains isolated in "he Netherlands during 1975-1980. Antonie van Leewwenhouk $1982 ; 48(1): 85-96$

123. Cherubin CE Epidemiological assessments of antibiotic resistance in Salmonella. In: Sted JH, Beran GW, edutors. CRC Handbook series in zoonoses. Boca Raton (FL): CRC Press Inc. 1984: 173-200

124. National Academy of Sciences. Committee to stady the human heallh aspects of subtherapeutic antibiotic use im annal feeds. Washington, DC: National Press, 1980

125. Throlfall EJ. Frost $\mathbb{A}$, Ward $\mathrm{LR}_{\text {, }}$ et al. Epidemie in catte and humans of Salmonella sphimurimo DT 104 with chromosomally megrated multiple drug resistance [see comments]. Vet Rec 1994: 134 (22): 577

126. Thelfall EJ, Frost JA. Ward LR, at all. Increasing spectrum of resistance in multiresustam Salmonella mphimuriwm [letter]. Lancet $1996: 347(9007): 1053-4$

127. Enduz HP, Ruijs GT, van Klingeren $B$, et all. Qumolone resistance in campylobacter isoleted from man and poultry following the introduction of fluoroquinolones in veterinary medicine. I Antimicrob Chemother 1991" 27 (2): 199-208

128. Jacobs-Reitsma WF, Kan CA, Bolder NM. The introduction of quinolone resistance in Campylobacter bacteria in broilcts by quimolone treatment Let Applied Microbiol $1994 ; 19(4)$ : $228-31$

129. Gant PN, Piddock LJ Ciprofoxacinmesistant Campyobacier spp. in humans: an epidemiological and laboratory study.J Antimicrob Chemother 1996, $37(4): 747-57$

130. Perez Trallero E, Zigottrga $\mathrm{C}$, Cilla $\mathrm{G}$, et al Amimal origin of the antibiotic resistance of human pathogenic Yersimia et. tenowolitich [letted]. Scand J Infect Dis $1988 ; 20(5): 572-3$

131. Wan der Waij D. Colonizution resistarce of the digestive tract: clinical consequences and implications. I Antimicrob Chemother 1982;10(4): 263-70

132. Vollarard Es, Clasener HA. Colonization resistance. Antimicrob Agents Chemother 1994:38 (3):409-14

133. Vollard EJ, Clasener HA, var Saene HK, et al. Effect on colonization resistance: an important ctiterion in selecting antibiotics. DICP 1990; $24(1) ; 60$ 6

134. Barrow PA, Smith HW, Tucker JPE The effect of feeding diets containing avoparcin on the excretion of salmonellas by chickens experimentally infected with nairal sources of salmonellin organisms. J Hyg Lord 1984; 93 (3): 439-4

135. Barrow PA. Further obserwations on the effect of feeding dient contaning avoparcin on the excretion of salmonellas by $\mathrm{ex}$ perimentally infected chickens. Epidemio Infect $1989 ; 102$ $239-52$

136. Custafson RH, Beck JR, Kohbland JD. The influence of Avoparcin on the establishment of Salmonella in chickens. Zentratbl Veterinär Med B 1981; 29:119-28

137. Abon Yousset MH, DiCuollo C. Miller CR, et a l. Intuence of a sub-therapentic level of virginiamycin in feed on the incidence and persistence of Salmonella rphimurimm in experimentally infected swine. J Anim Sci 1979; $49(1): 128-33$ 
138. Abou Youssef MH, DiCuollo CJ, Free $S M$, et al The influence of a feed additive level of virginamycin on the course of an experimentally induced Salmonethat typhwiwn infection in broilers. Poult Sci 1983:62 (1):30-7

139. Mathes S, Leuchtenberger WG. Loliger HC. Effect of antubiotic feed additives on the intestinal flora and the persistence of salmonellae in chickens. Ditsch Tierarzl Wochenschr 1982: $89(1): 19-22$

140. Smith HW Tacker JF. The effect of feeding diets containing permitted antibiotics on the faecal excretion of Salmonella typhimurium by experimentally infected chickens. I Hyg Lond 1975,75 (2): 293-301

141. Smith HW Tucker JF. The effect of antimicrobial feed additives on the colonization of the alimentary tract of chickens by Salmonella typhimuritum, J Hye Lond 1978; 80 (2): 217-31

142. Ford $A M$, Fagerberg DJ. Quarles $C L$. et all. Influence of salinomycin on incidence, shedding, and antimicrobial resistance of Salmonelia typhowurim in experimentally infected broiler chicks. Poult Sci 1981;60 (11):2441-53

143. Corpet DE. Antibiotic resistance from food [letter]. N Engl J Med 1988; $318(18): 1206-7$

144. Nijsten $R$, London N, van den Bogaard A, et at. Resistance in faecal Eschericha coll isolated from pigfarmers and abattoir workers. Epidemiol Infect 1994; 113 (1): 45-52

145. Nistem R, London $N$, van den Bogaard $A$, et al. Antibiotic resistance among Escherichia coli isolated from faecal samples of pig farmers and pigs. J Antimicrob Chemother 1996; 37 (6): $1131-40$

146. Edlund C. Barkholt L, OlssonLillequist B, et al. Effect of wancomycin on intestinal flora of patients who previously received antimicrobial therapy. Clin Infect Dis 1997; 25. $729-32$

147. van der Auwera P, Pensart $N$, Korten V, ef al. Influence of orat glycopeptides on the faecal flora of human volunteers: selection of highly glucopeptide resistant enterococci. Infect Dis $1996 ; 173(5): 1129-36$

148. Quednat M. Ahrne S, Petersson AC, et al. Antibiotic-resistant strains of Enterococcus ssolated from Swedish and Danish retailed chicken and pork. J Applied Microbiol 1998:84 (6): $1163-70$

149. Schotten MA, Voss A. Hoogkarmp-Konstanje JAA. Carnivorous humans, but not from vegetarians [letter]. Lancel 1997: 349: 1258

150. Levy SB. FitzGerald GB, Macone AB. Spread of antibioticresistant plasmids from ahicken to chicker and from chicken to man. Nature $1976 ; 260(5546): 40-2$

151. Levy SB, FitzGerald GB. Macone AB. Changes in intestinal flora of farm personnel after introduction of a tetracycline supplemented feed on a farm. N Engl I Med 1976; 295 (11): 583-8

152. Nikolich MP. Hong G, Shoenaker NB, et al. Evidence for natural horizontal transfer of tetQ between bacteria that normally colonize humans and bacteria that normally collonize fivestock. Appl Environ Microbiol 1994; 60 (9); 3255-160
153. Shoemaker NB, Wang CR, Sulyers A A Evidence for motum transfer of a retracyctine resistance gene between bacteria from the human colon and bacteria from the bovine rumen. Appl Environ Mictobiol 1992; $58(4): 1313,20$

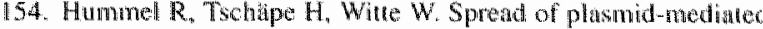
nourseothricin resistance due to antibiotic use in aninal husbandsy. J Basic Microbiol 1986:8:461-6

155. Chalus-Danclat $\mathbb{E}$, Glupczynski $Y$ Gerbaud $G$ et at. Detection of apramycin-resistant Enterobacteridece in hospital isolates. FEMS Microbiol Lett $1989: 61: 261-6$

156. Hunter $₫ \mathbb{E}$, Hart $\mathrm{CA}$, Shelley $J \mathrm{C}$ et al. Heman isolates of apramycin-resistant Excherichia di which contan the genes for the AAC (3)IV enzyme. Epidemiol Infeet 1993:110 (2): $253-9$

157. Threlfall EJ, Rowe B. Ferguson IL, et al. Characterization of plastmids conferring resistance to gentamicin and apramycin in strains of Sabmonella byphmurium phage type 2040 isolated in Britain. J Hyg Camb 1986; 97 (3): 419-26

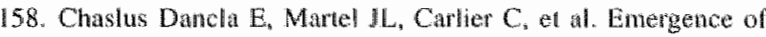
aminoglycoside 3-N-acetyltunsterase IV in Escherichio col and Salmonellatyphimurum isolated firom animals in France. Antimicrob Agents Chemother 1986; 29 (2):239-43

159. Salauze D, Otal 1, Gomez-Lus R, et al, Aminoglycoside acetyltransferase 3-IV (alacC4) and tyygromycin B 4.1 phospho. transferase (hphB) in bacteria isolated from human and animal sources. Antimicrab Agents Chemother 1990;34, (10): $1915-20$

160. Chaslus Dancla E, Poh P, Meurisse M, et all. High genetic homology between plasmids of human and animal origins conferring resistance to the aminoglycosides gentamicin and apramycin. Antirnicrob Agents Chemother 1991,35(3): $590-3$

61. Simonsen GS Haaheim H, Dah KH, et at Transmission of VanA-type vancomycin-vesistam enteroccci and VanA resislance elements between chicken and humans at avopurcin. exposed farms. Microb Drug Rusist Mech Epidemioll Di. 1998:4:313.8

162. Kitk M. Chen HY, Hill RLR, ef al. Novel insertion sequences from vancomycin-fesistant Enterweochs focchom isolated from poultry [abetract]. Procedings of 37 th international Conferenee on Antmicrobial Agents and Chemotherapy: $1997 \operatorname{sep} 28$ Oed I: Toronto. C. 134

163. van den Boguard AE. A velcrinary antibiotic policy: a personal view on the perspectives, in the Neherlands. Vea Mierobiol $1993: 35(3-4): 303-12$

Correspondence and reprints: A.E. waw den Bogard, Department of Medical Microbiology, University Menastricht, PO. Box 616,6200 MD Maastricht, The Netherlands.

E-mail: : A.vandenBogardaCPVUnimatas NL 

Chapter II

A veterinary antibiotic policy: a personal view on
the perspectives in the Netherlands 



\title{
A veterinary antibiotic policy: a personal view on the perspectives in the Netherlands
}

\author{
A.E.J.M. van den Bogaard \\ University of Limburg, Maastricht, Netherlands
}

\begin{abstract}
To reach a more adequate and responsible use of antibiotics in veterinary medicine a broad approach is required. The growing interest in the optimum use of antibiotics in veterinary medicine is stimulated by awareness of the necessity to prevent the emergence of resistance and the spread of resistant bacteria. This is a matter of primary importance to safeguard the efficacy of antibiotic therapy in animals now and in the future, but will also minimise possible public health risks. As resistance develops in rough relation to antibiotic use, the best way to minimise emergence of resistance, without interfering with optimal veterinary care, is to rationalize the use of antibiotics by, or under responsibility of, a veterinary surgeon. A second further improvement can be reached by developing a veterinary antibiotic policy to prevent emergence and spread of resistance as much as possible. Measures that must be taken in combination are:

1. Establishing a policy for the use of antibiotics jointly by veterinary practitioners and experts resulting in a formulary.

2. Systemic registration and analysis of patterns of bacterial resistance (not only of pathogens but. of faecal flora as well) and the use (qualiative and quantitative) of antibiotics in veterinary medicine.

3. Regular feedback of these data to the veterinary practitioners and consultation about the efficacy of the formulary guidelines in daily practise.

4. Systemic monitoring and evaluation the impact of the antibiotic policy and, if indicated, updating of the formulary.

5. Continuous education of veterinary surgeons about infectious diseases and antimicrobial therapy and development of a veterinary audit system.

The first step to rationalize the veterinary use of antibiotics was taken by publishing a veterinary antibiotic formulary in 1987, compiled by a group of experts. Despite the fact that this was a pure top down approach and bottom up input from veterinary practitioners was lacking, this first formulary was very well received. However the impact of this formulary on the weterinary use of antibiotics and prevalence of resistance has not been evaluated at this moment. Until now regular and nationwide systemic monitoring of resistance and registration of veterinary use of antibiotics is nol practically feasible in the Netherlands. A new formulary, based on a veterinary anibiotic policy, will be published by the end of 1992 . However, 10 be able to evaluate the impact of this policy on the prevalence of resistance and, if necessary, to adapt the policy the development of facilities for resistance epidemiology is urgently needed.
\end{abstract}

Correspondence to: A.E.J.M. van den Bogaard, DVM, DTVM, DipBact(Lon). Department of Medical Microbiology, University of Limburg, P.O. Box 616, 6200 MD Maastricht, the Netherlands.

0378-1135/93/\$06.00 C 1993 Elsevier Science Publishers B.V. All rights reserved. 


\section{INTRODUCTION}

Antibiotics are among the most used drugs in veterinary medicine and there is no field of veterinary therapy, which more directly invites intervention from outside than does antimicrobial therapy. The main reason is that the use of antibiotics inevitably leads to the emergence of resistance against the used antibiotics and spread of resistant bacteria, not only in animals but in their environment as well.

Compared with most other drugs of similar potency, antibiotics are in general remarkably safe and effective, because they are directed against invading bacteria, instead of, like most other drugs, altering a pathophysiological process in the host. This safety may have provoked liberal, even lavish use in man and animals arguing, if it doesn't do any good, it will do no harm either. Antibiotics, however, are not only effective against pathogenic bacteria, but also against the normal bacterial flora of the host. In addition the selective pressure of antibiotics, promotes the emergence of resistant bacteria among the endogenous flora. These, mainly enteric, microorganisms may colonize other animals and/or transfer their resistance plasmids to either the enteric flora of the animals treated with antibiotics or after excretion to the environmental bacterial population. The spread of these microorganisms can diminish the effectiviness of previously useful antibiotics, enforcing the use of more expensive or less safe alternatives.

On the other hand the resistance problem should not be overstated. Most specific infections have remained susceptible to antibiotics available for many years, while new and useful drugs are being marketed regularly. Therapeutic failure today is seldom due to the acquired resistance of bacteria to all the drugs available for treatment. The contribution of veterinary usage of antibiotics to the human load of resistant bacteria is still unclear. However the major selective pressure leading to resistant microorganisms in human patients is the use of antibiotics in human medicine. Nevertheless, like with all chemotherapeutics the benefit of treating animals must be weighted against the risk of unwanted side-effects. The veterinary profession in the Netherlands is well aware of the fact, that how well we use antibiotics, is a strong indicator of how effective we are in fulfilling our responsibility as veterinary surgeons. Therefore the Dutch Koninklijke Maatschappij voor Diergeneeskunde (Royal Society for Veterinary Medicine: KNMvD) has decided to develop a veterinary antibiotic policy to safeguard the continuous efficacy of veterinary antibiotic therapy now and in the future and to take responsibility for public health.

\section{Rationale}

As resistance to antibiotics develops in rough relation to the extent of use, emergence and spread of resistance should be prevented primarily by limiting 
the amounts of antibiotics used (Greenwood, 1989). However, our responsibility as veterinary surgeons requires that we do so without hampering optimal treatment of sick animals. Hence, antibiotics should be used by veterinary surgeons only if indicated: that is to cure or prevent infectious diseases in animals, and then in an optimal way. The necessity is certainly not to prohibit the use of certain antibiotics, but to encourage rational and responsible use of antibiotics.

\section{Methods by which this may be achieved}

It is often claimed, that veterinary surgeons and doctors alike use a lot of antibiotics inappropriately. This may be attributed to the complexity of decision making. Clinical diagnosis of infectious diseases in veterinary practice hinges on the predictive value of symptoms-sign complexes and the epidemiological situation or on the basis of the results of cultivation. When a bacterial infection is suspected, initial antibiotic therapy is in first instance empirically choosen on an "educated guess" basis. This is necessary when considering outbreaks of serious infections, where the initial antimicrobial therapy must be effective against all the likely pathogenic bacterial species before results of laboratory tests are available. The first objective is then to ensure effective care. Because antibiotic therapy is more effective if started early in the disease, it is very unrealistic to expect veterinary surgeons to wait until culture and susceptibility testing results are available, before initiating antibiotic treatment. Also the often-criticized use of antibiotics for so called trivial bacterial infections or for the prevention of secondary infections, may, especially in animals housed closely together, prevent much of these infections developing beyond the trivial.

It is also important to appreciate that the choice of antibiotics is to a large extent dependent on patient and farm factors. This requires not only extensive knowledge about pathology and antibiotics, but also up to date information on the disease history of the farm, drug susceptibilities in previous cases on that farm and in the neighbourhood. Moreover special care and nutrition, and other supportive therapeutic measures are also essential for the effective treatment of bacterial diseases. The only person who is qualified to advise on treatment and able to make the decision that antibiotics are indicated and to make a choice is the veterinary practitioner of that farm. Moreover, each time that the use of antibiotics is necessary, this should be considered as an abnormal situation that should have been prevented. So professional advice on other measures, which might prevent new infections in the future, such as changes in management, improving hygiene, housing or vaccination are indicated as well. When it has been decided that antibiotic treatment is indicated the efficacy of the treatment should always be the overriding aim of choice of antibiotic. Apart from the choice of antibiotic the correct dosage, route, frequency and time-span of administration are equally important. Under- 
treatment may be due to too low dosing, but also be caused by an inadequate route of application or pharmaceutical formulation. This may result not only in treatment failure, but might also enhance development of resistance. Overtreatment, however, is much more common. Either an antibiotic is being used when none is needed or a sledgehammer combination to crack a nut, or, worst of all, as a substitute for a professionally sound diagnosis. Again, the only person, qualified to make a diagnosis and to advise on proper use of antibiotics and prevention of future infections is the veterinary practitioner of that farm.

His or her main difficulty is, however, to make the appropriate choice among the many possibilities. This is becoming so for a number of reasons: firstly, because the choice of antibiotics is so bewilderingly large, that veterinary practitioners, who have to be experts in many other areas, can rarely keep up with all the new developments in antibiotic therapy. Moreover, clinicians and (in some countries like the Netherlands) even farmers, receive a great deal of confusing and sometimes biased "guidance" from the pharmaceutical industry. These promotional efforts of the pharmaceutical industry, the desire of veterinary surgeons to use the best drug available and client pressure, lead to a trend to use new antibiotics, when older drugs may be as effective. As it is difficult enough for specialists to assess the claims made for the many antibacterial products on the market, this is almost impossible for most practitioners. Therefore expert advice on rational antibiotic use is needed and welcomed. However, even in relatively straightforward clinical situations there are often several equally effective agents which might be used. Choice may then be determined by an agreed antibiotic policy.

\section{Antibiotic policy}

An antibiotic policy has been defined as a set of rules, which superimposes on the definition of rational treatment other considerations, being the most important: protection of the population and environment of the emergence and spread of resistant bacteria, which lead to a decision which agent or agents, among the several that are rational, should actually be used (Greenwood, 1989). The aim should be to achieve three goals:

1. Control of antibiotic resistance.

2. Optimal patient treatment and protection of animals at risk.

3. Treatment should be practical, affordable and awoid risks of residues in or damage to animal products for human consumption.

Prevention of drug resistance is the major consideration in an antibiotic policy, but should not interfere with the other two objectives.

Tactics to prevent emergence of resistance are (Gruneberg, 1980; Selkon, 1980):

1. Restriction of antibiotics mainly to oral or parenteral routes, unless specifically indicated, such as for treatment of mastitis or otitis. 
2. Diversification: for example betalactam antibiotics may be used primarily for respiratory tract infections and quinolones for enteric infections.

3. Usage of a combination of antibiotics when there is sufficient scientific evidence that it improves efficacy of treatment or diminishes the risk of resistance emergence.

4. Preventing, if possible, the situation where groups of animals are treated several times during their lives with the same antibiotic. So when a second condition occurs, which indicates the use of antibiotics, a drug should be selected which does not show crossresistance with the formerly used antibiotics.

5. Rotation. As soon as resistance emerges or on a regular time base the first choice antibiotic changed for another rational choice.

\section{Antibiotic formulary}

Application of these principles should result in a preferred and limited list of antibiotics for more than $90 \%$ of the conditions, commonly presented to a practising veterinary surgeon and provide a practical and rational treatment choice for these cases based on scientific data and practical experience. Such a list is called a formulary and includes data on appropriate dosage, method and time-span of application, possible side effects or interactions and tissue damage or residue problems (withdrawal times). If several antibiotics can be used, the formulary must differentiate between first, second and third choice antibiotics.

First choice antibiotics are the prefered antibiotics for a certain condition. Second choice antibiotics might be used if the responsible veterinarian has a good reason not to use a first choice antibiotic. In most cases this will be a resistance problem on a particular farm. Third choice antibiotics should be only used after susceptibility testing and/or consultation of a specialist. Consultation of a specialist is an effective means of controlling usage of third choice antibiotics while at the same time assuring that sick animals will be treated effectively and appropriately. Clinical consultations on diagnosis and management should be provided by experts in infectious diseases: veterinary microbiologists or species specialists.

Newer antibiotics should not be first choice antibiotics, except when there is overwhelming evidence of their advantages over established drugs.

A first veterinary antibiotic formulary, edited by W.D.J. Kremer was in 1987 published in the Netherlands and was very well received by the veterinary profession. It gave, however, mainly guidelines for rational usage of antibiotics and it was compiled completely by experts. A danger of such a formularium, could be that it is not always practical in all situations, that might occur in daily veterinary practice.

Ample experience with therapeutic formularies for family doctors has 
shown, that to be accepted and thus effective, formularies must be developed from the basis (bottom up) and cannot be designed from an "ivory tower" (top down) (Baker, 1988). In contrast to the hospital situation, where adherence to a formulary can be more or less enforced by the hospital pharmacy, this is not feasible with general medical and veterinary practitioners. The basis for an effective antibiotic policy in these populations is consensus among and agreement on the formulary by the practitioners. Even in a hospital setting the consensus model has been shown to be much more effective (Wyatt et al, 1990). A new updated and extended version of the Dutch veterinary formulary, that differentiates between first, second and third choice antibiotics, will be published by the end of 1993. As this formularium is compiled by the steering group for veterinary antibiotic therapy of the KNMvD with the help of specialists, it must again be considered as a top down approach. On the other hand a formulary does not dictate but merely advise on antibiotic treatment and force veterinary surgeons to consider and encourage discussions about the use and choice of antibiotics among themselves (veterinary audit) and with specialists. As a formulary must be updated regularly every new edition can be more influenced by general practitioners and becoming more and more the result of a bottom up approach, with advice of experts. This is the only way to ensure that in the long run a veterinary antibiotic policy will be effective.

\section{Laboratory testing and advice}

Provided antimicrobial susceptibility data should correlate with the policy. An important step is to give as little laboratory encouragement as possible to inapropriate use of antibiotics. A report on susceptibility data should only be sent to a veterinary practitioner when a pathogenic species has been isolated and than so censored that only first and second choice drugs listed in the formularium for that condition are included. Only when an organism is multiply resistant is full information given. This discourages the use of third choice drugs, as susceptibilities are seldomly reported. Reporting of sensitivities directly to the farmer, which unfortunately is becoming a more and more common policy among laboratories in the Netherlands, seems undesirable. It encourages self-vetting by farmers, inevitably resulting in inappropriate use of antibiotics.

The second step is to have a good network providing regular information about trends in resistance development. Careful record keeping of all pathogens, complete with antibiotic susceptibilities, is of crucial importance.

However, as culturing and susceptibility testing is requested mainly in cases of treatment failure, use of these data alone, can easily lead to an exaggerated view on resistance prevalence in a population. Therefore it may be as important to monitor regularly the prevalence of resistance of the faecal flora (e.g. Enterobacteriaceae) of groups of animals to follow the effect of antibiotic usage 
in that species. The results of such a surveyance system might predict the emergence of resistance in pathogens and be used to rotate the selection of first and second choice antibiotics.

A regular computer analysis of resistance patterns in faecal flora and of all pathogenic isolates by animal species, age group and organ system involved, should be made for regions and nationally and send to all involved in antibiotic policy-making. On a more confidential basis this could also be done for individual farms and for veterinary practices.

This gives early warning of emergence of resistance and/or cross-infection and clustering of resistant strains, which may need special attention. Moreover, since bacterial infections, as said previously, require immediate treatment, knowledge of local resistance trends may for practitioners even be more important than the results of susceptibility testing of single cases.

Standardisation among and automation of the laboratories of the Dutch animal health services by the laboratory information system (LIS) makes this feasible. Private laboratories doing bacteriological investigations for veterinary practitioners should be supervised by a certified veterinary microbiologist for quality assurance and also be obliged to make their susceptibility reports available.

\section{Pharmacovigilance}

However extensive and thorough clinical trials may have been performed, the true benefits of a new antibiotic as well as the possible hazards, are only confirmed by extensive clinical use. Realisation of this fact has lead to a postmarketing surveillance of drugs in human medicine. In the Netherlands there are also plans for a central office for the study of side-effects of veterinary drugs. In contrast to drugs intended for use in human beings, the risk of toxic side effects can be much better evaluated in preclinical studies in animals. As emergence and spread of resistance is the most serious side-effect of antibiotics intended for use in animals, the development of facilities to monitor and analyse regularly the prevalence and patterns of resistance should be the most important item for post-marketing surveillance by the pharmaceutical industry and pharmacovigilance by the government and funds should be made available for this purpose.

\section{Recording of antibiotic usage}

Recording, qualitative and quantitative, of the antibiotics used in veterinary medicine is of paramount importance, not only to monitor the impact of the antibiotic policy, but also to look for a possible correlation between the usage of a certain group of antibiotic ( $s$ ) and the emergence of resistance (resistance-epidemiology).

At this moment it is very difficult to obtain data on the amount of antibiotics used in veterinary medicine in the Netherlands. Most pharmaceutical companies are very reluctant to make these figures officially available even 
confidentially and for scientific purposes, The new Dutch Diergeneesmiddelenwet (Veterinary Medicines Act) requires, however, registration of the amounts of veterinary medicines sold by each company. Moreover, the Veterinary Medicines Act and the development of an integrated quality control (IQC) system in different sectors of animal production (pigs, calves and poultry) require the recording of use of veterinary drugs and the use of premedicated feeds by means of a logbook on each farm. This proposed recording system of health status and use of medicines from the breeding phase to the finishing and slaughterhouse phase will make it not only feasible to monitor the usage of antibiotics on a farm and per veterinary surgeon, but also the indications and efficacy under practice conditions. In fact reports of lack of efficacy are at least as important for an antibiotic policy as those recording adverse reactions or resistance spread. Negative reactions, however, often tend to go unnoticed or unrecorded. Such a farm logbook makes control on the appropriateness of antibiotic use by individual veterinarians also possible. So we can learn, who is using what drugs, for which indications, in which kind of animals and with what effect. This knowledge can be used to design and target education programs, reevaluate the advice in the formulary and to single out veterinary surgeons, who do not comply with the antibiotic policy on a regular basis. If an investigation proves that they do not have valid reasons to do so the Dutch law regulating veterinary medicine (wet op de uitoefening van de diergeneeskunde) makes it possible for the profession to take disciplinary measures. Again funds have to be found to effect these possibilities.

\section{Education and postgraduate training}

Veterinary students in the Netherlands are trained to use the veterinary antibiotic formulary. Postgraduate courses on antibiotic therapy are very popular among veterinary surgeons in the Netherlands. Although decisionmaking is a preeminent function of veterinary surgeons, veterinary (postgraduate) education mostly concentrates only on the methods of veterinary knowledge acquisition. This is due to the fact that to teach veterinary decision-making processes in their complexity is not possible by traditional forms of teaching. To improve the teaching process in this direction, the Dutch animal health services organised problem-based postgraduate courses on the rational use of antibiotics. In three sessions small groups of practitioners discussed a collection of four carefully constructed problems, together with relevant literature which they had received by mail a week before. These problems consisted of real life phenomena, derived from daily practice and adapted for educational purposes. The task of the students was to discuss these problems, find explanations and formulate ways to manage these problems, i.e. to solve them. The explanations and solving of the problems by the different groups were discussed by all students together and commented on by experts at the end of each session. This approach also stimulated exchange of 
ideas between teachers and students, the latter being often very experienced practitioners.

In this way practitioners can compare their way of using antibiotics with that of their colleagues and trying by criticizing each other to reach consensus. among peers. Doing this, one of the best educational methods is practised. Moreover, it is another way to find out which antibiotics are mainly used for certain indications and why. By using, in such courses, the formulary as the standard, acceptance of the formulary is improved, but also weaknesses or impractabilities in the formulary that need improvement can be revealed. In this way postgraduate training becomes an essential part of an antibiotic policy and it provides a vehicle for one of the most important functions of an antibiotic policy: ensuring that regular discussion between all concerned in optimal veterinary use of antibiotics does take place. It might also reduce the influence of pharmaceutical representation and advertising, which seem by now far too powerfull determinants of selection.

\section{Veterinary audit}

These problem-based courses could be the start of developing a veterinary audit system, in which veterinary surgeons regularly measure the quality of the care and advice they provide, by discussing real cases and problems among peers. This will provide a regular and systematic evaluation of the quality and effectiviness of veterinary services to the public and should be regarded as an important professional obligation.

\section{Conclusion}

Effective use of (limited) resources, such as antibiotics is a professional duty of the veterinary surgeon. An antibiotic policy with a formulary will assist veterinary surgeons in providing optimal therapy and prevention of bacterial infections with minimal risk of emergence and spread of resistance. The first formulary, that only tried to rationalize veterinary usage of antibiotics, was very well received by the Dutch veterinary surgeons, but it has not been feasible to evaluate its effect either on veterinary professional behaviour or on the bacterial population. However a recent study showed that pigfarms supervised by a veterinary surgeon on a regular basis (weekly or twice monthly) had not only better technical results but also used less antibiotics than farms on which a veterinarian was only consulted when this was thought necessary (Elbers, et al., 1990; Elbers, 1991).

It is of paramount importance that the introduction of the new extended formulary, which includes advice on optimal veterinary use of antibiotics, is followed by the development of facilities for monitoring resistance. This may then be related to the quantitative and qualitative use of antibiotics. Moreover correlation of these data with information on prevalence of resistance in the open (not hospital!) human population and the use of antibiotics by doc- 
tors, might give an indication of possible public health risks of veterinary use of antibiotics. All this is crucial information for a further development of a scientifically based veterinary antibiotic policy and regular adaptation of the guidelines in the formulary.

Regular consultation between veterinary practitioners and veterinary specialists on infectious diseases about the clinical efficacy of the recommendations in the formulary, laboratory procedures and resistance, as well as continuous education are an essential part of an antibiotic policy. It should be realised that a formulary, as essential part of an antibiotic policy, is by no means a way of simplifying veterinary practice and can therefore never be a substitute for or used without sound professional knowledge, experience and advice. Therefore a veterinary surgeon familiar with infectious disease problems on a farm and in the region is the only person qualified and able to decide if and what antibiotic is indicated. To strengthen his or her position and to decrease client pressure, which is one reason of misuse of antibiotics, pharmaceutical companies should not directly advertise to farmers and people other than qualified veterinarians, such as advisers from feedmills etc., should refrain from giving advice on the use of antibiotics. In this way we can improve animal health and decrease emergence of antibiotic resistance and spread of resistant strains of bacteria in a responsible way. And there is no reason to prohibit the use of certain antibiotics by qualified veterinary surgeons, provided the veterinary profession takes severe disciplinary measures against the very few who cannot, or are not, willing to behave professionally and take their responsibility.

\section{REFERENCES}

Baker, J.A., 1988. Seventeen years experience of a voluntary based drug rationalisation programme in hospital. Br. Med. $J_{4,} 297$ 465-469.

Elbers, A.R.W., Cromwijk, W.A.J., Hunneman, W.A. and Tielen, M.I.M., 1990. Logbook registration on pig fimishing farms in an integrated quality control (ICQ) project. I. Use of drugs and vaccines. Tijdschr. Diergeneeskd., 115:249-261.

Elbers, A.R.W., 1991. The use of slaughterhouse information in monitoring systems for herd hea th control in pigs. Thesis University of Utrecht, Utrecht, The Netheriands.

Greenwood, D., 1989. Antimicrobial chemotherapy, 2 nd edition Oxford Medical Publications, Oxford. UK.

Gruneberg, R.N., 1980. Antibiotic prescribing policies: a personal view In: Antibiotics and chemotherapy: current topics. 4: 203-21 1 MTP Press Lid., Lancaster, UK

Kremer, W.D.J. (editor); 1987. Veterinary antimicrobial therapy guide Alfasan Nederland bv., Woerden, The Netherlands

Selkom, J.B., 1980. Antibiotic policies. In: Antibiotics and chemotherapy: current topics. 4: 193-201 MTP Press Ltd., Lancaster, UK.

Wyatt, T.D., Passmore, C.M., Morrow, N.C. and Reilly, P.M., 1990. Antibiotic prescribing: the need for a policy in general practice. Br. Med. J., 300: 441-444. 


\title{
Chapter III
}

\section{Antimicrobial resistance in faecal samples of pigs from five abattoirs in the Netherlands and from Sweden}

\author{
A.E. van den Bogaard, N. London and E.E. Stobberingh \\ Department of Medical Microbiology, University Maastricht \\ PO Box 616, NL-6200 MD Maastricht, the Netherlands
}

Adapted from: A. E. J. M. wan den Bogaard, N. London and E. E. Stobberingh

The prevalence of antimicrobial resistance of indicator bacteria: Escherichia coli and enterococci, in pig faecal samples collecred

at 5 Durch abatroirs. Report Ministerie van Landboww, Naturbebecen Vissurij. August 1998.

and

A. E. J. M. wan den Bogaard, N. London and E. E. Stobberingh (2000)

Antimicrobial resistance in pig faecal samples from the Netherlands (five abartoirs) and 5 weden. Joumal of Antimicrobial Chemotherapy $45,663-671$. 


\section{AESTRACT}

The prevalence and degree of antibiotic resistance of faecal indicator bacteria, Escherichia coli and enteroccoci, were determined in 1321 faecal samples collected from pigs at five abattoirs in the Netherlands and in 100 samples from Swedish pigs. In the Dutch samples a high prevalence of resistance was observed in E. coli for three commonly used antibiotics in pig medicine, amoxycillin (70-94\%), oxytetracycline (78-98\%) and trimethoprim (62-96\%). Also, the prevalence for chloramphenicol (55.67\%) and neomycin (38-67\%) was relatively high. For the other compounds tested the prevalence was less than $10 \%$. The percentage of samples with a high degree of resistant $E$. coli showed the same tendency in all Dutch abattoirs a though significant differences between the abattoirs were observed. The percentage of Swedish samples with a high degree of resistant $E$. coli was significantly lower for all antibiorics except nitrofurantoin, gentamicin, flumequin and ciprofloxacin. All enterococci were susceptible to amoxycillin and high-level resistance to gentamicin was observed in $4-6 \%$ of the Dutch samples. A high prevalence of resistance and a high degree of resistance was found for erythromycin and oxytetracycline. The prevalence of resistance to dalfopristin-quinupristin ranged from 6 ro $8 \%$ and for wancomycin from 24 to $46 \%$. Significant differences between the abattoirs were found for all compounds tested except amoxycillin. In the Swedish population both the prevalence and degree of resistance in enterococci were significantly lower except for amoxycillin and gentamicin. This point prevalence study showed that the prevalence and degree of antibiotic resistance in indicator bacreria, E. coli and enterococci, in faecal samples from pigs differed between two countries and reflected differences in antibiotic usage in pigs. To analyse the differences observed between the slaughterhouses, additional information about the farms of origin and antibiotic consumption is necessary.

\section{INTRODUCTION}

The prevalence and extent of antibiotic resistance in a population are strongly correlated with antibiotic usage, as selection and dissemination of resistant bacteria are heavily augmented under selective pressure caused by antibiotics. As a consequence, resistance is most common where there is heavy use of antibiotics and appreciable host-to-host contact, as in hospitals, day-care centres for children and nursing homes. 1,2 Intensive farming units also represent a large reservoir of antibiotic-resistant bacteria. ${ }^{2}$ Here resistance is selected and perpetuated not only by the regular veterinary use of antibiotics, but also by the continuous feeding of antibiotics to enhance growth of animals. Moreover, resistant microorganisms are very easily disseminated within units via faecal contact. Many studies on bacterial resistance have been published, but mainly of hospiral and animal pathogens and based on data generated to support therapy. Therefore non-therapeutic antibiotics such as antimicrobial growth promoters (AMGP) have seldom been studied. Moreover, the selection of clinical cases from which samples are tested represents a worst-case scenario. Knowledge of the transfer of resistance via plasmids, phages, transposition and "free" $D N^{3}$ has increased considerably since the 1970 s and 1980 s, when transfer was considered to be uncommon, it was thought that only zoonotic bacteria from animals could infect humans and transfer of resistance genes from animal bacteria to human bacteria was thought to be rare. ${ }^{4-8}$ The fear now is that antibiotic-resistant bacteria, pathogenic or non-pathogenic to humans, are selected in the intestinal flora of animals, contaminate foods of animal origin and transfer their resistance to other bacteria in the human gut. ${ }^{9,10}$ Humans and animals live in close association with large numbers of bacteria, of which the majority are found in the large intestine, where they are exposed to antimicrobial agents, exchange genetic materiall with other bacteria and, on excretion, contaminate the environment or colonize other animals and humans. Hence, the intestinal flora of healthy animals and humans is considered to be the most important reservoir of resistant bacteria and resistance genes. ${ }^{11-13}$ As contamination of carcasses with faecal flora during slaughtering inevitably occurs, food of animal origin may serve as a vehicle ro transport resistant bacteria and resistance genes between animals and humans. The prevalence and degree of antibiotic resistance found in indicator bacreria in the faecal flora of humans and animals are considered to be a good indicator of the selective pressure of antibiotic usage. ${ }^{14-18}$ They correlate with 
the amounts and types of antimicrobial agents consumed by these populations ${ }^{19-21}$ and changes in resistance can be considered as an early warning system for resistance to be expected in potentially pathogenic bacteria. 20-21 Therefore it has been suggested that a low level of carriage of resistant intestinal (indicator) bacteria in humans should become a public health goal, as have normal blood pressure and low serum cholesterol levels. ${ }^{21}$ In food animals a low prevalence and degree of antibiotic resistance in the intestinal flora should be considered a distinguishing quality and safety mark. 22,23 Indicator bacteria such as Escherichia coli and enterococci are organisms that constitute a natural part of the intestinal flora of humans and animals. Using these species makes it feasible to compare levels of resistance between populations. The aim of the present study was to determine and compare the prevalence and degree of resistance to antibiotics commonly used in pig medicine and AMGP in indicator bacteria, E. coli and enterococci, in faecal samples from pigs sllaughtered in five regions in the Netherlands and in Sweden. In Sweden the use of AMGP was banned in 1986.

\section{MATERIALS AND METHODS}

\section{Collection of faecal samples}

Fresh faecal samples were collected in November and December 1995 ar the slaughterhouse in Weert and in March and April 1996 at the other four slaughterhouses (Table 1 and 3) by inspectors from the RVV (Rijkskeuringsdienst yoor Vee en Vlees: Dutch $\mathrm{Na}$ tional Inspection Service for Livestock and Meat). The sllaughterhouses were widely located in the Netherlands. The Swedish samples were collected during September 1997. To prevent multiple sampling from pigs from the same farm, faeces (approximately $20 \mathrm{~g}$ in a plastic vial) were collected from every 300 th or more pig after evisceration at the slaughtering line. The samples were stored at $4^{\circ} \mathrm{C}$ and sent weelly to the bacteriological laboratory. On the day of arrival at the laboratory they were diluted $\left(10^{-1}\right)$ in $0.9 \%$ saline containing $20 \%(v / v)$ glycerol and stored at $-20^{\circ} \mathrm{C}$ until examined. The faecal samples collected in the slaughterhouse in Weert and in Sweden were frozen immediately after collection and stored at $-20^{\circ} \mathrm{C}$ until examined. All faecal samples were analysed within $6 \mathbb{1}$ days of collection.

\section{BACTERIOLOGICAL ANALYSIS}

After thawing, the samples were inoculated on selective media with and without antibiotics. For $E$. coli, $40 \mu \mathrm{L}$ of $10^{-2}$ and $10^{-4}$ dilutions in $0.9 \%$ saline were inoculated on Levine agar plates (BBL 11221; Becton Dickenson BV, Etren-Leur, the Netherlands) with a spiral plater (Salm en Kip, Utrecht, the Netherlands). For enterococci, KF-Streptococcus agar plates (Oxoid CM701; Basingstoke, UK) were inoculated with $40 \mu \mathrm{L}$ of the $10^{-1}$ and $10^{-3}$ dilutions with a spiral plater. If no vancomycin-resistant enterococci (VRE) were detected on the vancomycin agar plate a new vancomycin agar plate was inoculated by swabbing $0.5 \mathrm{~mL}$ of the $10^{-1}$ dilution. For trimethoprim testing $5 \%$ lysed horse blood was added to the agar. The antibiorics tested and concentrations used are given in Tables 1 and 2. E. coll isolates from plates with chloramphenicol were tested for resistance to florfenicol (MIC $>8 \mathrm{mg} / \mathrm{L}$ ) by broth microdilution. The anvibiotics were selected because they, or related antibiotics, are or have been until recently regularly used in pigs, either on veterinary prescription or as AMGP. E. coligrows on Levine agar as purple colonies with a black centre and metallic shine. Only these colonies were counted after $18-24 \mathrm{~h}$ incubation at $37^{\circ} \mathrm{C}$. The minimum detection level by this method was $300 \mathrm{cfu} / \mathrm{g}$ faeces and it has been shown that more than $95 \%$ of the presumptively identified colonies are E coli, ${ }^{24}$ Previous studies also showed that all isolates from antibiotic-containing plates had MICs identical to or higher than the concentration of the antibiotic in the selective plate from which they had been isolated. 25-27.

Enterococci appear as typical red or pink colonies on KF-Streptococcus agar. After 48 h incubation at $42^{\circ} \mathrm{C}$ only the typical pink colonies were counted. At random, typical collonies collected from 100 KF-Streptococcus agar plates with and without antibiotics (five colonies per plate) were subcultured on blood agar (Oxoid CM854 with 5\% sheep blood) and. identified on the basis of tolerance for bile, aesculin hydrolysis, growth on $6.5 \% \mathrm{NaCl}(\mathrm{w} / \mathrm{v})$ and a positive pyrrollidonyl-arylamidase reaction (pyrrolidonyl-arylamidase tabless, Rosco, Taastrup, Denmark). In total 500 colonies were identified, and all belonged to the genus Enterococus. The minimum detection level was 
Table 1. Prevalence of resistant Escherichia coli and percentages of samples with a high degree of resistance in pig faecal samples collected in the Netherlands (five abattoirs) and Sweden.

\begin{tabular}{|c|c|c|c|c|c|c|c|c|c|c|c|c|c|c|}
\hline \multirow{4}{*}{$\begin{array}{l}\text { Antibiotic } \\
\text { (Concentration } \\
\text { in agarmg } / \text { ) }\end{array}$} & \multicolumn{10}{|c|}{ Slaughterhouses } & & & & \\
\hline & Apeldo & orn & Boxtel & & Meppe & & Olst & & Weert & & \multirow{2}{*}{\multicolumn{2}{|c|}{$\begin{array}{l}\text { the Netherlands } \\
\text { Total } \\
(n=1320)\end{array}$}} & \multirow{2}{*}{\multicolumn{2}{|c|}{$\begin{array}{l}\text { Sweden } \\
(n=100)\end{array}$}} \\
\hline & \multicolumn{2}{|c|}{$(n=249)^{1}$} & \multicolumn{2}{|c|}{$(n=265)$} & \multicolumn{2}{|c|}{$(n=254)$} & \multicolumn{2}{|c|}{$(n=253)$} & \multicolumn{2}{|c|}{$(n=299)$} & & & & \\
\hline & Prev. & $\mathrm{HD}$ & Prev. & HD & Prew. & $\mathrm{HD}$ & Prev. & HD & Prev. & HD & Prev. & $\mathrm{HD}$ & Prev. & $\mathrm{HD}$ \\
\hline Amoxycillin (25) & 89 & 12 & $94^{\prime \prime}$ & 17 & 92 & $20^{\circ}$ & 84 & $8^{*}$ & $70^{3 *}$ & 14 & $85^{+}$ & $13^{\div+4}$ & 51 & 3 \\
\hline Oxytetracycline $(25)$ & 98 & 45 & 97 & 44 & 98 & 44 & 96 & 39 & $78^{* *}$ & $30^{* *}$ & $93^{+}$ & $40^{+}$ & 69 & 6 \\
\hline Chloramphenicol (25) & 64 & 2 & 65 & 3 & 67 & 3 & $55^{\prime \prime}$ & $0.4^{n *}$ & $N T^{2}$ & & $63^{3 *}$ & 3 & 3 & 0 \\
\hline Nitrofurantoín (50) & $12^{\prime \prime}$ & 0 & $0.8^{2 *}$ & 0 & 2 & 0 & 0 & 0 & 3 & 0 & 3 & 0 & 0 & 0 \\
\hline Trimethoprim (B) & $96^{* *}$ & 27 & 91 & 19 & 94 & $31^{\circ}$ & 88 & $14^{2}$ & $62^{* n}$ & $15^{*}$ & $85^{+}$ & $21+$ & 46 & 1 \\
\hline Neomycin (32) & $67^{\circ}$ & 5 & $61^{\prime \prime}$ & 4 & 67 & 5 & 52 & 2 & $38^{* \prime \prime}$ & 3 & $56^{+}$ & 4 & 17 & 3 \\
\hline Gentamicin (16) & 3 & 0 & 2 & 0 & 2 & 0 & 2 & 0 & 0 & 0 & 2 & 0 & 0 & 0 \\
\hline Flumequin (16) & 2 & 0 & $0.8^{\circ}$ & 0 & $6^{\prime \prime}$ & 0 & 4 & 0 & 3 & 0 & 3 & 0 & 1 & 0 \\
\hline Ciprofloxacin (4) & 0.4 & 0 & 0.4 & 0 & 2 & 0 & 4 & 0 & 1 & 0 & 1 & 0 & 0 & 0 \\
\hline $\begin{array}{l}\text { number of samples te } \\
2 \text { not tested. } \\
3 n=1022 \text {. }\end{array}$ & & $\begin{array}{l}* s \\
* s \\
* s \\
4+s\end{array}$ & $\begin{array}{l}\text { ifficanty } \\
\text { ilficantly } \\
\text { ifficantly } \\
\text { ificantly }\end{array}$ & $\begin{array}{l}y \text { diffe } \\
y \text { diffe } \\
y \text { diffe } \\
y \text { diffe }\end{array}$ & $\begin{array}{l}\text { it from } \\
\text { it from } \\
\text { it from } \\
\text { it from }\end{array}$ & $\begin{array}{l}\text { the tol } \\
\text { the tat } \\
\text { Swedl } \\
\text { Swed }\end{array}$ & $\begin{array}{l}\text { of allo } \\
\text { of all } \\
p<0 . \\
p=0 .\end{array}$ & $\begin{array}{l}a p<0 \\
a p<0 \\
1 . \\
5 .\end{array}$ & 0.05 & & & & & \\
\hline
\end{tabular}

$10^{2} \mathrm{cfu} / \mathrm{g}$ faeces. For the prevalence of resistance to dalfopristin-quinupristin (Synercid ${ }^{\mathrm{TM}}$ ) a specimen was considered positive only if at least one Enterococcus facizim was isolated and identified from the dalfopristin-quinupristin agar plate. For this reason the degree of resistance could not be calculated. For identification to species level, acid producrion from different sugars was determined. 28 Isolates from a previous study had all MICs identical to or higher than the concentration of the antibiotic in the selective plate from which they had been isolared. 29

The samples from the abatroir in Weert were processed first and susceptibility was tested against a smaller number of antibiotics than the other samples.

\section{STATISTICA ANALYSIS}

A one-way analysis of variance was used to estimate overall differences between the group means. Group means were compared pairwise using $t$-tests controlled for overall error rate (Bonferroni test) where $p<0.05$ was regarded as statistically significant. ${ }^{30}$

\section{DEFINITIONS}

\section{Prevalence of antibiotic resistance}

The prevalence of resistance (\%) for either $E$. colt or enterococci in the population for an ancibiotic is given by the number of samples showing growth on the plates containing that antibiotic, divided by the total numbers of samples rested $\times 100$.

\section{Degree of antibiotic resistance}

The degree $(\%)$ of antibiotic resistance in each faecal sample to each antimicrobial agent tested was calcum lated as the number of cfu growing on the plate containing that agent divided by the total number of typical colonies on the antibiotic-free control plate $\times 100$.

Two degrees of antibiotic resistance to a particular antibiotic could be distinguished: low degree, i.e. less than $50 \%$ of the indicator microorganisms resistant; and high degree, $50 \%$ or more (thus the majority) of the indicator microorganisms being resistant to that agent.

The prevalence of high degree of resistance $(\%)$ is the number of samples with a high degree of resistance to a 
particular agent divided by the total number of samples tested $\times 100$.

\section{RESULTS}

$$
\text { E. coli }
$$

No significant differences in the population of samples from which $E$. coll were isolated and the total numbers of E. coli per positive sample were observed between the slaughterhouses or between the Swedish and Dutch samples (data not shown). The mean \pm S.D. number of E. coli $\left(\log _{10} \mathrm{cfu} / \mathrm{g}\right.$ faeces) was $6.4 \pm 1.1$ for the Durch samples and $6.2 \pm 0.9$ for the $S$ wedish samples. The prevalence and percentages of samples with a high degree of antibiotic-resistant $E$. coli in samples collected at the slaughterhouses in the Netherlands and from Sweden are depicted in Table 1 . A high prevalence of resistance in the samples from all slaughterhouses was observed for amoxycillin, oxytetracycline and trimethoprim, and a relatively high prevalence for chloramphenicol and neomycin. For the other compounds the prevalence was less than 10\%. Florfenicol resistance was present in only two samples from Meppel. The percentage of samples with a high degree of resistance showed the same trend in all abattoir popwations and was always highest for oxyterracycline followed by trimethoprim and amoxycillin. Significant differences $(P<0.05)$ in prevalence of resistance and prevalence of a high degree of resistance between samples received from the various slaughterhouses were observed for all compounds tested except gentamicin and ciprofloxacin. The prevalence of resistance to trimethoprim and nitrofurantoin in the samples from Apeldoorn was significantly higher than the mean of all Dutch samples tested. In contrast, the prevalence of resistance and/or a high degree of resistance to amoxycillin, trimethoprim and neomycin in the samples from Olst and Weert were significantly lower than the mean. Compared with the total Dutch population, and also with each of the abattoir populations, both the prevalence and degree of resistance in the Swedish popwlation were significantly lower $(P<0.005)$ for amoxycillin, oxytetracycline and trimethoprim. For chloramphenicol and neomycin, only the prevalence was significantly lower in the Swedish population. No differences were found for nitrofurantoin, gentamicin,
Table 2. Proportion (\%) of resistant E. coll of the total E. colipopulation in the faecal flora of pigs with high degree $(250 \%)$ and low degree ( $550 \%)$ of resistance.

\begin{tabular}{lccccc}
\hline Antibiotic & \multicolumn{2}{c}{ High degree } & & \multicolumn{2}{c}{ Low degrea } \\
\cline { 2 - 5 } & mean \pm S.EM & $(n)$ & mean \pm S.EM. & $(n)$ \\
\hline Amoxycillin & $74 \pm 16$ & $(185)$ & $12 \pm 0.5$ & $(941)$ \\
Oxytetracycline & $76 \pm 1$ & $(516)$ & $22 \pm 0.5$ & $(683)$ \\
Chloramphenicol & $77 \pm 4$ & $(21)$ & $4 \pm 0.3$ & $(620)$ \\
Trimethoprim & $79 \pm 1$ & $(280)$ & $13 \pm 0.5$ & $(845)$ \\
Neomycin & $76 \pm 3$ & $(44)$ & $5 \pm 0.3$ & $(699)$ \\
Gentamicin & 0 & & $0.2 \pm 0.1$ & $(24)$ \\
Ciprofloxacin & 0 & & $1 \pm 0.5$ & $(14)$ \\
Flumequin & 0 & & $1 \pm 0.3$ & $(29)$ \\
Nitrofurantoin & 0 & & $3 \pm 1$ & $(40)$ \\
\hline
\end{tabular}

Aumequin and ciprofloxacin. For all tested antibiotics combined, the proportion of resistant $E$. coli in faecal samples with a thigh degree of resistance was $76 \%$ (range 74-79\%) and for low-degree samples 7\% (range $0.2-22 \%$ ), as shown in Table 2. In Figure 1 the bimodal distribution of the samples with a high and low degree is visualised for amoxycillin and oxyterracycline respectively.

\section{ENTEROCOCCI}

No significant differences in the percentage of samples (91-100\%) from which enterococci were "isolated and the total numbers of enterococei per positive sample were observed berween the slaughterhouses or between the Swedish and the Dutch samples (data not shown). The mean \pm S.D. number of enterococi $\left(\log _{10} \mathrm{cfu} / \mathrm{g}\right.$ faeces) was $5.1 \pm 1.0$ for the Dutch samples and $5.1 \pm$ 1.3 for the Swedish samples. No amoxycillin-resistant enterococci were found. The prevallence of antibioricresistant enterococci and the prevalence of high-degree antibiotic resistance in enterococci in the various popum lations of pig faecal samples is presented in Table 3 . In the abattoir groups the prevalence of high-level gentamicin resistance ranged from 1 to $6 \%$. A high prevalence of resistance was found for erythromycin and oxyterracycline. The prevalence of resistance to dalfopristin-quinupristin ranged from 62 to $82 \%$, and for vancomycin from 24 to $46 \%$. Overall "a high degree 
A

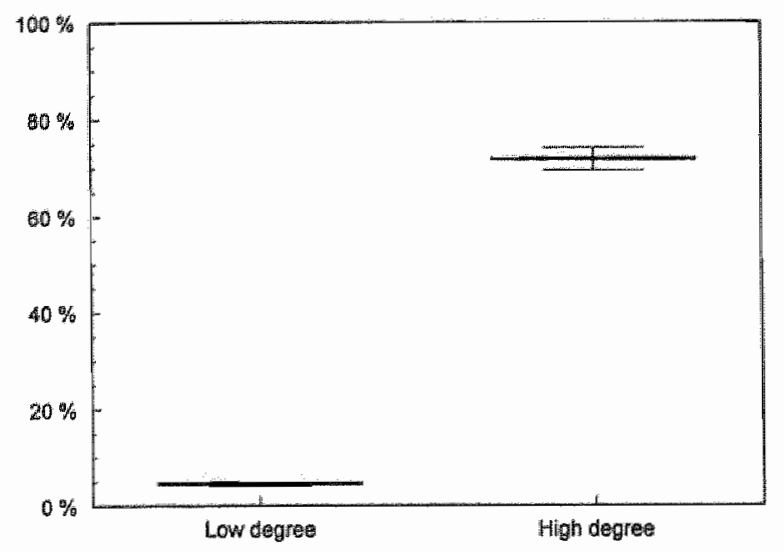

B

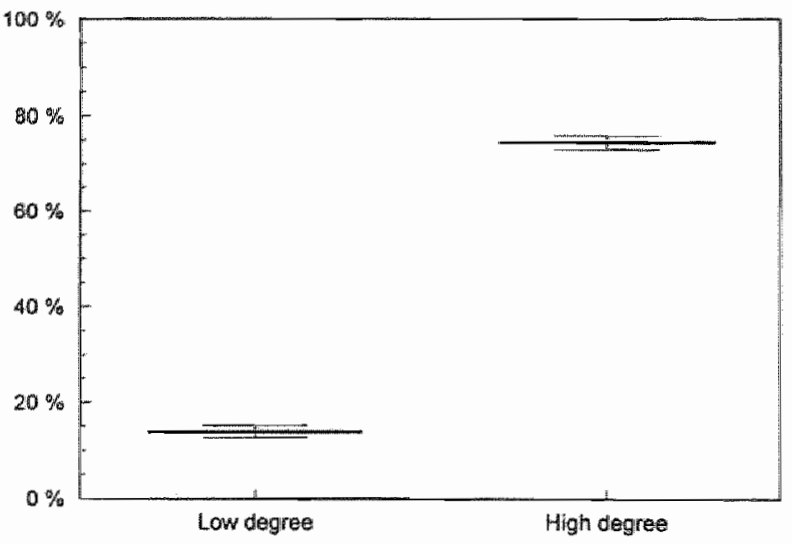

Figure 1. The percentage (mean \pm S.E.M.) of amoxycillin: A, and oxytefracycline: B, resistant E. coli of the total E. coli population in faecal samples of Dutch pigs with a low degree $(<50 \%)$ or a high degree $(250 \%)$ of resistantce.

A

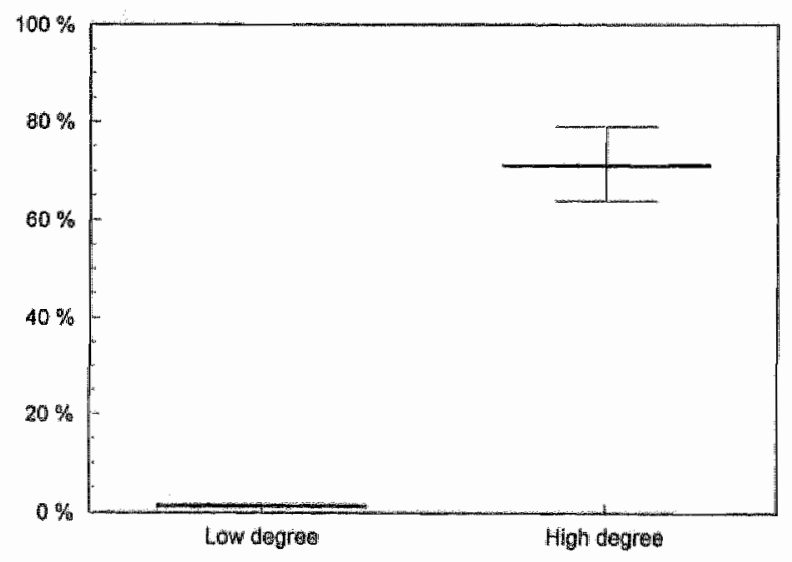

B

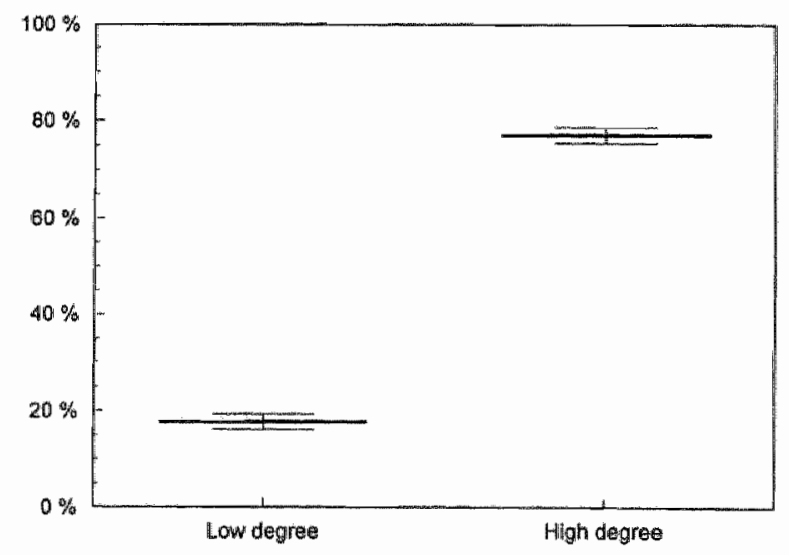

Figure 2. The percentage (mean \& S.E.M.) of vancomycin: A, and oxytetracycline: $B$, resistant enterococci of the total enterococcal population in faecal samples of Dutch pigs with a low degree $(<50 \%)$ or a high degree $(\geq 50 \%)$ of resistance.

of resistance was found for erythromycin and oxytetracycline: $70 \%$ and $46 \%$, respectively. Significant differences in prevalence and high degree of resistance between the slaughterhouses were found for all compounds tested except amoxycillin (no resistance). As shown in Table 3 significantly lower prevalences of resistance and high degree of resistance were found in the Swedish samples for oxytetracycline and erythromycin, and of resistance for dalfopristinquinupristin either compared with the total population. or with the various slaughterhouse populations separately $(P<0001)$. No VRE wrere found in the Swedish samples. The percentages of resistant enterococci in faecal specimens with low and high degree of resistance showed a bimodal distribution as depicted in Figure 2 for vancomycin and oxytetracycline respecrively. In samples with a high degree of resistance approximately $80 \%$ (range $73-86 \%$ ) of all the enterococci were resistant, whereas in samples with a low degree of resistance this varied from $2 \%$ to $28 \%$ (mean 17\%) as shown in Table 4. 
Table 3. Prevalence (Prev.) of antibiotic resistant enterococci and percentage of samples with a high degree (HD) of resistance in pig faecal samples collected at five abattoirs in the Netherlands and in Sweden.

\begin{tabular}{|c|c|c|c|c|c|c|c|c|c|c|c|c|c|c|}
\hline \multirow{4}{*}{$\begin{array}{l}\text { Antibiotic } \\
\text { (Concentration } \\
\text { in agamg/L) }\end{array}$} & \multicolumn{10}{|c|}{ Slaughterhouses } & & & & \\
\hline & Apeldo & orn & Boxtel & & Meppe & & Olst & & Weent & & \multirow{2}{*}{\multicolumn{2}{|c|}{$\begin{array}{l}\text { the Nethertands } \\
\text { Total } \\
(n=1320)\end{array}$}} & \multirow{2}{*}{\multicolumn{2}{|c|}{$\begin{array}{l}\text { Sweden } \\
(n=100)\end{array}$}} \\
\hline & \multicolumn{2}{|c|}{$(n=249)^{1}$} & \multicolumn{2}{|c|}{$(n=265)$} & \multicolumn{2}{|c|}{$(n=254)$} & \multicolumn{2}{|c|}{$(n=253)$} & \multicolumn{2}{|c|}{$(n=299)$} & & & & \\
\hline & Prew. & $\mathrm{HD}$ & Prew. & $\mathrm{HD}$ & Prev. & $\mathrm{HD}$ & Prew. & $\mathrm{HD}$ & Prev. & $\mathrm{HD}$ & Prev. & HD & Prev. & HD \\
\hline Amoxycillin (25) & 0 & 0 & 0 & 0 & 0 & 0 & 0 & 0 & 0 & 0 & 0 & 0 & 0 & 0 \\
\hline Gentamicin (500) & 6 & 0 & 3 & 0 & $1^{\circ}$ & 0 & 2 & 0 & $\mathrm{NT}^{2}$ & $N T$ & $3^{3}$ & 0 & 0 & 0 \\
\hline Oxytetracycline (25) & $96^{\circ}$ & 48 & 93 & $55^{*}$ & 92 & $35^{*}$ & $86^{*}$ & 47 & NT & $\mathrm{NI}$ & $93^{3+}$ & $46^{+}$ & 67 & 6 \\
\hline Erythromycin (10) & $98^{\circ}$ & 67 & 93 & 69 & 97 & 71 & 93 & $61^{* *}$ & 94 & $82^{\text {in }}$ & $95^{4}$ & $70^{+}$ & 63 & 3 \\
\hline Vancomycin $(10)$ & 46 & 1 & $24^{*}$ & $0.4^{* *}$ & $58^{\circ}$ & 3 & 36 & $0.4^{* x}$ & 34 & 3 & $39 *$ & 2 & 0 & 0 \\
\hline Dalfopristin- & & & & & & & & & & & & & & \\
\hline Qunupristin $(8)$ & 72 & $\mathrm{NT}$ & $62^{4 \text { tit }}$ & NT & $82^{* *}$ & NT & 71 & NT & 76 & NT & $72^{+}$ & NT & 45 & $\mathrm{NT}^{2}$ \\
\hline $\begin{array}{l}\text { number of samples } \\
2 \text { not tested. } \\
3 n=1022 \text {. } \\
\text { only } E \text {. faecium. }\end{array}$ & & * & $\begin{array}{l}\text { ifficant } \\
\text { ifficant } \\
\text { ificant }\end{array}$ & $\begin{array}{l}\text { differe } \\
\text { differen } \\
\text { differe }\end{array}$ & $\begin{array}{l}\text { from } \\
\text { from } \\
\text { from }\end{array}$ & $\begin{array}{l}\text { he tot } \\
\text { he tot } \\
\text { iwede }\end{array}$ & $\begin{array}{l}\text { of all d } \\
\text { of all d } \\
p<0.0\end{array}$ & $\begin{array}{l}a \mid \rho<0 \\
1 \text { a } p<0 \\
1 .\end{array}$ & $\begin{array}{l}.05) \\
005\end{array}$ & & & & & \\
\hline
\end{tabular}

Table 4. Proportion (\%) of resistant enterococci of the total enterococcal population in the faecal flara of pigs with high degree $(\geq 50 \%)$ and low degree $(<50 \%)$ of resistance.

\begin{tabular}{lccccc}
\hline Antibiotic & \multicolumn{2}{c}{ High degree } & & \multicolumn{2}{c}{ Low degree } \\
\cline { 2 - 3 } \cline { 5 - 6 } & mean \pm S.E.M. & $(n)$ & & mean \pm S.E.M. & (n) \\
\hline Oxytetracycline & $79 \pm 0.8$ & $(471)$ & & $24 \pm 0.7$ & $(471)$ \\
Eythromycin & $86 \pm 0.5$ & $(872)$ & $26 \pm 0.8$ & $(314)$ \\
Vancomycin & $73 \pm 4$ & $(19)$ & $6 \pm 0.4$ & $(492)$ \\
Gentamicin & 0 & & $2 \pm 1$ & $(29)$ \\
\hline
\end{tabular}

\section{DISCUSSION}

Given the large number of samples tested and their geographical distribution of origin, the resistance per"centages found in the present study can be considered to be representative of resistance in the faecal flora of pigs in the Netherlands. As the population of positive samples and the total numbers of bacteria isolated did not significantly differ between the populations, the different methods of storage of samples before testing did not seem to have had any influence on the results. All the antibiotics for which the prevalence of resistance in $E$. coli was determined are used only for therapy on veterinary prescription. The overall high prevalence of $E$. coli resistant to oxytetracycline and trimethoprim is in accordance with the amounts of these compounds used in pig medicine. Approximately $50 \%$ of all antimicrobial agents used in pigs are tetracyclines and $30 \%$ a combination of trimerhoprim with a sulphonamide. ${ }^{31}$ In the Dutch veterinary antibiotic guidelines both agents are recommended as first choice antibiotics for many indications for therapy in fattening pigs. ${ }^{32}$ Only $4 \%$ of the antibiotics used on wererinary prescription are penicillins, of which more than $90 \%$ are ampicillin or amoxycillin for oral medication. 31 The observed high prevalence of resistance to amoxycillin can therefore not be explained by a high usage. It has been recognized, however, that these broad-spectrum penicillins disturb the colonization tesistance of the intestinal tract profoundly, 33-35 facilirating overgrowth by and increasing excretion of resistant bacteria. The most important indication for mass medication of pigs with broad-spectrum penicillins is therapy and prevention of Streptococcus suis and clostridial infections. For both indications the treatment of choice is an acid fast small-spectrum penicillin. As no oral formulation of penicillin- $V$ has been registered in the Netherlands for use in pigs, in is strongly recommended to make such a product available. An additional explanation is that the genes encoding $\beta$-lactamase production are often located on the same 
Tabie 5. Increase of the prevalence $(\%)$ of resistance in the faecal $E$. coll population of fattening pigs in the present study compared with previous studies.

\begin{tabular}{|c|c|c|c|c|c|c|c|}
\hline $\begin{array}{l}\text { Year of study } \\
\text { (reference) }\end{array}$ & $\begin{array}{l}1956 \\
(50)\end{array}$ & $\begin{array}{l}1972 \\
(50)\end{array}$ & $\begin{array}{l}1979 \\
150)\end{array}$ & $\begin{array}{l}1980 \\
(51)\end{array}$ & $\begin{array}{l}1987 \\
(52)\end{array}$ & $\begin{array}{l}1992 \\
(49)\end{array}$ & $\begin{array}{l}1995 \\
\text { (this study) }\end{array}$ \\
\hline Number of samples & 100 & 100 & 100 & 100 & 47 & 291 & 1321 \\
\hline \multicolumn{8}{|l|}{ Antiblotic } \\
\hline Ampicillim & NT & 30 & 50 & 74 & 89 & 98 & 85 \\
\hline Tetracyctine & 53 & 93 & 99 & 97 & 98 & 100 & 93 \\
\hline Sulphonamide & 8 & 75 & 91 & 97 & NT & 94 & NT \\
\hline Trimethoprim & NT & 0 & 42 & 69 & NT & 88 & 85 \\
\hline Furazolidone or Nitrofurantoin & NT & 8 & 12 & 25 & NT & 17 & 3 \\
\hline Flumequin or Nalidixic acid & NT & 0 & 0 & 0 & NT & 2 & 3 \\
\hline
\end{tabular}

Table 6. Prevallence (\%) and percentage of samples with a high degree of resistant Escherichia colin pig faeces collected in 1992 ( $n=291$ ) and in 1995 (n $=299)$ at the abattoir in Weert.

\begin{tabular}{|c|c|c|c|c|c|}
\hline \multirow[b]{2}{*}{ Antiblotic } & \multirow[b]{2}{*}{$\mathrm{mg} / \mathrm{L}^{*}$} & \multicolumn{2}{|c|}{ Prevalence $(\%)$} & \multicolumn{2}{|c|}{ High degree } \\
\hline & & 1992 & 1995 & 1992 & 1995 \\
\hline Amoxycillin & 25 & 84 & 70 & 12 & 14 \\
\hline Apramycin & 32 & 1 & 0 & 0 & 0 \\
\hline Ciprofloxacin & 4 & 0 & 0 & 0 & 0 \\
\hline Fiumequin & 16 & 1 & 3 & 0 & 0 \\
\hline Neomycin & 8 & 73 & 38 & 2 & 3 \\
\hline Nitrofurantoin & 50 & 4 & 1 & 0 & 0 \\
\hline Oxyletracycline & 25 & 89 & 78 & 45 & 32 \\
\hline Trimethoprim & 8 & 77 & 62 & 3 & 20 \\
\hline
\end{tabular}

"mg/L: Antibiotic concentrations in the agar plates.

plasmid as the genes for tetracycline and chloramphenicol resistance. ${ }^{36}$ However, it is most likely that, as a result of co-selection, the prevalence of resistance to broad-spectrum penicillins (only limited) and chloramphenicol (use prohibited for more than 5 years) is higher than would be expected in comparison with the amounts of these drugs used in the pig population. In contrast, the observed resistance to nitrofurantoin was much lower. The use of nitrofurans in food animals has also been prohibired for more than 5 years and resistance to this class of agents seems to be disappearing from the population. This process might be faster than with other antibiotics because no transferable resistance to nitrofurans exists. Aminoglycosides represent only $2 \%$ of the veterinary use of antibiotics and neomycin is the most widely used agent of this group. For gentamicin and fluoroquinolones such as ciprofloxacin no oral formulations for mass medication of pigs are available in the Netherlands and therefore these agents have only limited use in pigs. In contrast, enrofloxacin accounts in the Netherlands for $14 \%$ of all veterinary antibiotic use in poultry and the prevalence of fluoroquinolone resistance in faecal $E$. colt from poultry is $50 \% .{ }^{19,37}$ If these molecules would become available for in feed medication an increase in resistance can be expected. Florfenicol is a structural analogue of chloramphenicol that is not inactivated by chloramphenicol acetyltransferase. ${ }^{38}$ In the Netherlands it is used only for parenteral therapy of bacterial respiratory tract infections in cattle. Nevertheless in 
wwo samples florfenicol resistant E. coli were found. Eventual use of florfenicol in pigs, would therefore be most likely result in a dissemination of resistant clones or genes conferring resistance to forfenicol in the exposed pig population. Also in the past introduction of a new antibiotic for usage in pigs has always been followed by an increase of resistance against that anribiotic in the faecal $E$. coli-population of fattening pigs. Sulphonamides became available in veterinary medicine direct after the war, and tetracycline in the early fifries. Around 1970 ampicillin and trimethoprim were introduced on the veterinary market and around 1980 flumequin. The results of several previous studies regarding the prevalence of resistant $E$. coli in faecal samples of healthy fattening pigs show all, despite the differences in methodologies used, the same trend: shortly after introduction of a new antibiotic for usage in pigs resistance against that antibiotic appeared as shown in Table 5. Comparison of the data on the prevalence and degree of resistance of faecal E. coli in this study with a similar study performed at the same abattoir in $1992^{49}$ showed a significant $(\mathrm{p}<0.05)$ decrease in prevalence of resistance for neomycin and an increase of the prevalence of high degree samples for trimethoprim from $3 \%$ to $20 \%$ (Table 6). This might be due to the fact that in the Dutch antibiotic guidelines for pigs of which the first edition was published in 1994 , neorrycin is onlly for neonatal diarrhoea recommended as a first choice antibiotic. This might have caused a decline in use of neomycin, but as in the present study neither the farms of origin were known, nor data on antibiotic use on the different farms were available, further analysis was not possible. The significant differences observed between the studied slaughterhouses underscore the need for information on the farm of origin as well as reliable data on antibiotic usage on farms.

In the present study no differentiation was made between Enterococcus spp., except for resistance to dalfopristin-quinupristin, because Enterococcu faccalis is considered intrinsically resistant to pristinamycins such as dalfopristin-quinupristin. The highest prevalence and degree of resistance was found for erythromycin and oxytetracycline. The resistance to tetracyclines was in line with the extensive usage of these drugs in pigs. Despite the relatively low susceptibility of enterococci to amoxycillin, with MICs of most
E. facalis of $1-8 \mathrm{mg} / \mathrm{L}$ and even higher for $E$. faecium, ${ }^{39}$ no amoxycillin-resistant enterococci (MIC $>25 \mathrm{mg} / \mathrm{L}$ ) were found. In recent clinical studies the majority of E. faecium isolates had MICs lower than 25 $\mathrm{mg} / \mathrm{L}$ and resistant isolates with higher MICs were related to hospital stay. ${ }^{40-42}$ The samples collected at the various slaughterhouses showed significant differences in resistance for most antibiotics tested. As most slaughterhouses tend to collect pigs from a particular region the differences observed are probably due to differences in antibioric usage, qualitatively and quantitatively, between these regions. However, the influence of differences in husbandry systems, stocking densities and density of animal populations between regions should also be considered.

In enterococci tylosin use is probably responsible for the high prevalence and degree of resistance to erythromycin, and virginiamycin use as AMGP for the observed prevalence of resistance to dalfopristinquinupristin in E. faccium. In this study the prevalence of VRE ranged from $24 \%$ in Boxtel to $46 \%$ in Apeldoorn, with a mean prevalence of $39 \%$. Similar ${ }^{43}$ or lower ${ }^{44}$ prevalences of VRE in pigs have been reported from other European countries that used avoparcin as AMGP. In the USA, where avoparcin has never been licensed for use in animals, no VRE have been isolated from food animals. 45,46 A high degree of vancomycin resistance was observed in only $2 \%$ of the samples, which might reflect the fact that use of avoparcin, a glycopeptide like vancomycin, as AMGP has been banned in the $\mathrm{EU}$ recently, because a relationship between avoparcin use and the prevalence of VRE in the faecal flora of food animals and humans was suggested. 47.48

The observed differences in resistance to antimicrobial growth promoters between abattoirs is probably a regional difference, because one or two feedmills provide pig feeds to the majority of the farms in a region and feedmills tend to use the same AMGP for a long time. Most striking was the difference in prevalence of VRE between the Dutch (39\%) and Swedish (0\%) population. Avoparcin, tylosin (a macrolide like erythromycin) and virginiamycin (a mixture of two pristinamycins like dalfopristin-quinupristin) were at the time of the study extensively used as AMGP in the Netherlands, but not in Sweden. The observed differ- 
ences are probably a result of the Swedish ban on AMGP in 1986, as before that year AMGP were also commonly used in pig feeds in Sweden. Unfortunately, no data on prevalence of resistance to AMGP from before 1986 are available.

Prevalence and degree of resistance to antibiotics in veterinary use was also significantly lower in Sweden than in the Netherlands. This contradicts the common opinion that a prohibition of the use of AMGP inevitably must lead to an increase in veterinary use of antibiotics. As the prevalence and degree of resistance in indicator bacteria is strongly correlated with the amounts of antibiotics used in a population, the present data show clearly that the prohibition of AMGP in Sweden has not increased the therapeutic usage of antibiotics in pigs in Sweden to such an extent that the selection pressure on the intestinal flora was higher than in a country using AMGP. The lower prevalence and degree of resistance to most antibiorics in $E$. coli and enterococci strongly suggests that veterinary use in Sweden is even lower. The observed prevalence of resistance to dalfopristin-quinupristin in E. faecium in the Swedish population is probably due to veterinary usage in Sweden of virginiamycin or macrolides such as tylosim, which show cross resistance and select for the same erm genes.

The marked bimodal distribution of the proportion of resistant bacteria in the indicator populations studied for all anribiotics was unexpected. There was a cllear difference between low- and high-degree resistance in the faecal samples studied. In the majority of positive samples only a low degree of resistance was found. For example, the mean \pm s.e.m. of the proportion of VRE in the total enterococcal population in samples $(n=$ 492 ) with a low degree of resistance was $6 \% \pm 0.4 \%$, but in samples $(n=24)$ with a high degree of resistance the proportion of VRE was $73 \% \pm 4 \%$. Therefore at random susceptibility testing of one to three isolates from faecal specimens as is commonly done inevitably results in a serious underestimation of the prevalence of resistance of indicator bacteria in a population, because mainly isolates of samples with a high degree of resistance will be found positive.

In this study, current frequent usage of a particular antibiotic in a pig population seemed to correlate not only with a high prevalence of resistance to that antibi- otic, but also with a higher prevalence of animals with a high degree of resistance in the population. Similarly frequent usage of an antibiotic in the past was associated with a relatively high prevalence of resistance in the population, but with a low prevalence of animals with a high degree of resistance. Increasing usage of an already commonly used antibiotic, against which there was a high prevalence of resistance in the population, was reflected in an increase in the prevalence of faecal samples with a high degree of resistance to that antibiotic.

In conclusion, because of the increasing problem of bacterial resistance, a rational usage of antibiotics including the implementation of a veterinary antibiotic policy is of utmost importance to safeguard the efficacy of veterinary antibiotic therapy for the future and to minimize public health risks from veterinary use. Surveillance is an essential part of an antibiotic policy and should consist of the regular or continuous monitoring not only of antimicrobial resistance, but also of antibiotic usage in the population under study or at risk, followed by analysis and dissemination of the results. Differences between countries, regions, farms and veterinary practices can be observed and investigated, and therapeutic recommendations adapted when resistance exceeds threshold levels. Moreover, emergence and spread of new resistance genes, resistant clones or new resistance profiles can be detected early and action taken to prevent further dissemination.

\section{ACKNOWLEDGEMENTS}

We would like to thank the inspectors of The Dutch National Inspection Service for Meat and Livestock (RVV) for collecting the Dutch faecal samples, Dr Christina Greko for providing the Swedish specimen, and Ms C. Driessen and Mr P. Terporten for technical assistance. This study has been made possible by a grant of The Dutch Veterinary Public Health Inspectorate and The Dutch Ministry for Agriculture, Nature Management and Fisheries. 


\section{REFERENCES}

1. Murray, B. E. (1991). New aspecrs of antimicrobial resistance and the resulring therapeutic dilemmas. Journal of Infectious Diseases 163, $1184-94$.

2. Murray, B. E. (1992). Problems and dilemmas of antimicrobial resistance. Pharmacotherapy $12,586-93$

3. Levy, S. B. (1996). The science of resistance. In Resistant arganism: global impact on continum of care, (Henderson, D. K. \& Lewy, S. B. Eds), pp. 7-26. The Royal Society of Medicine Press, London.

4. Knothe, H. (1977). Medical implications of macrolide resusrance and its relationship to the use of tylosin in animal feeds. Infection 5, 137-9.

5. Knothe, H. (1977). A review of the medical considerations of the use of tylosin and other macrollide antibiotics as additives in animal feeds. Infection 5, 183-7.

6. Lacey, R. W. (1980). Rarity of gene transfer between animal and human isolates of Staphylococcus aureus in vitro. Journal of General Microbiology 119, 437-42.

7. Lacey, R. W. (1985). Understanding antibioric resistance: did Swann get it wrong? Veterinary Practice 17,6.

8. Lacey, R.W. (1988). Rarity of rylosin resistance in human pathogenic bacteria. Veterinary Record 122, 438-9.

9. Donnelly, J. P., Voss, A., Witre, W. \& Murray, B. E. (1996). Does the use in animals of antimicrobial agents, including glycopepride antibiotics, influence the efficacy of antimicrobial therapy in humans? Journal of Antimicrobial Chemotherapy 37, 389-92.

10. Piddock, L. J. V. (1996). Does the use of antimicrobial agents in veterinary medicine and animal husbandry select anribiotic-resistan bacteria that infect man and compromise anrimicrobial chemotherapy? Journal of Antimicrobial Chemotherapy 38, 1-3.

11. Murray, B. E. (1994). Can antibiotic resistance be controlled? New England Journa! of Medicine 330, 1229-30.

12. Murray, B. E. (1997). Antibioric resistance. Advances in Internal Medicine 42, 339-67

13. Pohl, P. \& Lintermans, P. (1986). R-plasmid reserwoirs and circulation. Veterinary Science Compendium Medicine A Series $51-63$.

14. Wiggins, B. A. (1996). Discriminant analysis of antibiotic resistance pattern in fecal streprococci, a method to differenviate human and animal sources of fecal pollution in narural waters. Applied and Environmental Microbiology 62 , $3997-4002$.

15. Kibbey, H. J., Hagedorn, C. \& McCoy, E. L. (1978). Use of fecal streptococci as indicators of pollution in soil. Applied and Environmental Microbiology 35,711-7.

16. Avignon, M. \& Lafont, J. P. (1985). Survival of antibiotic resistant enteric bacteria in the effluent treatment plant of a pig farm. Annals of Vererinary Research 1.6, 245-53.

17. Aharr, J. C., Burton, G. C. \& Blenden, D. C. (1978). The influence of antimicrobial agents on the percentage of retracydine-resistant bacteria in faeces of humans and animals. Journal of Applied Bacteriology 44, 183-90.
18. Murrys, B. E. (1984). Emergence of diseases caused by bacteria resistant to antimicrobial agents. In Handbook Series in Zoonoses, Secrion D: Antibiotics, Sulfonamides and Public Health, (Steel, J.. Ed.) pp. 201-16. CRC Press Boca Raton, FL.

19. van den Bogaard, A., London, N., Driessen, C. \& Srobberingla, E. (1997). Wluoroquinolone usage in animals and resistance in human faecal $\mathrm{E}$. coli. Proceedings of the Thirry-Seventh ICAAC Conference, Toronto, Abstrac C-137. p. 70. American Sociery for Microbiology "Wahington, DC

20. Hummel, R., Tschape, H. \& Witre, W. (1986). Spread of plasmid-mediated nourseothricin resistance due to antibionic use in animal husbandry. Journall of Basic Microbiology 26. $461-6$.

21. Lester, S. C. del Pilar Pla, M., Wang, F., Perez Schad, I., Jiang, H. \& O'Brien, T. (1990). The carrage of Escherichia coli resistant to anrimicrobial agents by healthy children in Bostron, in Caracas, Venezuela and in Qim Pu, China. New England Journal of Medicine 323, 285.9.

22. van den Bogaard, A. E. \& Stobberingh, E. (1996). Is ir time to ban all antibiotics as animal growth-promoting agents? (and reply and author's reply) Lancet 348, 1454-6.

23. wan den Bogaard, A. E. (1997). Ancimicrobial resistance rela tion to human and animal exposure to antibiotics. Journal of Antimicrobial Chemotherapy $40,453-4$.

24. Nijsten, R., London, N., van den Bogaard, A. \& Stobberingh, E. (1993). Antibiotic resistance monicoring of Enterobacteriaceac isolated from the faecal flora of fattening pigs. Veterinary Quarterly 15, 152-6.

25. Bonten, M., Stobberingh, E., Philips, J. \& Houben, A. (1990). High prevalence of antibioric tesistant Escherichia coli in faecal samples of students in the sourh-east of the Nednerlands. Journal of Antmicrobial Chemotherapy $26,585-92$.

26. London, N. Nijsen, R, van den Bogard, A. \& Stobberngh E. (1993). Antibionic resistance of facal Enterobacteriaceac isolared from heallity wolunteers, a 15 -week follow-up study. Journat of Antimicrobial Chemotherapy $32,83-91$.

27. Nujsten, R., London, N., van den Bogaad, A. \&e Stobberingh, E. (1996). Antibiotic resistance among Escherichia coli isolated from faecal samples of pig farmers and pigs. Journal of Antimicrobial Chemotherapy 37, 1131-40.

28. Devriese, L. A., Hommez, J., Wijfels, A. \& Hasebrouck, F. (1991). Composition of the enterocaccal and streptococal intestimal flora of poultry. Journal of Applied Bacteriology 71 , $45-50$.

29. Wan den Bogard, A. E., Mertens, P., London N. H. 8 Stobberingh, E. E. (1997). High prevalence of colonization wish wancomycin and pristinamycin-resistant enterococci in healthy humans and pigs in the Netherlands. Jounal of Antimicrobial Chemotherapy 40, 454-6.

30. Armitage, P. \& Berry, G. (1987). Staristical methods in medical research. In Multiple Comparison, Pp. 200-5. Blackwell Scientific, London.

31. van den Bogaard, A. E., Breeuwsma, A. J. Julicher, C. H. M., Mostert, A. \& Niedwenhuijs, J. (1993). A veterinary antibi- 
otic policy; recommendations of a workgroup. Tijdschrift voor Diergenecskunde 118,565-8.

32. van den Bogatrd, A. E., Harman, E. G., van Mien, A. S., Pijpers, A., Werheijden, J. H. \& Voermans, J. J., Eds. (1995) Antibiotic Guidelines for Pigs-Formularium Varken. Royal Dutch Society for Veterinary Medicine, Utrecht.

33. wan Saene, H. K. F., Willems, F. T. C. \& Zweers. I. (1983). Influence of amoxycillin and cefaclor on the colonization resistance of the oropharynx. Scandinavian Journal of Infectious Diseases $39,97-9$

34. van der Waaij, D., van Vries Hospers, H. G., Snipders, J. A., Halie, M. R. \& wan de Nieweg, H. O. (1987). Colonization resistance of the digestive tract-mechanism and clinical consequences. Nahrung 31, 507-17.

35. Vollaard, E. J. \& Clasener, H. A. L. (1994). Colonization resistance. Antimicrobial Agents and Chemotherapy 38, $409-14$.

36. Nijsten, R., London, N., van den Bogaard, A. 8. Stobberingh, E. (1996). In vitro transfer of antibiotic resistance between faecal Eschertichia coli strains isolated from pig farmers and pigs. Journal of Antimictobial Chemotherapy 37. $1141-54$.

37. Stobberingh, E., van den Bogaard, A., London, N., Driessen, C., Top. J. \& Willems, R. (1999). Enterococci wich glycopeptide resistance in turkeys, turkey farmers, turkey sllaughterers, and (sub)urban residents in the sourh of the Netherlands: evidence for transmission of wancomycin resistance from animals to humans? Antimicrobual Agents and Chemotherapy $43,2215-21$.

38. Graham, R. Palmer, D., Prat, B. C. \& Harman, C. A. (1988). In vitro acrivity of florphenicol. European Journal of Clinical Microbiology and Infectious Disease 7, 691-4.

39. Muray, B. F. (1998). Diversity among multidrugaresistant enterococci. Emerging Infecrious Discases 4,3747 .

40. Patrerson, J. E, Sweeney, A. H., Simms, M. Carley, N., Mangi, R., Sabetta, J. ex al, (1995). An analysis of 110 serious enterococcal infections-epidemiology, antibiotic susceptibility and ourcome. Medicine 74, 191.200

41. Kaufhold, A. \& Klein, R. (1995). Species identification and antibiotic susceptibility of enterococei isolates from clinical specimens of hospitalized patients. International Joumal of Medical Microbiology, Virology, Parasitology and Infectious Disease $282,507-18$
42. Silverman, J., Thal, L. A., Pern, M. B. Bostic, G. \& Zervos, M. J. (1998). Epidemiology Evaluarion of antimicrobial resizance in community-acquired enterococil. Joumal of Clinical Microbiology 36, 830-1.

43. Bayer, F., Madson, M., Christensen, J. \& Aarestrup, F. M. (1997). Avoparcin used as growth promorer is associated with the occurrence of vancomycin resistant Enterococcus faecium on Danish poultry and pig farms. Preventive Vererinary Medicine 31, 95-112.

44. Dewriese, L. A., Iven, M., Goossens, H., Vandamme, P., Por, B., Hommez, J. et al. (1996). Presence of vancomycinresistant enterococci in farm and pet animals. Antimicrobial Agents and Chemorherapy $40,2285-7$.

45. Coque, T. M., Tomayko, J. F., Ricke, S. C., Okhyusen, P. C. \& Murray, B. E. (1996). Vancomycin resistant enterococci from nosocomial, community, and animal sources in the United States. Antimicrobial Agents and Chemotherapy 40, $2605-9$

46. McDonald, C. F., Kuiehnert, M. J., Tenover, F. I. \& Jarvis, W. R. (1997). Vancomycin-resistant enterococci outside the health-care setring: prevalence, sources, and public health implicarions. Emerging Infectious Diseases 3, 311-7.

47. Bates, J. Jordens, Z. \& Selkon, J. B. (1993). Evidence for animal origin of vancomycin resistant enterococci. Lancet $342,490-1$.

48. Bates, J., Jordens, Z. \& Selkon, J. B. (1994). Farm animalsas a putative reservoir for vancomycin-resistant enterococcal infection in man. Journal of Antimicrobial Chemotherapy 34, $507-14$

49. Kuske-Nijsten, R. (1995). Antibiotic resistance in humans and pigs. Is there a rellation? Thesis University Maastricht

50. Smith, H. \& Williams. (1980). Anribioric resistant Esche. richia coli in marker pigs in 1956 - 1979 the emergence of organisms wirh plasmid-borne trimethoprim resistance. Journal of hygiene 84, 476-77.

51. Smith, H., Williams \& Lovell, M.A. (1981). Escherichia coli resistant to teracyclines and to other antibiotics in the facces of U.K. chickens and pigs in 1980 . Joumal of hygiene 87,477 $-83$.

52. Nijisten, R, London, N, van den Bogaard, A.E \& Srobberingh, E.E. (1996) In vitro transfer of ancibiotic resis. tance berween faecal Escherichia coli strains issolared from pig famers and pigs. Journal of Antimicrobial Chemorherapy 37. $1145-54$ 


\section{Chapter IV}

\section{Vancomycin-resistant enterococci in turkeys and farmers}

and

Enterococci with glycopeptide resistance in turkeys, turkey farmers, turkey slaughterers, and (sub)urban residents in the south of the Netherlands: evidence for transmission of vancomycin resistance from animals to humans? 



\author{
Chapter IVa
}

\title{
Vancomycin-resistant enterococci in turkeys and farmers
}

\author{
A.E. van den Bogaard", L.B. Jensen ${ }^{* *}$ and E.E. Stobberingh ${ }^{*}$ \\ *University Maastricht, NL-6200 MD Maastricht, the Netherlands \\ **Danish Veterinary Laboratory, DK-1790 Copenhagen V, Denmark
}




\section{Correspondence}

VANCOMYCIN-RESISTANT ENTEROCOCCI IN TURKEYS AND FARMERS

\section{To the Editor:}

In enterococci vancomycin resistance of the VanA phenotype is usually due to the presence of seven genes organized in a cluster on a transposon $(\operatorname{Tn} 1540) 1,2$. The recent emergence of vancomycin-resistant enterococci is believed to be due to the vertical clonal spread of resistant strains and the horizontal spread of the transposon itself among different strains of enterococci in a selective environment. Use of avoparcin - a glycopeptide, like vancomycin - as an antimicrobial growth promoter in animal feeds creates such a selective environment and causes the selection of vancomycin-resistant enterococci in the intestinal flora.

To determine wherher vancomycin-resistant enterococci from animals can cause colonization in humans, we collected fecal samples from turkeys at 47 farms and from 47 turkey farmers. In addition, fecal samples from 48 turkey slaughterers and 188 healthy persons living in the same area were screened ${ }^{3}$. Vancomycin-resistant enterococci were isolated from 50 percent of the samples from the turkeys, 39 percent of the samples from the turkey farmers, 20 percent of the samples from the turkey slaughterers, and 14 percent of the samples from area residents. The prevalence of vancomycin-resistant enterococci in 12 turkey flocks not receiving avoparcin was 8 percent, as compared with 60 percent in flocks fed avoparcin $(p<0.001)$.

Almost all the vancomycin-resistant enterococci were Enterococcus facciom, and they were highly resistant to vancomycin (minimal inhibitory concentration $>64$ mg per liter). The resistance to teicoplanin waried (minimal inhibitory concentration, 0.5 to $8 \mathrm{mg}$ per liter).

Phenotypically identical strains were further analyzed by pulsed-field gel electrophoresis after digestion with Smal. Most isolates showed variations in patterns. Only in samples from one farmer and his turkey flock were indistinguishable strains of vancomycin-resistant enterococci isolated with an identical pattern of the 17 bands- Moreover, genetic characterization of the vanA gene cluster by the polymerase chain reaction and hybridization showed that the two strains were identical in the tested areas containing a unique genetic element; this element proved to be different from the published wanA gene clusters in BM4147 $7^{1,2,4}$ in that there was an insertion in the intergenic area between the $\operatorname{van} X$ and the $\tan Y$ gene and a deletion in the right end of the gene cluster that removed the van $Z$ gene and created a latger positive band when a $\operatorname{van} X$ probe was used, as shown in Table 1.

Table 1. Phenotypic and genetic characteristics of vancomycinresistant enterococci in fecal isolates from humans and turkeys in the Metherlands and in reference strain BM4147\%.

\begin{tabular}{|c|c|c|c|}
\hline Characteristic & $\begin{array}{l}\text { Human } \\
\text { Isolates }\end{array}$ & $\begin{array}{l}\text { Turkey } \\
\text { Isolates }\end{array}$ & $\begin{array}{l}\text { Reference Strain } \\
\text { (Human MB4147) }\end{array}$ \\
\hline \multicolumn{4}{|l|}{ Phenotype } \\
\hline Wancomycin (MIC) & $>64$ & $>64$ & $>64$ \\
\hline Teicoplanin (MIC) & 8 & base pairs & $>64$ \\
\hline \multicolumn{4}{|l|}{ PCR } \\
\hline $\operatorname{van} A$ & 535 & 535 & 535 \\
\hline wanh & 409 & 409 & 409 \\
\hline wanx & 423 & 423 & 423 \\
\hline wanX mutation" & $\mathrm{C}$ & $\mathrm{C}$ & $\mathrm{C}$ \\
\hline $\operatorname{van} Z$ & - & - & 323 \\
\hline WanXY & 1350 & 1350 & 750 \\
\hline wan $Y Z$ & 335 & 335 & 335 \\
\hline \multicolumn{4}{|c|}{ Insertion sequencesł } \\
\hline $1 S 1251$ & Absent & Absent & Absent \\
\hline 1S1246-HS3ike & \multicolumn{3}{|c|}{ killobase pairs } \\
\hline \multicolumn{4}{|l|}{ Hybridization $\$$} \\
\hline $\operatorname{van} A$ & 50 & 50 & 35 \\
\hline vanX (right end) & $>23$ & $>23$ & 3.5 \\
\hline vanZ (right end) & - & - & 3.5 \\
\hline \multicolumn{4}{|c|}{ 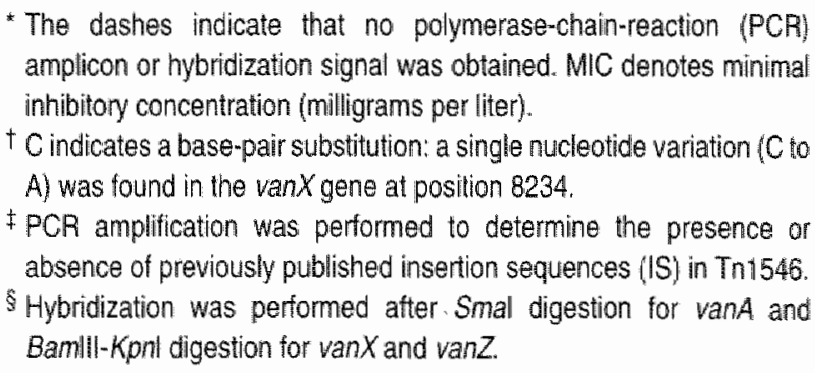 } \\
\hline
\end{tabular}


Given the wide use and the selective pressure created by antibiotics and the differences in the prevalence of vancomycin-resistant enterococci in the populations studied, the most plausible explanation for these findings is the spread of a vancomycin-resistant enterococcal strain from the turkeys to the farmer. The absence of the $\operatorname{van} Z$ gene may contribute to the observed low resistance to teicoplanin as compared with vancomycin ${ }^{2}$. These findings confirm the high prevalence of vancomycin-resistant enterococci in healthy persons living in areas where avoparcin is used as an antimicrobial growth promoter. Our study also shows that humans and animals can carry the same clone of vancomycin-resistant enterococci.

Anthony E. van den Bogaard, D.W.M., University Madstricht, NL-6200 MD Maastricht, the Netherlands.

Lars Bogo Jensen, Ph.D., Danish Veterinary Laboratory, DK-1790 Copenhagen V, Denmark.

Ellen E. Stobberingh, Ph.D., University Maastricht.

\section{REFERENCES}

1. Arthur M, Molinas C, Depardieu F. Courvalin P. Characterization of $\operatorname{Tn} 1546$, a Tn3-related ransposon conferring glycopeptide resistance by symthesis of depsipeptide pepridoglycan precursors in Emerococus farecism BM4147. I Bacterioll 1993; 175: 117-27.

2. Arthur M, Depardieu Folinas C, Reynolds P, Counvalin P. The wanZ gene of Tn 1546 from Enterocacm faeciam BM4147 confers resistance to teicoplanim. Gene 1995; 154: 87.92 .

3. van den Bogaard $A$, London $N$, Driessen $C$, Stobberingh $E_{\text {. }}$ Prevalence of resistant faecal bactera in turkeys, rurkey farmers and turkey slaughterers. In: Program and abstracts of the 30th Intersience Conference on Antimicrobial Agenrs and Chemotherapy. New Orleans, September 15-18,1996. Wasthington, D.C.: American Society for Microbiology, 1996.

4. Leclercq R, Derlot E, Duval ], Courvalin P. Plasmid-mediated resistance to vancomycin and teicoplanin in Enterocochs faeciam. N Engl ] Med 1988; 319:157 61. 


\section{Chapter IVb}

Enterococci with glycopeptide resistance in turkeys, turkey farmers, turkey slaughterers, and (sub)urban residents in the south of the Netherlands:

evidence for transmission of vancomycin resistance from animals to humans? 


\title{
Enterococci with Glycopeptide Resistance in Turkeys, Turkey Farmers, Turkey Slaughterers, and (Sub)Urban Residents in the South of The Netherlands: Evidence for Transmission of Vancomycin Resistance from Animals to Humans?
}

\author{
ELLEN STOBBERINGH, ${ }^{*}$ ANTHONY VAN DEN BOGAARD, ${ }^{\prime}$ NANCY LONDON, \\ CHRISTEL DRIESSEN,' JANETTA TOP, ${ }^{2}$ AND ROB WILLEMS ${ }^{2}$ \\ Department of Medical Microbiology, Unwersity Hospital Mastrichi, Maastricht, ${ }^{2}$ and Natonal Institute of \\ Public Heath and the Emiromment, Bithoven, ${ }^{2}$ The Netherlands
}

Received 29 December 1998/Returned for modification 2 March 1999/Accepted 2 July 1999

\begin{abstract}
The number of vancomycin-resistant enterocacei (VRE) relative to the total number of enterococci was determined in fecal samples from turkeys and three human populations in 1996, each with a different level of contact with turkeys, i.e., turkey farmers, torkey slaughterers, and (sub)urban residents. The percentage of VRE relative to the total enterococcal population (i.e., the degree of resistance) was low ( 2 to $4 \%$ ) in all groups (except in six samples). No difference was observed between farmers who used avoparcin and those who did not. The pulsed-field gel electrophoresis (PFGE) patterns of the VRE isolates from the different populations were quite heterogeneous, but isolates with the same PFGE pattern were found among animal and human isolates, in addition to the isolates which were described previously $\left(A\right.$. E. van den Bogaard, $L$. $B$. Jensen, and $\mathbb{L}_{\text {. }} \mathrm{E}_{*}$ Stobberingh, N. Engl. J. Med. 337:1558-1559, 1997). Detailed molecular characterization of wanA-containing transposons from different isolates showed, that in addition to a previously reported strain, similar transposons were present in VRE isolates from turkeys and turkey farmers. Moreover, similar VanA elements were found not only in isolates with the same PFGE pattern but allso in other strains from both humans and animals.
\end{abstract}

Vancomycin-resistant enterococci (VRE) were isolated for the first time in 1986 in Europe and in 1987 in the United States. Since then VRE infections have been reported from all wer the world. In 1993 enterococci accounted for $12 \%$ and VRE accounted for $1 \%$ of all hospital infections in the United States (10). In Europe the rate of fecal carriage of VRE in the community is much higher (e.g., 2 to $28 \%$ ) than that in the United States, where VRE seem to be more or less absent outside hospitals $(10,17)$. In Europe a diversity of VRE types has also been isolated from sewage, animal waste, meat and meat products, and feces of healthy persons, suggesting a heterogeneous pool of VRE outside hospitals $(7,8,25,26)$. The observation that in the United States VRE have not been isolated from animal sources $(6,10)$ might be due to the fact that in the United States glycopeptides were never approved for use in animal feeds as antimicrobial performance enhancers (APEs) for growth promotion (28). Until recently, avoparcin, a glycopeptide that shows complete cross-resistance with vancomycin, was commonly used in The Netherlands and in most other countries of the European Union for this purpose (23). The use of avoparcin as an APE has been suggested as a risk factor for carriage of WRE in food animals, as the usage of any antibiotic produces a selective pressure in favor of resistance $(5,12,26,27,29,34,39)$. Therefore, its use as an APE was suspended in the European Union in 1996.

Four main types of resistance to glycopeptides have been described: $\operatorname{Van} A, \operatorname{Van} B, \operatorname{VanC}$, and $\operatorname{VanD}(4,18,30,31)$. The

\footnotetext{
Corresponding author. Mailing address: Department of Medical Microbiology, University Hospital Maastricht, P.O. Box $5800,6202 \mathrm{AZ}$ Maastricht, The Netherlands. Phone: 00-31-43-3874644. Fax: 00-31-433876643. E-mail: EST OUMIB.AZM.NL.
}

vanA gene cluster is the one most commonly found and encodes inducible high-level resistance to both vancomycin and teicoplanin. Dissemination of vancomycin resistance can occur through both clonal expansion of resistant enterooocci and horizontal transmission of resistance genes $(21,22)$. Horizontal transfer of vancomycin resistance is explained by the fact that the genetic deferminant for the VanA type of vatucomycin resistance typically resides on a mobile DNA element such as Tn1546 (3), which can be transferred to enterococci by plasmids. Recently, in several studies, the heterogeneity of the VanA resistance determinant was described. In those studies, indistinguishable Tn/546-like elements could be found in VRE isolated from farm animals and humans, suggesting transfer of vancomycin resistance elements from fam animals and humans $(31,38,40)$.

In a previously published report of a study in which the prevalence of VRE in turkeys and farmers was assessed, we found that VRE could be detected in $50 \%$ of the fecal samples from turkeys $(n=47)$ and in $39 \%$ of the fecal samples from turkey farmers $(n=47)$ (33). Furthermore, VRE wore isolated from $20 \%$ of the fecal samples from turkey slaughterers $(n=$ 48 ) and $14 \%$ of the fecal samples from (subjurban residents from the same area $(n=117)$. In addition, an indistinguishable VRE and a vahA-containing element were found in one sample from a turkey and one from a turkey farmer, suggesting animal-to-human transmission of wancomycin resistance as a likely route $(33)$.

In the present study we analyzed in more detall the epide. miology of VRE in the context of the infuence of avoparcin use in turkey feed. The relative amount of VRE in fecal samples from turkeys and three groups of heallty volunteers with different risks of exposure to fecal bacteria from turkeys, i.e., turkey farmers, turkey slaughteress, and control group of 
(sub)urban residents, was determined by calculating the number of VRE relative to the total number of enterococci. The VRE that were isolated were identified and classified with respect to the rype of vancomycin resistance. In addition, the antibiotic susceptibilities to several antimicrobial agents of enterococci isolated from vancomycin free and vancomycin-conlaining selective agar plates were determined. Possible sharing of VRE between turkeys and humans was assessed by genotyping by pulsed-field gel electrophoresis (PFGE). In addition, the similarity of vancomycin resistance elements found in animal and human isolates was assessed by comparing Tn1546 derivatives of isolates of VRE from turkeys and the three groups of healthy human volunteers.

(Parts of this study were presented at the 37 th Interscience Conference on Antimicrobial Agents and Chemotherapy, Toronto, Ontario, Canada, 28 September to 1 October 1997.)

\section{MATERIALS AND METHODS}

Collection of tecal samples. In 1996 , the major turkey faterues in The Netharlands $(n=81)$ wone asked 10 collect one fresh fecal mample from themselves and one mixed focal sample from three randomly chosen turkews at their tams close to the time of shughter. Approximatch 100 workers on a plant that processed the andeys from these farms and workers who handled turkeys or turkey poducs on a daily basis were also requested by lonter to provide a fectil

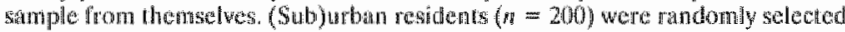
from the telephone directory of wo cinies in The Netherlands, Wuert and Roemond (approxinately 40,000 inhabitants each , wnd were asked to partici paste in the stady. Most partionants liwed in the same area, i.e., the province of Limburg in the southern part of the Netherlands, and all samples were collected within 3 months. The participants were asked to complete a questonnare about

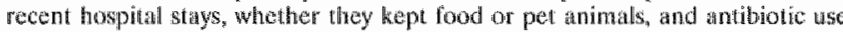
by thenselves, their family mernbers, of their anmats during the 3 months preceding the smple collection. "Turkey farners were also asked which APE was incorporated into the feed of their animals.

Isolation of (wineomycin-resistant) enterococe. The fecal samples and the questionnaire were, inmeditely after collection, sent to the bacteriological laboratory, where, on the same dhy. they were diluted $\left(10^{-1}\right)$ in $0.9 \%$ (whol) MaCl contuinim $20 \%$ (volwol) glycerol and were stored frozen at $-20 \mathrm{C}$ until

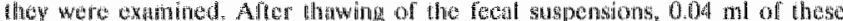

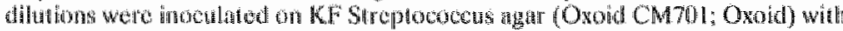

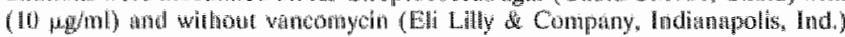

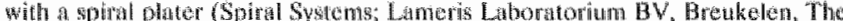

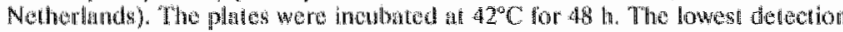

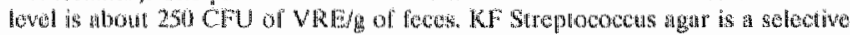

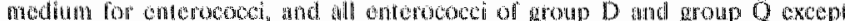

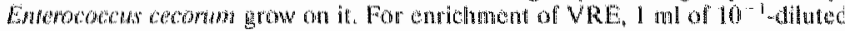

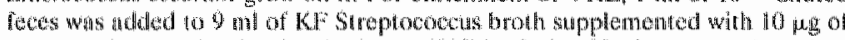

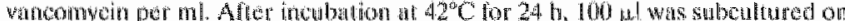

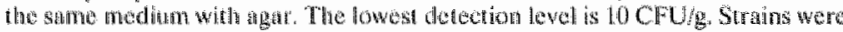

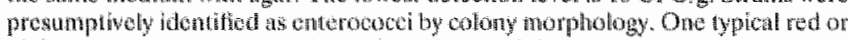
pink colony was randomly picked rom each KE streptococens at plate with

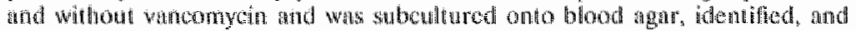

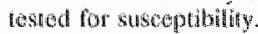

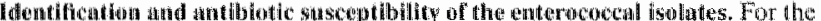

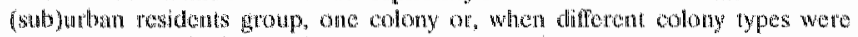
present, more colories per local sample were randomly picked from the vano-

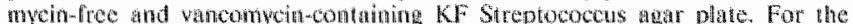
ohen groups, only one colony per foral sample was tested. The isolsted colonies ware identifed by using tolerinee to bile, esculia hydrolysis, growh in $6.5 \%$ (wevol) $\mathrm{NaCl}$, and a postive pyrolidonylanylandase renction (Welleomo) dentifiation to the spectes lewel was perforned by testing for angine dethy

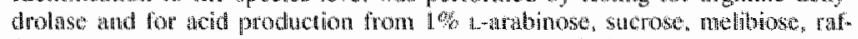

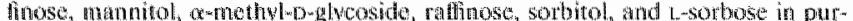
ple base broth. Reations were observed after 24 h of incubation at $37^{\circ} \mathrm{C}$. Motility was determined as described previousy (13). Tellow pigmentation wh scored on tryptono soy age (CM131; Oxom) arter wernget incubation at $37 \mathrm{C}$ and for 24 h a noom tomperature. Tellurite reduction was read on blond agar after oxeraight incuhation an $37^{\circ} \mathrm{C}$

The amtibiotio susceptibility was determined by at broth microditution me had in Iso-Sensitest Broth (CM47\%: Ondid) with an inowlum size of $5 \times 10^{5} \mathrm{CFU} / \mathrm{ml}$ The antimicrobalagents tested and the breakpont coneentrations used to define rasisfance in this stady were as follows: anoxieilin, $16 \mu \mathrm{g}$ mi: choramphenicol.

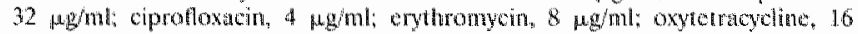

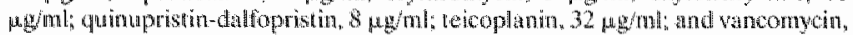

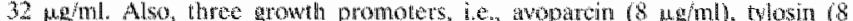

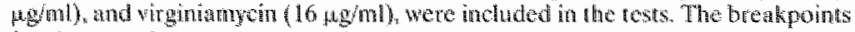
for the growll promolers tested were based on those reported in the literature

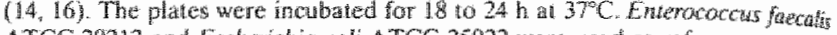
ATCC 29212 and Escherichia coll ATCC 25922 were used as reference sirain

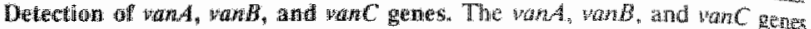
were detected by hybridiztion wh specific probes. The wat probe was

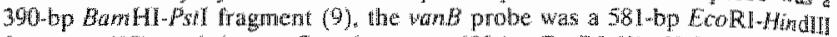

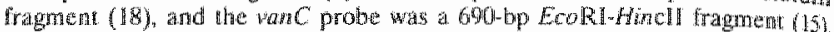
The $E$. coll sirains used for inolation of the protes were kindly prowder by Courvaliz. The DNA probes were isclated from $1 \%$ low meling point agrou gels and were labelled wh dgorgenin acoording to the manutheturers instuefons (Boethringer Mamhen Biochemica. Marnheurn, Germany). The straing were screened by makma colony blots on mylon membranes (Nytran; Schleicher * Schinell, Den Boseh, The Netherlands according to the manutactures's instructions.

Enterococci containing the different whenes were usch as posilve contols,

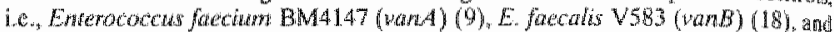
Enterocowas gollnamm BM4174 (vanC) (15). E. foecalis JH2-2 was used as a negattive control (20). Prebybridization and tybridization were performed under stringen conditions [50\% [wolwol] formamide and $5 \times 5 S \mathrm{C}[1 \times 55 \mathrm{C}$ is $0.5 \mathrm{M}$ $\mathrm{MaCl}$ phus $0.015 \mathrm{M}$ sodim citrate $42^{\circ} \mathrm{C}$, and the probes were washed in $2 \mathrm{x}$ SSC plus $0.1 \%$ (w/vol) sodium dodecyl sulfte at room temperature and $0.2 x$

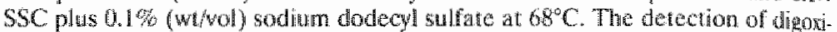
genin-libelled rucleic acids was performed by chemilaminescence on patio graphic fums (X-Omal $A R ;$ Kodalo).

PTCE analysis of VRE. The PFGE anslyses performed with enteronoed iso. lated from the agar plates with vancomycin were as described prevoushy, with minor modifcallions (35). To assess the singilarthes of the different parerns, the criteria of Temover al were used (32). If an isolate difleted from a nain type by only thee or fewer bands, it was constulered a subtype.

Moleculn characterizetion of Tu/5 46 derivatives. Characterization of the van 4 -contataing transposon was performed by means of combination of restris. lion fragnent length polymorphism analysis and DNA sectencing of Thisto. specific PCR products and classified by type as describec previously (18). PCR primer sequences and their positions relative to the Th/54to sequence used in this study are listed in Table 1. All VRE were analyzed for the presence of point multations at position $1226,4847,7658,8234$, and 9692 as described previousty (38). To defermine the DNA sequence of the left wad of the truncuted want containing tramsposon deriatives, type A2, E4, E8, and E 10 DNA fragryents were anplified with Tn1546 primer 184.R or $4511 . \mathrm{R}$ in combination with $151216 \mathrm{~V}$ primer $151216 \mathrm{~W}$. E and IS1216V.13. The exact integration site and orientation of the $1 S / 216 \mathrm{~V}$ alement downstream of ran $X$ was deternined by amplifying a DNA fagment with primers 7875 . F and $9580 \mathrm{R}$, and the sequence was determined with the primers $1 S 4216 \mathrm{~V} . \mathrm{E}$ and IS1216V.F.

\section{RESULTS}

Characterization of the (vancomycin resistant) enterococcal population. Forty-seven fecal samples were received from turkey farmers and their turkeys. The torkey farmers that responded comprised about $50 \%$ of all major turkey farmers in The Netherlands. In addition, 47 tecal samples were received from turkey slaughterers and 117 samples were received from the (sub) urban residents. Thirty farms used avoparcin, and 12 farms used virginiamycin; information on the use of APEs was not received from 5 farms.

None of the human participants or their family members were admitted to a hospital or had used antibiotics in the 3 months preceeding the start of the study. About $50 \%$ kept pet animals, mainly dogs or cats.

The mean number of enterococcil found was $6.9 \pm 1.2$ (mean \pm standard deviation) $\log _{10}$ CFU per $g$ of feces for the turkey samples and $5.6 \pm 1.6 \log _{10}$ CFU/g for the human samples. No differences were observed between VRE-positive and VRE-negative samples or between samples from animals fed avoparcin or not. The degree of resistance, i.e., the number of VRE relative to the total number of enterococci, was $3 \% \pm$ $3 \%$ for the turkey samples, $2 \% \pm 4 \%$ for the turkey farmers, and $4 \% \pm 10 \%$ for the turkey slaughterers. Again, no differences were found between samples from farms that used avoparcin and those that did not. In samples from two turkeys, one farmer, one turkey slaughterer, and two (sub)urban res:dents, more than $50 \%$ of the total number of enterococci were resistant to vancomycin.

A total of 283 colonies from vancomycin-free medium and 59 colonies from vancomycin-containing agar plates were fur- 
TABLE 1. PCR primers used in this study

\begin{tabular}{|c|c|c|}
\hline Primer group and primer & Sequence & Pasiling \\
\hline \multicolumn{3}{|l|}{ Tn.1546 primers } \\
\hline $22 F$ & 5-GGATTTACAACGCTAAGCC & $22-40$ \\
\hline $184 \mathrm{R}$ & 5-ACCATATGTCGCCCTTAG & $184-167$ \\
\hline 1890.F & 5'-TAAATAATCATAGTCGGCAGG & $1890-1910$ \\
\hline $1913 \mathrm{R}$ & $5^{\prime}=$ CGTCCTGCCGACTATO & $1913-1898$ \\
\hline $3514 . \mathrm{F}$ & 5'ACTGTAATGGCTGGTGTTAAC & $3514-3534$ \\
\hline $3560 \mathrm{R}$ & 5'-TATCCGAATAAGATCTCGCT & $3560-3542$ \\
\hline $3940 \mathrm{R}$ & 5'-ATTTATCAGATTATAGGGCCG & $3940-3920$ \\
\hline 3992.F & 5'-TTATTGTGGATGATGAACATG & $3992-4012$ \\
\hline 4511.R & 5'TCGGAGCTAACCACATTC & $4511-4494$ \\
\hline $5235 \mathrm{~F}$ & 5'-ATATCACGTTGGACAAAGC & $5235-5253$ \\
\hline $5374 . \mathrm{R}$ & 5'TTCATCGGTCATCTGCAC & $5374-5357$ \\
\hline $6964 . \mathrm{F}$ & 5.AAAGGAGACAGGAGCATG & $6964-6981$ \\
\hline 7035.R & 5'-TTACGTCATGCTCCTCTGAG & $7035-7017$ \\
\hline 7875.F & 5-CCGCATTGTACTGAACG & $7875-7891$ \\
\hline 7986.R & 5-CAAGCGGTCAATCAGTTC & $7986-7969$ \\
\hline $8544 . F$ & 5'-GCATATAGCCTCGAATGG & $8544-8561$ \\
\hline $8691 . R$ & 5.TTACATACGTCGGGTTTCC & $8691-8673$ \\
\hline 8969.R & 5'-GATTGTGCCGTTTTGC & $8969-8954$ \\
\hline 9580.R & 5-TCGTCAAGCTTGATCCTAC & $9580-9562$ \\
\hline 9970.R & 5'-GCCATCCTTACCTCCTTG & $9970-9953$ \\
\hline $10716 \mathrm{R}$ & 5'-TTTTCCCCTCACTTCACAC & $10716-10698$ \\
\hline \multicolumn{3}{|l|}{$151216 \mathrm{~V}$ primers } \\
\hline ISI216VE. & 51-AGCTTAAATCATAGATACCGTAAGG & $913-935$ \\
\hline ISI216V.F & 51-TTCATCGTATTCCTCCTCCTG & $243-225$ \\
\hline
\end{tabular}

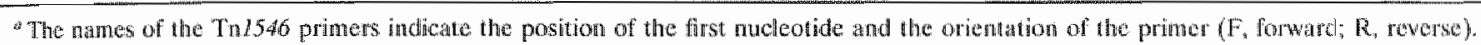

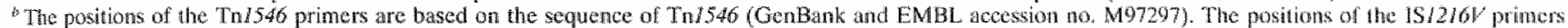
are based on the sequence of 151216 (Genbank and EMBL. accession no. L40841).

ther identified. No additional VRE were isolated after enrichment. All colonies belonged to the genus Enterococcus. Complete identification to the species level mainly yielded $E$. faecium, lollowed by $E$, faecalis.

The percentages of single isolates from the vancomycin-free and vancomycin-containing agar plates resistant to the antimicrobial agents tested are shown in Table 2. Among the isolates from the (sub)urban residents, one isolate was lost during culture; i.e., 161 enterococcal colonies were tested for this group. No resistance to amoxicillin was observed in any of the isolates tested. The percentages of resistance to avoparcin, vancomycin, and teicoplanin among the enterococci isolated from the plate without vancomycin were quite similar, ranging from 0 to $14 \%$ for the four groups of isolates tested. In contrast, the percentages of resistance to tylosin, erythromycin, and oxytetracycline were significant lower for the isolates from turkey slaughterers and (sub)urban residents than those from turkeys and turkey farmers.

Almost all enterococci isolated from turkeys and the three groups of humans with a selective concentration of $10 \mu \mathrm{g}$ of

TABLE 2. Antibiotic resistance patterns of enterococd isolated from fecal samples from turkeys, turkey farmers, turkey slaughterers, and (sub)urban residents

\begin{tabular}{|c|c|c|c|c|c|c|c|c|}
\hline \multirow{3}{*}{$\begin{array}{l}\text { Antbiotic } \\
\text { (breakpon tor nesiatance }[\mu \mathrm{g} / \mathrm{m} \|)\end{array}$} & \multicolumn{8}{|c|}{ 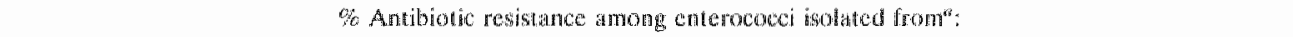 } \\
\hline & \multicolumn{4}{|c|}{ Vancomycin-frex pltates $(n=282$ ) } & \multicolumn{4}{|c|}{ Vancomyein-contaning pales $(n=50)$} \\
\hline & $T(46)$ & $T \prod(41)$ & $\operatorname{TS}(34)$ & UR (16!) & $\mathrm{T}(23)$ & Tf $(a)$ & $\mathrm{TS}(6)$ & $\cup R(14)$ \\
\hline Avoparcin (8) & 4 & 7 & 0 & 14 & 87 & 88 & 100 & 100 \\
\hline Varucomycin $(32)$ & 4. & 7 & 0 & 2 & 91 & 81 & 100 & 86 \\
\hline Teicoplanin (32) & 2 & 5 & 0 & 0 & 48 & 13 & 0 & 21 \\
\hline Tylosin $(8)$ & 41 & 42 & 24 & 23 & 70 & 75 & 67 & 93 \\
\hline Enythromycin $(8)$ & 37 & 42 & 21 & 28 & 70 & 75 & 67 & 93 \\
\hline Virginiamycit (16) & 13 & 0 & 3 & 2 & 13 & 13 & 0 & 20 \\
\hline Qunupristin-dalfopristin ${ }^{b}(8)$ & 13 & 5 & 3 & NT & $17^{d}$ & $13:$ & 0 & $N^{T}$ \\
\hline Amoxicillin (16) & 0 & 0 & 0 & 0 & 0 & 0 & 0 & 0 \\
\hline Chloramphenicol $(32)$ & 9 & 5 & 0 & 4 & 9 & 6 & 0 & 7 \\
\hline Oxytetracycline $(16)$ & 96 & 71 & 21 & 31 & 87 & 88 & 100 & 93 \\
\hline Ciprofloxacin $(4)$ & 28 & 2 & 12 & 6 & 35 & 13 & 0 & 0 \\
\hline
\end{tabular}

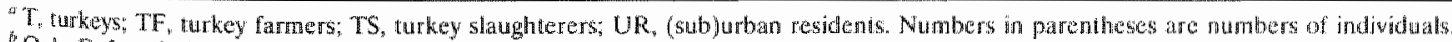

Only E faccolic isolates are not included.

NT, Not tested.

E. fuecum $(n=2)$ and E. durans $(n=2)$.

"E. harre $(n=2)$. 


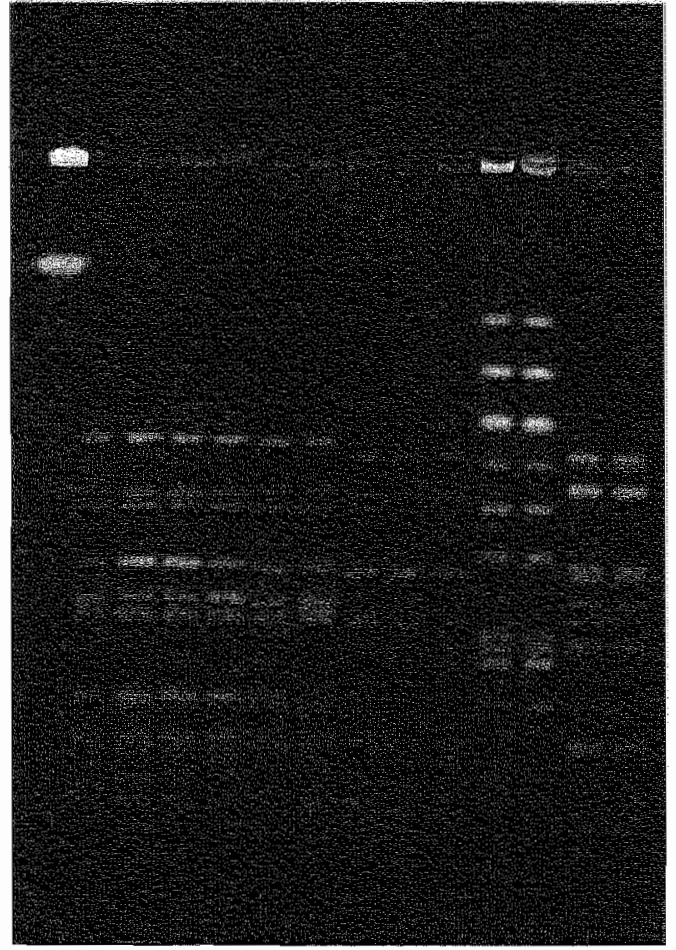

1. 2. 3. 4. $5.16 .77 .16 .79 .10 .111412 ! 13.114 \%$

FIO. 1. PFGE patterng of E. factum stans isolated from turkeys (T), turkey frmers (TF), and turkey slanghterers (TS) aftem digeston of total DNA with

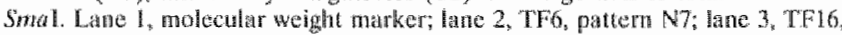

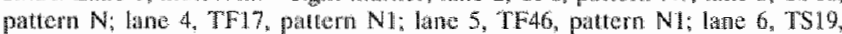
pattern N2, lane 7, TS31, pattern N3; lane 8, TF20, pattern Di lane 9, TF26,

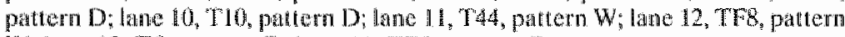
W; lane 13, T5, pattern B; lane 14, TFS, pattern $D$.

vancomycin per mo were resistant to avoparcin and vancomycin $(\mathrm{MlCs},>32 \mu \mathrm{g} / \mathrm{ml})$. The percentage of resistance to teicoplanin was significantly lower, i.e., from $0 \%$ for the isolates from the turkey slaughterers to $48 \%$ fior the turkey isolates. Two and three enterococci isolated from turkeys and turkey farmers, respectively, lost their vancomycin resistance after storage at $-70^{\circ} \mathrm{C}$ and were susceptible to vancomycin. By using colony blots, the vand gene could not be demonstrated in these isolates. The presence of the vava gene in the vanconycin-resistant isolates from turkeys $(n=21)$, turkey farmers $(n=13)$, turkey slaughterers $(n=10)$, and (sub) urban residents was confirmed $(n=14)$ by using colony blots. A high percentage of resistance to tylosin and erythromycin among these enterococci from turkeys and humans was observed, ranging from $67 \%$ among isolates from turkey slaughterers to $93 \%$ among isolates from (sub)urban residents. The same holds true for the resistance to oxytetracycline: from $87 \%$ among isolates from turkeys to $100 \%$ among isolates from turkey slaughterers. Resistance to ciprofloxacin was observed among isolates from turkeys $(35 \%)$ and turkey farmers $(13 \%)$ but was absent from isolates from turkey slawghterers and (sub)urban residents.

PFGE of VRE. The PFGE patterns of the VRE from the different populations were quite heterogeneous. Representative PFGE patterns fron VRE from turtheys, turkey farmers, and slaughterers are shown in Fig. 1. Among the 13 VRE isolated from turkeys, 12 different PFGE types could be discriminated. The nine VRE from turkey farmers contanned six different PFGE types, while among the VRE isolated from turkey slaughterers $(n=4)$ and (sub)urban residents $(n=14)$, three and five different $P F G E$ types, respectively, were found $P F G E$ type $B$ and type $D$ were found among isolates from both turkeys and turkey farmers (Table 3 ).

Tn1546 types among different VRE isolates. Analysis of the Tin 1546-like elements from the different VRE isolates showed that the 14 isolates from the (sub)urban residents almost ex. clusively contained the previously described Tn1546 of types $A 1$ and A2 (38). Only one isolate contained a type $\mathbb{E}$ transposon, E4 a subtype transposon, which is characterized by a $5^{\prime}$ end deletion that encompasses the entire transposase gene and the $5^{\prime}$ end of the resolvase gene (36). Furthermore, this type contains an $1 \$ 12.16 \mathrm{~V}$ insertion in the vanX-van $Y$ intergenic region. The four isolates from turkey slaughterers contained transposons of types $A 1$ and $A 2$. In contrast, the majority of the turkey isolates ( 10 of 13) contained a Tn1546 type E transposon (Table 3). Four different E subtypes, subtypes E8, E9, E10, and E11, were distinguished in these isolates; these sub. types differed in the sizes of the 5 ' end deletion and in the sizes of small deletions surrounding the IS121.6V insertion site (Fix. 2). In addition, Tn1546 subtypes E9, E10, and E11 contained a right-end deletion that included deletion of the van $Z$ gene, which has been shown to be involved in teicoplanin resistance (2).

For two isolates, T5 and TF5, the insertion of IST216V in the van $X$-van $Y$ intergenic region and the deletion of the van $Z$ gene have been described previously (33). The remaining three turkey isolates were type A1. The finding of isolates containing a Van $A$ transposon from which the van $Z$ gene was missing may explain the unexpected observation of VanA-positive isolates which were sensitive to teicoplanin (Table 3). Almost half (four of nine) of the turkey farmer isolates also contained a type $\mathbb{E}$, subtypes E9 and E11, transposon. The other five isolates contained a type $A$ transposon, four isolates contained a type A2 transposon, and one contained a type $A 1$ transposon. In three cases an identica! VanA transposon was found in a turkey and turkey farmer isolate from the same farm. In the samples that contained isolates. T5 and TF5, as published previously (33), and in more that contained isolates T20 and TF20, isolates with transposon type E9 were found in both the turkey and turkey farmers, and in the samples that contained isolates T32 and TF32, isolates of type A1 were found in both the turkey and the turkey farmer. Two different transposons were present only in the combination T36 and TF36.

\section{DISCUSSION}

In a previously published study on the dissemination of VRE from farm animals to humans, we showed high prevalences of VRE in turkey, turkey farmers, turkey slaughterers, and area residents $(50,39,20$, and $14 \%$, respectively). Furthermore, in samples from one farmer and his turkey flock, an indistinguishable VRE strain and varA-containing transposon were identified. This denonstrates that, at least in one case, an animal and human carried the same VRE clone (33). In order to extend this study on the controversial issue of spillover of VRE or vancomycin resistance genes between animals and humans, we have determined the relative number of VRE in feces isolated from turkeys, turkey farmers, turkey slaughterers, and (sub)urban residents. Furthermore, we have compared the PFGE types of a number of VRE isolated from turkeys and the three groups of human volunteers and finally characterized in detail the vanA-containing transposon of VRE isolated from the different sources.

Surprisingly, no significant difference in the number of VRE relative to the total number of enterococci was observed be- 
TABLE 3. Characteristios of VRE from different sources

\begin{tabular}{|c|c|c|c|c|c|c|}
\hline \multirow{2}{*}{ Soturce } & \multirow{2}{*}{ Species } & \multirow{2}{*}{ Strain no. } & \multicolumn{2}{|c|}{ MIC $(\mu \mathrm{g} / \mathrm{mi})$} & \multirow{2}{*}{ PFOE YPPe } & \multirow{2}{*}{ This 540 ype } \\
\hline & & & Vanconycin & Teicophunin & & \\
\hline \multirow{13}{*}{ Turkey } & E. faecinm & $\mathrm{T} 3$ & 64 & 4 & $A$ & Al. \\
\hline & E. faecium & TS & 32 & 1 & $\mathrm{~B}$ & 199 \\
\hline & E. faeciumt & $\mathrm{T} 8$ & 128 & 64 & $C$ & Al \\
\hline & E. faecism & $T 10$ & 32 & 4 & $\mathrm{D}$ & $\mathrm{Bg}$ \\
\hline & E. faecium & $\mathrm{Tl} 4$ & 32 & 0.5 & $\mathrm{E}$ & EN1 \\
\hline & E faecium & $\mathrm{T} 20$ & 64 & 0.5 & DI & $\mathrm{E9}$ \\
\hline & E. faechum & $\mathrm{T} 24$ & 32 & 0.5 & $\mathrm{~F}$ & E11 \\
\hline & E. hroe & $\mathrm{T} 28$ & 128 & 4 & $\mathrm{O}$ & Eil \\
\hline & E. faechun & T32 & 128 & 32 & $\mathrm{H}$ & Al \\
\hline & Ex hirae & $T 36$ & 64 & 4 & 1 & Elo \\
\hline & E. foecimon & $\mathrm{T} 38$ & 128 & 32 & $J$ & 88 \\
\hline & E. faecimm & $\mathrm{T} 39$ & 32 & 0.5 & $\mathbf{K}$ & $\mathrm{E} \| 1$ \\
\hline & E faecinm & $T 47$ & 32 & 0.5 & $L$ & EII \\
\hline \multirow[t]{9}{*}{ Turkey farmer } & E. hirae & TF2 & 32 & 4 & $M$ & El \\
\hline & E. foecinm & TFS & 1.6 & 0.5 & $\mathrm{~B}$ & E9 \\
\hline & E. faccium & TF 16 & 1.28 & 8 & $\mathbb{N}$ & $\mathrm{A2}$ \\
\hline & Es faechum & TFF 17 & 128 & 8 & Nu & $\mathrm{A2}$ \\
\hline & E. faecrum & TF20 & 64 & 1 & $\mathrm{D}$ & E9 \\
\hline & E. faecrum & TF26 & 64 & 2 & $\mathrm{D}$ & $\mathrm{Eg}$ \\
\hline & E. faecinum & TF 32 & 64 & 4 & $\mathrm{O}$ & Al \\
\hline & E. hirae & $\operatorname{Tr} 36$ & 128 & 0.5 & $\mathrm{p}$ & $A_{2}$ \\
\hline & E. faecunt & $\operatorname{Tr} 46$ & 64 & 8 & $\mathrm{NH}$ & $A_{2}$ \\
\hline \multirow[t]{4}{*}{ Turkey slaughterer } & E. faecium & TS19 & 128 & 8 & $N_{2}$ & Al \\
\hline & E. faecium & $\operatorname{TS} 31$ & 128 & 8 & N3 & $\mathrm{A2}$ \\
\hline & E. faecium & $\operatorname{TS} 32$ & 128 & 8 & $Q$ & $A 2$ \\
\hline & E. hirae & TS36 & 64 & 0.5 & $\mathbb{R}$ & $A I$ \\
\hline \multirow[t]{14}{*}{ (Sub)urban residents } & E. faecium & W31 & 32 & 32 & $\mathrm{~S}$ & E4 \\
\hline & E. frecium & HIO & 16 & 2 & $N$ & $A 2$ \\
\hline & E. faecium & $\mathrm{H} 1 \mathrm{~s}$ & 32 & 16 & $N$ & A2 \\
\hline & E. faecium & 117 & 128 & 16 & $\mathbb{N}$ & $A_{2}$ \\
\hline & E. faectum & $\mathrm{Ml}$ & 1128 & 32 & N4 & Al \\
\hline & E. faecoum & M13 & 128 & 16 & $N$ & $A 2$ \\
\hline & E. faecium & $M 27$ & 128 & 32 & $\mathrm{~T}$ & $A 2$ \\
\hline & E. faectum & $\mathrm{R} 2$ & 128 & 4 & $\mathbb{N}$ & $\mathrm{A2}$ \\
\hline & E. faecium & RI3 & 32 & 4 & $\mathbb{N}$ & $\mathrm{A}^{2}$ \\
\hline & E frecinum & R19 & 64 & 4 & $\mathrm{U}$ & $A 1$ \\
\hline & E faecturs & $\mathrm{R} 20$ & 64 & 8 & $V$ & $A 2$ \\
\hline & E. faeciwn & $\mathrm{R} 24$ & 64 & 8 & $N$ & $\mathrm{~A} 2$ \\
\hline & E. faeciun & $\mathrm{R} 25$ & 128 & 16 & $\mathrm{NS}$ & A2 \\
\hline & E. himae & $R 27$ & 16 & 0.5 & $\mathrm{~N} 6$ & Al \\
\hline
\end{tabular}

ween the farmers and the turkeys on farms where avoparcin was and was not used. This might be explained by the fact that farmers have been exposed to VRE in the recent past by former flocks fed avoparcin as an APE. If this were true, it would suggest that even in the apparent absence of exposure to VRE or glycopeptides, farmers can carry VRE for long periods of time.

The distribution of the different species in the present study differed from those described by Welton et al. (37). They studied different age groups of three flocks of turkeys from two different farms and found that the most prevalent species in the oldest age group was $E$. faecalis $(51 \%)$, followed by $E$. faecium $(22 \%)$. In our study, in which the samples were obtained from turkeys close to the time of slaughter, the reverse was found; i.e., $E$. faecium was the most prevalent $(74 \%)$, followed by E. faecalis (22\%). E. gallinarum, which was isolated from 8 of 41 samples from the oldest group 5 in the study of Welton et al. (37), was found only twice in our study and was found in (sub)urban residents. Enterococcus casselifavus which was not isolated from turkeys in age group 5 , was found in the samples from turkey farmers $(n=1)$, turkey slanghtorers $(n=$ 1), and (sub)urban residents $(n=8)$. In both studies, $E$ faccium and $E$ faecalis were the most prevalent species.

In general, the PFCE patterns of VRE isolated from animal and human sources were different. PFGE pattern type $\mathbb{N}$ was the most prevalent type among human isolates, whereas the PFGE patterns of the isolates from turkeys were heterogeneous. These results are in contrast to those described by van den Brak et al. (35), who found dominant PFGE types among poultry strains derived from throughout The Netherlands. Our results suggest that, in general, different enterococcal strains. are found in turkeys and turkey farmers and that the clonal dissemination of turkey strains and colonization of human is. less common. In addition to the previously described similar ities between one isolate from a turkey farmer and isollates. from his turkeys (33), similar PFGE types (types D and D1) were also found in isolates T20, TF20, T10, and TF26. In addition to these similar PFGE types found in turkeys and turkey farmers, similar wan $A$-containing transposons were also found in turkeys and turkey farmers. In fve of the nine turkey 


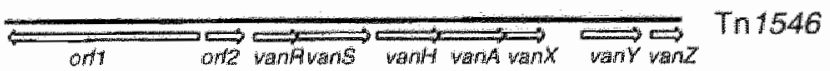

ond

ant2 wankwans want wanth wark want wanz

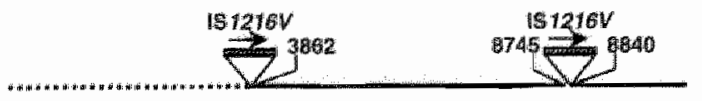

E8

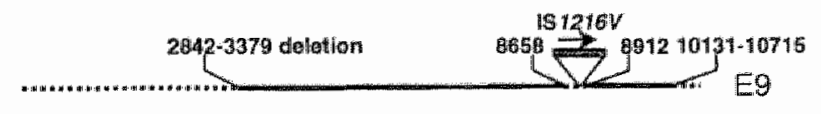

E9

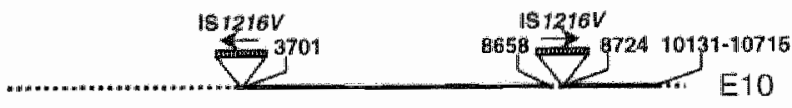

E10

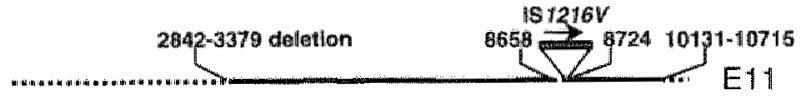

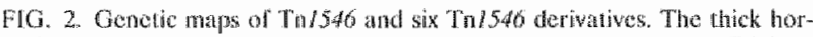
izontal bines represent Tn 546 (type A 1) (3) and Th1546 ivpes A2 (36), E4 (36), and E8 to to 12 . The positions of genes and open reading fratmes (orfs) and the dinctions of transcription are depicted by open arrows. Dotted boxes represent insertion sequence (1S) alements. The postions of the first mucleotide upstream and downstram from the insertion sectuence ingertion sites are depicted. Filled arrows indicate the tariscriptionat orientation of inserted insertion sequence elements. Deld hons have been indicated by dotted lines. The position of the base

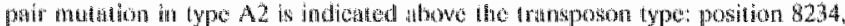
$(\mathrm{C} \rightarrow T(\mathbb{K} \rightarrow \mathbb{N})$.

farmer isolates, transposon-like elements identical to those in turkey isolates, i.e., types A1, E9, and E11, were found. Furthermore, in three cases (isolates T32 and TF32, T20 and TF20, and T5 and TF5) in which a VRE was isolated from a turkey farmer and a turkey of the sume farm, an identical vand-containing transposon was found (Table 3). The present data for strains T32, TF32, T20, and TF20 confirm previously published results (33). The most likely route of spread of vancomycin tesistance from turkeys to turkey farmers is by horizontal dissemination of derivatives of the vancomycin resistance transposon Tn/546. The finding of type $\mathrm{A} 2$ as the predominant transposon type in (sub)urban residents analyzed in this study is in agreement with previously published results, in which this type seemed to be common among human VRE from The Netherlands (36), and suggests that the frequency of transmission of vancomycin resistance from turkeys to the general population in The Netherlands is low but that transmission may occur. Howewer, we must tealize that only one isolate was tested from each fecal sample, and therefore, the method used is likely to have a very low sensitivity. Testing of more isolates was not possible because of the workload involved. Also, studies from others point to a similarity between van A-containing elements from animals and humans and suggest the spread of vancomycin resistance between the human and animal bacterial flora $(1,24,31,38,40)$, with the most likely way being food-borne transmission. However, more information on the prevalence of different PFGE types among VRE in meat prod- ucts in Weert and Roemond and the share of turkey meat consumption in relation to total meat consumption is needed before any conclusion can be drawn.

In the present study not only was resistance to vancomycin in the different populations observed, but resistance to quinupristin-dalfopristin, a combination of streptogramins $B$ and $A$ which is not approved for human use in The Netherlands, also found. Resistance to this combination was not only found in $E$ faecalis, which is considered intrinsically resistant, but was also found in E. faecium, Enterococcus durans, and Enterocac. cus hirae (Table 2). These data are consistent with previously published results by Welton et al. (37), in which resistance io this combination among $E$. faecium isolates was described, with the prevalence of resistance, depending on the age of the turkeys, being up to $100 \%$. The interesting finding of both studic is the isolation of $E$. faecium strains resistant to quinu pristin-dalfopristin before the compound has been used therapeutically in humans. The use of virginiamycin as an APE consisting of virginiamycin $\mathrm{M}$ (a streptogramin A type antibiotic) and virginiamycin $S$ (a streptogramin B type antibiotic). might be responsible for the resistance observed among isolates from animals, and the dissemination of enterococcal strains or tesistance determinants from animals to humans may account for the observed resistance to quinupristin-dalfopristin in humans (37).

There is still much debate on the hazard of the use of APE in food animals and on the possible dissemination of resistant strains or genes from animals to humans or vice versa. In a recent review, Corpet (11) discussed some examples suggesting that the use of APEs such as carbadox, nourseothricin, and streptothricin is hazardous for humans. However, reports with circumstantial evidence were also discussed in the same review, suggesting that the APEs allowed in Europe are not a threat to human health. On the basis of the prevalence of identical vancomycin resistance transposon types in human and animal isolates described in this and other $(35,24,38,40)$ studies, one might conclude that an animal source is likely to serve as a reservoir for the VanA type of resistance in humans in Europe and that the horizontal transmission of the resistance genes is probably more important than clonal spread in the dissemination of vancomycin resistance.

In conclusion, as was discussed $\$ 5$ years ago, the relative contribution of both APE use and human use of antimicrobial agents to antibiotic resistance in humans is still not known (19). Monitoring of antibiotic resistance, antibiotic resistance transfer, and antibiotic use (including APE use) and studies on the dissemination of antibiotic resistance genes in both animals and humans is essential to obtaining consistent and reliable data on the epidemiology of resistance of isolates from animals and humans.

\section{REFERENCES}

1. Aarestrup, F. M., P. Ahrens, M. Madlsen, L. V. Palleser, R. L. Poulsen, and 11. Westh. 1996. Glycopeptide susceptibility among Danish Entercocost. foecinm and Entrococcus foredis isolates of animal and homan orign. Antinicrob. Agents Chemother. 40:1938-1940

2. Arthur, M. F. Depardieu, C. Mohinas, P. Revnolds, and R. Courvatin. 1945 The wan $Z$ gene of Th 1546 from Eaterococts frecism BM4147 conters ac sistance to teicoplamin. Gene 154:87-92.

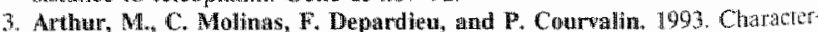
ization of Ta1546, a Tn 3 -related transposon conterring glycopeptide rexistance by symesis of depsipeptide peptidogycan precursors in enarocowe 1 . Butchol 175:117-127.

4. Arthur, M., and P. Comralin. 1993. Genetics and mechanisms of glycowe tide resistance in enterococel. Antinicrob. Agents chemother. 37:1561571 .

5. Bager, $F_{*}$ M. Madsen, J. Christensen, and F. M. Aarestrup. 997 . Avoparcin usul as a growth promoter is associated with the occurrence of vancomon. resstant Enterococcus faecith on Danish pouldy and pig farms. Prew Vol Mad. 31:95-112. 


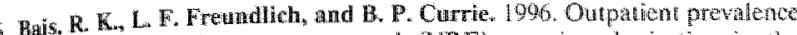
of wacomycin resistan enteracoctal (VRE) snteric colonization in the of vanconych of a hospital hyperendemic for VRE. Infect Control Hosp.

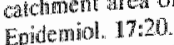

Bens, J 1997. Epidentology of yancomycin-resistant enterococe in the

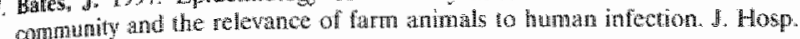
commingty and ine

Mastes, J.J. J. Jordens, and D. T. Grifliths. 1994. Fam animads a a putatixo

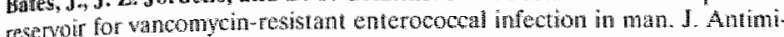
refo Chemoner. $34507-514$

- Brisson Noel, A. S, Detka Malen, C. Molinas, R. Leclereq, and P. Courvalin. 1900: Cloning and heterospecific expression of the ressistance deterninan ward ancoding high level resistance to glycopeptides in Enterococcus foregaw BM4147. Animicrob. Agents Chemother. 34:924-927

10 Cotue, T. M. J. I. Tornayko, S. Ricke, P. C. Okhywsen and B. E. Murray. 199\% Vanconycin-resistant sterococi from nosocomial, community, and animal sources in the United States. Ant microb. Agents Chemother. 40 $2605-2609$.

11. Corpet, D. E. 1996. Microbiological hazards for humans of antimicrobat wowth pronoter tse int inmal production. Rew. Med. Vet. 147:85 l - 862

Danish Veterinary Laboratory. 1995. The effect of apoparcin used as a feed additiwe on the occurrence of vanconycin resistant Enteracocous focrum in pag and poultry production, p. 1-105. Danish Veterinaty Labonatory, Copen Hagen, Demmark.

13. Dewriese, L. A, A. Van De Kercklove, R. Klipper-Balz, and K. H. Schleifer. 1987. Characterization and identification of Enerococcus species isolated from the intestines of animals. Int. 1 . Syst. Bactariol. 37:257-259.

14. Dewriese, L. A., G. Daube, J. Hommez, and F. Haesebrouck, 1993. In vitro susceptibinty of Clostritum perfringens isolated from farm animals to mowithenhancing antibiotics. J. Appl. Bactenol. 75:55-57.

15. Dutba-Malen, S., C. Molinas, M. Arthur, and P. Courvalin. 1992. Sequence of the whC gene of Enerococows gallinarum BMA174 encoding a D-allanine pralanine ligase-related protein necessary for wancomycin resistance. Giene $112+53-58$.

16. Dutha, G. N., and L. A. Devriese. 1984. Observations on the in witro sensitivity and resistance of gran positive intestinal bacteria of farm animats to growt pronoting antimicrobial agents. A. Appl. Bacteriol. 56:117-123.

17. Eudt2, H. P., N. พan den Braak, A. wan Belkum, A. J. W. Kluytmans, J. G. M. Konelenan, A. Spanjaard, A. Voss, A. J. I. Weersink, C. M. J. E. Vandenbroucke-Granls, A. G. M. Buiting, A. wan Duim, and H. A. Verbrugh. 1997 Focal carriage of vamcomycin-resistate enterococci in hospitalized patients and those living in the community in The Nerberlands. J. Clin. Microbiol $35: 3026-3031$

18. Evers, $S_{4}$ P. E. Reymolds, and P. Couryalin. 1994. Sequence of the vary are

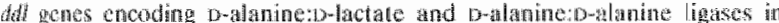

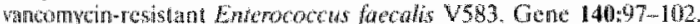

19. Frapparo, P. J. 1986. Risks to thaman healin from the use of antibiotics in

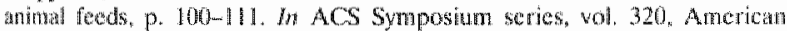
Chemical Socien, Washington, D.C. Agrictilual uses of antibiotics.

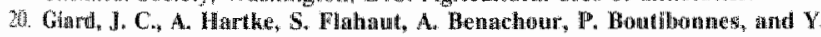
Autryy. 1996 . Stanat on JH2-2 Curr Micnoblol. 32:264-271.

1. Handwerger, S, J. Stwoble, Lin F. Discotto, and M. J. Pucct. 1995. Heterogeweily of the rand gone clastio in clinical isolates of Entersococi from the Norituetatom Unilod States. Antimicrob. Agents Chomother. 39:362 368

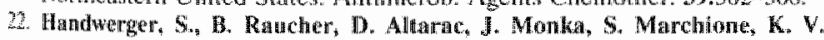

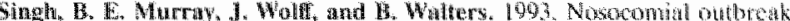

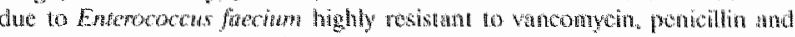
gentumicin. Clat. Iufed. Dis 16:750-75s.

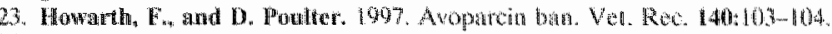

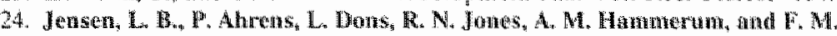

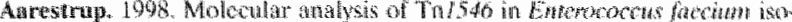

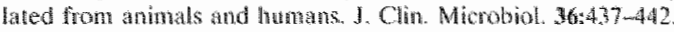

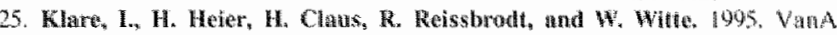

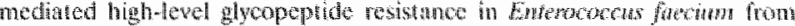
aninal husbandiy. FEMS Michobiol. 1.ett. 125:165-172.

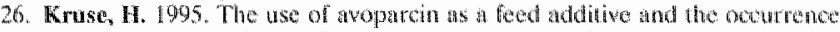

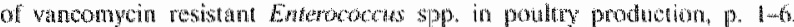
Report. 95. Womegan College of Veterinary Medicine and the Soute Vor erinary Laboratories, Oslo, Norway.

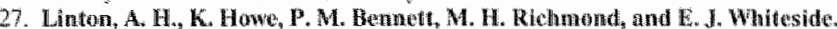

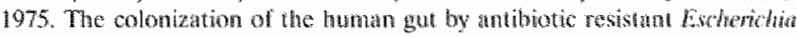
coll from chichens. I. Appl. Bacteriol 35:255-275.

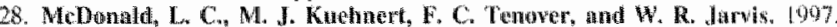

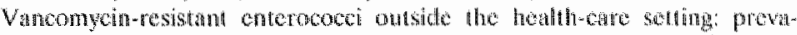

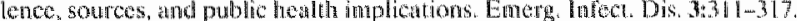

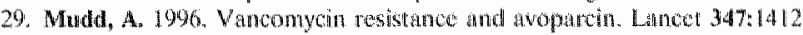

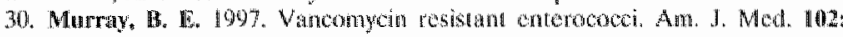
$284-293$

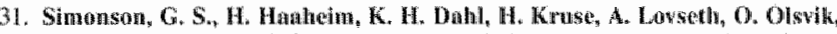
and A. Sundsfjord. 1998. Tramsunission of WanA-iype vancomycin-pesistan

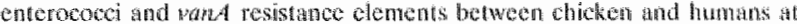
awoparcin-exposed furns. Mictob. Drug Pesist. 4:313-318.

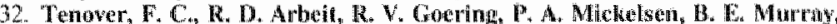

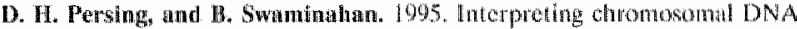

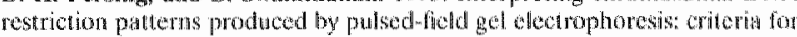

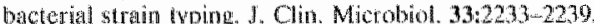

33. van den Bogaard, A. E., L. Jensen, and E. E. Stobluemgh. 1997. Varleo mycutresistant enterococoi in turkeys and famers. N. Eogl. J. Med. 337: $1558-1559$.

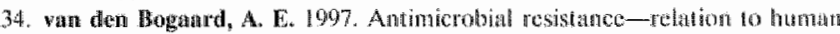
ard animal expostre to ancibiotics, J. Antimicrob Chemother 40,453-454

35. van den Bratk, N., A. wan Melkum, M. van Keulen, J. Vliegenturn, $H_{\text {, }}$ Verbrugh, and II. P. Endix. 1998. Molectalar shatreterization of vancumycin-

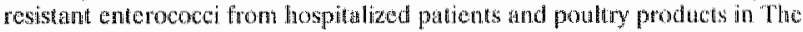
Netherlands. J. Clin. Microbiol. 36:1927-1932.

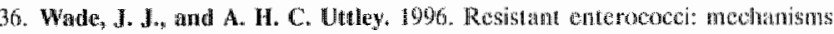
laboratory detection and oontrol in hospilats. I. Clin. Pythol. 49:700-70).

37. Wellon. L. A. L. A. Thal, M. B. Purri, S. Dondedian, J. McHahon, J. W.

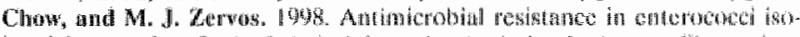

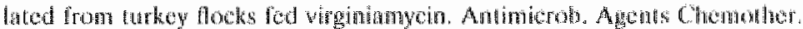
42: $705 \% 708$

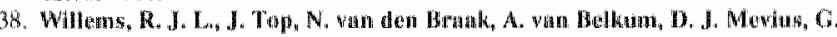

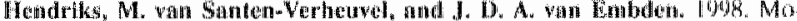

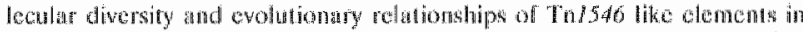

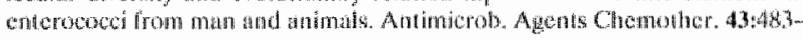
4 넹.

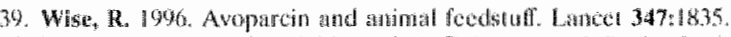

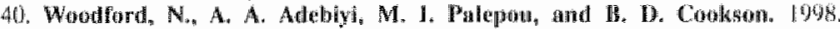

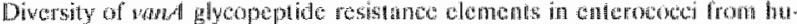

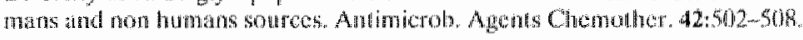



Chapter V

\title{
Fecal carriage of antibiotic resistant enterococci by poultry, poultry farmers and poultry slaughterers in the Netherlands
}

\author{
A.E. van den Bogaard*, R. Willems**, N. London*, J. Top ${ }^{* *}$ and E.E. Stobberingh* \\ "University Maastricht, Medical Microbiology, P.O. Box 616, NL-6200 MD Maastricht, the Netherlands \\ *** Research Laboratory for Infectious Diseases, National Institute of Public Health and the Environment, \\ 3720 BA Bilthoven
}


The numbers of enterococci resistant to antibiotics commonly used in poultry for therapy or as antimicrobial growth promoter (AMGP), relative to the total number of enterococci were determined in fecal samples from two poultry populations. One population were broilers in which use of therapeuric antimicrobials and AMGP use is common and the other was a population of laying hens with a low antibiotic usage. In addition fecal samples were examined from three human populations: broiler farmers, laying hen farmers and poultry slaughterers. From each fecal specimen the MIC for an extended panel of antibiotics of a single randomly selected enterococcal isolate was also determined. For all antibiotics tested the percentage of samples containing resistant enterococci was higher in broilers than in laying hens. The percentage of resistant enterococci, relative to the torall enterococcal populations (i.e. the degree of resistance) was significantly higher in broilers than in laying hens for terracycline, erychromycin, vancomycin and quinupristindalfopristin. For almost all antibiotics tested resistance in fecal enterococci of broiller farmers was more common than in laying hen farmers and poultry slaughterers. The overall resistance of enterococci from broilers correlated with the resistance of enterococci from broiler farmers and from poultry slaughterers. The pulsed field gel electrophoreses (PFGE) patterns of vancomycin resistant enterococci (VRE), isolated from the five populations, were quite heterogeneous, but Enterococous hirae isolates with the same or a closely related PFGE pattern were isolated at two farms from both the broiler farmer and from broilers. Molecular characterisation of vanA-containing transposons of these isolates showed that similar transposon types, predominantly found in poultry, were present. Moreover, similar wanA-elements were not only found in isolates with the same PFGE partern but also in other VRE isolated from both humans and chickens. The resules of this study strongly indicated transmission of antibiotic resistance in enterococci from poultry to man. For VRE this might reflect transfer of resistant clones of animal origin, but inter-strain transfer of resistance elements on transposons seems to be more common.
Acquired resistance against commonly used antibiotics has been observed since these agents were introduced in human and veterinary medicine. However, the rate of development of resistance appears to have accelerated in the past decade 78 and today multiple antibiotic resistant bacteria constitute a global problem $55,57,74,82$. In modern poultry industry antibiotics are used in large quantities not only for therapy and prevention of bacterial diseases, but also as antimicrobial growth promoters (AMGP) in animal feeds. In 1990 in the Netherlands $80,000 \mathrm{~kg}$ of antibiotics (active substance) were used in humans and $300.000 \mathrm{~kg}$ on veterinary prescriprion in animals ${ }^{92}$. In both humans and animals this is equivalent to approximately $100 \mathrm{mg}$ of active substance $/ \mathrm{kg}$ body weight/year. However about $26 \%$ of the antibiotics used in the vererinary sector were intended for poultry, mainly broilers, resulting in a yearly exposure of around $430 \mathrm{mg}$ of antibiotics $/ \mathrm{kg} /$ year for poultry. This was considerably higher than the antibiotic usage in other food animal populations. In addition to these therapeutic antibiotics, food animals received an approximately equivalent amount of antibiotics in their feed as antimicrobial growth promoters (AMGP). Similar figures have been published for $1997^{95}$ indicating that these amounts have not changed significantly in subsequent years. This high level of antibiotic use in poultry may compromise veterinary therapy but is also a public health concern. Anribiotic use selects for resistance, not only in pathogenic bacteria, but also in the endogenous flota of exposed animals. Enterococci are a component of the endogenous flora of man and other animals and are intrinsically resistant to a number of antibiotics including cephalosporins, penicillinase resistant penicillins, and clinically achievable levels of lincosamides and aminoglycosides. In addition to this intrinsic resistance, enterococci have acquired resistance to many other antimicrobial agents and have a propensity to acquire multiple antibiotic resistance traits by various mechanisms of conjugation: broad host-range plasmids ${ }^{53}$, conjugarive transposons and for $E$. faecalis pheromone responsive plasmids. As intestinal bacteria of food animals inevitably contaminate food products derived from these animals, animal enterococci can 
reach humans via the food chain and colonize the intestinal tract or transfer resistance genes to enterocooci of the human endogenous flora.

Enterococci are not important pathogens for animals. In humans, however, enterococci have been recognized as a cause of infecrive endocarditis and urinary tract infections for nearly a century 54 . In the past decade, enterococci have emerged as major nosocomial pathogens. Around $12 \%$ of all nosocomial infections in the United States are caused by enterococci 20,21 . The emergence of enterococci as a nosocomial pathogen may be attributed to their intrinsic resistance to many antibiotics commonly used in hospital practice in the last decade, in particular the third and fourth generation cephalosporins, and by the increasing numbers of immunocompromised patients. In the USA the observed increase in nosocomial enterococcal infections has been accompanied by the occurrence of $\beta$-lactamase producing 25 multiresistant strains that are also resistant to vancomycin and have high level resistance to aminoglycosides $45,52,53,75,88$. In the United States the vancomycin resistant enterococci (VRE) have increased from $0.3 \%$ of hospital isolates in 1989 to more than $20 \%$ in $1997^{34,50}$, however the occurrence of VRE is mainly limited to hospitals and the $\operatorname{van} A$ and $\operatorname{van} B$ type of resistance are both commonly encountered in this setting 23 .

In Europe VRE are much less frequently isolated from patients with hospital acquired infections $(1-4 \%)^{12,22,24,63,73}$. However vanA mediated resistance is common in enterococci isolated from the fecall flora of healthy people in the community, from companion and food animals $17,27,41,94,100$ and from raw meat and meat products $10,43,61,97$. Frequent isolation of VRE from these sources is thought to be related to the use of the glycopeptide antibiotic: avoparcin, as an antimicrobial growth promoter (AMGP) in food animals. Avoparcin, has never been licensed for use in the United States and VRE have not been isolated from healthy humans outside hospitals nor from poultry or other food animals in the USA $15,51,76,83,98$. Within the European Union the use of avoparcin was suspended in April 1997.

In addition to the observed differences in VRE prevalence between Europe and the USA, there are also differences in the resistance profile of VRE isolates from these regions. VRE isolates of European origin from outside of the hospital setting are highly polyclonal and glycopepride resistance of the wan $A$ type typically occurs as an isolated acquired resistance mechanism. Infection with such VRE can be effectively treated with the combination of amoxycillin and gentamicin. VRE isolates from European hospitals share the same characteristics of polyclonality and tsolated glycopeptide resistance observed in VRE isolated from the fecal flora of healthy animals and humans, raw meat and sewage. By contrast VRE isolares from US hospitals generally exhibit multiple acquired resistance mechanisms and show a limited genetic variability. To date, $\tan B$ resistance has not been found in non-human enterococci. Therefore it seems likely that avoparcin use selects only for wanA resistance 96 . This suggests that VanA resistance in VRE in Europe is not so much a result of selection in hospitals and intra- and inter hospital dissemination like in the USA, but is occasionally introduced into to hospitals from the community and that nosocomial VRE infection in Europe is mostly caused by a VRE from the patients own flora, acquired from a heterogeneous pool of VRE outside hospital ${ }^{23}$.

Since the emergence of multiresistant MRSA in the early 1980s and of VRE in the early 1990s the pharmaceurical industry has developed new antibiotics for treatment of serious infecrions due to multiresistant Gram-positive cocci. However, two of these: dalfopristin-quinupristin 9,48 and everninomicin ${ }^{33}$ are closely related to and show cross-resistance with virginiamycin and avilamycin respectively. These drugs have been used for many years as AMGP. As a result of this practice a bacterial population resistant to these compounds was present in the intestinal tract of food animals and healthy humans prior to introduction of these new antibiotics for clinical use 4,94,98. It has been shown that the prevalence and degree of resistance in intestinal bacteria is a good indicator for the selection pressure exerted by antibiotics 46,47 and that the intestinal flora serves as a reservoir of resistance genes for pathogenic bacteria 46 . Intestinal enterococci are therefore considered good indicator bacteria for the selection pressure exerted by antibiotics on bacterial populations. Investigation of the prevalence and degree of resistance of enteric indicator bacteria such as enterococci from different populations of humans and 
animals makes it feasible to compare the prevalence and degree of antibiotic resistance in these populations. In combination with identification and genomic fingerprinting of isolates and of resistance genes it is possible to detect evidence of transfer of antibiotic resistant bacteria and/or transfer of genes encoding antibiotic resistance berween the endogenous flora of animals and humans 95 .

\section{AIM OF" "THE STUDY}

The aim of this study was to analyze the influence of $e x$ posure to antibiotics used in the Netherlands as AMGP or for veterinary therapy in poultry on the resistance of fecal enterococci recovered from poultry, poultry farmers and poulrry slaughterers. In addition, the susceptibility of enterococci isolated from antibiotic free and from vancomycin and gentamicin containing agar plates to a variery of antibiotics was determined. The poultry population consisted of two populations with different antibiotic use profiles. Broilers are young chickens raised for slaughter within 8 weeks. Broilers are fed continuously with AMGP and there is a relam tively high level of use of veterinary prescription antibiotics. AMGP are not used in laying hens producing eggs for human consumprion and prescriprion only antibiotics are used infrequently. Reasons for these differences include the higher frequency of infection in broilers as with most young animals, but also reluctance on the part of farmers to administer antibiotics to laying hens as some antibiotics may cause a drop in egg production and sale of eggs for human consumption is not permitted during a specified withdrawal period after administration of antibiotics.

In addition, the prevalence and degree of resistance against the same antibiorics was assessed in fecal enterococci from three populations of humans with different risks of exposure to fecal bacteria from poultry. These populations are broiler and laying hen farmers, which have daily close contact with poultry with high and low level exposure to antibiotics respectively. The third human population are workers in a poultry processing plant, who handled broilers or broiler products on a daily basis. Finally, possible sharing of VRE between poultry and humans was assessed by genocyping of VRE by pulsed-field gel electrophoresis (PFGE).
The similarity of vancomycin resistance elements found in poultry and human isolates was evaluated by comparing $\operatorname{Tn} 1546$ derivatives found in poultry and human isolates of VRE.

\section{MATERLALS AND METHODS}

\section{Collection of fecal samples}

From September to December 1997 approximately 250 farmers in the south of the Netherlands keeping either broilers or laying hens were asked by letter to collect one fresh fecal sample from themselves and a mixed fecal sample from the oldest chickens at their farms. In addition 100 poultry slaughterers working at a poultry-processing plant in the same area were asked to provide one fecal specimen each. All participants were requested to send the samples on the day of collection to the bacteriology laboratory together with a completed questionnaire on recent hospital stay, antibiotic use by themselves, family members or their animals during the three months preceding sample collection and whether they kept food and/or companion animals. On the day of arrival at the laboratory the samples were diluted $\left(10^{-1}\right)$ in $0.9 \% \mathrm{NaCl}$ (wt/vol) with $20 \%$ ( $\mathrm{vol} / \mathrm{vol}$ ) $\mathrm{glyc}$ erol and stored frozen at $-20^{\circ} \mathrm{C}$ until assayed.

\section{Isolation of (resistant) enterococci}

After thawing the samples $40 \mu$ of $10^{-1}$ and $10^{-3}$ dilutions in $0.9 \% \mathrm{NaCl}$ (wt/vol) were inoculated on KF-Streptococcus agar ${ }^{T M}$ plates (Oxoid CM701; Basingstoke, UK) with and without antibiotics using a spiral plater (Salm en Kip BV, Urrechr, the Netherlands) as previously described ${ }^{56}$. The antibiotics were selected because these, or related antibiotics, are (or had been until recently) regularly administered to poultry either on veterinary prescription or as AMGP (Table 1). The concentrations used in the agar were based on guidelines and modified where appropriate to make results comparable with those of previous studies $49,79,89,90$. If after 48 hours of incubation no vancomycin resistant enterococci (VRE) were detected on the vancomycin containing agar plate, $0.5 \mathrm{~mL}$ of the $10^{-1}$ dilution was incubated overnight in nutrient broth containing $10 \mathrm{mg} / \mathrm{L}$ vancomycin and $0.4 \mathrm{~g} / \mathrm{L}$ sodium azide Next morning $0.5 \mathrm{ml}$ of this broth was 
plated on a vancomycin containing agar plate and checked for growth after 48 hrs of incubation.

Enterococci appear as typical ted or pink colonies on KF-Streptococcus agar. After 48 hrs of incubation at $42^{\circ} \mathrm{C}$ only the typical pink colonies were counted. The minimum detection level, as assayred with spiked feces samples, was approximately $300 \mathrm{CFU} / \mathrm{g}$ feces.

The prevalence of antibiotic resistance $(\%)$ in a population was calculated as the number of samples showing growth of enterococci on the antibiotic containing plates, divided by the total numbers of samples tested $\times 100 \%$.

The degree $(\%)$ of antibiotic resistance of each fecal sample tested is the number of enterococcal colonies on the antibiotic containing plate divided by the total number of enterococcal colonies on the antibiotic free plate $\times 100 \%$. Two degrees of antibiotic resistance can be distinguished: low degree resistance, i.e. less than $50 \%$ of the total number of enterococci in a sample is resistant and high degree resistance, $50 \%$ or more (thus the majority) being resistant to that particular agent 47,91 . The prevalence of high degree resistance $(\%)$ is the number of samples with a high degree of resistance to a particular antibiotic divided by the total number of samples tested $\times 100 \%$.

Because E. faeralis is considered to be intrinsically resistant to dalfopristin-quinupristin, a sample was only considered to contain resistant enterococci to this drug if at least one Enterococcus faecium was isolated and identified from the dalfopristin-quinupristin containing agar plate. The (prevalence of high) degree of resistance against dalfopristin-quinupristin could only be calculated for the rotal enterococcal population in the specimen.

\section{Identification and antibiotic susceptibility testing of enterococcal isolates}

From each sample one typical enterococcal colony was randomly chosen from the antibiotic free plate for identification and determination of the MIC for an extended panel of antibiotics. MIC were determined by a microbroth dilution method in Iso-Sensitest Broth TM (Oxoid CM 473) using an inocullum size of $5 \times 10^{5}$ $\mathrm{cfu} / \mathrm{ml}$. The panel of antibiotics for the MIC determination (Table 3 ) included the same antibiotics as used in the agar plates and in addition related antibiorics of the same chemical groups were added. If growth was observed on the vancomycin or gentamicin containing agar plate, one colony was also selected randomly for identification and MIC determinations. Enterococous facalis ATCC 29212 and E. coli ATCC 25922 were used as reference strains. Identification to species level was performed as described previously 18,79 .

If VRE were recovered from a chicken and a farmer from the same farm these isolates were genotyped by PFGE, the resistance genes identified and the vanA transposons analyzed.

\section{Detection of wanA, waw $B$ and wanC genes}

The $\tan A$, van $B$ and $\operatorname{van} C$ genes were detected by hybridization with specific probes as described previ. ously ${ }^{79}$.

\section{Pulsed-field gel electrophoresis analysis of VRE} The PFGE analysis of the enterococci isolated from the agar plates with vancomycin was performed after DNA digestion with $S m a I$ as described previously 97 . To assess similarity of the different patterns the criveria of Tenover were used : if an isolate differed from a main type by only three or less bands, it was considered as a subtype.

The computer-assisted analysis of the PFGE fingerprints was done with BioNumerics (Applied Marhs, Kortrijk, Belgium). Comparisons of patterns were done by the unweighed pair group method using arith metic averages (UPGMA) clustering method by using the Dice coefficient.

\section{Molecular characterization of $T n 1546$ derivatives} Characterization of the vanA containing transposons was performed by means of a combination of restricrion fragment length polymorphism (RFLP) analysis and DNA sequencing of Tn 1546 specific PCR products as described previously 79,99 . Tn 1546 derivatives were classified by type in concordance with the nomendature used previously 79,99 . All VRE isolates were analyzed for the presence of the point mutations at positions 1226 , $4847,7658,8234$, and 9692 for left and righr end deletions and for the exact integracion site and orientation of IS $1216 \mathrm{~V}$ downstream of $\operatorname{van} X$ in the type $B$ and $E$ transposons. 


\section{Statistical analysis}

A one-way analysis of variance was used to estimate overall differences between the group means. Group means were compared pairwise using t-tests controlled for overall error rate (Bonferroni test) where $p<0.05$ was regarded statistically significant. Correlations between populations were calculated using the Pearsons product moment correlation coefficient test.

\section{RESULTS}

\section{Study population}

Of the persons asked to participate in the study approximately $50 \%$ of the poultry slaughterers and $30 \%$ of the poultry farmers responded. One broiler farmer had no animals on the farm at the time of sample collection so that only a human fecal sample was supplied. Of 46 fecal samples of slaughterers received $41(89 \%)$ yielded enterococci. Enterococci were detected from all 50 samples from broilers, from all 25 samples of laying hen farmers, form $24(96 \%)$ of 25 samples from laying hens, and from $49(96 \%)$ of 51 stools of broiler farmers. Growth of enterococci on the vancomycin containing agar plates was detected from 65 specimens (33\%) and additionally from 19 samples (10\%) after enrichment (Table 1).

The mean \pm SD $\log _{10} \mathrm{CFU}$ of enterococci per gram feces in positive fecal samples was $5.4 \pm 1.4$ for human fecal specimens and $7.7 \pm 0.4$ in poultry specimens. In the three months preceding the sample collection, two poultry slaughterers and one laying hen farmer had been hospitalized. None of the laying hen farmers had received antibiorics in the preceding three months. However in four cases a member of the family has received antibiotics. Four of 51 broiler farmers $(8 \%)$ and two family members of broiler farmers, and four $(9 \%)$ slaughterers and two of their family members had used antibiotics in the preceding three months. In the three groups approximately $55 \%$ kept companion animals; mainly dogs and cats. Thirteen laying hen farmers $(52 \%)$ and $35 \%$ of broiler farmers also kept other food animals on the farm. Other food animals were mainly pigs (32\% of laying hen farmers and $29 \%$ of broiler farmers). Six of the (13\%) of the slaughterers kept pigs. There were no farmers in the study that kept both laying hens and broilers. None of the poultry slaughterers

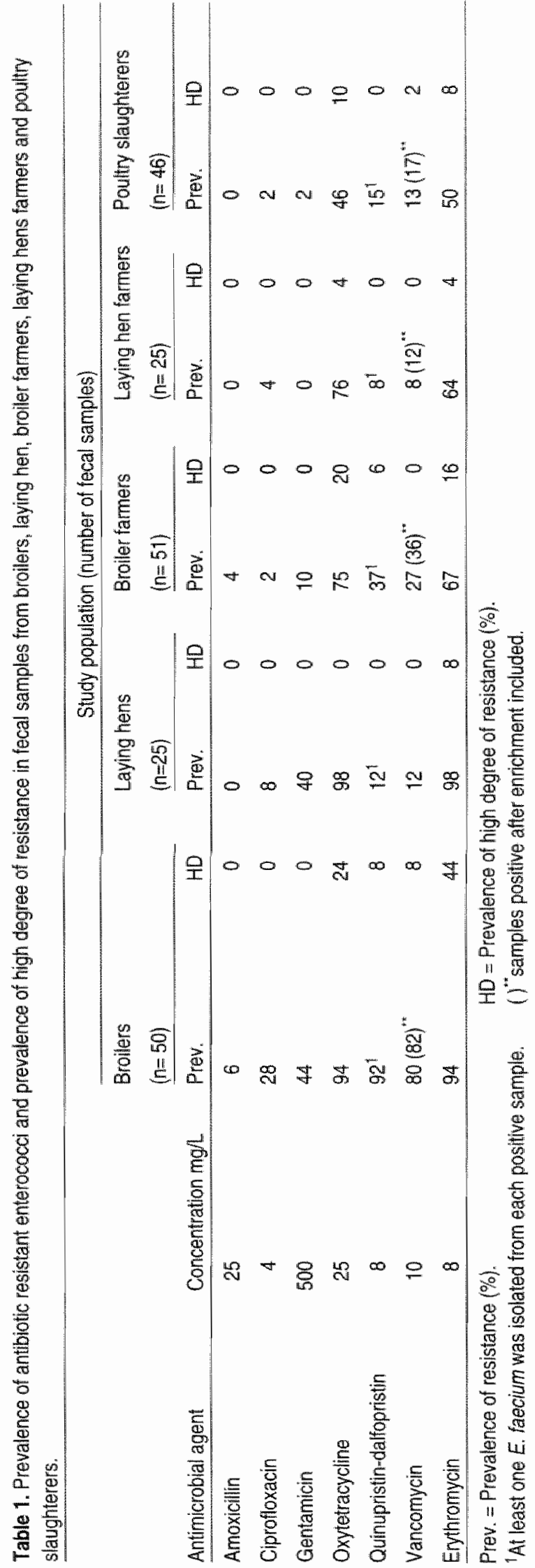




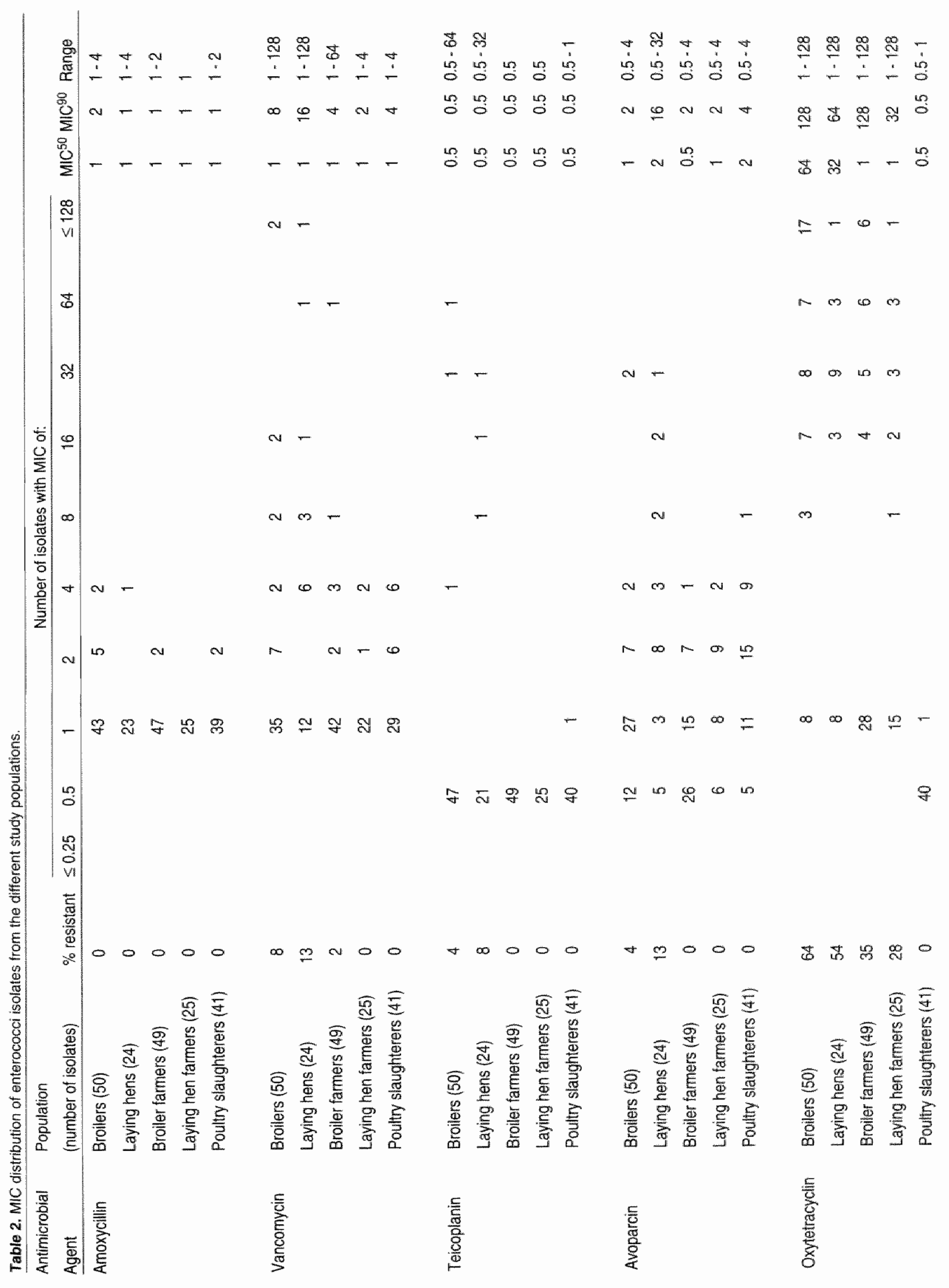




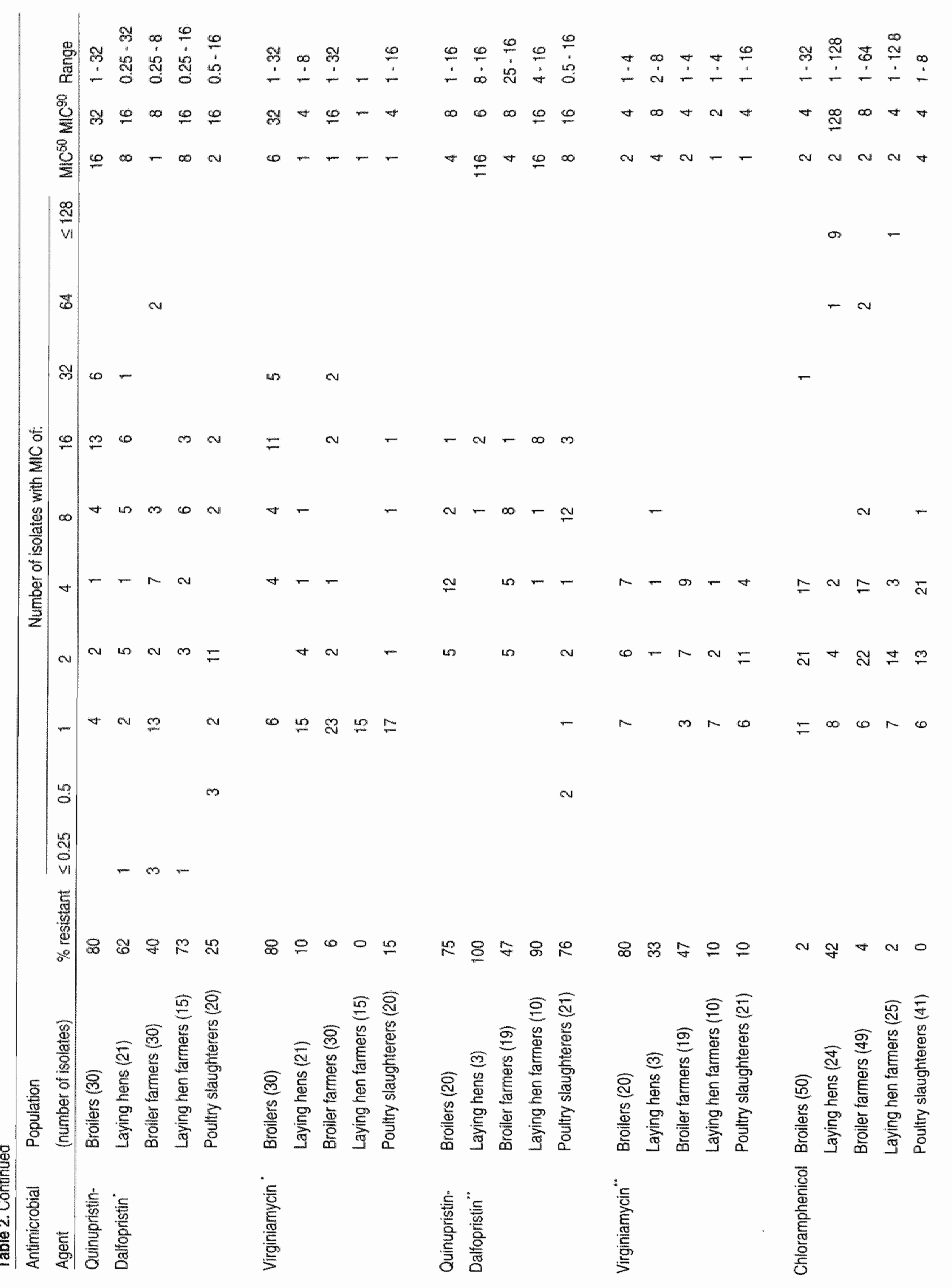




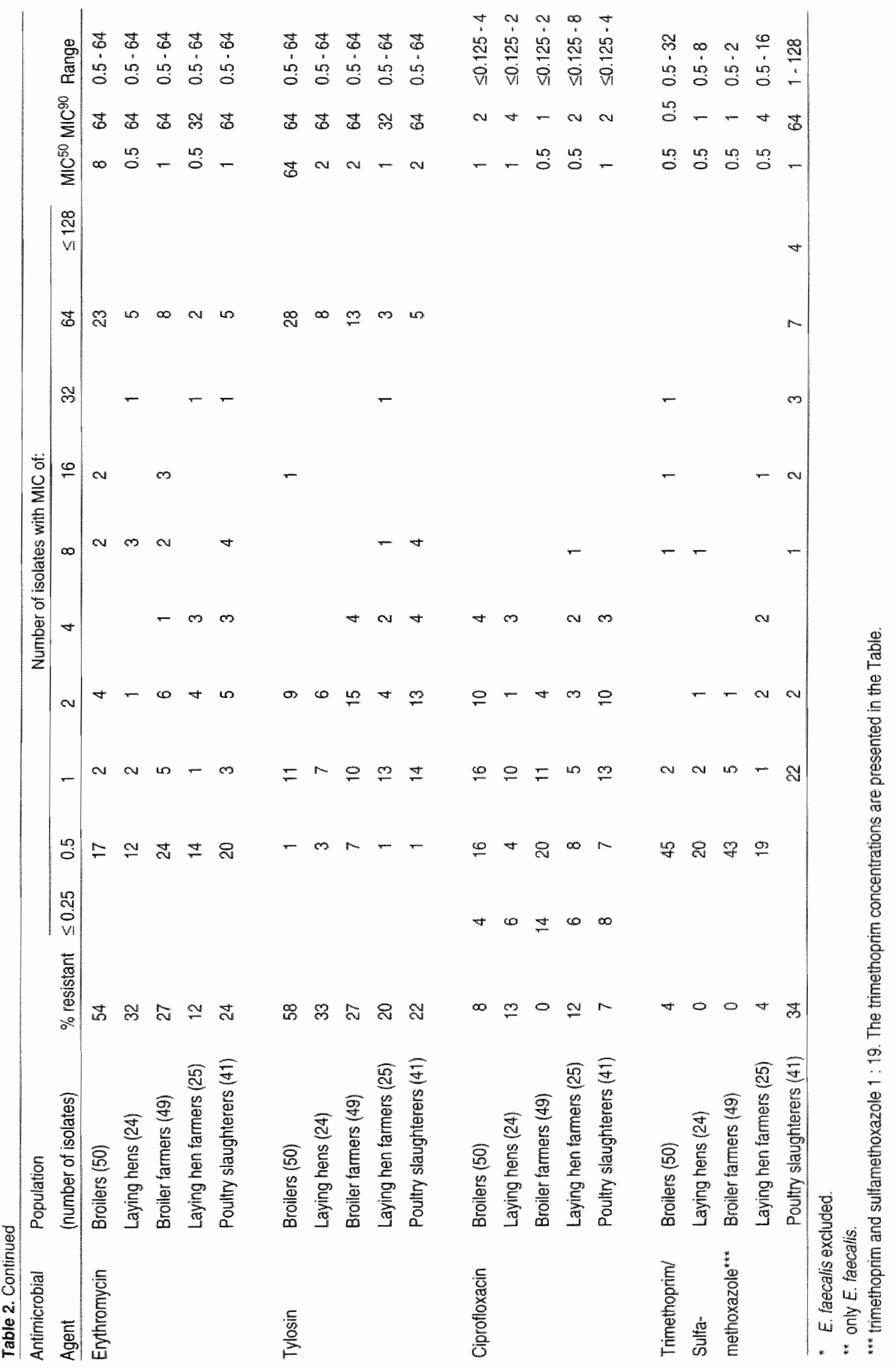


Table 3. Identification of enterococcal isolates from broilers, laying hens, broiler farmers, laying hen farmers and poulty slaughterers.

\begin{tabular}{|c|c|c|c|c|c|}
\hline & Broilers & Laying hens & Broiler famers & Laying hen farmers & Pouttry slaughterers \\
\hline Species & $n=50$ & $n=24$ & $n=49$ & $n=25$ & $n=41$ \\
\hline E. faecalis & 20 & 3 & 21 & 10 & 21 \\
\hline E. faecium & $26(52 \%)$ & $5(29 \%)$ & $6(32 \%)$ & $8(32 \%)$ & $1.4(34 \%)$ \\
\hline E. casseliftawus & 1 & 6 & 2 & 1 & 2 \\
\hline E. mundti & 1 & 1 & & & 1 \\
\hline E. avium & 1 & & & 1 & 1 \\
\hline E. Thrae & 1 & & 6 & 2 & 1 \\
\hline E. durans & & 2 & 1 & & \\
\hline E. gallinarum & & 4 & 2 & & \\
\hline Unidentiffed & & 3 & & 3 & 1 \\
\hline
\end{tabular}

$n=$ number of isolates

kept poultry. There were no significant differences observed within the same group berween people keeping pigs and those that did nor (data not shown). Of the laying hen flocks $2(8 \%)$ had received a course of antibiotics on veterinary prescription while on the farm, compared with $23(46 \%)$ of the 50 broiler flocks. No information was obtained about AMGP use.

\section{Prevalence and degree of resistance}

The prevalence of resistance and the prevalence of high degree resistance for the tested antibiotics and of the populations studied are depicted in Table 1.

"The highest percentage of samples with a high degree of resistance was observed in the fecal samples of broilers. The prevalence of resistance to quinupristindalfopristin and wancomycin was significantly $(\mathrm{p}<$ $0.05)$ higher in broilers than in laying hens. The prevalence of resistance to oxyretracycline, erythromycin and gentamicin was of the same order in both chicken populations, but the number of erythromycin and oxyteracycline resistant enterococci per gram feces (prevalence of high degree resistance) was significantly higher $(\mathrm{p}<0.05)$ in broilers than in laying hens. In the human samples, amoxycillin resistance was observed only in fecal samples from broiler farmers and high level gentamicin resistance only in a few samples from broiler farmers and poultry slaughterers. Tetracycline resistance was common in all three human populations. The prevalence of resistance for vancomycin and quimupristin-dalfopristin was higher in broiler farmers than in laying hen farmers and poultry slaughterers, but staristical significance was achieved only for vancomycin $(p<0.05)$.

In general there was a close correlation of the prevalence of resistance to all antibiotics between broilers and broiler farmers (correlation coefficient: 0.95 ) and between broilers and poultry slaughterers (correlation coefficient: 0.96$)(\mathrm{p}<0.01)$. No significant correlation was observed between the prevalence of antibiotic resistance strains in laying hens and those observed in any of the three human popularions studied.

\section{MIC distributions}

As shown in Table 3, E. facalis, 73 (39\%), and $E$. faecium, $74(39 \%)$, were the most prevalent enterococcal species among the 189 isolates from the antibiotic free control plates. No significant differences in MIC distribution between the different populations were observed for amoxycillin, chloramphenicol, cotrimoxazole and oxytetracycline. Resistance against all three glycopeptide antibiotics was observed in both chicken populations, while only one fecal sample of a broiler farmer yielded a VRE. On average the MIC of isolates from poultry and from broiler farmers were higher than those from the laying hen farmers and poultry slaughterers. Marcrolide resistance was significandly higher in broilers than in laying hens and also higher in broiler farmers and in poultry slaughterers 
Table 4. MIC values of enterococcal isolates $(n=64)$ from vancomycin containing ( $10 \mathrm{mg} / \mathrm{L})$ selective agar plates.

\begin{tabular}{|c|c|c|c|c|c|c|c|c|c|}
\hline Antibiotic MIC (mg/L) & 0.5 & 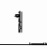 & 2 & 4 & 8 & 16 & 32 & 64 & 128 \\
\hline Vancomycin & & 2 & & & 3 & 3 & 8 & 23 & 25 \\
\hline Awoparcin & 2 & & & 4 & 13 & 29 & 14 & 2 & \\
\hline Teicoplanin & 14 & 6 & 5 & 11 & 9 & $\| 1$ & 8 & & \\
\hline
\end{tabular}

Table 5. Patterns of resistance of multiple resistant enterococcal isolates from fecal samples of broilers, laying hens, broiler farmers, laying hen farmers and poultry slaughterers.

\begin{tabular}{|c|c|c|c|c|c|c|c|c|c|c|}
\hline Population & Species & $n$ & Ey & $0 x y$ & dalfo & cipr & amo & chlor & Van & TPM/S \\
\hline Brollers & E. laecium & 8 & $\mathrm{R}$ & $\mathrm{R}$ & $\mathrm{A}$ & & & & & \\
\hline \multirow[t]{4}{*}{$n=18$} & E. faecium & 5 & $\mathrm{R}$ & $\mathrm{R}$ & $\mathrm{R}$ & $\mathbb{A}$ & & & & \\
\hline & E. faecium & 3 & $R$ & & $\mathrm{R}$ & $\mathbb{R}$ & & & & \\
\hline & E. raecium & 1 & $R$ & $R$ & $\mathrm{R}$ & $\mathrm{A}$ & $\mathbb{R}$ & $\mathrm{A}$ & $\mathrm{R}$ & \\
\hline & E. laecalis & 1 & $R$ & $\mathrm{R}$ & * & & & & & 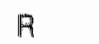 \\
\hline
\end{tabular}

\begin{tabular}{|c|c|c|c|c|c|c|c|}
\hline Laying hens & E. taecium & 1 & & $\mathrm{R}$ & $\mathbb{A}$ & & \\
\hline \multirow[t]{4}{*}{$n=6$} & E taecium & 2 & & $\mathrm{R}$ & $\mathbb{R}$ & $R$ & \\
\hline & E durans & 1 & $R$ & R & & & $\mathrm{A}$ \\
\hline & E. durans & 1 & $\mathrm{R}$ & $\mathrm{R}$ & $\mathbb{R}$ & & $\mathrm{R}$ \\
\hline & E. casseliflavus & 1 & R & $\mathrm{R}$ & $R$ & $R$ & \\
\hline
\end{tabular}

\begin{tabular}{|c|c|c|c|c|}
\hline Broiller Farmers & E. faecium & 2 & $\mathrm{R}$ & f \\
\hline \multirow[t]{3}{*}{$n=5$} & E hirae & 1 & R & 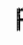 \\
\hline & E. hirae & 1 & & \\
\hline & E. durans & 1 & $R$ & F \\
\hline
\end{tabular}

$\begin{array}{lllllll}\text { Laying hen farmers } & \text { E. faecium } & 1 & & R & R & R \\ n=3 & \text { E. faecium } & 1 & R & R & R & \\ & \text { E. faecalis } & 1 & R & R & \end{array}$

Poultry-slaughters $\quad$ E. faecium $\quad 2 \quad R \quad R \quad R$

$n=2$

$A=$ resistant.

MC mg/L: ery = erythromycin MIC $>4$, axy $=$ oxytetracyclin MC $>8$, dalfopristin quinupristin MIC $>2$, Cipro = ciprofloxacin MLC $>2$, am $=$ amoxycillin MIC 16 , chlo = chloramphenicol MIC $>16$, van = vancomycin $M I C>8$ and TPM/S = trimethoprim-sulfamethoxazole MIC $>8 / 152$.

$n=$ number of isolates.

* $=$ resislanit but mot included.

than in laying hen farmers. No amoxycillin resistant VRE were isolated from the control plates. As shown in Table 4 mulriple resistance to three or more of the tested antibiotics was found in $36 \%(18), 25 \%(6)$, $10 \%(5), 12 \%(3)$ and $4 \%(2)$ of broiler, laying hen, -broiler farmer, laying hen farmer and poultry slaughterer isolates respectively. Of these multiresistant isolates $24(71 \%)$ were E. faecium. The most observed resistance pattern was resistance against erythromycin, oxytetracycline and quinupristin-dalfopristin. This 
Table 6. Pulsed-field get electrophoresis patterns and characteristics of 20 paired vancomycin resistant enterococcal isolates from fecal samples of farmers and chickens from the same farm.

\begin{tabular}{|c|c|c|c|c|c|}
\hline Source & Species & MIC wanco (mg/L) & MiC teico (mg/L) & PFGE Pattem & Transposon type \\
\hline Laying hen (2) & E. faecium & 128 & 8 & A. & $\mathrm{B} 2$ \\
\hline Laying hen farmer (2) & E faeciunt & 128 & 8 & $\mathrm{~B}$ & $A 2$ \\
\hline Brciler (3) & E. hirae & 64 & 4 & $\mathrm{C}$ & E11 \\
\hline Broiler farmer (3) & E. hirae & 64 & 4 & D & E11 \\
\hline Broiler (4) & E. frecium & 64 & 8 & $E$ & $\mathrm{ND}^{1}$ \\
\hline Broiler farmer (4) & E. faecium & 1 & 0.5 & $\mathrm{~F}$ & $\mathrm{~A} 1$ \\
\hline Broiler (14) & E. hirae & 64 & 4 & G & E11 \\
\hline Broiler famer (14) & E. hirae & 64 & 0.5 & $G$ & E11 \\
\hline Broiler (31) & E. hirae & 64 & 4 & $H$ & E11 \\
\hline Broiler farmer (31) & E. hirae & 32 & 1 & $\mathrm{H} 1$ & E11 \\
\hline Broler (36) & E. fracium & 64 & 4 & 1 & $\mathrm{~A} 1$ \\
\hline Broiler farmer ( 36 ) & E. faecium & 64 & 16 & J & E7 \\
\hline Broiler (37) & E farcium & 128 & 32 & k & A1 \\
\hline Broiler farmer (37) & E. faecium & 128 & 16 & L & A2 \\
\hline Broiler (39) & E faecium & 32 & 0.5 & M & E19 \\
\hline Broiler farmer (39) & E. hirae & 64 & 1 & $\mathbb{N}$ & E14 \\
\hline Broiler (40) & E. faecium & 32 & 1 & 0 & At \\
\hline Broiler farmer $(40)$ & E hirae & 64 & 0.5 & G1 & E11 \\
\hline Broiller (45) & E. faecium & 32 & 2 & $\mathrm{P}$ & $\mathrm{ND}^{1}$ \\
\hline Broiler farmer (45) & E. hirae & 64 & 0.5 & $Q$ & E17 \\
\hline
\end{tabular}

${ }^{\prime} \mathrm{ND}=$ Not determined.

pattern was found in $13(38 \%)$ isolates, all except one E. fatecium.

From the gentamicin containing agar plates 27 enterococci were isolated with high level resistance (HLR) to gentamicin. Three of these, isolates from

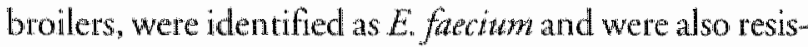
tant to amoxycillin and two were additionally resistant to nearly all antibiotics tested: oxytetracycline, erythromycin, quinupristin-dalfopristin, cotrimoxazole and the tested related molecules, but not to wancomycin. Of the other 24 gentamicin HLR isolates the majority was identified as $E$. faccalis except for 4 isolares from broilers and 3 from broiler farmers, which were identified as En frecium.

Of 58 quinupristin-dalfopristin resistant $E$. faecalis isolates from the antibiotic free control plates the MIC for virginiamycin was more than one dilution step lower than for quinupristin-dalfopristin for 37 isolates $(64 \%)$ (data not shown) and $33(57 \%)$ isolates were susceptible to virginiamycin. For the 64 non-E. faecalis quinupristin-dalfopristin resistant isolates, of which 44 were $E$. facitum these figures were $50 \%$ and $48 \%$ respectively. All except one of 119 isolates from the quinupristin-dalfopristin containing agar plate were resistant to quinupristin-dalfopristin. The $\mathrm{MlC}$ for virginiamycin was more than one dilution step lower than for quinupristin-dalfopristin resistance in 32 $(27 \%)$ isolates. Of these 32 isolates 19 were susceprible for virginiamycin. Isolates with MIC for virginiamycin higher than for quinupristin-dalfopristin were not isolated.

The MIC for glycopeptides of isolates from the vancomycin containing plates are shown in Table 5 . Only 64 isolates were tested as one was lost during storage and in all but two the van $A$ gene cluster was detected by blot hybridization. No $\operatorname{van} B$ or $\operatorname{van} C$ genes were found. Most van $A$ containing isolates were identi- 

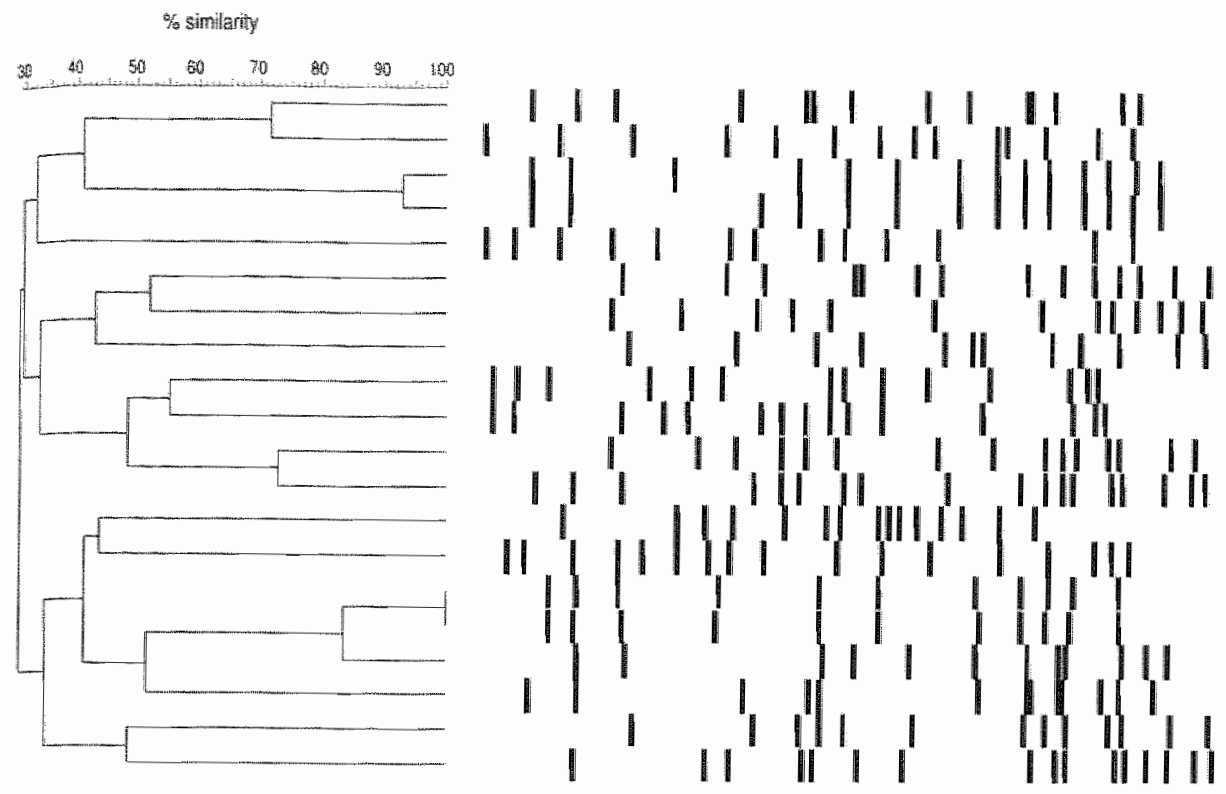

\begin{tabular}{|c|c|c|}
\hline Souton & Spocies & PFOE tWW \\
\hline 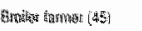 & 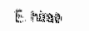 & $a$ \\
\hline 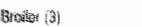 & 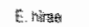 & $\mathrm{c}$ \\
\hline 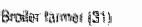 & E. titat & mis \\
\hline Prodtar (y: & E. hima & 租 \\
\hline Laty & 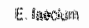 & th \\
\hline 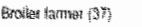 & 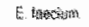 & \&. \\
\hline Certathar (a) & 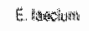 & $\ddot{d}$ \\
\hline 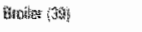 & E tosciasta & is \\
\hline 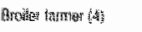 & E tradura & 5 \\
\hline 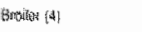 & 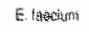 & $\mathrm{E}$ \\
\hline 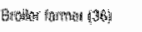 & FE, fakcium & s \\
\hline Wroles fath & E. atcisin & 0 \\
\hline Bitutang & E. Mista & i) \\
\hline 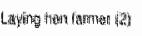 & 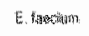 & g \\
\hline 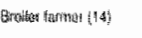 & E. hing & is \\
\hline 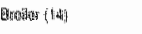 & E thing & 0 \\
\hline 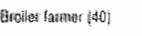 & E ntiae & 0 \\
\hline 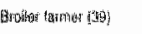 & E: ingate & $N$ \\
\hline Broltar (in) & E: \{ased & is \\
\hline Evalitar (45j) & 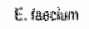 & $p$ \\
\hline
\end{tabular}

Figure 1. PFGE patterns and dendrogram of 10 paired vancomycin resistant enterococci isolated from lecal samples of farmers and pouttry from the same farm after total DNA digestion with Smal.

fied as $E$. faecium $(\mathrm{n}=37)$, but 5 isolates were E. faecalis, 15 E. hirae and 5 E. durans.

\section{Pulsed-Field Gel Electrophoresis}

The 10 paired VRE isolates from farmer and chicken recovered from the same farm were analyzed by PFGE (Fig. 1, 2 and Table 6) In general the obrained PFGE patterns were wery diverse. In two cases, SK14/SKH14 and SK31/SKH31, strains isolated from broiler farmers and their broilers, all identified as $E$. hirate, were identical $100 \%$ or very similar $(93 \%)$. In addition, isolate $\$ \mathrm{KH} 40$, isolated from a broiler farmer, but from a different farm, showed a high degree of similarity with isolates SK14 and SKH14. $y$ with isolates SKI4 and SKHI4.

\section{Tn1546 types among different VRE isolates}

Eight different wanA transposon types were found among the $18 \mathrm{VRE}$ isolated from poultry and farmers (Fig. 2). Tn rypes A1, A2, B2, E7 and E11 have been described previously. In short rype Al is identical to $T_{n} 1546$. Type $\mathrm{A} 2$ is characterized by a $G \rightarrow T$ point mutation at posicion 8234 and an IS1216 W-IS3 insertion at the left end of the transposon. Type $B 2$ contains an IS $1216 \mathrm{~V}$ insertion in the $\operatorname{san} X$-van $Y$ intergenic re- gion. Type E7 contains also the IS1216 Vinsertion in the same region as in type B2 as well as a large left end deletion encompassing the orf gene and a part of the orf 2 gene, while type E11 contains an additional deletion at the right end of the transposon including the vanZ gene. Three new transposon types were found, type E14, E17, and E19. Types E14 and E17 are closely relared to type $\mathbb{E} 11$. The only difference resides in the size of the small deletion flanking the $151216 \mathrm{~V}$ insertion site downstream of wax . Type E19 is comparable to type $\mathrm{E} 7$, with differences in the size of the left end deletion and in the size of the small deletions adjacent to the $1 S 1216 \mathrm{~V}$ insertion site in the van $X$-van $Y$ intergenic region. Comparative analysis of the Tn1546-like elements of the paired VRE strains revealed that in addition to the two scts of paired strains with comparable PFGE patterns, 14 and 31 , the paired strains broiler and broiller farmer 3 also contained identical transposon types. In the other cases different transposon types were present in poultry and poultry farmer isolates. In conclusion, in three of the eight paired strains which were analyzed an identical vanA transposon was present in both the animal and farmer isolate. 

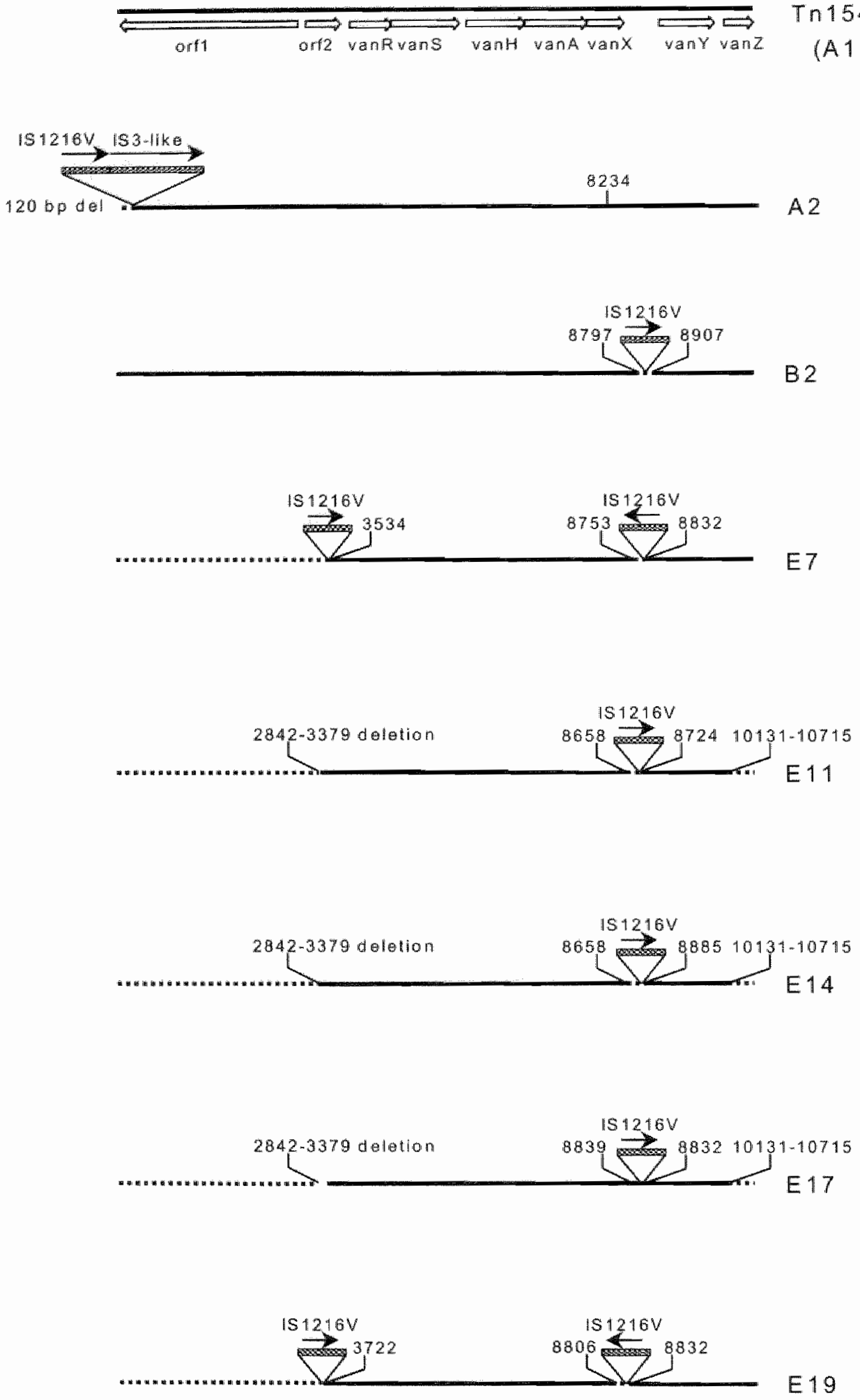

Figure 2. Genetic map of Tn 1546 and four Tn 1546 derivatives. The thick horizontal lines represent Tn 1546 and Tn1546 types E8-112. The position of genes and open reading frames (orf"s) and direction of transcription is depicied by open arrows. Dotted boxes represent IS elements. The position of the first nucleotide up and downstrean Irom IS insertion sites are depicted. Filled arrows indicate the transcriptional orientation of inserted IS elements. Deletions have been indicated by dotted lines. 


\section{DISCUSSION}

Enterococci are not important animal pathogens. As antibiotic susceptibility testing is usually performed to guide antimicrobial therapy, no data on antibiotic resistance rates in clinical isolates of enterococci from poultry were available in the literature. Until quiet recently only a few studies were performed about the resistance found in the fecal enterococci of food animals, but since Bates suggested an animal reservoir for VRE in man, the issue of selection pressure exerted by the use of antibiotics on the fecal flora of exposed animals and the potential for transfer of resistant fecal bacteria from food animals to humans has contracted considerable interest. Because of differences in methodology as often only resistance in one species, mostly $E$. faecium, is investigated, direct comparison of figures and percentages of different studies is not feasible.

Comparison of the results of Tables 1 and 3 showed a difference between the quantitative determination of resistance (direct plating on antibiotic containing plates) and the qualitative determination based on the MIC of a single randomly selected isolate per sample. As expected the quantitative method was more sensitive than the qualitative method. For most tested antibiotics results obtained by the qualitative method correlated better with the prevalence of high degree of resistance in a sample than with the prevalence of resistance. Because this difference in sensirivity direct comparison of the obtained figures is not feasible. However, comparing the results of MIC of single isolates of enterococci of the populations studied to the direct plating results, the same trends were observed and therefore conclusions drawn from the results of both methods might be compared. The increase in sensitivity of VRE detection that was obtained after enrichment of fecal samples in vancomycin containing broth as compared to direct plating was relatively low and did not influence the conclusions. As AMGP are selected for addition to broiler feeds by the feed miller many broiler farmers were not even aware that they were feeding AMGP to their animals. Therefore it was not possible to acquire reliable data on AMGP usage. In broilers the prevalence of resistance for antibiotics most frequently used for therapeutic purposes was higher than in laying hens. Similarly prevalence, but also high degree of resistance to substances (vanoomycin and erythromycin) for which cross-resistance to commonly used AMGP occurs was more common in broilers than in laying hens. This corroborates with the results of another study showing that a high degree of antibiotic resistance against an antibiotic in pigs was correlated with current or recent high or continuous use of that antibiotic in these animals". Animals with a high degree of resistance in their fecal flora excrete more resistant bacteria in their environment, which increases the risk for acquisition of these strains by humans. Moreover it has been shown that people with a high degree of resistance against a certain antibiotic carry these resistant bacteria more consistently and over a longer time span than persons with a low degree of resistance in their fecal flora 47,49 . This might also be the case in poultry. Although the overall prevalence of antibionic resistance was indeed lower in laying hens than in broilers, it was nonetheless unexpectedly high.

This may be associated with regular usage of $A M P G$ and of therapeutic antibiotics like tetracyclines during the rearing period. AMGP like virginiamycin and tylosin are commonly mixed in the feeds of laying hens during the rearing period for prevention of bacterial infections. Regular antibiotic usage also selects also for the more incrinsically resistant E. facizm among enterococci in the fecal flora of exposed individuals. Fifry two percent of the total number of enterococci isolated from broiler fecal samples was identified as $E$. faciam compared with $30 \%$ in the other populations studied.

The overall prevalence of antibiotic resistant enterococci among broilers, broiler farmers and poultry slaughterers points to contact with broilers as a risk factor for colonization with resistant enterococci for humans. In laying hen and laying hen farmers this was the case only for tetracycline and erythromycin resistance. The prevalence of $6 \%$ amoxycillin resistant fecal enterococci in broiler flocks and the absence of amoxycillin resistant enterococci from laying hens are most likely a result of the higher overall use of antibiotics in broilers compared to laying hens. Regular antibiotic use favors the selection of intrinsically less susceptible $E$. faceium in the intestinal flora and the majority of broiler isolates were $E$. faecium compared to only one third of the laying hen isolates. All amoxycillin resistant 
enterococci isolated in the study were $E_{\text {. factumbin }}$ except one $E$. durans. This is in agreement the results of a study of human isolates, where consideraby less amoxycillin resistant $E$. faecalis than $E$ faectzm have been found ${ }^{73}$. In the USA Thal et al. found only in the feces from one of 12 healthy chickens from diferent farms amoxycillin resistant enterococci. In Denmark, one tandomly chosen isolate from each feal sample having been examined, the prevalence of amoxycilin resistant $E$. faecium in broilers was $2 \% \%^{3}$. In this study no amoxycillin resistant enterococci were found among the individual isolates, which corresponded with the low degree of amoxycillin resistance observed in posirive samples. The presence of amoxycillin resistant enterococci only in the fecal flora of broilers and broiler farmers and not in any other of the studied populations nor in healthy (sub)urban residents in the Netherlands ${ }^{94}$ is suggestive of a broiler to farmer transfer of resistant enterococci.

Resistance to fluoroquinolones was significantly more common in broilers than in the other populations. This is most likely due to the more common use of enrofloxacin and flumequine (a less potent fluoroquinolone than enrofloxacin), in broilers than in laying hens. The fluoroquinolone resistant enterococci isolated from laying hens might be due to use of quinolones during the rearing period. In Denmark $63 \%$ of fecal $E$. facium from broilers were resistant to fluoroquinolones ${ }^{3}$. Resistance to fluoroquinolones is frequenty observed among enterococe isolated from human infections $72,73,87$. The prevalence of fluoroquinolone resistance in broiler farmets was, however, not different from the other populations studied. Resistance against fluoroquinolones is caused by mutations and not by transferable genes. Clonal transmission of fluoroquinolone resistant $E$. coli strains from turkeys to humans has been described ${ }^{89}$. This indicates that colonization of humans by poultry enterococci occurs less readily than by poultry $E$. colt. In that case it is likely that for the transfer of resistance in enterococci from poultry to thumans exchange of resistance genes between poultry enterococci and endogenous human enterococci is a more important phenomenon than colonizarion of the human intestinal tract by poultry enterococci.
The high prevalence of HLR to gentamicin in the enterococcal fecal flora of both broilers and laying hens in this study was unexpected. Thal et al. found no high level gentamicin resistant enterococci in fecal samples of poultry despite their presence in wild birds and in environmental samples ${ }^{64}$. In Denmark only $1 \%$ of the E. faecalis isolared from healthy broilers at slaughter were resistant to gentamicin and no gentamicin resistant E. faecum were isolated ${ }^{3}$. In this study in both species HLR to gentamicin has been observed. As gentamicin is not registered for use in poultry in the Necherlands this might have been due to regular off $\mathrm{l}_{\text {a- }}$ bel use in young chickens. The most common cause for high level gentamicin resistance in enterococci is acquisition of a gene encoding for AAC6'-APH2, which is transferable between enterococcal species $35,36,60,80$. However, other genetic determinants encoding for HLR to gentamicin in enterococci have been described $^{53}$. Rice et al. described a large transferable element, tentatively named In5385, which contains within it a conjugative transposon ( $\operatorname{Tn} 5381$ ) encoding tetracycline resistance and an IS256-based composite transposon conferring resistance to gentamicin and erychromycin $65-67$. Tetracyclines are the most widely used antibiotics in poultry and tylosin, a macrolide and completely cross-resistant with erythromycin, was used regularly as AMGP at the time of the study and on veterinary prescription. Therefore co-selection might be another reason for the observed high prevalence of HLR to gentamicin among fecal enterococci of Dutch poultry. This is confirmed by the observation that nearly $50 \%$ of the isolates with HLR to gentamicin were also resistant to tetracyclines and macrolides. Further investigarions are required to determine if an epidemic of Tn5385 or a related resistance determinant is responsible for the observed high prevalence of multiple resistance in the isolated enterococci with HLR to gentamicin. The prevalence of HLR to gentamicin of $10 \%$ in broiler farmers is most likely derived from their animals as in human medicine in the Netherlands gentamicin is used almost exclusively in hospitals and none of the farmers or family members had been in hospital in the three months preceding the study. High-level gentamicin resistance in enterococci has been reported in several studies from human infections 25,59 . In a recent European study of more than 
4208 enterococci isolated from human infections $23 \%$ of the isolates was HLR to gentamicin: $20 \%$ of the isolated $E$ faecalis strains and $14 \%$ of E. faecium isolates. However in fecal enterococci from healthy Dutch (sub) urban residents in 1997 no high-level gentamicin resistant enterococci were detected ${ }^{94}$.

The high prevalence of resistance and the high percentage of fecal samples with a high degree of resistance against oxytetracycline in both chicken populations clearly reflected the large amounts of tetracyclines (approximately $60 \%$ of all antibiotics on a weight basis of pure drug) used in poultry in the Necherlands. The facr that both farmer groups had a significantly higher prevalence of resistance than the prevalence of $36 \%$ observed in fecal samples of healthy (sub)urban residents collected at the same time in the Netherlands (unpublished results) suggested direct transfer of resistant strains or genetic determinants of resistance from animals to humans. Tetracycline resistance is easily disseminated and several different transferable resistance determinants have been described $14,55,69,86$. The Tet $M$ gene of the conjugative transposon Tn916 has even spread beyond the enterococci into Gramnegative bacterial species ${ }^{68,70}$. In Danish study $61 \%$ of the $E$. facalis isolates from broiler faeces were tetracycline resistant, compared to a more limited number (31\%) of E. faecium isolates ${ }^{8}$. Terracycline resistance among clinical enterococci from humans is com$\operatorname{mon}^{87}$.

The cross-resistance of erythromycin with tylosin was confirmed by the MIC results as shown in Table 3 . The prevalence of erythromycin resistance was in all populations high, but the proportions of erythromycin resistant enterococci per gram feces (high degree of resistance) were significantly higher $(p<0.05)$ in both poultry groups than in the three human populations. The meam percentage of erythromycin resistant enterococci in positive fecal samples of broilers was $79 \%$. Such high numbers of resistant enterococci per gram feces facilitates transfer from broilers to humans. Several studies have shown that in chickens raised on tylosin containing feed not only the percentage resistant enterococci in the fecal flora of exposed animals increased over time but that also an selection for $E$. faecium occurred $30,37-39$. In Finland, where tylosin is only used therapeutically when indicated and only on weterinary prescription the prevalence of tylosin resistant fecal enterococci was $9 \%$ in broilers, whereas in Denmark where tylosin was also widely used as AMGP at the time of the study the prevalence of tylosin resistance was $59 \%$. Similarly, in Sweden, where no AMGP have been used since 1986 , the prevalence of tylosin resistant fecal enterococci from poultry was $17 \% 26$, whereas in Belgium the percentages ranged from $50 \%$ $67 \%$. Also the percentage of erythromycin resistant enterococci isolated from meat from Danish poultry was significantly higher than from Swedish poultry meats 36\% and 7\% respectively ${ }^{62}$. Quinupristindalfopristin $^{8}$ is like virginiamycin a mixture of two pristinamycins that act synergistically and crossresistance between both drugs has been described. Virginiamycin use in human medicine has been limited to a few EU countries for therapy of staphylococcal infections. In contrast virginiamycin thas been used extensively as AMGP for many years in the EU. At the time of the study quinupristin-dalfopristin was not registered for any use in the EU. The high prevalence of resistance to this agent observed in broilers is most likely due to the common use of virginiamycin in broiler feeds as a replacement for avoparcin, after the EU suspension of glycopeptide usage as AMGP. It has been shown that the prevalence of resistance to pristinamycins in chickens fed virginiamycin is significantly higher than in controls borh for E. faecalis $(46 \%$ and $25 \%$ respectively) and for E. fatium (88\% and $26 \%$ ). This increase in prevalence of resistance was associated with an increase in the numbers of $\mathbb{E}$. faecium isolates relative to the total number of enterococci in the fecal flora of the exposed birds. In Denmark $60 \%$ of E faecium isolates from fecal samples of thealthy broilers were resistant to virginiamycin and $74 \%$ to quinupristin-dalfopristin. Resistance to the last compound in clinical isolates from humans in Europe was $75 \%$ for $E$. faecalis and $8 \%$ for $E$. faecium isolates. $E$. facalis is considered intrinsically resistant against pristinamycins. The MIC of single isolates showed this to be true for the majority of $E$. farecalis isolates for quinupristin-dalfopristin, but not for virginiamycin. In this study the isolated enterococci tended to be more susceptible to virginiamycin than to dalfopristin and $E$. facalis isolates were less susceptible to pristinamycins, but not all resistant. 
VRE were most common in the fecal samples from broilers. In fecal samples of broiler farmers a significantly higher prevalence and degree of vancomycin resistance among enterococci was observed than in the orher two human populations in this study and in Dutch (sub)urban residents 22 . Several studies have been performed on the prevalence of VRE in chickens. In Denmark and Germany VRE were found in the fecal flora of broilers from intensive farming units using AMGP, whereas no VRE were detected in fecal samples from laying chickens from organic farms, that do not use AMGP2,42. In another Danish study (broilers), a Norwegian (broilers and turkeys) and a Dutch study (turkeys) comparing farms using and not using awoparcin the relative risk ratio for the presence of VRE in the fecal flora of the animals at these farms was 2.9, 5.4 and 3.3 respectively $7,44,79$. In Japan fecal carriage was common in farms using avoparcin as AMGP but no VRE were detected in animals from farms not using avoparcin $^{103}$. The MIC of the isolates from the vancomycin containing agar plates showed a good correlation between vancomycin and avoparcin resistance, but not with teicoplanin. "The vanA gene cluster, that was shown to be present in these isolates, consists of 9 genes of which 6 are involved in conferring phenotypic glycopeptide resistance. It resides on a small Tn3-like transposon, $\operatorname{Tn} 1546^{\circ}$, and on elements that appear to be closely related (e.g. Tn5488, which thas an insertion sequence IS1251 within Tn154628,29 or is lacking $\operatorname{van} Z^{79}, 92$. Isolates with the $\operatorname{man} A$ gene clusters that lack a functional waZ gene are susceptible to teicoplanin. In this study more than $50 \%$ of the VRE were phenotypically susceptible to teicoplanin. The most prevalent rransposon variant was a $T \mathrm{n} 1546$ derivative which contained a large left end deletion including the orfl gene, an $151216 \mathrm{~V}$ insertion in the varXwar $Y$ intergenic region and a deletion of the $z a n Z$ gene. These features found in the homologous types E11, $\mathrm{E} 14$, and $\mathrm{E} 17$ were present in half of the transposon types, which were analyzed. Interestingly, type E11 and the homologous types $\mathrm{E} 9$ and $\mathrm{E} 10$ were also predominantly (9/13) present in isolates recovered from turkeys and in almost half (4/9) of the isolates recovered from rurkey farmers in the Netherland 79,92 . All $\mathrm{Tn} 1546$ variants found in the isolates from broilers and laying hens contained at position 8234 the " $G$ " which is consistent with the results reported previously $31,79,99$. This variant is also found in humans although the majorty of human isolates and all isolates recovered from pigs contain a " $\mathrm{T}$ " at this position $31,79,99$. The finding that human isolates analyzed in this study contain vanA transposon types predomi. nantly found in poultry and not the most prevalent human transposon type is again a strong indication that poultry farmers have contracted the van $A$ resistance genes from their animals. Since, the isolates recovered from poultry and poultry farmers were in most cases genetically different, it is most likely that vancomycin resistance was transmitted from farm animals to farmers through horizontal transfer of $\operatorname{Tn} 1546$ variants. From the fact that this was only found in three combinations of a farmer isolates and one of his poultry, does, however, not imply that such a transfer is a rarely occurring event. One must realize that only one isolate was tested from each sample and, therefore, the chance to detect such a combination is extremely low, but testing of more isolates was not feasible because of the workload involved. Other studies have also pointed to a similarity between vanA containing elements in animals and humans $2,16,32,77,79,99,102$. It was interesting to note that all $E$. birae isolates, irrespective whether they originated from animal or human sources contained the highly homologous vanA transposon types E1 1, E14, and E17. This could suggest a certain level of enterococcal species specificity of vanA transposon types which, to our knowledge, has never been described before. This could be observed because nor only single isolates identified as $E$. faecium were tested and is consistent with the results of Butaye et al. who found also that $50 \%$ of VRE from boilers and nearly all VRE from laying hens were $E$. birat ${ }^{13}$.

Since the EU suspension of the use of avoparcin in food animals significant decreases of the prevalence of vancomycin resistance in fecal enterococci have been observed in Danish broilers, on chicken meat in Germany ${ }^{40}$ and in Italy ${ }^{58}$ and from humans in Germany 40 . In the Netherlands the prevalence in fecal samples of broilers collected at slaughter decreased significantly ( $p<0.001$ ) berween 1997 and 1999 from $80 \%$ till $31 \%$ and in humans from $12 \%$ till $6 \%$ (p 0.05 ). This could be considered as additional evidence that food animals are the reservoir of glycopeptide re- 
sistance in fecal enterococci of healthy humans but also showed that intervention measures are effective.

In conclusion the results of this study point again to a transfer of resistant enterococci and/or enterococcal resistance genes from animals to man. Continued monitoring of antibiotic resistance and antibiotic use is necessary to study the epidemiology of resistance and to be able to evaluate the effect of intervention methods. As resistance is not restricted to E. faecium and also found in other enterococcal species, monitoring should nor be restricted to $E$. faecium isolates alone. Transfer of resistance between different species of enterococci has been described and most human enterococcal infections are caused by $E$. faecalis.

\section{REFERENCES}

1. Aurestrup, F. M. 1998. Association beween decreased suscepribility to a new antibiotic for treatment of human diseases, everninomicin ( $\mathrm{SCH} 27899$ ), and resistance to an antibiotic used for growth promotion in animals, awilamycin Microbial Drug Resistance Mechanisms Epidemiology and Disease. $4: 137-141$.

2. A.arestrup, F. M. 1995. Occurrence of glycopeptide resistance anong Enterococcus faecium isolates from conventional and ecological poultry farms Microb Drug Resist. 1:255-7.

3. Aarestrup, F. M., F. Bager, N. E. Jensen, M. Maddsen, A. Meyling, and H. C. Wegener 1998. Resistance to Antmicrobial Agents Used for Animal Therapy in Pathogenic-Bacteria, Zoonotic-Bacteria and Indicator Bacteria Isolated from Different Food Animals in Denmark - A Base-Line Study for the Danish Integrated Antimicrobial Resisrance Monitoring Program (Danmap) APMIS. 106:745-770.

4. Aarestrup, F. M., F. Bager, N. E. Jensen, M. Madsen, A. Meyling, and H. C. Wegener 1998. Survellance of antimicrobial resistance in bacteria isolated from food animals to antimicrobial growth promorers and relared therapeutic agents in Denmark APMIS, 106:606-22.

5. Arthur M., C. Molinas, F. Depardieu, and P. Courvalin 1993. Characterization of $\operatorname{Tn} 1546$, a Tn3-related ruansposon conferring glycopeptide resistance by synthesis of depsipeptide pepridoglycan precursors in Enterococcus faecium BM4147 J Bacteriol. 175:117-27

6. Bager, F., F. M. Aarestrup, M. Madsen, and H. C. Wegener 1999. Glycopeptide resistance in Enterococcus faecium from broilers and pigs following discontinued use of awoparcin Mierobial Drug Resistance Mechanisms Epidemiology and Disease. 5.53-56.

7. Bager, F, M. Madsen, J. Christensen, and F. M. Aarestrup 1997. Awoparcin used as a growth promozer is associated with the occurrence of vancomycin-resistant Enterococcus faccium on Danish poultry and pig farms Prev Ver Med. 31:95-112.
8. Bager, F, 1999. Danmap 1998. Danish Veterinary Laborarom.

9. Barriere, J. C., N. Berthaud, D. Beyer, S, DutkaMalen, J. M. Paris, and J. F. Desnottes 1998. Recent developments in streptogramin research Current Pharmaceutical Design. $4: 155-180$.

10. Bares, J. 1997. Epidemiology of Vancomycin-Resistant Enterococe in the Community and the Relevance of Farm-Animals to Human. Infection Joumal of Hospital Infeccion. 37:89-101.

11. Bates, J., Z. Jordens, and J. B. Selkon 1993 . Evidence for an Animal Origin of Vancomycin-Resistant Enterococci. Lancet. $342: 490-491$.

12. Boisivon, A., M. Thibault, and R. Leclercq 1997. Colonization by wancomycin-resistant enterococci of the intestinal tract of parients in intensive care units from French general hospi* tals. Clinical Microbiology and Infection. 3:175-194.

13. Butaye, P., L. A. Devriese, H. Goossens, M. lewen, and F. Haesebrouck 1999. Enterococi with acquired vancomycin resistance in pigs and chickens of different age groups. Antimicrobial Agents and Chemotherapy, 43:365-366.

14. Charpentier, E., G. Gerbaud, and P. Courvalin 1994. Presence of the Listeria terracycline resistance gene ter $(S)$ in Enterococous faecalis. Antimicrob Agenrs Chemother. 38:2330-5.

15. Coque, T. M. J. F. Tomayko, S. C. Ricke, P. C. Okhyusen. and B. E. Murray 1996. Vancomycin-resistant enterococci from nosocomial, community, and animal sources in the United States. Antimicrobial Agents and Chemorherapy. 2605-2609: 1996.

16. Descheemaeker, P. R. M. S. Chapelle, L. A. Devriese, P. Butaye, $\mathbb{P}$. Vandamme, and H. Goossens 1999. Comparison of glycopeptide-resistant Enterococous faecium isolates and glycopeptide tesistance genes of human and animal origins. Antumicrobial Agencs and Chemotherapy. 43;2032-2037.

17. Devriese L. A. M. Jeven, H. Goossens, P. Vandamme, 8 . Pot $_{i}$ I. Hommez, and F. Haesebrouck 1996. Presence of wancomycin-resistant enterococci in farm and per aximals. Antimicrobial Agencs and Chemotherapy, 40:2285-2287.

18. Devriese, L. A., A. w Kerchove, R. Klipper-Batly and K. H. Schleifer 1987. Characrerization and identification of Enterococcus species isolated from the incestines of animals. Int I Systematic Bacteriol. 37:257-259.

19. Durta, G. N., and L. A. Devriese 1984. Observations on the in vitro sensitivity and resistance of Gram positive integtinal. bacteria of farm animals to growth promoting antimicrobial agents. Journal of Applied Bacteriology. 56:1 17-123.

20. Edmond, M. B. S. E. Wallace, D. K. McClish, M. A. B'faller, R. N. Jones, and R. P. Wenzel 1999. Nosocomial bloodstram infections in United States hospitals: A three-year analysis. Clinical Infecrious Diseases. 29:239-244.

21. Emori, T. G., and R. P. Gaynes 1993. An overview of nosacomial infections, including the role of the microbiology laboratory. Clin. Microbiol. Rev. 6:428-442.

22. Endez, H. A. van Belkum, N. van den Bratk, ]. wan Duin, J. Kluymans, J. Koeleman, L. Spanjaard, A. Voss, A. Weersink, C. Vandenbroucke-Grauls, and H. Verbrugh Prewalence vancomycin-resistant enterococci (VRE) in hospital- and 
community-based patients in the Netherlands Study group University hospital \& CBL Rotterdam. Abstract 1998.

23. Goosens, H. 1998. Spread of vancomycin-resistant enterococci: Differences between the United Stares and Europe. Infection Control and Hospical Epidemiology. 19. $9.46-551$.

24. Gordts, B. H. Vanlanduyt, M. Ieven, P. Vandamme, and $H$. Goossens 1995. Vancomycin-resistant enterococi colonizing the intestinal tracts of hospitalized patients. Journal of Clinical Microbiology. 33:2842-2846.

25. Grayson, M. L., G. M. Eliopoulow, C. B. Wennersten, K. L. Ruoff, P. C. De Girolami, M. J. Ferraro, and R. C. Moellering $\mathrm{J}$. 1994 . Increasing resistance to beta-lactam antibiotics among dinical isolates of Enterococcus faecium: a 22-year review at one institurion. Antimicrob Agents Chemother, 35:2180-4.

26. Greko, C. 1996. Inventering av resisens mot antibacteriella medel hos enterokocker fran kyckling. Rapport National Veterinary Instixute Uppsala.

27. Guerin, F., J. D. Perrier Gros Claude, $V$. Foissand, $T$. Masseron, and J. Thierry 1998. Enterocoques resistants a la vancomycine en Firance. Haute prevalence dans une population ambulatoire de sujers jeunes. Presse Med. 27:1427-9.

28. Handwerger. $S_{.}$, and J. Skoble 1995. Identification of chromosomal mobile element conferring high-level vancomycir resistance in Enteroccocus faeciuma. Antimicrobial Agenrs and Chemotherapy. $39: 2446-2453$.

29. Handwerger, S. J. Skoble I. F. Discotto, and M. J. Pucci 1995. Heterogeneiry of the vand gene cluster in clinical isolates of enterococci from the Northeastern United States. Antimicrob Agents Chem. 39:362-368.

30. Hinton, M. 1986. "The ecology of Escherichia coli in animals including man with particular reference to drugresistance. Vet Rec. $119: 420,426$

31. Jensen L. B. 1998. Differences in the occurrence of two base pair variants of Tn1.546 from wancomycin-resistant enteroeoci from humans, pigs, and poultry. Antimicrobial Agents and Chemotherapy. 42:2463-2464.

32. Jensen, L, B., P. Ahrens, L. Dons, R. N. Jones, A. M. Hammerum, and AarestrupFn 1998. Molecular Analysis of Tn1546 in Enterococus-frecium lsolated from Animals and Humans Jounnal of Clinical Micnobiology. 36.437-442.

33. Jones, R. N., S. A. Marshall, and M. E. Erwin 1999. Antimicrobial activity and spectrum of SCH27899 (Ziracin (R) rested against Cram-positive species including recommendations for routine susceptibility testing methods and qualiry control Diagnostic Microbiology and Infecrious Disease 34:103-110.

34. Jones, R. N. H. S. Sader, M. E. Erwin, S. C. Anderson, K. A. Addridge, S. Allen, J. Anhalr, P. Appelbaum, K. L. Arrington, L. Ayers, C. Baker, K. Beavis, J. Berger, and G. Berthold 1995. Emerging multiply resistane enterococei among clinical isolates: 1. Prevalence data from 97 medical center surveillance study in the United States Diagnostic Microbiology and Infectious Disease. $21: 85-93$.
35. Kaufhold, A.y and P. Ferrieri 1993. Molecular investigation of clinical Enterococcus faecium isolates highly resistant io gentamicin Int J Med Microbiol Virol Parasitol Infect Dis. $278: 83-101$.

36. Kaufhold, A. A. Podbielski, T. Horaud, and P. Ferrieri 1992. Idencical genes confer high-level resistance to gentamicin upon Enterococcus faecalis, Enterococcus faccium, and Streprococcus agalacriae. Antimicrob Agents Chemother. 36: $1215-8$.

37. Kaukas, A., M. Hinton, and A. H. Linton 1986. Changes in the faecal enterococcal population of young chickens and its effect on the incidence of resistance to certain antibiotics. Lett Appl Microbiol. 2:5-8.

38. Kaukas, A., M. Hinton, and A. H. Linton 1988. The effect of growh-promoting antibiotics on the faecal enterococi of healthy young chickens. Journal of Applied Bacteriology. $64: 57-64$

39. Kaukas, A. M. Hinton, and A. H. Linton 1986. The speciation and biotyping of enterococcal isolates from chickens. Letrers in Applied Microbiology. 3:113-116.

40. Klare, I., D. Badstubner, C. Konstabel, G. Bohme, H. Claus, and W. Witre 1999. Decreased incidence of VanA-type vancomycin-resistant enterococci isolated from poultry mear and from fecal samples of humans in the community after discontinuation of avoparcin usage in animal husbandry Microbial Drug Resistance Mechanisms Epidemiology and Disease. 5:45-52.

41. Klare, I., H. Heier, H. Claus, G. Bohme, S. Marin, G. Seltmann, R. Hakenbeck, V. Antanassova, and W. Witte 1995. Enterococcus faecium strains with vanA-mediated high-level glycopeptide resistance isolated from animal foodstuffs and fecal samples of humans in the community Microbial Drug Resistance Mechanisms Epidemiology and Diseasse. $1: 265-272$

42. Klare, I. H. Heier, H. Claus, R. Reissbrod, and W. Witte 1995. VanA mediated high-level glycopeptide resistance in Enterococcus faecium isolates from conventional and colog. ical poultry farms. FEMS Microbiol Lerr. 125:165-71.

43. Klein, G., A. Pack, and G. Reuter 1998. Antibiotic resistance parterns of enterococci and occurrence of vancomycin. resistant enterococci in raw minced beef and pork in Germany Applied and Environmental Microbiology. 64:1825-1830.

44. Kruse, H., B. K. Johansen, L. M. Rorvik, and G. Schaller 1999. The use of avoparcin as a grownth promorer and the occurrence of vancomycin-resistant Enterococcus species in Norwegian poultry and swine production Microbial Drug Resistance Mechanisms Epidemiahogy and Disease: $135-139$.

45. Ledercq, R., E. Derlot, J. Duval, and P. Courvalin 1988. Plasnid-mediated resistance to vancomycin and reicoplanin in enterococcus faecium New Eng J Med. 319:157-161.

46. Lester, S. C., M. del Pilar, F. Wang, I, Perez-Schrel, H. Jiang, and T.F. O'Brien 1990. The carriage of Escherichia coli resistant to antimicrobial agents by healthy children in Boston, in Caracas, Venezuela, and in Qin Pu, China New Eng J Med. 323:285-289.

47. Levy, S. B., B. Marshall, S. Schluederberg, D. Rowse, and ]. Davis 1988. High Frequency of Antimicrobial Resistance in 
Human Fecal Flora Antimicrobial Agents and Chemotherapy. 32.1801-1806.

48. Linden, P. K. A. W. Pasculle, D. McDevirr, and D. J. Kramer 1997. Effecr of quinupristin-dalfopristin on the outcome of vancomycin-resistant Enterococcus faecium bacteraemia: Comparison with a conrol cohort Journal-of-AntimicrobialChernotherapy May. 39 Suppl A:145-151.

49. London, N., R. Nijster, A. Van den bogaand, and E. Srobberingh 1993. Anribiotic Resistance of Faecal Enterobacteriaceae Isolated from Heathy Volunteers, a 15-Week Follow-Up Study Journal of Ancimicrobial Chemotherapy. 32:83-91.

50. Martone, W. J. 1998. Spread of vancomycin-resistant enterococci: Why did ir happen in the United Stares? Infection Control and Hospital Epidemiology. 19:539-545.

51. McDonald, L. C., M. J. Kuehnert, F. C. Tenower, and W. R. Jarwis 1997. Vancomycin-Rresistant Enterococci Ourside the Health-Care Setting: Prevalence, Sources, and Public Health Implicarions Emerging Infectious Diseases. 3:311-317.

52. Moellering, R. C. 1991. The enterococcus: a classic example of the impact of antimicrobial resistance on therapeutic options. (The Garrod Lecture) J Antimicrob Chem. 28:1-12.

53. Murray, B. E. 1998. Diversity among Mulridrug-resistant Enterococci Emerging Infectious Diseases. 4:37-47.

54. Murray, B. E. 1990. The life and times of the Enterococcus Clin Microbiol Rew, 3:46-65.

55. Murray, B. E. 1991. New aspects of antimicrobial resistance and the resulting therapeutic dilemmas J Infect Dis. 163:1184-94.

56. Nijsten, R. N. London, A. Van den bogaard, and E, Stobberingh 1994. Resistance in faecal Escherichia colt isolared from pigfarmers and abattoir workers Epidemiology and Infection. $13: 45-52$.

57. Obrien, T. F. 1997. The global epidemic nature of antimicrobial resistance and the need to monitor and manage it locally Clinical Infecrious. Diseases. 2452-\$8.

58. Pantosti, A. M. Del Grosso, S. Tagliabue, A. Macri, and A. Caprioli 1999. Decrease of vancomycin-resistant enterococci in poultry meat after avoparcin ban Lancet. 354:741-742.

59. Patterson, J. E., and M. J. Zerwos 1990. High-Level gentamicin resistance in Enterococcus: microbiology, generic basis, and epidemiology Rev Infect Dis. 12:644-52.

60. Parterson Je, Z. M. J. 1990. High-llevel gentamicin resistance in Enterococcus: microbiology, genetic basis, and epidemiology Rev Infiect Dis. 12:644-52.

61. Perner-Gros-Claude, J. D., P. L. Courrier, J. M. Breard, V. J. L., T. Masseron, D. Garin, and e. al. 1998. Enterocoques tesistants aux glycopeptides dans les viandes. Bulletin Epidemiologique Hebdomadaire. 12:50-51.

62. Quednau, M., S. Ahrne, A. C. Petersson, and G. Molin 1998. Antibiotic-resistant strains of Enterococcus isolated from Swedish and Danish retailed chicken and pork Journal of Applied Microbiology. 84:1163-1170.

63. Reinert, R. R., G. Conrads, J. J. Schlaeger, G. Werner, W. Witte, R. Lutricken, and I. Klare 1999. Survey of antibiotic resistance among enterocoeci in North Rhine Westphatia, Germany Journal of Clinical Microbiology. 37:1638-1641.

64. Rice, E. W. , W. Messer, C. H. Johnson, and D. J. Reasoner 1995. Occurrence of high-level aminoglycoside resistance in environmental isolates of enterococci Applied and Environmental Microbiology. 61:374-376.

65. Rice, L. B., L. L. Carias, and S. H. Marshall 1995. Tn5384. a composite enterococcal mobile element conferring tesistance to erythromycin and gentamicin whose ends are directly repeated copies of 15256 Antimicrob Agents Chemother. 39:1147-53.

66. Rice, L. B., L. L. Carias, S. H. Marshall, and M. E. Bonafede 1996. Sequences found on staphylococoal betawacramase plasmids integrated into the chromosome of Enterococcus faecalis CH116 Plasmid. 35:81-90.

67. Rice, L. B., and S. H. Matshall 1994. Insertions of 15256-like element flanking the chromosomal beta-lactamase gene of Enterococcus faecalis CX19 Antimicroly Agents Chemother. 38:693-701.

68. Roberts, M. C. 1990. Characterizarion of the TeeM dererminants in urogenital and respinarory tract bacteria. Anrimicrob Agents Chemorher. 34:47:67-8.

69. Roberts, $M, C_{n}$ 1996. Tetracycline resistance determinants: Mechanisms of action, regulation of expression, genetic mobility, and distribution FEMS Microbiology Reviews. 1-24:1996.

70. Robers, M. C. and S. L. Hillier 1990. Genetic basis of tetracycline resistance in urogenital bacteria Antimicrob Agents Chemorher. 34:261-4.

71. Robredo, B., K. V. Singh, F. Baquero, B. E. Murray, and C. Torres 1999. From vanA Enterococas hire to vanA Enterococcus faccium: s study of feed supplementation with woparcin and cylosin in young chickens Antimicrobial Agents and Chemotherapy. 43:1137-1143.

72. Sader, H. M. A. P'Faller, F. C. Tenower, R. I. Hollis, and J. R. N. 1994. Evaluation and charactization of muluresistan Enterococcus faccium from 12 U.S. medical centers $\$ Clin Microbiol. 32:2840-2.

73. Schouten M. A., A. Voss, and J. A. A. Hoogkamp Korsanje 1999. Antimicrobial suscepribility pattems of enterococe catusing infections in Europe Antimicrobial Agenta and Chemotherapy. 43:2542-2546.

74. Shanahan, P. M. A., C. J. Thomson, and S. G. B. Amyes 1994. The global impace of antibiotic-resistant bacteriat their sources and reservoirs Rev med bacteriol. 5:174-182.

75. Shlaes, D. M. A. Bouver, C. Devine, I. H. Shlacs, 5, al Obeid, and R. Williamson 1989. Inducible, transferable resistance to wancomycin in Enterococcus faecalis A256 Antimictob Agents Chemother. 33:198-203.

76. Silverman, J. L. A. Thal, M. B. Peri, G. Bostic and M. J. Zerwos 1998. Epidemiologic evaluation of antimicrobial resisrance in communityacquired enterococci J Clin Microbiol. $36.830-2$.

77. Simonsen, G. S, H. Haheim, K. H. Dahl, H. Kuse, A. Lovseth, O. Olswik, and A. Sundsford 1998. Transmission of VanA-rype vancomycin-resistant enterococci and wanA resis- 
eance elements berwen chicken and humans at avoparcin-expored farms Microbial Drug Resistance Mechanisms Epidentology and Disease. 4:313-318.

78. Smith, D. W. 1999. Decreased antimicrobial resistance after changes in antibiotic use Pharmacontherapy, 19:129s-132s.

79. Stobberingh, E., A. van den Bogaard, N. London, C. Driessen, J. Top, and $\mathbb{R}$. Willems 1999. Enterococci with glycopeptide resistance in vurkeys, curkey farmets, turkey slaughterers, and (sub)urban residencs in the South of the Netherlands: Evidence for transmission of vancomycin resis. rance from animals to humans? Antimicrobial Agents and Chemotherapy. 43:2215-2221.

80. Straur, M. G. Decespedes, and T. Horaud 1996. Plasmid-borne high-level resistance to gentamicin in Enterococcus hirac, Enterococcus awium, and Enterococe us raffnosus Antimicrobial Agents and Chemotherapy. 40:1263-1265.

81. Tenover, F. C., R. D. Arbeit, P. A. Mickelsen, B. E. Muray, D. H. Persing, and B. Swaminathan 1995. Interpreting chromosomal DNA restriction patrems produced by pulsed-field gel electrophoresis: criteria for bacterial strain typing J Clin Microbiol. 33:2233-2239.

82. Tenower, F. C. 1995. The best of times, the worst of timesThe global challenge of antimicrobial resistance Pharmacy World \& Sicience. 17:149-151.

83. Thal, L. A. J. W. Chow, R. Mahayni, H. Bonilla, M. B. Perri, S. A. Donabedian, J. Silverman, S. Taber " and M. J. Zervos 1995. Characterization of antimicrobial resistance in enterococci of animal origin Anrimicrobial Agents and Chemotherapy. 39:2112-2115.

84. Thal, L. A., L. A. Welron, P. M.B., S. Donabedian, J. W. McMahon, J. W. Chow, and M. J. Zervos 1996. Antimicrobial tesstance in enterococci isolated from turkeys fed vinginlamycin 36 th Intersance Conference on Antimicrobial Agents and Chenotherapy. Sept $15-18$ New Orleans:C-120.

85. Thal, L. A. and M. I. Zerwos 1999. Occurrence and epidemology of resistance to virginamycin and streptogramins Joumal of Antimicrobial Chemotherapy. 43:171-176

86. Torres, O. R., R. Z. Korman, S. A. Zahler, and G. M. Dunny 1991. The conjugative transposon Tn925: enlancemenc of conjugal transfer by teracycline inEnterococcus facalis and mobilization of chromosomal genes in Bacillus subrilis and $\mathrm{E}$. thecal is Mol Gen Gener. 225:395-400.

87. Tutano. A. G. Ravizola, L. Petoni, T. Ceruri, L. M. Greco, E. Pitzus, G. Santimi, S. Cresti, and G. Satra 1994. A multicentre study: Staphylococous and Enterococcus susceptibility to antibiotics European Jounal of Epidemiology. 10:567-572.

88. Untley, A. H. C. C. H. Collins, J. Naidoon and R. C. George 1988. Vancomycin-Resistan Enterococci Lancer. 1:57 -58.

89. wan den Bogaard, A., N. London, C. Driessen, and E. Stobberingh 1997. Fluoroquinolone usage in animals and resistance in human facal $\mathrm{E}$. coli 36 th Inrerscience Conference on Antimicrobial Agents and Chemotherapy. Sept 28 Oat 1 Toronto: $\mathrm{C}-137$.
90. yan den Bogatard, A., N. London, C. Driessen, and E. Stobberingh 1996. Prevalence of resistant fecal bacteria in turkeys, rurkey farmers and rurkey slaughteres 36th Interscience Conference on Antimicrobial Agents and Chemotherapy. Sept 15-18 New Orleans:E-27.

91. van den Bogaard, A, N. London, and E. E. Srobberingh 2000. Antimicrobial resistance in pig faecal samples from the Netherlands (five abattoirs) and Sweden Journall of Antimicrobial Chemotherapy, 45:663-671.

92. van den Bogaard. A. E. 1997. Antimicrobial resistance-relation to human and animal exposure to antibionics lournal of Antimicrobial Chemotherapy. 40:453-454.

93. van den Bogaard, A. E., N. Bruinsma, and E. E. Stobberingh 2000. The effect of banning avoparcin on VRE carriage in the Netherlands J Antimicrob Chemother. 46: 146-148.

94. van den Boggard, A. E., P. Mertens, N. H. London, and E. E. Stobberingh 1997. High prewalence of colonization with vancomycin and pristinamycin-resistant enterococci in healthy humans and pigs in the Netherlands: is the addition of antibiotics to animal feeds to blame? J Antimicrob Chemother. $40.454-6$.

95. wan den Bogaand, A. E., and E. E. Stobberingh 1999. Anribiotic usage in animals - Impact on bacterial resistance and public health Drugs. 58:589-607.

96. van den Bogaard, A. E., and E. E. Stobberingh 1999. Contam. inarion of animal feed by multiresistant enterococci Lancer. 354:163.

97. van den Braak, N., A. van Belkum, M. van Keulen, J Vliegenthart, H. A. Verbrugh, and H. P. Endtz 1998 . Molecular characterization of vancomycin-resistant enterococi from hospitalized parients and poultry products in the Netherlands ] Clin Microbiol. 36:1927-32.

98. Wetron, L. A., L. A. Thal, M. B. Perri, S. Donabedian, ). McMahon, I. W. Chow, and M. J. Zerwos 1998. Antimicrobial resistance in enterococci isolared from Thurkey flocks fed virginiamycin Ancimicrob Agents Chemother. 42:705-8.

99. Willens, R. I. L., J. Top, N. vandenBrak, A. vanBelkum, D. J. Mevius, G. Hendriks, M. wanSanten Werhewwel, and J. D. A. vanEmbden 1999. Molecular diversity and evolutionary rellationships of Tn1546-like elements in enterococoi from humans and animals Antimicrobial Agents and Chemotherapy. $43.483-491$.

100. Winte, W., and I. Klare 1995. Glycopeptide-resistant Enterococcus faecium ourside hospitals: A commentary Micro. bial Drug Resistance Mechanisms. Epidemiology and Disease. 1:259-263.

101. Woodford, N. 1998. Glycopeptide-resistant enterococci: a decade of experience Journal of Medical Microbiology. $47.849-862$

102. Woodford, N., A. M. Adebiyi, M. F. Palepou, and B. D. Cookson 1998. Diversity of VanA glycopeptide resistance elements in enterococci from humans and non-human sources Antimicrob Agents Chemother. 42:502-8.

103. Yoshimura, H., M. Ishimaru, Y. S. Endoh, M. Suginaka, and S. Yamatani 1998. Isolation of glycopeptide-resistant enterococci from chickens in Japan Antimicrobial Agents and Chemotherapy, $42: 3333$. 
Chapter VI

\title{
Antibiotic resistance of faecal Escherichia coli from poultry, poultry farmers and poultry slaughterers
}

\author{
A.E. van den Bogaard*, N. London, C. Driessen, E.E. Stobberingh \\ * University Maastricht, Department of Medical Microbiology \\ P.O. Box 616, 6200 MD Maastricht
}




\section{ABSTRACT}

The percentage of faecall samples containing resistant Escherichata coli and the numbers of resistant $E$. coli per faecal sample, rellative to the total number of $E$. coli were derermined in faecal samples of three poultry populations: broilers and turkeys (animals commonly given antibiotics) and laying hens (with a low usage of antibiotics). In addition faecal samples were examined from five human popularions: turkey farmers, broiler farmers, laying hen farmers, broiler slaughterers and turkey slaughterers. Resistance to antibiotics commonly used in poultry medicine were tested. (including MIC determinations). Ciprofloxacin resistant strains isolated from these eight populations as well as from turkey meat were genoryped by pulsed-field gel electrophoresis (PFGE) after Smal digestion. The percentages of samples containing antibiotic resistant $E$. coli and the percentages of antibiotic resistant $E$. coli relative to the total $E$. coli population (i.e. the degree of resistance) was significantly higher in turkeys and broilers than in the laying hen population. The prevalence of antibiotic resistance in faecal $E$. coli isolated from turkey and broiler farmers, and from turkey and broiler slaughterers, was for nearly all antibiotics tested higher than those observed in laying hen farmers. Mulriresistant isolates were common in turkey and broiler farmers but absent in the laying hen farmer population. The same resistance parterns were found in turkeys, turkey farmers and turkey slaughterers and in broiler, broiler farmers and broiler slaughterers. The PFGE parterns of the isolates from the eight populations were quite heterogeneous. However, E coli with an identical PFGE pattern were isolated at two farms from a turkey and the farmer, and also from a broiler and a broiler farmer but of different farms. Moreover, three $E$. coli isolates from turkey meat were identical to faecal isolates of turkeys. The results of this study strongly indicated that transmission of resistant clones and resistance plasmids of $E$. coli from poultry to humans commonly occurred.

\section{INTRODUCTION}

Penicillin was discovered in 1928 by Sir Alexander Fleming and its clinical introduction more than 12 years later in human medicine was soon followed by other antibiotics. The use of these antibiontics was the most significant advance in the treatment of bacterial infections not only in humans but also in animals. Un fortunately, sixty years later many of these antibiotics that were formerly very effective are becoming less potent and in some cases even inactive. We are now encountering some micro-organisms that are resistant to all clinically available antibiotics. Antibiotic usage is considered the most important factor for the emergence, selection and dissemination of antibiotic resistant micro-organisms both in veterinary and human medicine ${ }^{1,2}$. Antibiotic usage not only selects for resistance in pathogenic bacteria but also in the endogenous flora of the exposed individuals (animals and humans) or populations ${ }^{3-8}$. In animals, as is the case in people, antibiotics are used for therapy as well as control of bacterial infections. In contrast to human medical therapy in intensively reared food animals antibiotics are for practical reasons usually administered to the whole flock and not just to individual animals. In addition antimicrobial agents are continuously fed to food antmals, like broilers and turkeys, for economical reasons as antimicrobial growth promoters (AMGP). Therefore the pressure by this antibiotic use to select for antibiotic resistance in bacteria in these animal populations is high. Consequently the faecal flora of food animals contains a relatively high proportion of resistant bacteria'. Most AMPG, however, that are or were commonly used in the Netherlands until recently, are mainly effective against $\mathrm{Gram}$ positive bacteria. Therefore resistance found in faecal Escherichia coli of food animals is likely to be mainly associated with veterinary use of antibiotics. During the slaughter of food animals resistant strains from the gut readily soil poultry carcasses. As a result poultry meats are often contaminated with (multi) resistant $E$. coli ${ }^{10-16}$ and also eggs ${ }^{17}$. Resistant faecal $E$. coli from poultry can reach the intestinal tract of humans not only by direct contact, but also via the food chain. These resistant bacteria can either colonise the human intestinal tracr or transfer resistance genes to the human endogenous flora. In both cases this superimposes an additional load to the resistance in the intestinal flora already present in man.

The importance of this dissemination of antibiotic resistance from animals to humans remains, however, a point of much debate. Colonisation of the human in- 
testinal tract with resistant $E$. coli of chicken origin has been shown in volunteers ${ }^{18}$. One of the first studies that presented evidence that animals serve as reservoir for $E$. coli found in humans was performed by Cooks et al in the early seventies ${ }^{19}$. Antibiotic resistant E. coli from pigs and chickens, that were brought into the hospiral kitchen on raw mear, were subsequently found in the faecal flora of hospitalised parients. Spread of an antibiotic resistant plasmid pSL222-6 in E. coli from chickens to human handlers was described by Levy et $a^{20}$. The plasmid encoding for resistance to chloramphenicol, tetracycline, sulphonamides and streptomycin that was originally present in chickens was allso detected in two of the fourteen faecal samples from family members living on the farm and from handlers. Others studies have also presented evidence on the spread of antibiotic resistant micro-organisms from poultry to humans in different countries. Linton et al found the same O-serotype in chickens from a commercial rearing centre, in oven-ready birds and in humans ${ }^{13,18}$. Oieniji described direct transmission of $E$. coli resistant to streptomycin, sulphonamide and tetracycline from poultry to poultry caretakers in Ibadan, Nigeria 21,22 . No drug resistant micro-organisms were isolated from workers outside the poultry plant. Administration of antibiotics to animals over long periods favoured the persistence of resistanc micro-organisms and resulted in a higher incidence of infections in man caused by arnibiotic resistant micro-organisms ${ }^{21,22}$ Chicken have also been described as a source of antibiotic resistance in humans in northern India ${ }^{23}$, in $\mathrm{Mo}-$ rocco 24 and in Saudi Arabia 25 . In the last study $27 \%$ of the E. coli strains isolated from patients and $11 \%$ of the chicken isolates belonged to the same serotypes. As the prevalence of multidrug resistance among isolates from chickens was significantly higher than that from patients, chickens could serwe as a source for antibiotic resistance in humans. The authors strongly recommended restricting the use of antibiotics in veterinary medicine to only the treatment of bacterial infections. Recently Bass et al ${ }^{26}$ described a high incidence of integrons encoding multidrug resistance among chicken isolates as part of transposon $\operatorname{Tn} 21$. In addition, they described the dissemination of Tn21 among pathogenic poultry isolates and suggest the possibility of the mobility of $\operatorname{Tn} 21$ among pathogenic mi- cro-organisms in humans as well as in poultry. In contrast to these studies, which describe poultry as a possible source for antibiotic resistance in humans, others have concluded that human and poultry isolates belong to two distinct pools of resistant $E$. coli. In one of the first studies analysing transfer of antibiotic resistance between animals and humans Smith concluded that the antibiotic resistance transfer was limited and that animal strains were poorer than the human ones at colonising the human alimentary tract. He stated that in view of the high prevalence of antibiotic resistance in humans, animals are not an important source of resistant $E$. coli in man 27 . Shooter et al serotyped both animal and human $E$. coli isolates using 150 O-antiseral. Of the animal strains tested $289(36 \%)$ out of 798 could be serotyped, whereas all but two out of 1580 human isolates could be typed ${ }^{28}$. They concluded that strains from animal origin may comprise other $\mathrm{O}$ groups than those present in humans. Differences in chloramphenicol and streptomycin resistance berween poultry and their caretakers in Northern India has been described 29 i.e. $26 \%$ versus $58 \%$ for chloramphenicol and $69 \%$ versus $94 \%$ for streptomycin.

The risk for human health after exposure or prolonged contact with animals was assessed in a population of female workers at a poultry abattoir, not receiving antibiotic therapy, but who had prolonged. exposure to resistant micro-organisms of animal origin. In these workers urinary tract infections were only infrequently caused by poultry isolates. Among recent antibiotic users, the resistance patterns of uropathogens, however, matched at least one of the poultry isolates. A more detailed analysis using restriction enzyme analysis of plasmid DNA showed that none of the plasmids from human isolates appeared to be related to any of the poultry isolates ${ }^{30}$. Caya er al ${ }^{31} \mathrm{com}-$ pared the phenotypes and genotypes of $E$. coli isolates from sick broilers in abattoirs in the province of Quebec with human isolates from hospitalised patients low cated in the same geographic area as the abattoir (3403). A rotal of 142 poultry isolates were compared to 91 human isolates. A higher prevalence of resistance was found among the poultry isolates especially against gentamicin, spectinomycin, tetracycline and sulfamethoxazole. Only two poultry isolates demonstrated a possible relationship with human isolates. Comparing 
E. coli isolates from a poultry processing plant in Kenya and isolates from children with diarthoea living in close contact with poultry, Kariuki et al. ${ }^{32}$ observed differences in antibiotic resistance patterns and in the levels of multidrug resistance. The authors concluded that human and poultry isolates represent two distinct pools of resistance plasmids. A similar conclusion was drawn by Nijsten et al. comparing resistance patterns of faecal E. coli isolates of pig farmers and their pigs ${ }^{33}$.

In this study the relation berween antibioric use and the prevalence of resistance in faecal $E$. colit was analysed in the following populations: broilers and turkeys, (both populations with a relarively high antibiotic use) and laying hens (with a relatively low antibiotic use). To study the possible dissemination of resistant $E$. coli or resistance genes from these poultry populations to humans the farmers, participating in the study were also requested to submit their own faecal sample. In addition faecal samples of turkey and poultry slaughterers were studied. Farmers have daily contact with their animals and are directly exposed to animal faeces. Slaughterers have daily contact with poultry carcasses or meat. All faecal samples were analysed as to the prevalence and degree of resistance in $E$. coll.

Fluoroquinolones are considered as "critical", "essential" or "last line" antibiotics for human medicine i.e. no or few alternative agents to treat serious or life-threatening infections in humans are available 34 , and are commonly used in poultry medicine. As the possibility of transfer of ciprofloxacin resistant bacteria from animals to humans, is a hotly debated issue, ciprofloxacin resistant $E$. coli isolates from poultry and humans and turkey carcasses were genotyped using pulsed-field gel electrophoresis (PFGE).

\section{MATERIALS AND METHODS}

\section{Collection of faecal samples}

Fresh faecal samples were collected from farmers in the south of the Netherlands keeping either turkeys, broilers or hens producing eggs for human consumprion. The farmers were requested to provide one fresh faecal sample from themselves and a mixed faecal sample from the oldest flock of poultry at the farm and to send these on the day of collection with the completed questionnaire to the bacteriological laboratory. In a ques- rionnaire the farmers were asked about other animals kept at the farm, recent hospital stay and antibiotic usage by themselves, family members or their animals during the three months preceding the sample collection. In addition poultry slaughterers working at a poultry-processing plant in a similar area were asked to send in a faecal specimen of themselves and to fill in the same questionnaire. The faecal samples from the turkey farmers, their turkeys and the turkey slaughterers were the same as described previously 35 . On the day of arrival at the laboratory the samples were diluted $\left(10^{-1}\right)$ in $0.9 \% \mathrm{NaCl}$, containing $20 \%(\mathrm{v} / \mathrm{v})$ glycerol and stored at $-20^{\circ} \mathrm{C}$ until assayed. In addition 50 turkey wing tips (one a day) were collected ar the end of the slaughtering line immediately after slaughtering and send frozen at $-20^{\circ} \mathrm{C}$ to the laboratory.

\section{Bacteriological analysis}

The methods used were as previously described 36,37 . In short, after thawing the samples, $10^{-2}$ and $10^{-4}$ dilutions in $0.9 \% \mathrm{NaCl}$ were inoculated on Levine agar plates (BBL 11221, Becton Dickenson BV, Etten-Leur, the Netherlands) using a spiral plater ( $S p$ piral Systems, Lameris Laboratory BV, Breukelen, the Netherlands). The antibiotics and the concentrations used in the Levine agar plates are mentioned in Table 1. The antibiotics were selected because they, or related cross reacting antibiotics, have been regularly used in poultry on veterinary prescription and on basis of their activity against $E$ coli. The concentrations used were based on NCCLS guidelines and modified where appropriate to make results comparable with those of prewious studies ${ }^{36-38}$. For trimethoprim testing 5\% lysed horse blood was added to the agar. The curkey wings were defrosted, shaken using a turrax mixer with $20 \mathrm{ml}$ of peptone water and $1 \mathrm{ml}$ of the peptone water was plated only onto a ciprofloxacin $(4 \mathrm{mg} / \mathrm{l})$ containing agar plate.

\section{Susceptibility testing}

From each faecal sample one $E$. coli colony was randomly chosen from the control plate withour antibiotics for antibiotic susceptibility testing using a micro broth dilution method in Iso-Sensitest Broth ${ }^{\text {TM }}$ (Oxoid CM473, Basingstoke, UK) using an inocullum size of $5 \times 10^{5} \mathrm{cfu} / \mathrm{ml}$. The antimicrobial agents tesred 
and the breakpoints for resistance were as follows: amoxycillin $(16 \mathrm{mg} / 1)$, chloramphenicol $(16 \mathrm{mg} / \mathrm{l})$, ciprofloxacin ( $4 \mathrm{mg} / \mathrm{l})$, flumequine $(8 \mathrm{mg} / \mathrm{l})$, gentamicin $(8 \mathrm{mg} /)$, neomycin $(16 \mathrm{mg} / \mathrm{l})$, nitrofurantoin $(64 \mathrm{mg} / \mathrm{l})$, oxytetracycline $(16 \mathrm{mg} / \mathrm{l})$, streptomycin $(32 \mathrm{mg} / \mathrm{l})$, sulfamethoxazole (128 mg/l) and trimethoprim (16 mgll). E. coli ATCC 25922 was used as reference strain.

\section{PULSED-FIELD GEL ELECTROPHORESIS}

Ciprofloxacin resistant $E$. coli isolates were genotyped using PFGE after $X b a I$ digestion. PFGE was performed as previously described with minor modifications ${ }^{39}$. The criteria of Tenover were used ${ }^{40}$ to assess similarity of the different patterns obtained.

\section{DEFINITIONS}

The prevalence of resistance to a certain antibiotic was defined as the percentage of the total number of faecal samples tested showing growth of $E$. coli on agar plates containing that antibiotic.

The degree of resistance of each sample was calculated as the ratio between the number of colonies on the agar plates with and without antibiotics multiplied by $100 \%$. Two degrees were disringuished: a high degree of resistance i.e. ratio $>50 \%$ being defined as the majority of the $E$. coli isolates of a sample showing resistance to a particular antimicrobial agent. A ratio of less than $50 \%$ was defined as a low degree of resistance.

\section{STATISTICAL ANALYSIS}

To assess significant difference in prevalence and high degree of antibiotic resistance between the different populations the chi-square test was used.

\section{RESULTS}

\section{Study population}

In toral 47 faecal samples were received from turkey farmers (i.e. about $50 \%$ of the major turkey farmers in the Nerherlands) and their turkeys and also 47 samples from turkey slaughterers. About $50 \%$ of the poultry slaughterers responded and $30 \%$ of the poultry farmers. In total faecal samples from 46 poultry slaughter- ers, 51 broiler farmers and 50 broilers, 25 laying hen farmers and 25 laying hens were received. One broiler farmer had no broilers on the farm at the time of sample collection and only sent a faecal sample of himself. None of the turkey farmers and slaughterers, or a fanily member had been hospitalised or used antibiotics in the three months proceeding sample collection. Two poultry slaughterers and one laying hen farmer had been hospitalised in the last three months. Antibiotic use during that time span was mentioned by four broiler farmers and slaughterers and by two of their respective family members. Laying hen farmers had not use antibiotics themselves but a few family members had during the three month preceding the study.

\section{Prevalence of resistance}

Of the three poultry populations tested, the highest prevalence and degree of resistance (to almost all compounds tested) was observed in the faecal samples from turkeys. This was closely followed by those from broilers, but distinctly lower in the laying hen population (Table 1). The prevalence of resistance for ciprofloxacin, flumequine and neomycin was significantly higher $(p<0.005)$ in turkeys and broilers than in laying hens. Nitrofurantoin resistance was only found in turkey isolates. For amoxycillin and oxytetracycline the percentage of samples with a thigh degree of resistance among turkey and broiler isolates was significantly higher $(p<0.005)$, compared to laying hens.

In the human populations the same tendency was observed. Turkey farmers showed the highest resistance percentages to all agents tested both in terms of prevalence and high degree of resistance. The lowest resistance percentages were observed in the laying hen farmers. The prevalence of resistance in turkey and broiler farmers was significantly higher than in laying hen farmers for amoxycillin, ciprofloxacin, flumequine, neomycin, oxytetracycline and trimethoprim. In the human populations tested the only high degree of resistance was against quinolones in turkey and broiler farmers. The resistance percentages in turkey slaughterers and poultry slaughterers were of a similar magnitude except for resistance to neomycin, which was significantly lower in turkey slaughterers $(p<0.05)$. The observed prevalence of resistance was significantly higher in slaughterers than in laying hen farmers for 
Table 1. Prevalence (Prev) and percentage samples with a high degree (HD) of antibiotic resistant faecal Escherichia coli from poultry, poultry farmers and poultry slaughterers.

\begin{tabular}{|c|c|c|c|c|c|c|c|c|c|c|c|c|c|c|c|c|}
\hline \multirow[t]{2}{*}{$\begin{array}{l}\text { Antimicrobial agent } \\
\text { (concentration mg/l) }\end{array}$} & \multicolumn{2}{|c|}{$\begin{array}{l}\text { Turkeys } \\
(n=47)\end{array}$} & \multicolumn{2}{|c|}{$\begin{array}{l}\text { Broilers } \\
(n=50)\end{array}$} & \multicolumn{2}{|c|}{$\begin{array}{l}\text { Laying } \\
\text { hens } \\
(n=25)\end{array}$} & \multicolumn{2}{|c|}{$\begin{array}{l}\text { Turkey } \\
\text { famers } \\
(n=47)\end{array}$} & \multicolumn{2}{|c|}{$\begin{array}{l}\text { Broiler } \\
\text { famers } \\
(n=51)\end{array}$} & \multicolumn{2}{|c|}{$\begin{array}{l}\text { Laying hen } \\
\text { farmers } \\
(n=25)\end{array}$} & \multicolumn{2}{|c|}{$\begin{array}{l}\text { Turkey } \\
\text { slaughterers } \\
(n=47)\end{array}$} & \multicolumn{2}{|c|}{$\begin{array}{l}\text { Broiler } \\
\text { slaughterers } \\
(n=46)\end{array}$} \\
\hline & Prev & $\mathrm{HD}$ & Prev & $\mathrm{HD}$ & Prew & $\mathrm{HD}$ & Prov & $\mathrm{HD}$ & Prev & $\mathrm{HD}$ & Prev & $\mathrm{HD}$ & Prev & $\mathrm{HD}$ & Prev & $\mathrm{HD}$ \\
\hline Amoxycillin (25) & 87 & 32 & 82 & 24 & 68 & 4 & 66 & 19 & 57 & 22 & 32 & 4 & 45 & 9 & 48 & 20 \\
\hline Ciprofloxacin (4) & 45 & 0 & 50 & 0 & 0 & 0 & 23 & 4 & 8 & 2 & 0 & 0 & 0 & 0 & 7 & 0 \\
\hline Flumequine $(16)$ & 66 & 0 & 64 & 0 & 8 & 0 & 26 & 4 & 14 & 2 & 0 & 0 & 0 & 0 & 9 & 0 \\
\hline Neomycin (32) & 81 & 0 & 72 & 2 & 24 & 0 & 57 & 6 & 20 & 2 & 8 & 0 & 32 & 0 & 54 & 15 \\
\hline Nittrofurantoin (50) & 13 & 0 & 0 & 0 & 0 & 0 & 2 & 0 & 2 & 2 & 0 & 0 & 0 & 0 & 0 & 0 \\
\hline Oxyetracycline (25) & 87 & 51 & 78 & 26 & 76 & 12 & 79 & 28 & 61 & 16 & 36 & 4 & 55 & 19 & 43 & 13 \\
\hline Trimethoprim (8) & 85 & 17 & 80 & 20 & 68 & 12 & 72 & 15 & 47 & 14 & 28 & 4 & 38 & 11 & 37 & 11 \\
\hline
\end{tabular}

Table 2. Prevalence of (multi)resistant Escherichia coll $(\%)$ in the different populations studied.

\begin{tabular}{|c|c|c|c|c|c|c|c|c|}
\hline $\begin{array}{l}\text { Number of } \\
\text { antibiotics } \\
\text { resistant } 10\end{array}$ & $\begin{array}{l}\text { Turkey } \\
(n=43)\end{array}$ & $\begin{array}{l}\text { Broilers } \\
(n=45)\end{array}$ & $\begin{array}{l}\text { Laying hens } \\
(n=20)\end{array}$ & $\begin{array}{l}\text { Turkey } \\
\text { farmers } \\
(n=45)\end{array}$ & $\begin{array}{l}\text { Broller } \\
\text { faumers } \\
(n=42)\end{array}$ & $\begin{array}{l}\text { Laying hen } \\
\text { farmers } \\
(n=20)\end{array}$ & $\begin{array}{l}\text { Tukey } \\
\text { Slaughterers } \\
(n=45)\end{array}$ & $\begin{array}{l}\text { Poultry } \\
\text { slaughterers } \\
(n=39)\end{array}$ \\
\hline 0 & $7(16)$ & $9(20)$ & $13(65)$ & $15(33)$ & $17(40)$ & $11(55)$ & $15(33)$ & $16(41)$ \\
\hline 1 & $8(19)$ & $5(11)$ & $3(15)$ & $13(29)$ & $7(17)$ & $1(5)$ & $15(33)$ & $8(20)$ \\
\hline 2 & $7(16)$ & $7(16)$ & 0 & $4(9)$ & $3(7)$ & $5(25)$ & $1(2)$ & $5(13)$ \\
\hline 3 & $2(5)$ & $7(16)$ & $3(15)$ & $2(4)$ & $3(7)$ & 0 & $3(7)$ & $1(3)$ \\
\hline 4 & $5(12)$ & $7(16)$ & $1(5)$ & $5(11)$ & $2(7)$ & $2(10)$ & $4(9)$ & $5(13)$ \\
\hline$\geq 5$ & $14(32)$ & $10(23)$ & 0 & $6(14)$ & $9(22)$ & $1(5)$ & $7(15)$ & $4(10)$ \\
\hline
\end{tabular}

Table 3. Most prevalent resistant patterns found in Escherichia coli isolates in the different populations studied.

\begin{tabular}{|c|c|c|c|c|c|c|c|c|}
\hline Antibiotic(s) & Turkeys & Broilers & $\begin{array}{l}\text { Laying } \\
\text { hens }\end{array}$ & $\begin{array}{l}\text { Turkey } \\
\text { farmers }\end{array}$ & $\begin{array}{l}\text { Eroiler } \\
\text { farmers }\end{array}$ & $\begin{array}{l}\text { Laying hen } \\
\text { farmers }\end{array}$ & $\begin{array}{l}\text { Turkey } \\
\text { slaughterers }\end{array}$ & $\begin{array}{l}\text { Poultry } \\
\text { slaughterers }\end{array}$ \\
\hline Amoxycillin & 5 & 2 & - & 8 & 2 & - & 11 & 1 \\
\hline Oxytetracycing & 2 & 2 & 2 & 3 & 2 & - & 4 & 1 \\
\hline Amoxycillin + oxytetracycine & 5 & - & - & 2 & 1 & - & 1 & 1 \\
\hline Streptonycin + sulfamethoxazols & - & - & - & - & 1 & 4 & - & 1 \\
\hline \multicolumn{9}{|l|}{$\begin{array}{l}\text { Amoxycillin + oxytetracycine + } \\
\text { streptomycin + sulfamethoxazole + }\end{array}$} \\
\hline trimethopim & 6 & 2 & & 3 & 1 & & 2 & 1 \\
\hline \multicolumn{9}{|l|}{ Amoxycillin + oxytetracycine + } \\
\hline sulfamethoxazole & & & 2 & & & & & \\
\hline \multicolumn{9}{|l|}{ Amoxycillin + sireptomycin + } \\
\hline sulfamethoxazole + trimethoprim & & & & & 1 & & & 2 \\
\hline \multicolumn{9}{|l|}{ Amoxycilin oxytetracycine + } \\
\hline streptomycin + trimethoprim & & 1 & & & 2 & & & \\
\hline
\end{tabular}


neomycin, and oxytetracycline. Also the percentage of samples with a high degree of resistance was signifcantly higher for oxytetracycline and trimethoprim and only in the broiler slaughterer population also for amoxycillin and neomycin $(\mathrm{p}<0.05)$.

\section{Antibiotic susceptibility}

In approximately $10 \%$ of the human and animal samples no $E$ coli grew on the antibiotic free control plate. This means that in these samples were less than $300 \mathrm{cfu}$ E. coli were present per gram of faeces (minimum detection level).

Resistance to five or more antibiotics was found with the highest frequency among isolates from turkeys $(32 \%)$, followed by broilers (23\%) and broiler farmers $(22 \%)$ as shown in Table 2 . The majority of the isolates from laying hens and laying hen farmers were susceptible to all antibiotics tested $(65 \%$ and $55 \%$ respectiwely). For the turkey and broiler isolates the percentage of isolates, that were susceptible to all antibiotics were significantly lower (16\% and $20 \%$ respectively).

The most prevalent resistance patterns (maximally 5) of each population are depicted in Table 3, and compared with the prevalence of these patterns in other populations. The resistance patterns most frequently observed, (especially among turkeys, turkey farmers and turkey slaughterers) were resistance to amoxycillin alone and in combination with oxytetracycline, streptomycin, sulfamethoxazole and trimethoprim. Resistance to oxytetracycline alone was found in isolates of all populations studied with exception of the laying hen farmers and oxytetracycline resistance in combination with amoxycillin mainly in turkey isolates.

The most frequent resistance pattern observed from laying hen farmers i.e. resistance to streptomycin and sulfamerhoxazole was not found among laying hen isolates. The resistance patterns found in turkey isolates was similar to those of turkey farmers and slaughterers. Resistance patterns of broilers isolates were in general also found in isolates from broiler farmers and slaughterers.

\section{Pulsed-field gel electrophoresis patterns}

The obtained PFGE patterns of the ciprofloxacin resistant isolates from turkeys $(n=21)$, turkey farmers $(n=$ 11 ), broilers $(n=25)$ and broiler farmers $(n=4)$ were

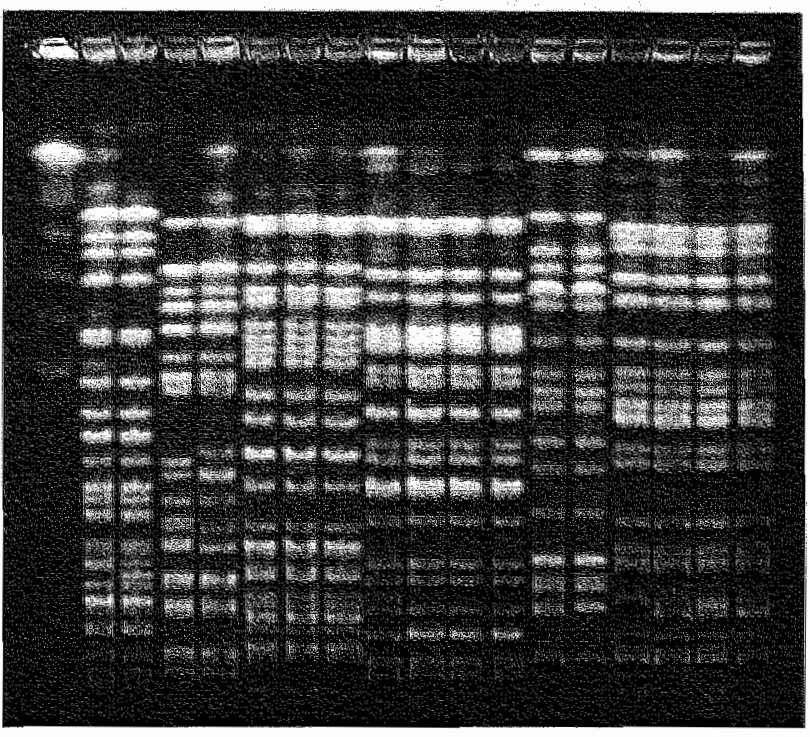

Figure 1. Pulsed-field gel electrophoresis patterns of a ciprolloxaxin resistant E. coli isolated from Turkey (T) and Turkey Farmers (TF) and Turkey Wings (TW) after digestion of total DNA with Xba.

Lane 1: molecular weight marker. Lane 2: T1, Lane 3: TF1, Lane 4: T12, Lane 5: TF12, Lane 6: T47, Lane 7: TF47, Lane 8: T27, Lane 9: T24, Lane 10: TF26, Lane 11: TF29, Lane 12: TF45, Lane 13: T28, Lane 14: TF10, Lane 15: TF28, Lane 16: TW, Lane 17: TW, Lane 18: TW

quite heterogeneous. Of the isolates from the rurkey and rurkey farmer populations 27 patterns could be discriminated. Five patterns were found both in turkeys and rurkey farmers. The patterns of three farmer isolates were identical to those of the turkeys of the same farm. The three ciprofloxacin resistant $E$. coli isolated from the turkey wings showed the same pattern as a farmer isolate (Figure 1). Also 2 broilers and broiler farmer isolates showed similar patterns but the isolates were not from the same farm.

\section{DISCUSSION}

The major factor selecting for antimicrobial resistance in bacteria is antibiotic use. For dissemination of resistant bacteria and resistance genes in populations, in addition to antibiotic consumption, important factors are crowding and poor sanitation. These three factors are typical features of intensive farming units. The prevalence and degree of resistance among bacteria of the intestinal flora of intensively reared animals is high? Ojeniyi found all $3444 E$ coli isolates from bartery 
hens to be multiresistant to antibiotics compared to none of 2284 isolates from free ranging chickens ${ }^{21}$. Antibiotics are seldom given ro laying hens producing eggs for human consumption. This is because in these adult animals less bacterial infections occur than in young animals like broilers and also farmers are reluctant to give antibiotics because the possibility of antibiotic residues in eggs. Therefore the major difference with respect to factors favouring selection and dissemination of antimicrobial resistance between the turkey and broiler population compared to the laying hen population, was that laying hens received few antibiotics. However, during the rearing period of these animals antibiotics are also commonly used and it has been shown that resistance in $E$. coli in the avian intestinal tract may persist for a long time even in the absence of selecrion by antibiotic use 41 . For the frwe rested human populations these three key factors were, however, not different, i.e. similar antibiotic consumption in aach group.

Significant higher prevalences and degrees of antibiotic resistance for nearly all antibiotics tested were observed in the turkey and broiller populations, compared to the laying hens. Resistance to 5 or more antibiotics occurred commonly in turkey and broiler isolates but not in laying hen isolates. These differences clearly reflected more recent antibiotic usage in broilers and rurkeys.

Similarty, a higher prevalence of resistance was found among faecal samples and single isolates from both turkey and broiler farmers and slaughterers compared to those from laying hen farmers. Moreover the same resistance pattems were found in turkeys, turkey farmers and slaughcerers and in broilers, broiler farmers and broiler slaughterers. Dissemination of resistant bacteria and/or resistance plasmids from turkeys and broilers to their respective farmers is the most likely explanation for the high antimicrobial resistance observed in the faecal $E$. colli of the farmers and slaughterers as there had been no difference of any importance in antibiotic consumption among these populations and the use of antibiotics was also very low. Both the prevalence and high degree of resistance to neomycin was very high in the broiler slaughterers compared to other human populations. As neomycin resistance was higher in turkeys than in broilers, it is unlikely that this was caused by direct contact with poultry mear prod ucts. However, the same phenomenon has been obserwed in another study in pig slaughterers ${ }^{42}$. The common use in that specific abattoir of neomycin containing ointments for treatment of minor cuts and skin diseases, both occupational diseases for slaughterers could have provoked this high resistance. No information, however, about the use of ointments could be obtained from the two abattoirs in the present study.

A striking observation was the difference in resistance to ciprofloxacin i.e. respectively $45 \%$ and $50 \%$ for turkey and broiler isolates, $25 \%$ and $8 \%$ for their respective farmers and $7 \%$ for broiler slaughterers. These relarively high percentages especially among the animal isolates were very likely due to the therapeuric use of fiuoroquinolones in poultry. The use of flumequine and enrofloxacin accounts for $14 \%$ of all antibiotic use in poultry, especially in turkeys and broilers ${ }^{43}$. Enrofloxacin is a methylester of ciprofloxacin and borh molecules are completely cross resistant. Flumequine, the first fluoroquinolone developed, might select for low level resistance against ciprofloxacin just as nalidixic acid does 44,45 . In the Netherlands fluoroquinolones usage in humans is low and tesistance in faecal $E$. coli in the open population is mearly absent ${ }^{38,42,46}$. Similarly, because no formulation for mass medication of pigs is on the market in the Netherlands, enrofloxacin use in pigs is low and the prevalence of resistance of faecal $E$ coli in pigs is approximately two percent, in pig farmers one percent and in pig slaughterers less than one percent $t^{37,42,47}$.

As resistance to fluoroquinolones occurs by chromosomal mutations, all sufficiently large populations of bacteria will probably contain small numbers of spontaneously resistant mutants, which may then undergo clonal expansion under the selective pressure of fluoroquinolone use resulting in a increased prevalence of resistance. This will in first instance only occur within the population, but as the numbers of resistant bacteria within that population (degree of resistance) increase the chance of spilling over to other populations became larger. This is what likely has occurred in the Dutch poultry and poultry farmer populations. Absence of resistance among poultry and turkey slaughterers suggested that daily intensive contact with animals and their faeces, like farmers have, is a higher risk 
factor for transfer of resistant clones than handling poultry carcasses and meat.

A similar course of events have been described in Spain, where the increased use of fluoroquinolones for therapy in humans, was followed by increase in resistant $E$. coli from urinary tract infections up to $18 \%{ }^{48}$, 49. Prior exposure of a patient to a fluoroquinolones was the single most important risk factor for an infection, mostly urinary tract infections, with a fluoroquinolones resistant $E$. coli. Further analysis as to the prevalence of fluoroquinolone resistant $E$. coli in the intestinal tract of healthy persons showed a prevalence of $24 \%$ in adults and of $26 \%$ in children. Carriership is the healthy population was not correlated with previous quinolone use, which constituted a strong argument for the pre-existence of resistant strains in the community.

As the prevalence of fluoroquinolone resistance in faecal E. coli of Spanish chickens and pigs is very high: $90 \%$ and $45 \%$ respectively, they postulated that food animals were the primary reservoir for fluoroquinolone resistance in humans. Fluoroquinolone use in humans might have caused a further selection in the human intestinal tract and a secondary dissemination in the human population. However, as they did not genorype the resistant isolates, they could not prove that clonal transmission had occurred.

In this study PFGE of ciprofloxacin resistant isolates from turkey and turkey farmers, and broiler and broiler farmers showed a variety of patterns but in two combinations of a turkey farmer and his rurkeys and in one broiler farmer and a broiler identical patterns were observed, which showed that identical clones were present in humans and in poultry. Moreover, the ciprofloxacin resistant $E$. coli isolates from the turkey wings tips showed similar patterns as in those from turkey farmers.

Because of the relatively low sensitivity of the method used in this study (only one $E$. coli was tested from each sample), it is possible that clonal transmission of resistant bacteria from animals to humans is occurring much more frequently than the data in this study suggest. The results in the present study strongly suggest a spread of antibiotic resistant $E$. coli from animals to people. High antibiotic use in turkeys and broilers appears to be the cause for the high resistance against antibiotics in the faecal flora of these animals and appears to be a risk for the respecrive farmers. Most likely these resistant bacteria have also been disseminated but at a lower scale to the consumers of poultry meats and therefore are present in the Durch human population at a low level. Therefore it is likely that further increase of fluoroquinolone use in human primary health care will not only be followed by a clonal expansion of these resistant strains, that are already present in the human intestinal flora, but that, as a result the isolation of fluoroquinolone resistant $E$. coli from infections in humans will increase, as already has been noticed among uroparhogenic E. coli isolates 50 .

\section{REFERENCES}

1. Witte, W. (1998). Medical Consequences of Antibionic Use in Agriculture. Science 279, 996-997.

2. Neu, H. C. (1992). The crisis in antibiotic resistance. Science $257,1064-73$.

3. Hinton, M., Al Chalaby, Z. A. M. and Allen, V. (1982). The persistence of drug resistant Escher"ichia coli in the incestinal flora of healthy broiller chicks., Journal of Hygiene, 269-278.

4. Baldwin, B. B., Bromel, M. C., Aird, D. W., Johnson, R. L., and Sell, J. L. (1976). Effect of dietary oxytetracycline on microorganisms in turkey faeces., Poult. Sci. 55,2147-2154.1

5. Howe, K., and Linton, A. H. (1976). The effect of tetracycline on the colform gut flora of broiler chickens with special reference to antibioric resistance and $O$-gerotypes of Escherichis coli., Joumal of Applied Bacreriology, 453-464.

6. Chaslus Danda, E., Guillor, J. F., and Lafonc, J. P. (1979). [Evolution of bacterial antibioresistance in poultry beeding flocks (aurhor's transl)] Evolution de l"antibioresistance bacterienne dans des eldevages awicoles. Aun. Rech. Ver. 10 , $77-86$

7. wan den Bogaard, A. E. (1997). Antimicrobial Resistance Relarion to Human and Animal Exposure to Antibiotics. Journal of Antimicrobial Chemotherapy $40,453-454$.

8. Piddock, L. I. V. (1996). Does the use of antimicrobial agents in veterinary medicine and animal husbandry select antibiotic-resistant bacteria that infect man and conpromise antimicrobial chemotherapy?, Journal of Antimicrobial Chemotherapy $38,1.3$.

9. van den Bogaard, A. E., and Strobberingh, E. E. (1999). Antibiotic usage in animals - Impact on bacterial resistance and public health., Drugs $58.589-607$.

10. Caudry, S. D., and Stanisish, V. A. (1979). Incidence of antibiotic resistant Escherichia coli associated with frozen chicken carcasses and characterizacion of conjugative R-plasmids derived from such strains, Antimicrobial Agents Chemotherapy $16,701-709$. 
11. Nazer, A. H. (1980). Transmissible drug resistance in Escherichia coli isolated from poulery and their carcasses in Iran. Cornell Vet 70, 365-371.

12. Bensink, J. C. and Bothatin, F. P. (1983). Antibiotic resistant coliform bacilli, isolated from freshly sllaughered poultry and from chilled poultry at retail oudecs., Australian Veterinary Journal $60,80-83$.

13. Linton, A. H., Howe, K., Hartey, C. L., Clements, H. M., Richmond, M. H., and Osbome, A. D. (1977). Antibiotic resistance among Escherichia coli $O$-serorypes from the gur and carcases of commercially slaughtered broiler chickens: a potential public healnh hatard, Journat Applied Bacteriology $42,365-378$.

14. Chastus Dancla, E., and Lafone, J. P. (1985). IncH plasmids in Eschericha coli strains isolated from broiller chicken carcasses. Applied and Enwironmental Microbiology 49. 1016-1018.

15. Jayaratne, $A_{\text {, }}$ Collins Thompson, D. L., and Trevors, J. T. (1990). Occurrence of aminoglycoside phosphotransterase subclass I and II structural genes among Enterobacteriaceate spp. isolated from meat samples, Appl. Microbiol. Biotech. $33,547-552$.

16. Turtura, G. C., Massa, $S$, and Ghazvinizadeh, H. (1990). Antibiotic resistance among coliform bacteria isolated from carcasses of commercially slaughtered chickens, Int. I. Food Microbiol. 11 1, 351-354.

17. Lakhotia, R. L., and Stephens, J. F. (1973). Drug resistance and $R$ factors among enrerobacteria isolated from eggs., Poultry Science 52, 1955-1962.

18. Linton, A. M., Howe, K., Bennert, P. M., and Richmond, M. H. (1977). The colonization of the human gut by antibiotic resistant Escherichia coli from chickens. Joumal of Applied Bacteriology 4 3, 465-46\%.

19. Cooke, E. M., Braden, A. L., Shooter, R. A., and O' Fartell, S. M. (1971). Antibiotic sensitiviry of Escherichia coli isolated from anmals, food, hospital patients, and normal poople, Lanoer 2, 8-10.

20. Levy, S. B. FitzGerald, G. B., and Macone, A. B. (1976). Spread of antibioric-resistant plasmids from chicken to chicken and from chicken to man., Nature $2606546,40-42$

21. Ojeniyi, A. A. (1985). Comparative bacterial drug resistance in modem battery and free-mange poultry in a tropical environment., Veterinary Record 117, 11-12.

22. Ojeniyi, A. A. (1989). Direct transmission of Escherichia coli from poultry to humans. Epidemiology and Infecrion 103. 513.522

23. Mahipal, S. Chaudhry, M. A., Yadava, J. N. S., and Sanyal, S. C. (1992). "The spectrum of antibiocic resistance in human and veterinary isolates of Escherichia coli collected from 1984-86 in Northern India.. Journal of Antimicrobial Chemotherapy, 159-168.

24. Amara. A., Ziani, Z., and Bouzouba, K. (1995). Antibiotic resistance of Escherichas coli strains isolated in Morocco from chickens with colibacillosis. Veterinary Microbiology 43. $325-330$.
25. Al Ghamei, M. S., El Morsy, F., Al Musrafa, Z. H. A Ramadhan, M., and Hanif, M. (1999). Antibiotic resistance of Escherichia coli isolated from poulny workers, patients and chicken in the eastern province of Saudi Arabia., Tropical Medicine and International Health 4, 278-283.

26. Bass, L., Liebert, C. A. Lee, M. D., Summers, A. O., Whire, D. G., Thayer, S. G., and Maurer, J. J. (1999). Incidence and characrerizarion of integrons, generic elements mediaring multuple-drug resistance, in avian Escherichia coli., Antimicrobial Agents and Chemotherapy 43, 2925-2929.

27. Smith, H. W. (1969). Transfer of antibiotic resistance from animal and human strains of Escherichia coli to resident $E$. coli in the alimentary tract of man., Lancer $1,1174-1176$.

28. Shooter, R. A., Cooke, E. M., O'Farrell, Berrelheim, K. A., Chandler, M. E., and Bushrod, F. M. (1974). The isolation of Escherichia coli from a poultry packing station and an abatoir., J. Hyg. Camb. 73, 245-247.

29. Kapoor, K. N., Mallick, B. B., and Kulshrestha, S. B. (1978). A note on the drug resistance of $\mathrm{E}$. coli isolares from chickens and their close attendants., Indian Journal of Animal Sciences $48,150-151$.

30. Parsonnet, K. C., and Kass, E. H. (1987). Does prolonged exposure to antibioric-resistant bacteria increase the rate of antibiotic-resistant infection?, Antimicrobiology Agents Chemotherapy 31.911-914.

31. Caya, F., Faatbrother, I. M., Lessard, L., and Quessy, 5. (1999). Characterization of the risk to human health of pathogenic Escherichia coli isolates from chicken carcasses. Joumal of Food Protecrion 62,741-746.

32. Kariuki, $S_{n}$, Gilks, C. F, Kimari, J., Muyodi, J., Wayaki, P., and Hart, C. A. (1997). Plasmid diversity of multi-drugresistant Escherichia coli isolated from children with diarmoea in a poultry-farming area in Kenya, Annals of Tropical Medi. cine and Parasitology 91, 87-94.

33. Nijsten, R., London, N., van den Bogaard, A., and Stobberingh, E. (1995). In-vivo transfer of resistance plasmids in rat, human or pig-derived intestinal flota using a tat model. Journal of Antimicrobial Chemotherapy 36, 975-985.

34. Conkanment of bacterial resistance in food animals WHO, Geneva (2000).

35. Stobberingh, E, van den Bogaard, A. London, N., Driessen, C., Top, J., and Willems, R. (1999). Enterococci winh glycopeptide resistance in turkeys, rurkey farmers, turkey slaughterers, and (sub)urban residents in the South of the Nerherlands: Evidence for transmission of vancomycin resistance from animals to humans?, Antimicrobial Agents and Chemotherapy $43,2215-2221$.

36. London, N., Nijsten, R., van den Bogaard, A., and Stobberingh, E. (1994). Carriage of antibiotic-resistant Esche richia coli by healthy volunteers during a 15 -week period. Infection 22, 18?-192.

37. Nijsten, R., London, N., van den Bogard, A., and Srobberinglh, E. (1996). Antibiotic-Resistance Among Escherichia coli Isolated from Fecal Samples of Pig Farmers and Pigs. Journal of Antimicrobial Chemotherapy 37, 1131-1140. 
38. Bonten, M., Srobberingh, E., Philips, J., and Houben, A. (1992). Antribiotic resistance of Escherichia coli in fecal samples of healthy people in two different areas in an industrialized country "Infection 20, 258-262.

39. Conrad, S., Oethinger, M., Kaifel, K., Klotz, G., Marre, R., and Kern, W. V. (1996). gyrA mutations in high-level Auoroquinolone-resistant dinicall isolates of Escherichia coli., Journal of Antimicrobial Chemotherapy 38, 443-455.

40. Tenover, F. C., Arbeir, R. D., Goering, R. V., Mickelsen, P. A. Murray, B. E., Persing, D. H., and Swaminathan, B. (1995). Interpreting chromosomal DNA restriction patterns produced by pulsed-field gel elecrophoresis: criteria for bacterial strain typing, Journal Clinical Microbiology 33 , 2233-2239.

41. Chashus Danda, E., Gerbaud, G., Lagorce, M., Lafont, J. P., and Courvalin, P. (1987). Persistence of an ancibiotic resistance plasmid in intestinal Escherichia coli of chickens in the abrence of selective pressure, Antimicrobial Agents and Chemotherapy 31, 784-788.

42. Nijsten, R., London, N., van den Bogaard, A., and Stobberingh, E. (1994). Resistance in faccal Escherichia coli isolated from pigfarmers and abattoir workers., Epidemiology and Infection $113,45-52$.

43. van den Bogaard, A., Breeuwsma, A. J., Julicher, C. H. M., Mostert, A., Nieuwenhuijs, J. H. M., Vaarkamp, H., Verhoeff, I., and Vulto, A. (1994). Veterinary Antibiotic Policy; Recommendations of a workgroup., Tijdschrift Voor Diergeneeskunde 119, 160-183.

44. Wray, C., Piddock, L. J. V., and McLaren, I. M. (1991). Nalidixic acid-resistant salmonellas from animals [[Abstract] ], Journal of Medical Microbiology 34 (4).
45. Medders, W. M., Wooter, R. E., Gibbs, P. S., Shorrs, E. B., and Brown, ]. (1998). Mutation-Rate of Avian Intestinal Coliform Bacteria When Pressured with Fluoroquinolones., Avian Diseases 42, 146-153.

46. London, N., Nijsten, R, van den Bogarad, A., and Stobberingh, E. (1993). Antibiotic Resistante of Faecal Enterobacteriaceae Isolated from Healthy Volunteers, a 15-Week Follow-Up Study., Joumal of Antimicrobial Chemotherapy $32,83-91$.

47. wan den Bogaard, A., London, N., Driessen, C., and Stobberingh, E. (1997). Fluoroquinolone usage in animals and resistance in human faecal $\mathrm{E}$. coli., 36h Interscience Conference on Antimicrobial Agents and Chemotherapy Sept 28- Ocr $\mathbb{L}$ Toronto, C-137.

48. Oteo, J., Aracil, B., Hoyo, J. F, Perianes, J., Gomez Garces, J. L, and Alos, J. I. (1999). Do the quinolones still constitute walid emperical therapyfor community-acquired urinary aract infection in Spain?. Clinical Microbiology Infecrion 5, 654 $-656$.

49. Garau, J., Xercawins, M., Rodriguez Carballeira, M., Gomez Vera, J. R., Coll, I., Vidal, D., Llovet, T, and Ruiz Bremon, A. (1999). Emergence and dissemination of quinolone-resistant Escherichia coli in the community, Antimicrobial Agents and Chemorherapy 43, 2736-2741.

50. Goetsch, W, wan Pelt, W., Nagelkerke, N., Hendrix, M. G. R., Buiting, A. G. M., Perit, P. L., Sabbe, L. J. M., van Griethuysen, a. j. an, and de Neeling, A. J. (2000). Increasing resistance to fusoroquinolones in Escherichia coli from urinary tract infecrions in the Netherlands., Journal Antimicobial Chemotherapy $46,223-228$. 
Chapter VII

The effect of flavophospholipol on the prevalence and degree of resistance of the faecal flora of fattening pigs under field conditions, using Escherichia coli and enterococci as indicator bacteria

\begin{abstract}
A.E. van den Bogaard*, M. Hazen*, M. Hoyer**, P. Oostenbach** and E.E. Stobberingh*
*Department of Medical Microbiology, University Maastricht, P.O. Box 616, NL-6200 MD Maastricht,

**Intervet International, Whesbaden, Germany
\end{abstract}




\section{ABSTRACT}

A "plasmid curing effect" of multiresistant Escherichia coli by flavophospholipol, an antibiotic used as antimicrobial growth promoter (AMGP) in animal feeds, has been described to occur in vitro and in vivo. To study this effect of flavophospholipol under field conditions the prevalence and degree of resistance (proportion of resistant strains to the total numbers present per $\mathrm{g}$ faeces) of indicator bacteria: $E$. coli and enterococci, was determined in faecal samples of three groups of pigs originating from the same breeder and fattened at the same commercial farm in three different compartments under identical conditions. During the last 12 weeks before slaughtering the pigs in compartment $A$ were fed a commercial finisher feed without any AMGP (negative control group), in compartment B the same feed with $9 \mathrm{mg} / \mathrm{kg}$ flavophospholipol (study group) and in compartment C with $15 \mathrm{mg} / \mathrm{kg}$ avoparcin (positive control). Faecal samples of each pig were collected at the start and at the end of the study and assessed for the prevalence and degree of resistance against antibiotics either commonly used for therapy in pig medicine or as AMGP. Before the start of the study all pigs were colonised with multiresistant $E$. coli by mixing three resistant pig isolates through their feed after a three day course with lincomycin and spectinomycin. Antibiotic use either for prevention or for therapy in the three groups of pigs was similar during the study period.

At the end of the study no significant difference in performance (rechnical results) between the three groups were observed. The overall prevalence and degree of resistance of $E$. coli in the faecal flora increased significantly in groups $A$ and $C$, but remained at the same level as at the start of the study in group B. Before the study the numbers of vancomycin resistant enterococci (VRE) in all three groups were below the detection limit of the laboratory methods used. At the end of the study the prevalence of vancomycin resistance was $44 \%$ and $41 \%$ in group $A$ and $B$ respectively but only very low numbers of VRE per $\mathrm{g}$ faeces were found. In the avoparcin fed group the prevalence was. $72 \%$ and in $57 \%$ of the samples more than $50 \%$ of all enterococci present were vancomycin resistant. Only in the Hawophospholipol exposed group the prevalence of resistant $E$ faecalis increased from $23 \%$ before the start of the study to $43 \%$ at the end of the study. It was concluded that flavophospholipol effectively suppresses the augmentation and dissemination of multiresistant $E$. coli in the intestinal flora of fattening pigs and that avoparcin use strongly selects for VRE. Because flawophospholipol nor any related molecule is used therapeutically, no cross-resistance with therapeuric antibiotics exists and no transmissible resistance has been shown, the benefir of a major decrease of resistance in intestinal E. colt of flavophospholipol fed animals seems to outweigh the small increase of the risk of transfer of flawophospholipol resistant E. faecalis from animals to humans via the food chain.

\section{INTRODUCTION}

The interest in antimicrobial resistance has increased considerably in recent years, mainly because of resistance problems in hospitals $25,44,46$. Despite the fact that these problems are largely caused by the inevitable high usage of antibiotics in hospital setrings, it has become clear that the selective pressure of antibiotic use in other populations e.g. healthy people outside hospitals and animals, also contributes to the problem ${ }^{37}$, 38.53. Many hospital infections these days are so called endogenous infections, which means that immunocompromised patients are infected by their own intestinal flora. The prevalence and degree of resistance found in indicaror bacteria of the intestinal flora: Escherichiat coli and enterococci, of different human populations are proportional to the amounts of antibiotics used by these populations and correlate with the classes of antibiotics used. Moreover they are predictive of the resistances to be found in human pathogens isolated from the same populations 37,39 . Therefore 4 thas been proposed that a low level of resistance in the endogenous flora of man should be considered a public health goal like a normal blood pressure and low cholesterol levels ${ }^{37}$.

Humans in close contact with food animals like farmers have a higher prevalence and degree of resistance in their faecal flora, closely related to the resistances found in their animall 69 . Molecular microbiological techniques have made it feasible to trace the transfer of resistant bacteria and resistance genes from 
these animals via the food chain to the human endogenous flora and finally to human pathogens. This has been shown by several authors $30,31,66$.

Therefore, a low level of resistance in the intestinal flora should be considered as at safety and benchmark for food animals ${ }^{69}$. Moreover, not only will this protect public health, but it might also help to safeguard the future efficacy of antibiotics used in animals on veterinary indication.

The most effective way to decrease the prewalence and degree of resistance in faecal indicator bacteria is to reduce the amount of antibiorics used in a population. In food animals antibiotics are not only used for therapy and prevention of bacterial infections, but are also added continuously to animal feeds as antimicrobial growth promoters (AMGP) to enhance growth, improve feed conversion and to decrease waste production. In Europe more than $30 \%$ of all antibiotics used in animals are used for growth promotion, but in some countries this percentage is even higher e.g. in the Netherlands nearly $50 \% 68$. This continuous feeding of antibiotics to animals causes a strong selection force for resistance against these and related antibiotics in particular (cross-resistance) and via co-selection for multiresistance against other antibiotics for which the resistance genes are located on the same plasmid. This is the reason that it has been proposed from several sides to phase out the usage of antibiotics as AMGP 12, $32,51,58,64$

The most imporrant way of emergence and dissemination of resistance in bacteria in the gut, is the spread of plasmids carrying resistance genes among and between the many species of bacteria in the intestinal flora of animals. So if there would be a safe substance that could be fed to animals and either eliminates resis. tance plasmids from bacteria or prevents transfer of these plasmids between intestinal bacteria, the prevalence and degree of resistance of bacteria in the intestinal flora of these animals might be reduced significantly.

A plasmid curing effect in $E$ coli and other enterobacteriaceae has been described for mitomycin, rifampicin and flavophospholipol, and, for non antibioric substances such as acridine orange, acriflavine and nitroacridine $11^{9,14}$. Of these molecules only flavophospholipol has been licensed for use in pigs, calves and poultry. Further research, however, has shown that flavophospholipol, as described for another phospholipid antibiotic macarbomycin ${ }^{41}$ had no plasmid curing effecr but suppressed plasmid transfer depending on the plasmid involved and selectively inhibited the growth of bacteria harbouring certain plasmids 36 , 59. In vitro flavophospholipol decreased the rransfer frequency of some R-plasmids in $E$ coll, but had no effect on the transfer of other types of R-plasmids. It also inhibited the growth of bacreria harbouring certain R-plasmids but not had no effect on other strains ${ }^{23}$, 57,77 . These differences are most likely caused by an increased susceptibility for flavophospholipol of bacteria with sex pili and pilin protein precursors in the bacterial cell wall 77 . Corpet, using a mouse model showed that animals given flavophosphollpol in their drinking water, had significandy less terracycline resistant $E$. coli in their faeces than control animals ${ }^{13}$.

Also in studies with limited numbers of pigs and calves, addition of flavophospholipol as AMGP to the feed caused a decrease in resistance against ampicillin, tetracyclines, streptomycin and/or sulphonamides in faecal $E$. coli and/or salmonellace $15-17,56,60,61$. Rifampicin has also been shown to decrease the prevalence of multiresistant $E$. coli in the faecal flora of pigs ${ }^{33}$.

Flavophospholipol, also known as bambermycins or moenomycin, is a phosphorus containing glycolipid antibiotic in which the lipid moiety (moenocinol) is a C-25 compound structurally analogous to undecaprenylphosphate 54 and is produced by a group of Streptomyces spp. including S. ghanaensis $14,29,63,76$. It inhibits the peptidoglycan synthesis in the cell wall by inhibining peptidoglycan polymerases through impairment of the transglycolase activities of penicillin binding proteins. $(P B P s)^{28,73,74}$. There is, however, no cross resistance between $\beta$-lactam antibiotics and flavophospholipol, as they act on different PBP 50 .

Flavophospholipol is mainly effecrive against Gram positive bacteria, because it cannot penetrate the outer membrane of Gram-negative bacteria. However, some activity against Pasteurella spp. and Brucella spp. has been reported ${ }^{28}$. Its spectrum is similar to that of penicillin and to some extends to that of macrolides. It covers staphylococci and streptococci. Enterobacteriaceae such as salmonellae and $E$. coli, are only slightly susceptible $^{36}$. 
As flavophospholipol is not used therapeurically no official breakpoints for resistance have been determined and very few data on acquired resistance against flavophospholipol are available. Clostridium perfringers and E. faecium are considered intrinsically resistant $t^{18,21,22}$ but some susceptible strains of $E$ faccium have been reported recently ${ }^{2}$. Differences in PBPs between the different species of enterococc might explain the different susceptibilities among enterococcal species $^{78}$. In a large collecrion of Staphylococcus aureus isolates from chickens and chicken slaughterers, no resistance against flavophospholipol was detected 27 .

No publications about genes conferring resistance to flavophospholipol, transfer of resistance or other resistance determinants in bacterial hosts were found. So far: no cross-resistance with other non phosphorolipid class antibiotics has been shown.

At the moment it is used as AMGP in pig, calf and poultry feeds only. Neither flavophospholipol nor any relared molecules are used for therapy in human or veterinary medicine. It is not absorbed to any great extend from the gut after oral administration ${ }^{6,52,76}$ and when parenterally administrated it is excreted unchanged via the urine but at a very slow rate ${ }^{52}$. It has, therefore, a very prolonged activity in blood 76 . In chickens given feed containing $20 \mathrm{mg}$ per $\mathrm{kg}$ flavophospholipol no residues were detected in tissues and organs ${ }^{43}$.

Limited information is available on the effect of flavophospholipol containing feeds on the intestinal flora of food animals and the results of studies are variable. In studies with pigs and calves the duration and the numbers of salmonellae excreted were reduced ${ }^{15-17}$, but in other studies using chickens a decrease $^{7}$, no effect ${ }^{24}$ (Humpert 1991 \#4), or a slight increase in excretion was observed ${ }^{55}$. Flavophospholipol has been shown to reduce the numbers of $C$. perfringens in the faecal Hora of chickens despite its unsusceptibillity in vitro 7,62 .

\section{AIM OF HE STUDY}

This study was performed to study the effect under field conditions of the use of flavophosholipol (9 $\mathrm{mg} / \mathrm{kg}$ Flavonycin ${ }^{\mathrm{TM}}$, Intervet International, Wiesbaden, Germany) as AMGP in pig feed on the preva- lence and degree of antibiotic resistance of E. coli and enterococci in the faecal flora of fattening pigs.

\section{MATERIALS AND METHODS}

\section{Animals}

Three groups of fattening pigs, originating from the same breeder were individually weighed at arrival and, based on weight basis and gender, equally divided in three groups of 56 animals. Each group was housed in a separate compartment of the same pig stable under identical conditions. The animals had free access to feed and water was supplied twice daily. During the first four weeks after arrival at the farm all pigs were fed a starter pig diet containing $100 \mathrm{mg} / \mathrm{kg}$ tylosin (Tylan-100 premix 10\% TM, Elanco Animal Health, Nieuwegein, the Netherlands) and from week 5 until slaughtering at week 17 the same commercial finisher pig feed with the exception of differences in inclusions of AMGP. The pigs in compartment A (negative control) received feed containing no $A M P G$, in compartment B (study group) feed containing $9 \mathrm{mg} / \mathrm{kg}$ flavophospholipol and in compartment $\mathrm{C}$ (positive control) feed with avoparcin $(15 \mathrm{mg} / \mathrm{kg}$ ).

Once daily the animals were observed by an animal caretaker for general health status and for any clinical symproms of disease, to insure constant feed and water supply and check the proper functioning of heating and wentilation systems. The amounts fed to the pigs were recorded separately for each compartment. During the loading of the truck for transport to the abattoir all pigs were individually weighed again.

\section{COLONISATION OF THE ANIMALS WITH MULTIRESISTANT E. COLI}

Immediately after arrival all animals were treated orally with a lincomycin-spectinomycin combination (Lincospectin 12.5\% TM, Pharmacia \& Upjohn Animal Health, Woerden, the Netherlands) for three days to disturb the intestinal flora and facilitate colonisation by multiresistant $E$. coli strains. Lincospectin $12.5 \% \mathrm{TM}$ (240 g) was dissolved in $2400 \mathrm{ml}$ water. One hundred $\mathrm{ml}$ of this solution was thoroughly mixed through $7 \mathrm{~kg}$ of pig feed and the feeding trough of each pen was filled with this mixture on day 1,2 , and 3. Cultures of three 
multiresistant non-pathogenic E. coli strains, originally isolated from pig faeces in a former study 49 were prepared by growing them overnight in $800 \mathrm{ml}$ of brain heart infusion (CM225 Oxoid, Basingstone, UK). The next morning the three bottles were mixed together resulting in $2400 \mathrm{ml}$ of an $E$. coli mixture containing approximately $0.5 \times 10^{9} \mathrm{CFU}$ of each strain per ml. Of this mixture $13 \mathrm{ml}$ was mixed through $1 \mathrm{~kg}$ of pig feed. After emprying the troughs, if necessary, in the morning of day three, $7 \mathrm{~kg}$ of feed, mixed with the bacterial suspension containing $4 \times 10^{11} \mathrm{CFU} E$. coli and the antibiotic solution, was given to each pen containing 7 animals. On day 4 and 5 again a freshly prepared culture identical to that used on day 3 was mixed through the feed, but without the antibiotic solution and again $7 \mathrm{~kg}$ were supplied to each pen.

\section{FAECES SAMPLING}

During week 4 individual faecal samples of approximately $25 \mathrm{~g}$ from all pigs present in the three compartments were collected directly from the anus in plastic containers marked with the identification code of the pig and stored in an icebox for transport to the laboratory. At the day of collection the faecal samples were diluted $1: 10$ in peptone water containing $20 \%(\mathrm{v} / \mathrm{v})$ glycerol, kept overnight at $+4^{\circ} \mathrm{C}$, then frozen at $-70^{\circ} \mathrm{C}$ and stored subsequently at $-20^{\circ} \mathrm{C}$ until assayed. This was done in the laboratory. The same procedure was repeated in week 10 of the study and just before slaughtering.

\section{BACTERIOLOGICAL ANALYSIS}

After thawing the samples were inoculated on selective media with and without antibiotics. For $E$. colt $37 \mu \mathrm{L}$ of $10^{-1}, 10^{-3}$ and $10^{-5}$ dilutions in $0.9 \%$ sodium chloride solutions were inoculated on Eosin Methylene Blue Agar TM (EMBA) plates (CM 69 Oxoid) using a spiral plater (Salm en Kip, Utrecht, the Netherlands); for enterococci KF-Streptococcus agar ${ }^{\mathrm{TM}}$ plates (Oxoid CM701) with the $10^{-1}, 10^{-2}$ and $10^{-3}$ dilutions were used. For trimethoprim testing 5\% lysed horse blood was added to the agar. The antibiotics tested and concentrations used are shown in Tables 2 and 5. These antibiotics were selected because of common use in human and weterinary medicine or as AMGP or cross resistance with AMGP.

E. coli grows on EMBA as purple colonies with a black centre and merallic shine. Only these colonies were counted after $18-24$ hrs incubation at $37^{\circ} \mathrm{C}$. The minimum detection level was 300 colony forming units (cfu) per gram faeces and it has been shown that more than $95 \%$ of the in this way presumptively identified colonies are E. coll 48 . Previous studies have also shown that all isolares from antibiotic containing plates had MICs identical or higher than the concentration of the antibiotic in the selective plate from which they had been isolated $8,40,49$.

Enterococci appear as typical red or pintk colonies on KF-Streptococcus agar TM. After 48 hrs incubation at $42^{\circ} \mathrm{C}$ only the typical pink colonies were counted. One randomly sampled typical colony was collected from all KF-Streptococcus agar plates without antibiotics, subcultured on blood agar (Oxoid CM854 with $5 \%$ sheep blood) and identified using tolerance for bile, aesculin hydrolysis, growth on $6.5 \% \mathrm{NaCl}(\mathrm{w} / \mathrm{v})$ and a positive pyrolidonyl-arylamidase reacrion (pyrolidonyl-arylamidase tablets, Rosco, Denmark). All isolates proved to belong to the genus Enterococcus. The minimum detection level was $300 \mathrm{cfu} / \mathrm{g}$ faeces. For the prevalence of resistance against flavophospholipol a specimen was only considered positive if at least one Enterococcus faccalis was isolated and identified from the flavophospholipol containing agar plate. For this reason, for flavophospholipol only the prevalence of resistance could be calculated. In a previous study using the same methodology all enterococci had MIC identical or higher than the concentration of the antibiotic in the selective plate from which they had been isolated ${ }^{67}$.

\section{IOENTIFICATION AND MIC DERERMINATIONS OF ENTEROCOCCAL ISOLATES}

From each antibiotic free control plate one colony was randomly picked and identified using API-strep TM (Api-Benelux, Den Bosch, the Netherlands). If necessary in addition acid production from different sugars was determined according to the criteria of Devriese 19 , 20.

The MIC of the isolates were determined using two fold dilurions of antibiotics incorporated in Iso- 
Sensitest agarm (CM 471, Oxoid). Using a Steers inoculator plates were inoculated (droplets of approximately $2 \mu \mathrm{L}$ and 52 droplets per plate) with an overnight culture of the individual isolates in brain heart infusion (CM225, Oxoid) diluted to an optical density of approximately $0.5 \mathrm{McF}$ arland and read after $24 \mathrm{hrs}$ incubation at $37^{\circ} \mathrm{C}$. E. faecalis (ATCC 51299) was used as control strain.

\section{STATISTTCAL ANALYYSS}

To estimate the differences in prevalence and percentage of high degree of resistance between the groups a Pearsons Chi-square and, where appropriate, a Fishers exact test was used. For the degree of resistance a one-way analysis of variance was used to estimate overall differences between the group means. Group means were compared in pairs using the Student t-rests to control for overall error rate (Bonferroni test) and $\mathrm{p}<$ 0.05 was regarded as statistically significant.

\section{DEFINITIONS}

The prevalence of resistance (\%) in the population for a certain antibiotic is calculated as the number of samples showing growth of $E$. coli or enterococci on the plates containing that antibiotic, divided by the total numbers of samples tested $\times 100 \%$.

The degree of resistance (\%) of each faecal sample to each of the antimicrobial agents tested was calculated as the number of cfu growing on the plate containing that agent divided by the toral number of typical colonies on the antibiotic free control plate $x$ $100 \%$.

Two degrees of antibionic resistance to a particular antibiotic could be distinguished:

low degree of resistame, i.e. less than $50 \%$ of the total number of the indicator micro-organisms present per gram faeces was resistant and

bigh degree of resistance, i.e. $50 \%$ or more (thus the majority) of the indicator micro-organisms being resistant to that agent. The prevalence of high degree (\%) is the number of samples with a high degree of resistance to a particular antibioric divided by the total number of samples tested $\times 100 \%$.

\section{RESULTS}

During the study six animals died: one in group A, 2 in group $B$ and 3 in group $C$, mostly of endocarditis. Apart from some respiratory problems in individual animals, a few abscesses and a broken pelwis, there were no serious health problems observed during the study. Numbers of indiwidual antibiotic treatments for either respiratory problems or severe wounds caused by fighting were 4 injections in group A, 8 in group $B$ and 8 in group $C$. There was no statistically significant difference in performance between the three comparments.

\section{E. coli}

The total numbers of E. coli in the faecal samples of all the pigs collected at the start of the study and of the pigs in the different compartments at the end of the study are depicted in Table 1. At the start of the study there were no differences between the three compartments (data not shown). In compartment B the total numbers of $E$. coli were significantly lower at the end of the study than at the start and in compartment $A$ the total number was higher $(p<0.05)$. For compartment $C$ there was no difference. At the end of the study the to-

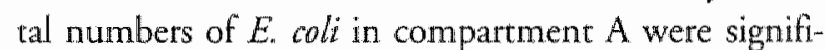
cantly higher than in compartments $B$ and $C(p<0.05)$.

The prevalence of resistant $E$. coli and the percentage of samples with a high degree $(>50 \%)$ of resistant E. coli in the faecal samples of the pigs collected at the start of the study and at the end of the study are shown in Table 2. No differences berween the three compartments were observed at the start of the study (data not shown). There was no difference in prevallence of resistance at the start compared with the prevalences found at the end of the study in all three compartments for ampicillin, streptomycin, oxytetracycline, trimethoprim, sulfamethoxazole and the combination of ampicillin and oxytetracycline. The prevalence of chloramphenicol resistance increased significantly ( $\mathrm{p}<$ 0.001 ) during the study in all three compartments; neomycin resistance, however, increased only in compartments $A$ and $C(p<0.001)$ and gentamicin resistance only in compartment $A(p<0.001)$.

At the end of the study the prevalence of resistant $E$. cali in faecal samples of comparment B was significantly lower for neomycin and gentamicin as com- 
Table 1. Total numbers of $E$. colf (109) per gram faeces of all pigs at the start of the study and of the different compartirients $A, B$ and $C$ at the end of the study.

\begin{tabular}{llll}
\hline Compartment & Mean & SEM & Range \\
\hline Start total of all pigs $(n=168)$ & 6.50 & 0.10 & $3.94-9.42$ \\
End compartment $A(n=55)$ & 6.87 & 0.10 & $5.43-8.63$ \\
End compartment $B(n=54)$ & 6.24 & 0.10 & $4.96-7.66$ \\
End compartment $C(n=53)$ & 6.41 & 0.08 & $4.90 \cdot 7.48$ \\
\hline
\end{tabular}

Standard error of the mean

Table 2. Prevalence (Prev) of resistant E. coli and percentage of samples with high degree (HD) of resistance in faecal samples of pigs.

\begin{tabular}{|c|c|c|c|c|c|c|c|c|c|}
\hline \multirow[t]{4}{*}{ Antibiotic } & \multirow{4}{*}{$\begin{array}{l}\text { Concentration } \\
\text { in agar } \\
\mathrm{mg} / \mathrm{L}\end{array}$} & \multirow{3}{*}{\multicolumn{2}{|c|}{$\begin{array}{l}\text { Start of study } \\
n^{*}=165\end{array}$}} & \multicolumn{6}{|c|}{ End of study } \\
\hline & & & & \multirow{2}{*}{\multicolumn{2}{|c|}{$\begin{array}{l}\text { Compartment A } \\
n=55\end{array}$}} & \multirow{2}{*}{\multicolumn{2}{|c|}{$\begin{array}{l}\text { Compartment } 13 \\
n=54\end{array}$}} & \multirow{2}{*}{\multicolumn{2}{|c|}{$\begin{array}{l}\text { Compartment } \mathrm{C} \\
n=53\end{array}$}} \\
\hline & & & & & & & & & \\
\hline & & Prev & $H D$ & Plev & $H D$ & Prev & $\mathrm{HD}$ & Prev & $\mathrm{HD}$ \\
\hline Ampicillin & 50 & 99 & 11 & 100 & 89 & 100 & 7 & 100 & 81 \\
\hline Streptomycin & 25 & 99 & 29 & 100 & 73 & 100 & 26 & 100 & 74 \\
\hline Neomycin & 25 & 36 & 0 & 98 & 0 & 44 & 0 & 66 & 0 \\
\hline Gentamicin & 25 & 21 & 0 & 78 & 0 & 13 & 0 & 17 & 0 \\
\hline Oxytetracycline & 25 & 99 & 43 & 100 & 89 & 100 & 20 & 100 & 85 \\
\hline Chloramphenicol & 25 & 66 & 2 & 100 & 2 & 96 & 0 & 98 & 2 \\
\hline Trimethoprim & 8 & 99 & 14 & 100 & 40 & 98 & 17 & 100 & 42 \\
\hline Sulfiamethoxazole & 150 & 99 & 38 & 100 & 78 & 100 & 39 & 100 & 62 \\
\hline Amoxyloxytetra & $50 / 25$ & 99 & 4 & 100 & 75 & 100 & 4 & 100 & 70 \\
\hline
\end{tabular}

" number of samples

pared to compartments $A$ and $C(p<0.001)$ and for neomycin in compartment $C$ in comparison with compartment $\mathrm{A}(\mathrm{p}<0.001)$.

For all antibiotics with a high degree of resistance in the faecal E. coli of the pig samples in this study the percentages of high degree samples were lower in compartment $B$ than in the comparments $A$ and $C$. The high degree percentages in compartment $B$ were not significantly different from those found in the faecal samples of all pigs at the start of the study except for oxyterracycline which were significantly lower $(p<0.05)$. In contrast all percentages of samples with a high degree of resistance in compartments $A$ and $C$ were significantly ( $p$ $<0.001$ ) higher compared with the percentages at the start of the study with the exception of chloramphenicol, gentamicin and neomycin. This was significant for ampicillin, streptomycin, oxytetracycline, trimethoprim, sulphamethoxazole and the combination of ampicillin and oxyterracycline $(p<0.001)$.

Similar differences were obtained comparing the degree of resistance found before the start of the study and in the three different groups at the end of the study (Table 3).

As a typical example the differences in ampicillin and oxytetracycline resistant $E$ coli in faecal samples of all pigs at the start of the study and at the end in the comparments $A, B$, and $C$ is shown in Figure $\mathbb{1}$ by means of a boxplot.

\section{ENTEROCOCCI}

The total numbers of enterococci in the faecal samples of pigs collected at the start and at the end of the study are presented in Table 4 . At the start of the study there were no differences between the three comparments 
Table 3. Mean resistant strains of $E$. coll in posifive samples at the start of the siudy (Total of comparment $A+B+C$ ) and at the end of the study in the separate compartinents.

\begin{tabular}{lcccc}
\hline Antibiotic & $\begin{array}{c}\text { Total of } \mathrm{A}+\mathrm{B}+\mathrm{C} \\
(\%)\end{array}$ & $\begin{array}{c}\text { Compartment A } \\
(\%)\end{array}$ & $\begin{array}{c}\text { Compartment B } \\
(\%)\end{array}$ & $\begin{array}{c}\text { Compartment C } \\
(\%)\end{array}$ \\
\hline Ampicillin & 15 & 82 & 18 & 73 \\
Streptomycin & 66 & 64 & 36 & 62 \\
Neomycin & $<1$ & 2 & 2 & $<1$ \\
Gentamicin & $<1$ & 1 & $<1$ & $<1$ \\
Oxytetracycline & 45 & 39 & 31 & 78 \\
Chloramphenicol & 2 & 6 & 2 & 9 \\
Trimethoprim & 17 & 49 & 27 & 43 \\
Sulfamethoxazole & 36 & 71 & 43 & 59 \\
Ampicillin/oxytetracycline & 8 & 68 & 10 & 65 \\
\hline
\end{tabular}

(data not shown). At the end of the study the total numbers of enterococci in all three compartments were significantly higher than at the start $(p<0.05)$. At the end of the study the total numbers of enterococci in faecal samples of the compartments $A$ and $B$ were significantly $(p<0.05)$ lower than in compartment $C$, bur no significant difference was found between compartments $\mathrm{A}$ and $\mathrm{B}$.

The prevalence of resistant enterococci and the percentage of samples with a high degree $(>50 \%)$ of resistant enterococci in the fareal samples of pigs collected at the start and at the end of the study are shown in "Table 5.

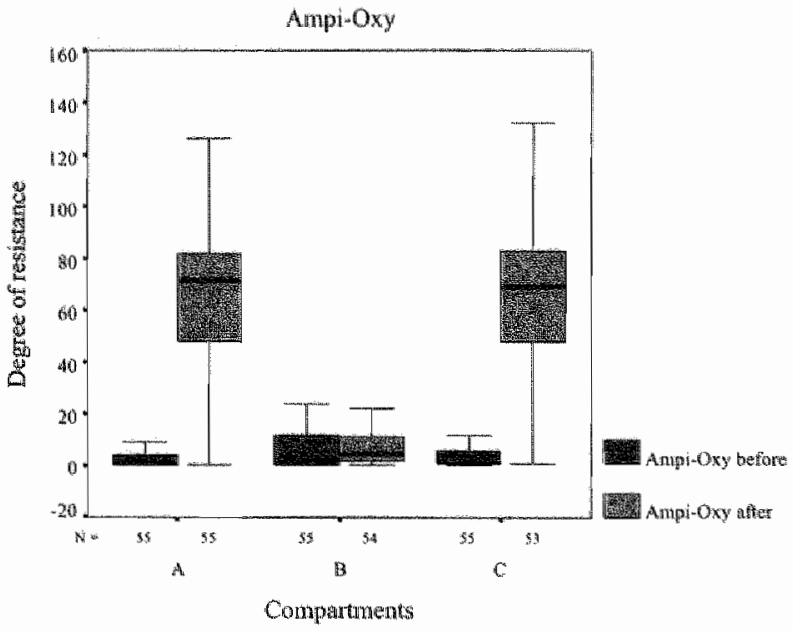

Figure 1. Degree of resistance of $E$. coli before and after the study.
No differences between the three compartments were observed at the start of the study (data not shown). There was no significant difference in prevalence of resistance found in samples taken before the start and at the end of the study for ampicillin and erythromycin. In all the compartments the prevalence of gentamicin resistance was lower at the end of the study than at the start ( $\mathrm{p}<0.001$ ), but in compartment $A$ also significantly lower than in the two other compartments $(\mathrm{p}<$ $0.01)$. The prevalence of vancomycin resistance increased significantly in all three compartments $(p<$ 0.001 ). The prevalence in group $A$ and $B$ increased rill approximately $44 \%$ but only one animal with a high

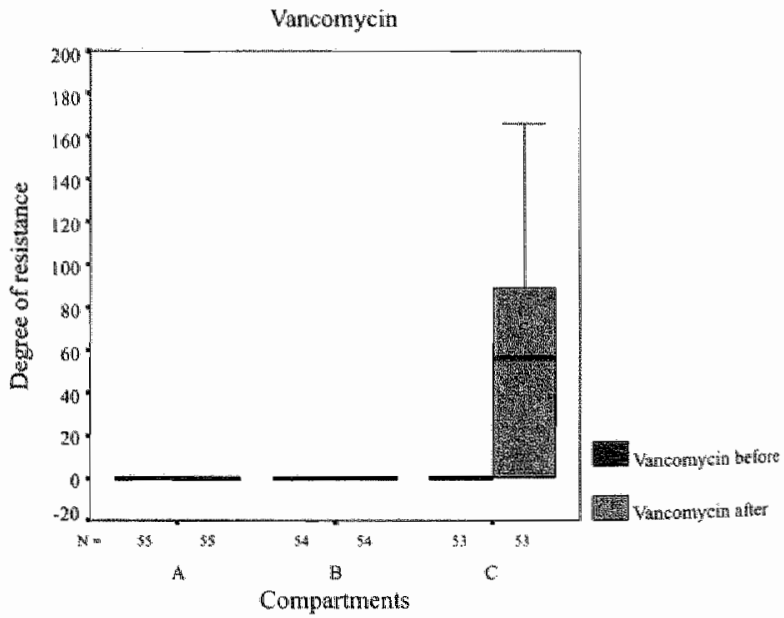

Filgure 2. Degree of resistance of faecal enterococci before and after the study, 
Table 4. Total number of enterococci $\left({ }^{10} \mathrm{log}\right.$ ) per gram faeces at the start of the study in comparison to the total number at the end of the siudy in the compartments $A, B$ and $C$.

\begin{tabular}{llll}
\hline Compartment & Mean & SEM & Range \\
\hline Start total of all pigs & 5.04 & 0.07 & $3.21-7.24$ \\
End compartment A & 5.49 & 0.12 & $3.83-7.36$ \\
End compartment B & 5.43 & 0.12 & $3.73-7.20$ \\
End compartment C & 6.00 & 0.10 & $3.98-7.18$ \\
\hline
\end{tabular}

Standard error of the mean.

Table 5. Prevalence (Prew) of resistance in faecal enterococcl and percentage of samples with high degree (HD) of resistance in faecal samples of pigs.

\begin{tabular}{|c|c|c|c|c|c|c|c|c|c|}
\hline \multirow[t]{4}{*}{ Antibiotic } & \multirow{4}{*}{$\begin{array}{l}\text { Concentration } \\
\text { in agar } \\
\mathrm{mgh}\end{array}$} & \multicolumn{2}{|c|}{ Stant of study } & \multicolumn{6}{|c|}{ End of study } \\
\hline & & & & Comp & & Camp & ent $B$ & Comp & ment $C$ \\
\hline & & \multicolumn{2}{|c|}{$n^{*}=165$} & \multicolumn{2}{|c|}{$n=55$} & \multicolumn{2}{|c|}{$n=54$} & \multicolumn{2}{|c|}{$n=53$} \\
\hline & & Prev & $\mathrm{HD}$ & Prev & $\mathrm{HD}$ & Prev & $\mathrm{HD}$ & Prew & $\mathrm{HD}$ \\
\hline Gentamicin & 1000 & 63 & 3 & 7 & 0 & 26 & 0 & 25 & 0 \\
\hline Ampicillin & 25 & 0 & 0 & 4 & 0 & 0 & 0 & 0 & 0 \\
\hline Enythromycin & $B$ & 99 & 80 & 100 & 85 & 100 & 98 & 100 & 96 \\
\hline Flavophospholipol & 8 & $23^{* *}$ & (9) & $13^{*}$ & (0) & $43^{*}$ & (2) & $28^{*}$ & $(0)$ \\
\hline Vancomycin & 8 & 0 & 0 & 44 & 0 & 41 & 2 & 72 & 57 \\
\hline
\end{tabular}

" number of samples.

* only Enterococcus faecalis.

() all enterococci.

Table 6. Percentage of of enterococci in faecal samples resistant at the start of the situdy and at the end of the study in the comparments $A_{9} B$ and $C$.

\begin{tabular}{|c|c|c|c|c|}
\hline Antibiotic & $\begin{array}{c}\text { Total of } A+B+C \\
(\%)\end{array}$ & $\begin{array}{c}\text { Compartment A } \\
(\%)\end{array}$ & $\begin{array}{c}\text { Compartment B } \\
(\%)\end{array}$ & $\begin{array}{c}\text { Compartment C } \\
(\%)\end{array}$ \\
\hline Gentamicin & 6 & $<1$ & $\Leftrightarrow$ & $<1$ \\
\hline Ampicillin & $<1^{*}$ & $<1$ & $<1$ & $<1$ \\
\hline Exthromycin & 80 & 102 & 101 & 163 \\
\hline Flavophospholipol & 21 & 2 & 6 & 1 \\
\hline Vancomycin & $<1$ & 1 & 2 & 71 \\
\hline
\end{tabular}

- below detection level.

degree vancomycin resistance was observed in compartment $B$ and the proportion of VRE on the total number of enterococci in positive animals remained low, approximately $2 \%$. In compartment $\mathrm{C}$, however, the prevalence of VRE was significantly ( $\mathrm{p}<0.01$ ) higher than in $A$ and $B, 57 \%$ of the animals had a high degree of resistance and the proportion of VRE was $71 \%$ as shown in Table 5, Table 6 and Figure 2. The prevalence of flavophospholipol resistant $E$. faecalis de- creased during the study in compartment $A$ and increased significantly $(p<0.05)$ in compartment $B$.

\section{IDENTIFICATION AND MIC DISTRIBUTION}

The identifications of the single isolates of faecal samples collected before and at the end of the study are shown in Table 7. There were no significane differences in species and MIC distribution between the three compartments at the start of the study (data not shown). 
Table 7. Identification of faecal enterococci from pigs betore $(A+B+C)$ and at the end of the study (compartments $A, B$ and $C$ ).

\begin{tabular}{lcccc}
\hline & $A+B+C$ & $A$ & $B$ & $C$ \\
\hline Species & $n^{*}=168$ & $n=55$ & $n=54$ & $n=53$ \\
E. faecalls & 11 & 20 & 2 & 3 \\
E. laecium & 35 & 26 & 32 & 45 \\
E. durans & 122 & 6 & 20 & 7 \\
E. gallinarum & - & 1 & - & - \\
E. casseliflavus & - & 2 & - & - \\
\hline
\end{tabular}

All isolates were resistant to erythromycin (MC $>64 \mathrm{mg} / \mathrm{L}$ ). The MIC distributions of the E faecium, E. faecalis and E. durans isolates are shown im the Tables 8.9 and 10 respectively.

* number of samples.

\section{DISCUSSION}

Comparing the three groups of pigs in the study, the growth rate and feed intake tended to be less in the group of animals not receiving any AMGP than in the other two groups. This resulted in a slightly berter feed conversion, but there were no statistically significant differences in performance between the three groups observed. However, it should be kept in mind that the study was primarily designed to study the resistance in the faecal flora of the pigs and not performance. The total numbers of $E$. coli and enterococci per gram faeces at the start of the study were of the same size of order as the results obtained in a former study 65 . The total numbers of enterococci per gram faeces increased during the study in all three different groups, but significantly more in the avoparcin exposed group. In contrast the total numbers of $E$ coli decreased in the flavophospholipol group, increased in the negative control group and remained stable in the avoparcin group. According to the concept of colonisation resistance (CR), (part of) the endogenous obligate anaerobic flora limits the concentration of (potentially) pathogenic bacteria in the intestinal tract 71,72 . Impairment of the CR of the intestinal tract causes an increase in the faecal concentration of facultative aerobic enterobacteriaceac as well as enterococci, if resistant (or unsusceprible) strains are present ${ }^{75}$. At the end of the study both the total numbers of $E$. coli and enterococci per gram faeces were lower in the flawophospholipol group than in the avoparcin group. Within the flavophospholipol group the toral number of $E$. coli was lower at the end than at the start of the study and of $E$. coli more or less similar to the number at the start of the study. The total number of enterococi in the faecal flora of flavophospholipol fed pigs increased during the study less compared to both other groups of pigs. Therefore it might be concluded that the CR of flavophospholipol fed pigs was not or only slightly affected and in any case less than in both other groups of animals. The increase in the numbers of $E$. coli in the negative control group $A$ is difficult to explain, but might have been caused by bacterial overgrowth in the small intestinal tract which was controlled in both other groups by the used AMGP. As the CR of the intestinal tract also protects against colonisation with salmonellae, these observations are in concordance with the results of others. In flavophospholipol fed pigs a reduction of the number of salmonellae per gram faeces and of the duration of excretion of salmonellae has been observed, but in avoparcin fed animals the minimal infection dose of salmonellae decreased and numbers and duration of excretion increased compared to controls ${ }^{4}$, 5,26 .

\section{E. coli}

Prevalence and degree of resistance in a population is correlated with antibiotic use, but this is not a monocausal relation ${ }^{65}$. Resistance in farrening pig increases with age, crowding and stress, caused by for instance high temperatures and transport ${ }^{10,35,42}$. Some of these factors might be interrelared such as age, transport and holding time at the abattoir. It has been shown that in pigs the degree of resistant $E$. coli is higher in the faecal contents than in the colon. Stress enhances the transit time in the intestinal tract of pigs 
Table 8. Enterococcus faecium: MlO distribution before (compartment $\mathrm{A}+\mathrm{B}+\mathrm{C}$ ) and at the end of the study (compartments $\mathrm{A}, \mathrm{B}$ and $\mathrm{C})$.

\begin{tabular}{|c|c|c|c|c|c|c|c|c|c|c|c|c|c|c|c|c|}
\hline \multirow{2}{*}{$\begin{array}{l}\text { Antimicrobial } \\
\text { agent }\end{array}$} & \multirow[b]{2}{*}{ Compartment } & \multirow{2}{*}{$\begin{array}{l}\text { resistant } \\
\text { ro }\end{array}$} & \multicolumn{12}{|c|}{ Number of isolates with MC of: } & \multirow[b]{2}{*}{$M: C_{50}$} & \multirow[b]{2}{*}{$M I G_{50}$} \\
\hline & & & $<0.12$ & 0.12 & 0.25 & 0.5 & 1 & 2 & 4 & 8 & 16 & 32 & 64 & $>64$ & & \\
\hline \multirow[t]{4}{*}{ Flavophospholipol } & $A+B+C$ & 97 & & & & & & 1 & 2 & 9 & 10 & 8 & 5 & & 16 & 64 \\
\hline & A & 100 & & & & & & & & 3 & 23 & & & & 16 & 16 \\
\hline & $\mathbb{B}$ & 94 & 1 & & & 1 & & & 2 & 14 & 14 & & & & 8 & 16 \\
\hline & $\mathrm{C}$ & 95 & & & 1 & & & 1 & & 39 & & 1 & 1 & & 8 & 8 \\
\hline \multirow[t]{4}{*}{ Vancomycin } & $A+B+C$ & 0 & & & & 29 & 3 & 3 & & & & & & & 0,5 & 1 \\
\hline & $A$ & 0 & & & & 23 & 3 & & & & & & & & 0,5 & 0.5 \\
\hline & $B$ & 16 & & & & 23 & 4 & & & 1 & & & & 4 & 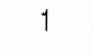 & $>64$ \\
\hline & $\mathrm{C}$ & 86 & & & & 5 & & 1 & & & & & & 37 & $>64$ & $>64$ \\
\hline
\end{tabular}

Table 9. Enterococcus faecalis : MIC distribution before (compartment $A+B+C)$ and at the end of the study (compartments $A, B$ and $C$ )

\begin{tabular}{|c|c|c|c|c|c|c|c|c|c|c|c|c|c|c|c|}
\hline \multirow{2}{*}{$\begin{array}{l}\text { Antimicrobial } \\
\text { agent }\end{array}$} & \multirow[b]{2}{*}{ Compartment } & \multirow{2}{*}{$\begin{array}{l}\% \\
\text { resistant }\end{array}$} & \multicolumn{11}{|c|}{ Number of isolates with MIC of: } & \multirow[b]{2}{*}{$M C_{50}$} & \multirow[b]{2}{*}{$\mathrm{MIC}_{90}$} \\
\hline & & & $<0.12 \quad 0.12$ & 0.25 & 0.5 & 1 & 2 & 4. & 8 & 16 & 32 & 64 & $>64$ & & \\
\hline \multirow[t]{4}{*}{ Flavophospholipol } & $A+B+C$ & 18 & & 4 & 2 & 1 & 2 & & & & 1 & 1 & & 0,5 & 32 \\
\hline & $A$ & 0 & 1 & 19 & & & & & & & & & & 0,25 & 0,25 \\
\hline & $\mathrm{B}$ & 0 & & 2 & & & & & & & & & & 0,25 & 0,25 \\
\hline & $C$ & 0 & & 2 & 1 & & & & & & & & & 0,25 & 0,5 \\
\hline \multirow[t]{4}{*}{ Vancomycin } & $\mathrm{A}+\mathrm{B}+\mathrm{C}$ & 0 & & & 3 & 8 & & & & & & & & 1 & 1 \\
\hline & A & 50 & & & & 5 & 5 & 10 & & & & & & 2 & 4 \\
\hline & $\mathrm{B}$ & 0 & & & & 2 & & & & & & & & 1 & 1 \\
\hline & $\mathrm{C}$ & 0 & & & & 2 & 1 & & & & & & & 1 & 2 \\
\hline
\end{tabular}

Table 10. Enterococcus durans: MlC distribution before (compartment $A+B+C)$ and at the end of the study (compartments $A, B$ and $C$ ).

\begin{tabular}{|c|c|c|c|c|c|c|c|c|c|c|c|c|c|c|c|}
\hline \multirow{2}{*}{$\begin{array}{l}\text { Antimicrobial } \\
\text { agent }\end{array}$} & \multirow[b]{2}{*}{ Campartment } & \multirow{2}{*}{$\begin{array}{l}\% \\
\text { resistant }\end{array}$} & \multicolumn{11}{|c|}{ Number of isolates with $M$ MIC of: } & \multirow[b]{2}{*}{$\mathrm{MIC}_{50}$} & \multirow[b]{2}{*}{$M \| C_{90}$} \\
\hline & & & $<0.12 \quad 0.12$ & 0.25 & 0.5 & 1 & 2 & 4 & 8 & 16 & 32 & 64 & $>64$ & & \\
\hline \multirow[t]{4}{*}{ Flavophospholipol } & $\mathrm{A}+\mathrm{B}+\mathrm{C}$ & 88 & & & 0 & 0 & 15 & 28 & 10 & 18 & 16 & 26 & 9 & 16 & 64 \\
\hline & A & 100 & & & & & & & 5 & & & & 4 & 8 & 8 \\
\hline & $B$ & 30 & & 1 & 1 & & 12 & & & & 1 & 2 & 3 & 2 & $>64$ \\
\hline & C & 83 & & & & & $y$ & & 1 & 1 & & 2 & 1 & 16 & 64 \\
\hline \multirow[t]{4}{*}{ Vancomycin } & $A+B+C$ & 0 & & & 61 & 25 & 36 & & & & & & & 0.5 & 2 \\
\hline & A & 0 & & & 1 & 4 & 1 & & & & & & & 1 & 1 \\
\hline & $\mathrm{B}$ & 0 & & & 2 & 18 & & & & & & & & 1 & 1 \\
\hline & $\mathrm{C}$ & 17 & & & 2 & 3 & & & & & & 1 & & 1 & 1 \\
\hline
\end{tabular}


and thus the numbers of resistant bacteria per gram faeces, because these numbers are higher in the caecum. In this study there were neither differences in housing conditions nor other stress factors or relevant differences in therapeutic use of antibiotics among the three study groups. Therefore the observed differences must be due to the differences in the AMGP supplied. The observed high prevallence of antibiotic resistant $E$. coli was in accordance wirh previous studies 47,65 . Resistance against nearly all antibiotics with the exception of chloramphenicol, neomycin and gentamicin were found in almost all pigs at the start and at the end of the study. It was interesting that in group $A$ and $C$ the degree of resistance for ampicillin, streptomycin, oxyterracycline, trimethoprim, and the combination of oxytetracycline and ampicillin was significantly higher at the end of the study than at the start. In the flavophospholipol group, however, the degree of resistance remained at the same size of order for almost all antibiotics and was even lower for oxytetracycline. The animals in this group excreted considerably lower numbers of resistant $E$. colt in their faeces, indicating that the reservoir of resistance genes present in the intestinal flora of these animals was much lower than in the two other groups. Flavophospholipol in a concentration of $9 \mathrm{mg} / \mathrm{kg}$ added to the feed of fattening pigs prevented either overgrowth by resistant strains and/or transmission of plasmids carrying resistance genes among intestinal $E$ coli of these animals. Both phenomena have also been observed in witro $9,23,36,57$. Consequendy the chance of transfer of resistance genes to other bacteria in the intestinal tract of these animals, and the risk of transfer of resistant $E$. coli via meat(products) to humans, decreased as well.

\section{ENTEROCOCCI}

The observed high prevalence and degree of resistance of enterococci in all three groups against erythromycin was to be expected. Just before the start of the study all animals were treated with tylosin, which is known to select for erythromycin resistance in faecal enterococci of pigs 1.11 .

At the start of the study the number of vancomycin resistant enterococci in all pigs was below the detection level of the method used. The increase in both preva- lence and degree of resistance in the avoparcin fed group was most striking. Of all excreted enterococci per gram faeces in VRE positive animals $72 \%$ were VRE. Gentamicin resistance, however, reduced in the avoparcin group during the study and was significantly lower at the end of the study than in both other groups. This might have been due to a replacement of gentamicin resistant non- $E$. faecium enterococcal species by vancomycin resistant $E$ faecium strains Vancomycin resistance is more common in $E$. facciwm and gentamicin resistance in $E$. faecalis, as indicated in $\mathrm{Ta}$ ble 11. The prevalence of flavophospholipol resistant E. faecalis increased in the flavophospholipol group during the study, but the numbers of flavophospholipol resistant enterococci per gram faeces (degree of resistance) even decreased.

The results of the MIC determinations of single isolates clearly indicate that mass medication with tyllosin causes a selecrion and spread of erythromycin resistance in all enterococcal species. Awoparcin selects for vancomycin resistant $E$. faecium. Like $E$. faecium, $E$. durans is probably unsusceptible for flavophospholipol, which is not very surprising as $E$. durans is closely related to $E$. faecium and has long been considered a subrype of E. faecium 45 . However, in this study vancomycin resistance was not observed in $E$. durans. No resistance against flavophospholipol emerged during the study in the flavophospholipol fed group B, nor in the avoparcin group, but nearly all $E$. faecalis were eradicated from the faecal flora of pigs in these two groups as shown in Table 7 .

\section{CONCLUSIONS}

As was to be expected from the results of other publications $3,34.79$, the use of awoparcin as AMGP selected strongly for vancomycin resistant enterococci in the faecal flora of exposed pigs. No influence on the resistance of the faecal $E$. coli flora was observed. In the flavophospholipol treated group the prevalence of $E$. faecalis increased but the total numbers of flavophospholipol resistant enterococci per gram faeces decreased during the study, however, less than in both other groups. Flavophospholipol addition to the feed prevented almost totally the increase in numbers of resistant E. coli, in the faecal flora of group B. As a result 
the numbers of resistant $E$. coli, excreted with the faeces in the flavophospholipol group were significantly lower than in the other two groups. This has been proposed to be a safety mark for the protection of public health. Consequently flavophospholipol use as AMGP might decrease the public heal th risk of dissemination of resistant Gram negative bacteria and plasmid born resisrance genes from animals to humans via the food chain. In case of a risk-benefit analysis the benefits of adding flavophospholipol to pig feeds in order to reduce resistance might be considered larger than the potential risk of selection in the intestinal tract of pigs and transfer of flavophospholipol resistant E. faecalis to humans. However, as this study was performed on just one farm with pigs previously colonised with only three multiresistant $E$. colistrains, the results have to be confirmed in a field study comparing pigs from farms using flavophospholipol as AMGP with others that do not. It would also be interesting to investigate whether flavophospholipol addition to pig feed prevents an increase in the prevalence and degree of antibiotic resistant $E$. coli in the intestinal tract of animals when they are treated with antibiotics, such as ampicillin, oxytetracycline and trimethoprim-sulfonamide combinations.

\section{REFERENCES}

1. Aarestrup, F. M., and B. Carstensen 1998. Effect of rylosin used as a growth promoter on the accurrence of macrolide-resistant Enterococci and Staphylococi in pigs. Microbial Drug Resistance Mechanisms Epidemiology and Disease. 4:307-312.

2. Bager, F. 1999. Danmap 98-Consumption of antimicrobial agents and occurrence of antwicrobial resistance in bacteria from food animals, food and humans in Denmark. Danish Zoonosis Centre. Danish vererinary laboratory.

3. Bager, F., M. Madsen, J. Christersen, and F. M. Aarestup 1997. Awoparcin used as a growth promorer is associated with the occurrence of vamcomycin-resistant Enterococcus faecium on Danish poultry and pig farms. Preventive Veterinary Medicine. $31: 95-112$.

4. Barrow, P. A. 1989. Further obserwations on the effect of feeding diets containing avoparcin on the excretion of salmonellas by experimentally infected chickens. Epidemiology and lnfection. 102:239-252.

5. Barrow, P. A. H. Williams Smith. J. F. Tucker, and H. W. Smith 1984. The effect of feeding diets containing avoparcin on the excretion of salmonellas by chickens experimentally infected wirh narural sources of satmonella organisms. Journal of Hygiene. $93: 439-444$.

6. Bauer, $\mathrm{F}$., and $\mathrm{G}$. Dost 1965. Moenomycin in amimal nutricion. Ancimicrobial Agents and Chemotherapy:749-752.

7. Bolder, N. M., J. A. Wagenar, F. F, Putirulan, K. T. Veldman, and M. Sommer 1999. The effect of Mavophospholipol (Flavomycin (R)) and salinomycin sodium (Sacox (R) on the excretion of Clostridium perfringens, Salmonella enteritidis, and Campylobacter jejun in brollers afer expenimental infection. Poultry Science. 78: 1681-1689.

8. Bonten, M. E. E. Stobberingh, J. J. Philips, and A. Houben 1990. High prevalence of antibiotic resistant Escherichia coli in faecal samples of students in the sourh-east of the Netherlands I Antimicrob Chem, 26:585-592.

9. Brana, H. J. Hubacek, and I. Konig 1974. The effect of actinomycin $D$ and Aavomycin on Eschericha coli $R+$ strains Folia microbiologica. 18:257-259.

10. Butaye, P., L. A. Devriese, H. Goossens, M. leven, and F. Haesebrouck 1999. Enterococi with acquired vancomycin resistance in pigs and chickens of different age groups. Antimicrobial Agents and Chemotherapy, 43:365-366.

11. Christie, P. J., J. N. Davidson, R. P. Novick, and G. M. Dunny 1983. Effects of tylowin feeding on the antibiotic resistance of selected gram-positive bacteria in pigs. Am J Ver Res. 44: 126-128.

12. European Commission. 1999. Opinion of the scientific steering committee on antimicrobial resistance. Directorate general XXIV: consumer policy and consumer health protection, Brussels.

13. Corpet, D. E. 1984. The effect of bambermycin, carbadox, chlortetracycline and olaquindox on antibionic resistance in intestinal coliforms: a new animal nodel. Anmales de Microblologic. 135A:329-339.

14. Crawford, L. M. 1984. Bambermycins, p. $351-354$. In T" H. Jukes, H. L. Dupont, and L. M. Crawford (cds), antribiotic, sulphonamides, and public healthi, vol, volune 1 . CRC press incorpotation, Boca Raton.

15. Dealy, J, and M. W. Modler 1977. Effect of bambermycins on Escherichia coli and antibiotic resistance in calves. J Anim Sci. $45: 1239-1242$

16. Dealy, J., and M. Wheller 1977. Influence of bambermycins on Samonella infection and antibiotic resisrance in calves. J Anim Sci. 44:734-738.

17. Deally, J., and M. W. Moeller 1976. Influence of bambermycins on Salmonella infection and antibiotic resistance in swine. Journal of Animal Science, 42:1331-1336.

18. Dewriese, L. A., G. Daube, J. Honmex, and F. Hasebrouck 1993. In vitro susceptibility of Clostridium perfringens isolared from farm animals to growth enhancing ancibiotics. J applied microbiology. $75.55-57$.

19. Dewriese, L. A., J. Hommez, R. Wiffels and F. Haesebrouck. 1991. Composition of the enterococcal and streprococcal. intestinal flora of poultry. Joumal of applied bacteriology. 71:46-50.

20. Dewriese, L. A. A. v.d Kerckhowe, R. Kulpper-Balw, and K. H. Schleifer 1987. Characterisation and identification of 
Enterococcus species solated from the intestines of animals. Int ) Systematic Bacteriol. 37:257-259.

21. Duta, G. N., and L. A. Devriese 1984. Observations on the in virto sensitivity and resistance of Gram posinive intestinal bacteria of farm andinals to growth promoring antimicrobial agenrs. Journal of Applied Bacteriology. 56:117-123.

22. Dutta, G. N., and L. A. Devriese 1980. Susceptibility of Clostridium perfringens of animal origin to fifteen antimicrobial agents. Journal of Veterinary Pharmacology and Therapeutics. $4,227-236$

23. George, B. A.s and D. J. Fagerberg 1984. Effect of bambermycins, in vitro, on plasmid-mediated antimicrobial resistance. Am I Ver Res. 45:2336-2341.

24. George, B. A., D. J. Fagerberg, C. L. Quarles, J. M. Fenton, and $G$. A. Mckinley 1982. Effect of bambermycins on quantity, prevalence, duration, and antimicrobial tesistance of Salmonella typhimurium in experimenally infected broiler chickens. American Joumal of Veterinary Research. $43: 299-303$

25. Gold, H. S., and R. C. Moellering, Jr. 1996. Antimicrobialdrug resistance. $N$ Engl I Med. 335:1445-53.

26. Gustafson, R. H, J. R. Beck, and J. D. Kobland 1982. The influence of avoparcin on the establishment of Samonella in chickens. Zentralblatt fuer Veterinaemedizin B. 29:1 19-128.

27. Hentschel, S., D. Kusch, and H. J. Sinell 1979. Staphylococcus aureus in poultry, biochemical chanacteristics, antbiote resistance and phage parterns. Zbl Bakr Hyg I Abr Orig B. 168:548-561.

28. Huber, $G_{*,}$ and $G$. Nesemann 1968. Moenomycin, an inhibitor of cell wall synthesis. Biochem and Biofys Res Com. 30:7 13.

29. Huber, $\mathrm{G}_{\mathrm{n},}$ U. Schlecht, $H$. L. Weidenmuller, I. Schmidt"Thome, J. Duphom, and $\mathbb{R}$. Tschesche 1965. Moenomycin, an new anribiotic II, Chanacrerisacion and Chemistry. Antmicrobial Agents and Chemotherapy. 1967:737-742.

30. Humme, $R_{n}, H$. Tschape, and W. Wine 1986. Spread of plasmid-mediated nourseothricin resistance due to antibionic use in animal husbandry: \Basic Microbiol. 26:461-466.

31. Hunter, I. E. B., M. Bunnert, C. A. Hatr, J. C. Shelley, and J. R. Walton 1994. Apramycin-resistant Escherichiacoli isolated from pigs and atockman. Epidemiology and Infection. $112: 473-480$

32. (JETACARJ Joint Expert Advisory Committee on Anribiotic Resistance 1999. The use of antibiotics in food producing animals: antibioric resistane bacteria in animals and humans. Commonwealth deparment of thealth and aged care. Commonwealth deparment of agriculture, fischeries and forestry, Camberran, Australia.

33. Karavanov, L., P. Koleva, M. Bonovska, M. Mateev, and A. Kozarev 1980. AArtempt at eliminating the multiple drug resistance of $\mathrm{E}$. coll in pigs with enteritis using Rimactin]. Vet Med Nauki, 17:31-37.

34. Kruse, H., B. K. Johansen, L. M. Rorvik, and G. Schaller 1999. The use of awoparcin as a growth promorer and the accurrence of vancomycin-resistant Enterococcus species in Norwegian poultry and swine production. Microbial Drug
Resiscance Mechanisms Epidemiology and Disease 2:135-139.

35. Langlois, B. E., K. A. Dawson, I. Leak, and D. K. Aaron 1988. Anrimicrobial resistance of fecal coliforms from pigs in a herd not exposed to antimicrobial agents for 126 months. Vet Microbiol 18:147-153.

36. Lebek, G. 1971. Die wirkung von Gavomycin auf episomal resistente Keime Zentralblat Veterinaer Medizin, Reihe B. $19.532-539$.

37. Lester, 5. C., M. del Pilar, F. Wang, L. Perez-Schael, H. Jiang, and T. F. O'Brien 1990. The carriage of Escherichia coli resistant to antimocrobial agents by healthy children in Boston, in Caracas, Menezuela, and in Qin Pu, China. New Engl J. of Med. 323:285-289.

38. Levy, 5. B. 1992. The antibioric paradox: how miracle dungs are destroying the miracle. Plenum Press, New York.

39. Levy, S. B., B. Marshall, S. Schluederberg, D. Rowse, and D. J. 1988. High Frequency of Antimicrobial Resistance in Human Frecal Flora. Antimicrobial Agents and Chemotherapy. 32:1801-1806.

40. London, N., R. Nijsten, A. E. van den Bogaard, and E. E. Stobberingh 1994. Carriage of antibiotic-tesistant Escherichia coli by healthy wolunteers during a 15 -week period Infection. 22:187-192.

41. Mitsuhashi, S., M. Inoue, and S. Masuyostii 1970. Preferential inhibition of the growth of Escherichia coli strains carrying episomes. cefotaxime J Amtibiot. 23:319-323.

42. Molitoris, E., D. J. Fagerberg, C. L. Quarles, and M. J. Krichevsky 1987. Changes in antimicrobial resistance in faecal bacteria associated with pig transit and holding times at slauglater plants. Applied and Enwironmental Microbiology. 53:1307-1310.

43. Mulder, R.W. A. W., and M. C. van der Hulst-wan Arkel 1976. Residuen van antibiotica in organen en pluimveevlees. Tijdschr. Diergenesskunde. 101:1194-1198.

44. Mutray, B. E. 1997. Antibiotic Resistance. Advances in Inremal Medicine. 42:339-367.

45. Murray, B. E. 1990. The life and times of the Enterococcus. Clin Microbiol Rev. 3:46-65.

46. Neu, H. C. 1992. The crisis in antibiotic resistance. Science. 257.106473 .

47. Nijsten, R. N. London, A. van den Bogaard, and E. Scobberingh 1993. Antibiotic-Resistance of Enterobacteriaceae Isolated from the Faecal Flora of Fattening. Pigs Veterinary Quarterly. 15:152-156.

48. Nijsten, R., N. London, A. E. van den Bogaard, and E. E. Stobberingh 1993. Antibiotic resistance monitoring of enterobacteriaceae isolated from the faecal flora of fattening pigs. Vet Quarterly. 15:152-156.

49. Nijsten, R. N. London, A. wan den Bogaard, and E. Stobberingh 1996. Antibioric-Resistance among Escherichia coll Isolated from Faecal Samples of Pig Farmers and Pigs. journal of Antimicrobial Chemotherapy. 37:1131-1140.

50. Paik, J, I. Kern, R. ILurz, and R. Hakenbeck 1999. Murational analysis of the Srreptococcus preumoniae bimodular class $A$ penicillin-binding proteins. J Bacteriology. 181:3852-3856. 
51. Commission on Antibiotic Growth Promoters. 1998. Ancimicrobial growth promoters 15/E. Fealth Conncil of the Netherlands.

52. Sambeth, W., G. Nesemann, F. Bauer, and G. Dost 1969. Inwestigations of the excretion and retentiom of flavomycin. Prccedings Flavomycin Symposium, Rortach Egern:133. 139.

53. Shlaes, D., S. Levy, and G. Archer 1991. Antimicrobial resisrance: New directions. A grearer systematic effort from several secrors is needed to combat this steadily increasing problem. ASM News. 57:455-458.

54. Singleton, $P$, and D. Sainsbury 1993. Dictionary of microbiology and molecular biology, 2nd edition ed. John Wiley 8 Sons, Chichester.

55. Smith, H. W. T. J. F. 1975. The effect of feeding diers containing permirted antibiotics on the faecal excretion of Salmonella ryphimurium by experimentally infected chickens. Journal of Hygiene 1975; 75(2): 293-301.

56. Sokol, A. F. Federic, V. Kremery, V. Rejtar, and J. Janouskowa 1973. Inhibirory effect of flawomycin as a feed additive on $\mathrm{R}$ factors in Escherichia coli isolated from pig weanlings, 8th International Congress on Chemotherapy in Athens. Absrract book: $176-179$.

57. Sokol, A.y V. Krenery, F. Federie, V. Rejtar, and J. Janouskova 1973. The influence of flawomycin on the elimination of $R$ factors of Escherichia coli in witro. Folia microbiologica. 18:176-179.

58. (SOU) Commission on Anrimicrobial Feed Additives. 1997. Ancimicrobial feed additives: 132. Ministery of Agriculture, Srockholm.

59. Spring, W. G. 1975. Das Wesen der extrachromosalen Resistenz und eren Bekampfung durch Flavomycin. Tieraratliche Unschau. 30:591-596,598.

60. Spring, W. G. 1978. Der Einfluss won Flavomycin auf die Salmonelleninfektion und Antibiotikaresistenz bei Schweinen. Tierartliche Umschas. 33:594, 596-594, 599.

61. Spring, W. G. 1978 Der Einfuss von Flavomycin auf die Salmonelleninfekrion und Anribiotikaresistenz bei Kalbern. Therarzatliche Umschau. 33:467-468,470.

62. Stutz $M$. W. and G. C. Lawron 1984. Effects of diet and antimicrobials on growth, feed efficiency, intestinal Clostridium perfringens, and illeal weight of broiler chicks. Poult Sci. 63:2036-2042.

63. Subramaniam-Niehaus, B., "T.'Schneider, J. W. Merger, and W. Wohlleben 1997. Isolation and analysis of moenomycin and its biosynthetic intermediates from Streptomyces ghanaensis (ATCC 1.4672) wildtype and selected mutants. Z. Narurforschung. $52: 217-226$.

64. Select Commitee on Science and Technology. 1998. Resisrance to antibiotics and other antimicrobial agents. Report to the house of lords. Seventh report. The House of Lords, London.

65. van den Bogaand, A. N. London, and E. E. Srobberingh 2000. Ancimicrobial resistance in pig faecal samples from the Netherlands (five abatroirs) and Sweden. Joumal of Antimicrobial Chemotherapy. 45:663-671.
66. wan den Bogard, A. E, L. B. Jensen, and E. E. Srobberingh 1997. Antimicrobial reisistance - relation to human and animal exposure no antibiotics. N Engl I Med. 337:1558-9.

67. wan den Bogaard, A. E. P. Mertens, N. H. London, and E. L. Stobberingh 1997. High prevalence of colonization with vanconycin- and pristinamycin-resistant enterococc in healmy humans and pigs in the Netherlands: is the addirion of antibiotics to animal feeds ro blame? I Antimicrob Chemother, 40:454-6.

68. van den Bogaard, A. E., and E. E Srobberingh 1999. Anribioric usage in animals - Impacr on bacterial resistance and public health. Drugs. 58:589-607.

69. van den Bogaard, A. E., and E. E. Stobberingh 2000. Epidemiology of resistance to antibiotics - Links between animals and humans. Truternational Joumal of Anrimicrobial Agents. $14: 327-335$.

70. van den Bogand, A. E., and E. E. Srobberingh 1996. Is it rime to ban all antibiotics as animal growth-promoting agents? + reply and authors reply. The lancer 1996:348:619+ $1454-1456$.

71. Wan der Waiij, D. 1982. Colonization resistance of the digestive ract: dinical consequences and implications. I Antimicrob Chemorharapy. 10:263-270.

72. wan der Waaij, D., H. G. de Vries Hospers, I. A. Snijder, M. R. Hallie, H. O. Nieweg, S. D. van der Werf, $\mathbb{T}$. M. Nagengast, and $\mathrm{v}$. B. Henegouwen 1987. Collonisarion resistance of the digesrive tract-mechanism and clinical consequences. Nahrung, 31:507-17.

73. van Heienoort, Y., M. Leduc, H. Singer, and J van Heienoor 1987. Effects of moenonycin on Escherichia coli. J Gen Microbiol. 133.

74. Vanderwel, D., and E. E. Isgiguro 1984. Properties of cell wall peptiodoglycans symthesized by aminoacid deprived rall mutants of Escherichia coli. Can J Microbiol, 30:1239-1246.

75. Vollatard, E. J., and H. A. L. Clasener 1994. Colonization Resistance. Antimicrobial Agents and Chemotherapy. 38:409-414.

76. Wasielewstri, E. R. Mushawed, and E. Schuerze 1966. Moenomycin, a new antibioric III. Biological propenties. Antimicrobial Agencs and Chemotherapy. 1966:74, -748.

77. Watanabe, T., Y. Ogata, K. Sugawara, and K. Oda 1971. Increase of flavomycin sensicivity of bacteria by R-factors. Procedings of the 7th International Congress on Chemotherapy. Abstract book:A-8/11.

78. Williamson, R., L. Gutmann, T. Horaud, J: Delbos, and J. F. Acar 1986. Use of penticilin-binding protems for the identification of enterococci. I Gen Microbiol. 132:1929-1937.

79. Witte, W. I. Klare, and $G$. Werner 1999. Der einsatz von awoparcin als leistungsfordere und die resistenzertwicklung gegetn glykopeptide bei enterokokken. Therartliche Praxis. 27 (G):310-315.

80. Humpert F, Lalande $F, 1 \mathrm{H}, \mathrm{R}$, Salwat $\mathrm{G}$, Bennejean G. Effect of four antibion additives on the Salmonella contamination of chicks prorected by an adult crecal flora. Avian Pathology $1991 ; 20: 577.584$. 

Chapter VIII

\section{The effect of banning avoparcin on VRE carriage in the Netherlands}




\section{The effect of banning avoparcin on VRE carriage in The Netherlands}

\author{
$J$ Antimicrob Chemother 2000; 46: 146-148
}

A. E. van den Bogaard*, N. Bruinsma and

E. E. Stobberingh

University Hospital Maastricht, Medical Microbiology, PO Box 5800, 6202 AZ Maastricht, The Netherlands

* Corresponding author. Tel: +31-43-3881016;

Fax: +31-43-3670996;

E-mail: A.vandenbogaard@CPV.UNIMAAS.NL

Sir,

Acquired resistance against antibiotics is closely related to the amount of drug used, a fact observed ever since these agents were introduced into human and veterinary medicine. However, the rate of development of resistance appears to have accelerated in the past decade. In animals, antibiotics are not only used for therapy and prevention of bacterial infections, but are also added to animal feed to act as growth promoters. In some countries, antibiotic use for growth promotion is greater than veterinary usage.

In countries using avoparcin, al glycopeptide antibiotic, as a growth promoter, vancomycin-resistant enterococci (VRE) are commonly found in the commensal fora of food animals, on meat from these animals and in the commensal flora of healthy humans despite very limited use of vancomycin in hospitals. ${ }^{1}$ In The Netherlands in 1996 and 1998 , approximately 1500 and $1260 \mathrm{~kg}$ of vancomycin, respectively, was used for human therapy, whilst an estimated $80000 \mathrm{~kg}$ of avoparcin was used yearly in farming until 1997. By contrast, in those countries not allowing the use of avoparcin, no VRE have been detected in food animals, food of animal origin or healthy humans in the general population. "Sweden banned the use of all antibiotics as growth promoters in 1986 and no VRE have been found in the faecal flora of animals, foods of animal origin or in healthy humans from the general population ${ }^{1}$ or in hospitallized patients. The only VRE isolated from a hospital patient contained the VanB gene cluster and was acquired abroad. ${ }^{2}$ The Swedish example strongly suggests that removal of the selective pressure in animals can remove VRE from the human population in time. Moreover, not only has clonal spread of VRE occurred from animals to humans, but it has also been shown that the VanA gene cluster can be disseminated from animal to human enterococcal strains. ${ }^{3}$

In April 1997, the European Commission suspended the use of avoparcin in animals. Denmark had already for bidden its use in 1995 and Germany in 1996. After the ban in Denmark the prevalence of VRE in poultry decreased from $>80 \%$ in 1995 to $<5 \%$ in $1998 .{ }^{4}$ By contrast, the prevalence in pigs (c. $20 \%)$ did not change during this time. Similarly, in Germany a decrease in the prevalence of VRE in poultry meat decreased from $100 \%$ in 1995 to $25 \%$ of samples tested by $1997 .^{5} \mathrm{~A}$ decline in the prevalence of VRE was also seen in faecal samples of healthy persons, from $12 \%$ in 1994 to $3 \%$ in 1997 . In Italy the prevalence of VRE in poultry meats decreased from $15 \%$ to $8 \%{ }^{6}$

In this report we have shown that, in The Netherlands, within 2 years of stopping the use of avoparcin, the prevalence and numbers of VRE have decreased significantly, not only in the faecal flora of food animals but also in the endogenous flora of healthy humans. Faecal samples of (sub)urban residents and of pigs and broilers from different farms were collected in 1996 and 1999. The prevalence and degree of resistance to vancomycin, erythromycin and quinupristin/dalfopristin was determined and calculated as previously described. ${ }^{3}$

The observed decreases in the prevalence of VRE and of samples with a high degree of VRE in broilers is in accordance with the results described by others ${ }^{4-6}$ (Table). By contrast with the situation in Denmark, ${ }^{4}$ the prevalence of VRE in Dutch pig faecal samples also declined. The unexpected finding was the significant decrease in prevalence of enterococci resistant against dalfopristin/quinupristin in all three populations studied. This decrease probably, however, resulted from the antimicrobial growth promoter virginiamycin (a mixture of pristinamycins like quinupristin/ dalfopristin) being in short supply in The Netherlands during 1997 and 1998, because of production problems. No significant differences were noted for erythromycin resüstance between 1997 and 1999.

The Swedish situation and the observed decrease in VRE in Germany, ltaly, Denmark and The Netherlands after the ban on avoparcin makes it likely that discontinuation of the use of avoparcin in animals will eradicate VRE not only from animals exposed to this compound but also from the healthy human population. The observed decrease in faecal enterococci resistant to dalfopristin/quinupristin shows that the recent EU ban on the use of virginiamycin as a growth promoter may reduce the number of pristinamycin-resistant enterococci in the intestinal fiora of healthy 


\section{Correspondence}

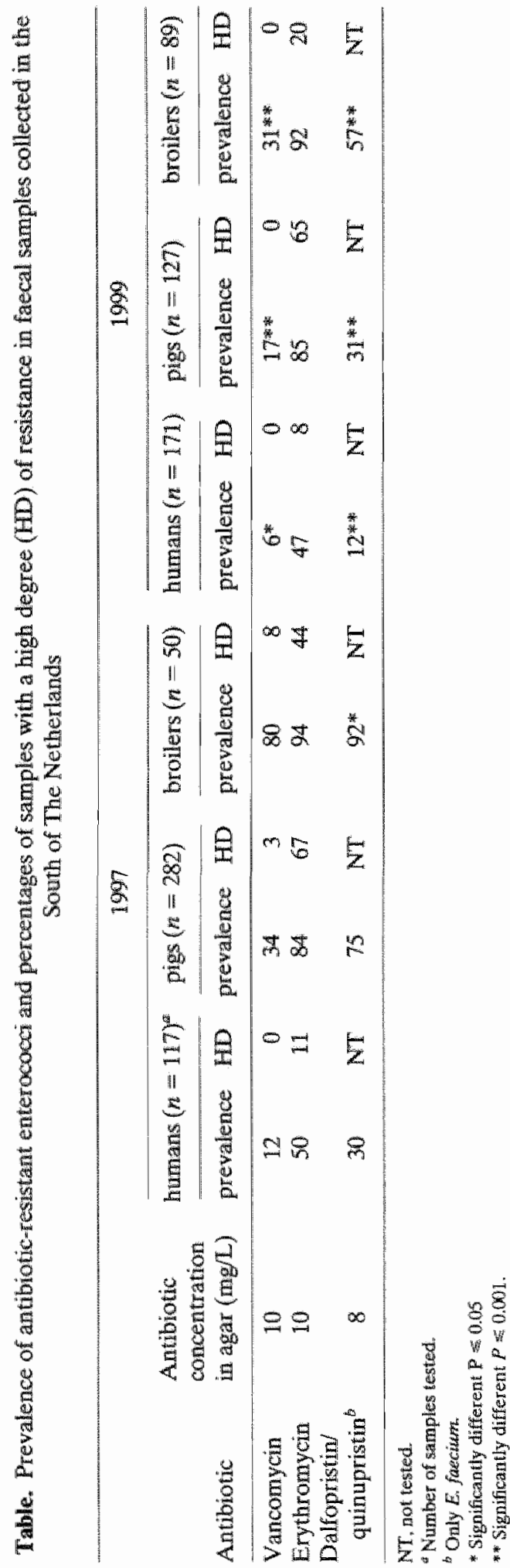

humans. However, because of cross-resistance with macrolides and lincosamides, which are both commonly used in human and veterinary therapy "complete disappearance of resistance to this antibiotic is less likely to occur.

\section{References}

1. Van den Bogaard, A. E. \& Stobberingh, E. E. (1999). Antibiotic usage in animals: impact on bacterial resistance and public health. Orugs 58, 589-607.

2. Torell, E., Cars, O., Ollsson-Liljequist, B., Hoffman, B. M., Lindbăck, J. \& Burman, L. Gi, (1999). Near absence of wancomycin resistant enterococci but high carriage rates of quinolone-resistant, ampicilin-resistant enterococci among hospitalized patients and non-hospitalizad individuals in Sweden. Joumal of Clinical Microb:ology 37, 3509-13.

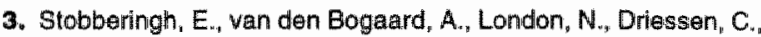
Top, J. \& Willems, R. (1999). Enterococci with glycopeptide resistance in turkeys, turkey farmers, turkey siaughterers and (sub)urban residents in the South of the Netherlands: evicience for transmission of vancomycin resistance from animals to humans? Antimicrobial Agents and Chemotherapy 43, 2215-21.

4. Bager, F., Aarestrup, F. M. Madsen, M. \& Wegener, H. C. (1999). Glycopeptide resistance in Enterococcus faecium from broilers and pigs following discontinued use of avoparcin. Microbial Drug Fiosistance $5,53-6$.

5. Kare, I. Badstrübner, D., Konstabell, $C$. Böhme, $G$, Claus, $H_{\text {. }}$ Witte, W. ot al. (1999). Decreased incidence of VanA-type vancomycin-resistant enterococci isolated from poultry meat and from faecal samples of humans in the community after discontinuation of avoparcin usage in animal husbandry. Microbial Drug Resistance 5 , 45-52.

6. Pantosti, A, Del Grosiso, M. Tagliabue, S., Nacri, A. \& Caprioli, A. (1999). Decreased of vancomycin-resistant enterococci in poultiry meat after avoparcin ban. Lancet $354,74 \|=2$. 


\section{Discussion}

"So far pericillin has been under strict control, but soon it will be on sale in the chewists shops. It is to be boped that it will not be abused, as were the sulfonamides. It is the only chemotherapeutic drug which bas no toxic properties so there is no medical reason for under dosage. It is the administration of too small doses. which leads to the production of resistant stratis of bacteria, so the rule in penicillin treatment should be to give enough. If more than enough is given there is no barm to the patient but merely a litle waste -but that is not serious when there is a plentiful supply. But I am not giving you a discourse on penicillin. Suffice it to say that it bas made medicine and surgery easier in many directions, and in the neat futwre its merits will be provided in veterinary medicne and possibly in borticulture."

Sir Alexander Fleming (1946) 1

Although the "antibiotic era" dates from Fleming's discovery of the effects of the fungus Pevicillium notatum in 1928 , it was not until the early 1940 s that penicillin could be produced in a sufficiently concentrated and pure form to treat a human. Over the following six decades the development and marketing of new classes of antibiotics increased exponentially and now more than 50 penicillins, 70 cephalosporins, 12 tetracyclines, 9 macrolides, 8 aminoglycosides and 9 fluoroquinolones (among many others) are clinically available ${ }^{2}$.

Few developments in the history of medicine have had such a profound effect on human life and sociery as the possibility to control bacterial infections. The first advances following the discovery of micro-organisms as causes of diseases, were mainly the results of improved sanitation and hygiene, which removed some of the worst foci of infectious diseases and limited the spread of infections by insects, vermin, and contaminated water and food. The development of antisera, vaccines and the introduction of antisepsis and later aseptic techniques, which still play an important part in the prevention of infections today, achieved the earliest effective direct control of infections. The arrival of antibiotics, however, changed human and veterinary medicine completely. For the first time in history the cause of a bacterial infection could be treated and often-lethal bacterial diseases cured easily. Indeed it has been suggested that the introduction of antibiotics has added ten years to the average life expectancy of humans ${ }^{3}$.
The availability of antibiotics made the future look bright and the successes helped to foster the belief among the general public, the medical community, politicians and researchers that bacterial diseases would soon be conquered. In 1969 the Surgeon General of the United States stated that it was time "to close the book on infectious diseases" and that research and public health attentions could safely shift to orher problems. For the past 60 years these life-saving drugs have been used wirly unrestrained enthusiasm far surpassing the needs of therapy, control and prevention of infection, despite the early warnings about the emergence of resistance in pathogenic bacteria and in the intestinal flora ${ }^{4-6}$. Consequently there has been steady progressive erosion of the efficacy of antibiotics by a rising tide of acquired resistance in parhogenic bacteria. Fortunately total inability to control resistant bacteria is, so far, a rarity. The trouble is that this situation may not persist and that it will ultimately jeopardise our continued ability to cure bacterial infections. Not many real new antibiotics are expected to become clinically available in the near future and the new ones being marketed will mainly be used to treat infections with multiresistant bacteria, making sure that eventually resistance will also emerge in these pathogens.

When antibiotics became available to veterinary surgeons their approach was not different to that of the medical profession. Prior to that time veterinary practice was characterised by local and systemic bacterial infections for which only palliative treatment was avail- 
able. In addirion for a few animal diseases antisera existed. Economic losses due to epidemics could be devastating, which caused farmers to keep only limited numbers and several species of animals on their farms to spread risks. Apart from the successful trearment of individual animals, the availability of safe and (too) cheap antibiotics made it possible to treat, control and prevent epidemics caused by pathogenic bacteria that traditionally interfered with large scale animal production. As a result herd sizes increased and farmers often specialised in keeping only one species. In this so-called intensive-farming animals are kept in large numbers closely housed together. Infection control measures are aimed at the prevention of introduction of pathogenic micro-organisms into a stable or farm, but within a stable or unit micro-organisms can spread unchecked among the animals present. As animals intended for human food in intensive farming systems have short lives and bacterial infections among young animals are common, large amounts of antibiotics are necessary to control these infections and to prevent severe economic losses. Because crowding, poor hygiene and high antibiotic use are typical features of intensive farming, resistance is commonly encountered among for animals pathogenic bacteria in such premises. This causes therapy failures with increased morbidity and mortality. Moreover it promotes the veterinary use of new antibiotics, which are "critical" or "essential" for human use (i. e. little or no alternate agents to treat serious or life-threatening infections in humans) and the use of which should be restricted both in human and in veterinary medicine.

Because of the growing national and international concern about the increasing resistance of bacteria to antibiorics, the need for more concerted action to prevent, delay and control is recognised. Antibiotics are some of the most acrive drugs known and their benefits for therapy and control of bacterial infections in man and orher animals are obvious. However they exert not a direct effect on humans or other animals, but kill an infecting parhogen. Unfortunately they are not narrowly targeted and will try to kill any bacterium they encounter. Animals consist of some $10^{12}$ cells per $\mathrm{kg}$ bodyweight, but only $10 \%$ of these are animal cells. The remainder are micro-organisms, mainly bacteria that make up the normal endogenous flora. Each time an antibiotic is administered, the normal flora is also exposed. These bacteria have infinitely expandable and mutable populations to adapt to the presence of antibiotics in their environment. Resistant mutants and unsusceptible species of bacteria have in the presence of antibiotics a selective advantage and will replace susceptible bacterial strains. In addition genes conferring resistance are not only passed on vertically from generation to generation, but also horizontally via plasmids and transposons to neighbouring bacteria even of different species. Furthermore, large plasmids encoding multidrug resistance can be assembled by sequential addition of other mobile resistance conferring elements (integrons and transposons) and transfer multiresistance from one bacteria to another, and from a mere commensal to a pathogen. Because this is easily acconnplished in places where a high densiry of bacteria is present, the intestinal tract forms a reservoir in which resistant bacteria and resistance genes accumulate under antibiotic pressure. Consequently the prevalence and degree of resistance in the intestinal flora of a population can therefore be used to estimate the antibiotic use in that population and to predict resistance to be encountered in pathogens ${ }^{7}$. That man and animals share a common pool of resistant bacteria and resistant genes is clear. Hence it remains logical to accept that antibiotic resistance in animals contributes to antibiotic resistance in humans. Resistant animal bacteria can reach humans either directly or indirectly via food products of animal origin. Control of resistance in animals is thus not only of importance to maintain the clinical efficacy of antibiotics in veterinary medicine, but is also a public health issue.

In this thesis the prevalence and degree of resistance of Escherichia coli and enterocooci (these are considered indicator bacteria) in faecal samples of different human and animal populations were used to detect dissemination of resistant bacteria and resistance genes from food animals to the human intestinal flora. The results indicated that the prevalence and degree of resistance observed in E. coli and enterococci in the faecal flora of poultry and fartening pigs strongly correlared with the amounts of antibiotics these animals were exposed to. Recent exposure to high doses or prolonged exposure not only caused an increase in the prevalence i.e. the numbers of animals colonised with resistant bacteria, 
bur also in the numbers excreted per gram faeces. In humans it has been found that persons with a high degree of resistance in their faecal flora also excreted resistant bacteria more persistently and over a longer period of time than people with a low degree of resistance ${ }^{8}$. In food animals an increase of resistant bacteria in the faecal flora means that more resistant bacteria are excreted into the environment and a heavier contamination of carcasses with resistant bacteria. Foods of animal origin are frequently contaminated with resistant bacteria and humans can acquire resistant bacteria in their intestinal flora via food 9 . Persons in direct contact with animals, with a high prevalence or degree of resistance, have also more resistant bacteria in their faecal flora than other human populations and the observed resistances correlate with those in the animals they are in direct contact with. Moreover, direct clonal transmission of resistant bacteria from animal to humans and transfer of resistance genes of animal bacteria to bacteria of the endogenous flora of humans and to human pathogens have been shown. These observations provide strong evidence that antibiotic resistant bacteria and resistance genes spread to man via the food chain. To minimise public health risks it has been proposed that a low prevalence and a low degree of resistance in the faecal flora should be considered as a safety and quality mark of food animals 10,11 . As prevention of cross-infection is not feasible in these animals, the large volumes of antibiorics used in food animals must be reduced. Of course we cannot stop treatment of animals we are responsible for in cases of serious bacterial infections. However the dependency on antibiotics in intensive farming should be diminished. Antibiotics should no longer be considered as a mere management tool to make up for suboptimal husbandry practices, but as a non-renewable resource only to be used in case of an outbreak of a bacterial infection. On every occasion that the therapeutic use of antibiotics is indicated, measures should be taken at the same time to prevent the reappearance of this infection in the future. These preventive measures could include improved housing and animal husbandry, adaptation of feed and feeding practices, and disease eradication or vaccination. Cost should never be the prevailing factor and even if these measures are more expensive than regular medication of the whole herd or flock with antibiotics they must be applied. Antibiotics are not intended for prevencion of infections or suppression of disease symproms. Therefore preventive usage of antibiotics in whole herds or flocks should only be allowed if the efficacy of such a practice has been proven, and no other preventive measures are available. Every time, that antibiorics are used, a risk-benefit assessment should be made. Certain public health risks are acceptable in case of therapy to prevent animals suffering and to stop an outbreak of a bacu terial disease on a farm; in contrast antibiotic usage for mere economic reasons is not acceptable. The use of AMPG is responsible for nearly $50 \%$ of all antibiotics used world wide in animals and is justified on the assumption that it might facilitate production of more food more cheaply. Apart from the fact that these effects in a serting of good animal husbandry are very minimal, most AMGP are used in food rich societies, where obesitas rather than hunger is the major public health problem. What are the potential benefits in this case, that justify any delay in elimination of the risk? The argument that AMGP suppress bacterial infections in food animals is not valid, as these drugs are not registered for therapy and prevention of bacterial diseases but registered only as a feed additive to enhance performance. Continuous feeding of antibiotics is not a suitable way to tackle infection problems. However, certain drugs, until recently used as $A M G P$ in the $\mathrm{EU}$. could be valuable supplements to the existing veterinary antibiotic arsenal e.g. for treatment of clostridial and Brachyspira-infections in poultry and pigs. The amounts used for therapy will be considerably lower than as AMGP, because only a small proportion of all food animalls will need these drugs and only during a short period of time. Stopping the lavish use and misuse of antibiotics in food animals will be an important step forward in increasing the safety of foods of animal origin and help to maintain the efficacy of antibiotics in veterinary medicine in the future. Phasing out of antibiotics as AMGP is a first and major step forward and the development of concensus formularia for antibiotic therapy in animals a second. These measures alone, however, will by no means solve the resistance problem in human medicine. The major cause of resistance in human pathogens is the (over) use of antibiotics in humans. Other sectors witli a high use of antibiotics are aquaculture, plant culture, and food and wood conser- 
vation. It is fruitless, however, to apportion blame. A more productive route for all sectors involwed is to recognise the problem and agree on strategies to slow down the loss of important drugs from our therapeutic armament. With the phasing out of AMGP use and strict adherence to an agreed upon veterinary antibiotic policy the animal production sector and the veterinary sector in the Netherlands are heading for the right direction. Decontamination of animal carcasses with organic acids such as lactic acids might help to decrease the public health risk of antibiotic use in animals and of zoonotic infections, e.g. salmonellosis and campylobacteriosis even further. However, continuous information and eduction of butchers and consumers about meat handling and hygiene remains necessary.

\section{REFERENCES}

1. Flemming, A. (1946) Chemotherapy: yesterday, today and tomorrow, Cambridge University Press, Cambridge.

2. Bartlert, J. G., and Froggatt, J. W. (1995). Antibiotic resistance, Archives of Otolaryngology Head \& Neck Surgery 121, $392-396$
3. Donowit, G. R., and Mandell, G. L. (1988). Beta-Lactam antibiotics., New Eng J Med 318, 419-426.

4. Abraham, E. P., and Chain, E. (1940). An enzyme from bacteria able to destroy penicillin, Nature 146,837 .

5. Kirby, W. M. M. (1944). Extraction of a highly porent penicillin inactivator from penicillin resistant staphylococci. Science $99,452-455$.

6. Finland, M. (1955). Energence of antibiotic resistant bacteria, New Eng I Med 21/22/23, 909-922 969-979 1019-1028.

7. Lester, S. C., dell Pilar, M., Wang, F., Perez-Schael, I., Jiang, $H_{\text {, and }} \mathrm{O}^{\prime}$ Brien, T. F. (1990). The carriage of Escherichia coli resistant to antimocrobial agents by healthy children in Boston, in Caracas, Venezuela, and in Qin Pu, China, The New England Journal of Medicin 323, 285-289.

8. London, N., Nijsten, R, wan den Bogaard, A., and Stobberingh, E. (1994). Carriage of antibiotic-resistant Escherichia coli by healthy volunteers during a 15-week period, Infecrion 22, 187-192.

9. Corpet, D. (1988). Anribiotic resistance from food, New Engl Med J 318, 1206-1207.

10. van den Bogaard, A. E. (1997). Antimicrobial Resistance Relation to Human and Animal Exposure to Antibiotics, Journal of Antimicrobial Chemocherapy 40, 453-454.

11. van den Bogaard, A. E., and Stobberingh, E. E. (1996). Is it. time to ban all antibiotics as animal growth-promoting agents? + reply and authors' reply. The Lancet 1996; 348:619 and $1454-1456$. 


\title{
Summary
}

\author{
"De roos heeft gauw gedaan, de doornen blijven staan." \\ (Roses wither soon, but their thorns remain.) \\ Jacob Cats (1577 - 1660), Dutch statesnan, poet and moralist.
}

Antibiotics are the most effective and safest drugs ever developed. Their efficacy as therapeutics is, however, threatened by the emergence of antimictobial resistance in pathogenic bacteria.

In the introduction the reasons for the antimicrobial resistance problems encountered today in (potentially) pathogenic bacteria are discussed. This seems to be the result of an important unwanted side effect of antibiotics. Because these drugs are not selective they kill not only pathogenic bacteria, but all susceptible bacteria that they encounter. This results not in a decrease of bacterial numbers, because susceptible bacteria are replaced by unsusceptible species and strains with acquired resistance. This is called selection of resistance. Because resistant bacteria exchange genes conferring resistance relatively easily, the lavish use of antibiotics in human and veterinary medicine, animal husbandry and agriculture, has caused an enormous increase of resistant bacteria in the intestinal flora of man and other animals, which are excreted into the environment. These resistant bacteria form an enormous reservoir of resistance genes for (potentially) pathogenic bacteria. Resistant bacteria of food animals can reach the intestinal tract of humans either directly or via the food chain. In the case of pathogenic bacteria this is a cause of zoonotic food borne infections like salmonellosis, but non-pathogenic species might either colonise the human intestinal tract or transfer their resistance genes to bacteria of the human intestinal flora. This is called dissemination of resistance. Despite that resistance is an inevitable sequel of antibiotic use, it can be limited by decreasing the selection pressure i. e. using less antibiotics (read: use them only if necessary) and by prevention of dissemination of resistant bacteria by improving hygiene and sanitation.
In chapter I the usage of antibiotics in animals is attended to. Antibiotics are given to animals not only for therapy, control and prevention of bacterial infecrions on prescription of a veterinary surgeon, but also continuously added as antimicrobial growth promoter (AMGP) to feeds of food animals to enhance growth, feed digestion and performance and to decrease animal waste. In the EU and the USA approximately $50 \%$ of all antibiotics ( $\mathrm{kg}$ active ingredient at 100\% purity) are used for animals and more than $95 \%$ of these antibiotics are given to animals producing food for human consumption. However, large differences between countries exist. The selection pressure on animal bacteria by therapeutic antibiotics and AMGP is high, which causes not only resistance in animal pathogens, but also in zoonotic pathogens and in the intestinal flora of these animals. As to the excent to which antibiotic use in animals contributes to ancibiotic resistance in humans is still under debate, the literature on this aspect is reviewed. Clonal spread of antibiotic resistant bacteria such as E. coli, Salmonella spp. Campylobacter spp. and enterococci from food animals to humans has been described as well as transfer of resistance genes of animal bacteria to the human endogenous flora and human pathogens. At this moment the only way to minimise this public health risk is to use fewer antibiotics in food animals. Stopping the mere economic use of antibiotics as AMPG would diminish the overall use in animals by $30 \%-50 \%$.

In chapter II ways to minimise the use of antibiotics in veterinary medicine without hampering optimal weterinary care are discussed. This might be done by developing a veterinary antibiotic policy or prudent use guidelines for optimising the use of antibiotics by, or under supervision of, veterinary surgeons, also taking into account prevention of selection and dissemination 
of resistant bacteria. The backbone of such a policy is the establishment of antibiotic formularies or guidelines: preferred and limited lists of antibioners for more than $90 \%$ of the indications for which antibiot therapy is warranted and regularly encountered in vererinary practice. If several antibiotics can be used, a formularium must differentiate berween hrots, second and third choice antibiorics. Antbiotics that are very important in human medicine or that are andalogues of such antibiotics are always third chotce antibiotics. They can only be used after susceptriblity testing has shown that first or second choice antibiotics are not effective. Such practical cinical guidelines are not only of great help to veterinary surgeons but also prevent policies and prudent use guidelines of becoming a dead letter or only a politically intended lip service. The need. for continuous surveillance of antibioric resistance and use in animals is discussed as being essential a key factors for evaluation of the impact of formularia and a timely adaptation of the formularium recommendations, and to provide an early warning system for new resistance problems that might occur.

In the following chapters the prevalence and degree of resistance in faecal indicator bacteria: $E$. coli and enterococci were used to detect selection and dissemination of resistant bacteria and resistance genes among animals and from food animals to the human intestinal fora. The prevalence $(\%)$ of resistance against a certain antibiotic is the number of samples containing bacteria (Escherichia coli or enterococci) resistant against that antibiotic divided by the total number of samples and multiplied by 100 . The degree of resistance (\%) against an antibiotic in a faecal sample is the percentage of $E$. colior enterococci resistant to that antibioric relative to the total number of $E$. coli or enterococci present in a sample.

In chapter III the prevalence and degree of antibiotic resistance of the faecal indicator bacteria: $E$. colt and enterococci, were determined in faecal samples of pigs collected at five Durch abattoirs and in samples of Swedish pigs. In the Durch pig populations the prevalence and degree of resistance both of $E$. coli and enterococci were high for antibiotics regularly used in pig medicine or as AMGP. Differences were observed between the five abatroirs, but could not be explained as no data on antibiotic consumption of the different pig populations could be obtained. In the Swedish samples the resistance of enterococci against antibiotics. used as AMGP was significantly lower than in the Dutch populations and avoparcin resistance was even absent. This was to be expected as Sweden had already banned the use of AMGP in 1986. The overall lower prevalence and degree of resistance against therapeutically used antibiotics observed in the Swedish pig samples compared to the Dutch pig populations, clearly indicated that banning the use of antibiotics as AMGP does not inevitably cause a higher therapeutic use of anribiotics in pigs. Moreover comparison of the results of the Swedish and Dutch samples showed that monitoring the prevallence and degree of resistance in faecal samples collected at slaughterhouses can be used ro derecr differences in antibioric consumption berween different pig populations.

In chapter IV the prevalence and degree of resistance against antibiotics commonly used for therapy or as AMGP in poultry were determined in the faecal flora of rurkeys and three human populations, each with a different level of contact with turkeys: turkey farmers, turkey slaughterers and (sub)urban residents, was described. The prevalence of vancomycin resistant enterococci (VRE) was significantly higher $(62 \%)$ in turkeys fed avoparcin than in turkeys not exposed to this drug $(8 \%)$. No significant differences between farmers using avoparcin (37\%) and those who did nor $(42 \%)$ were observed. The prevalence in turkey slaughterers and (sub)urban residents was $20 \%$ and $13 \%$ respectively. The Pulsed-field gel electrophoresis (PFGE) patrerns of the isolated VRE in the different populations were quite heterogeneous, but isolates with the same pattern (similar genotypes) were found among turkey and turkey farmer isolates. On two occasions Enterocacus faecinm isolates with identical PFGE patterns were found in the faeces from the farmer and turtheys of the same farm, which in addition, contained an indistinguishable $\operatorname{Van} A$ containing element not found in human isolates before. This strongly suggested transfer of resistant enterococci from animals to humans. Moreover similar VanA elements were nor only found. in isolates with the same PFGE patterns, but also in other strains isolated from humans and turkeys, which indicated that not only did clonal spread of resistant strains occur, but also a spillover of resistance genes of 
turkey enterococci to enterococci in the human intestinall flora.

In chapter VI the prevalence and degree of antibiotic resistance of enterococci in the faecal flora of two chicken populations, i.e. laying hens with a low, and broilers with a high exposure to antibiotics were determined and likewise in faecal samples of laying hen farmers, broiler farmers and poultry slaughterers. The prevalence and degree of resistance for most antibiotics tested was higher in broilers than in laying hens, and in broiler farmers and broiler slaughterers than in laying hen farmers. Hence a clear correlation was found between the prevalence and degree of resistance found in faecal enterococci and the amounts of antibiotics the chicken populations were exposed to. Among the hum man populations there was no difference in antibiotic consumption and the observed prevalence and degree of resistance correlated with these parameters in the animals they were in contact with. The overall prevalence of resistance of faecal enterococci was significantly higher in broilers and broiler slaughterers than in laying hen farmers. The PFGE patterns of the isolated VRE (one per VRE positive faecal sample) of the five populations were quite heterogeneous, but in two cases Enterococcus birae with identical PFGE parterns were isolated from the farmer and from broilers from the same farm. Moreover, similar VanA-elements were not only found in isolates with the same PFGE-patterns but also in other VRE isolated from humans and chickens. These results strongly indicate transmission of resistant enterococci from poultry to man, both by clonal spread and by transposon transfer from animal strains to enterococci in the human intestinal flora.

In chapter VI the prevalence and degree of resistance of $E$. coli were derermined in faecal samples of three poultry populations: broilers and turkeys commonly exposed to antibiotics and laying hens with a low usage of antibiotics. In addition faecal samples of five human populations were examined: turkey and broiler farmers, laying hen farmers and broiler slaughterers and turkey slaughterers. The antibiotics tested or analogues are commonly used in poultry medicine. Ciprofloxacin resistant isolates from these 8 populations and from poultry mear samples were genotyped by PFGE. The prevalence and degree of resistance was significantly higher in turkeys and broilers than in the laying hen population. Also for most antibiotics the observed resistance in faecal $E$. cols of turkey and broiler farmers, and of turkey and broiler slaughterers, was higher than in laying hen farmers. The same resistance patterns were found in turkey, turkey farmer and turkey slaughterer isolates, and in broiler, broiler farmer and broiler slaughterer isolates. Multiresistant isolates were common in turkey and broiler farmers but absent in the laying hen farmer population. The PFGE parrerns of the isolates from the eight populations were quite heterogeneous, but on two occasions $E$ coli strains with an identical PFGE pattern were isolated from turkeys and the farmer from the same farm, and also from a broiler and a broiler farmer but from two different farms. Moreover, three $E$. coli isolates from turkey meat were identical to faecal isolates from tur"keys. The results of this study strongly suggest that transmission of resistant clones of $E$. coli and resistance plasmids from poultry strains to human E. coli does commonly occur.

In chapter VII another approach, different from reducing antibiotic usage, to lower the prevalence and degree of resistance in faecal $E$. coli of food animals, was investigated. The "plasmid curing effect" of an AMGP: flavophospholipol, which had been described to occur in vitro and in vizo under experimental conditions, was studied under freld conditions. The prevalence and degree of resistance of the indicator bacteria $E$ coli and enterococci, were derermined in faecal samples of three groups of pigs being fattened at the same farm. During the last 12 weeks before slaughtering, one group received feed without any AMGP (negative control group), another group was given the same feed with 9 mg/kg flavophospholipol (study group) and the third group the same feed with $15 \mathrm{mg} / \mathrm{kg}$ avoparcin (positive control group). Faecal samples of each pig were collected at the start and at the end of the study and assessed for the prevalence and degree of resistance against antibiotics or analogues, either commonly used for therapy in pig medicine or as AMGP. Before the start of the study all pigs were colonised with multiresistant $E$. coli by mixing three resistant pig isolates through their feed.

The overall prevalence and degree of resistance of $E$. coli in the faecal flora increased significantly during the study in the negative control group and avoparcin ex- 
posed group, but in the flavophospholipol group levels remained the same as at the start of the study. Before the study, in all three groups, the numbers of VRE were below the detection limit of the used isolation methods. At the end of the study the prevalence of vancomycin resistance was $44 \%$ and $41 \%$ in the negative control and flavophospholipol group respectively but only wery low numbers of VRE per gram faeces were found. In the avoparcin fed group the prevalence was $72 \%$ and in $57 \%$ of the samples the majority of all enterococci present were vancomycin resistant. It was concluded that flavophospholipol under the study conditions effectively suppresses the amplification and dissemination of multiresistant $E$. coli in the intestinal flora of fattening pigs and that avoparcin use strongly selects for VRE. After confirmation of this effect of flavophospholipol in a large field study including several different farms, the significantly lower prevalence and degree of resistance of faecal $E$. coli in flavophospholipol fed animals might in a risk-benefit analysis outweighti the small increase of the risk of transfer of flavophospholipoll resistant $E$. faecalis from animals to humans via the food chain. In chapter VIII the effect of the suspension of avoparcin usage as AMGP in the Netherlands in 1997 was assessed. The prevalence and degree of enterococci against three antibiotics important for human therapy and closely related to and cross resistant with three commonly used AMGP were analysed in faecal samples of pigs and broilers collected at the same slaughterhouses in 1997 and 1999, and from healthy human (sub)urban residents from the same cities and collected in the same years. The prevalence of VRE decreased significantly in all three populations. Erythromycin resistance did not change, but dalfopristin-quinupristin resistance had declined, despite the fact that the use of the related AMGP i.e. virginiamycin, was not forbidden at that time. Virginiamycin, however, was in short supply in the Netherlands in 1998 and 1999, because of production problems. These results indicate that continuation of the ban in the Netherlands on the use of avoparcin in animal feeds will not only eradicate VRE from food animals but also from the human population. Because of cross-resistance with macrolides and lincosamides, which are both commonly used in human and veterinary medicine, complete disappearance of pristina- mycin resistance after a ban of virginiamycin is less likely to occur. The use of vancomycin in humans had not changed berween 1997 and 1999. Therefore the results of this study again show that use of antibiotics in food animals not only causes resistance in the intestinal flora of these animals but that these resistant bacteria or rheir resistance genes are transferred to humans via the food chain.

In the discussion it is concluded that 60 years of lavish usage of antibiotics in human and veterinary has progressively eroded the clinical efficiency of antibiotics because of a rising tide of acquired resistance in parhogenic bacteria. However resistance in pathogens is only the top of the resistance iceberg and an enormous reservoir of resistance genes has accumulated in the intestinal flora of man and other animals. Fortunately there is a growing national and international concern about the increasing resistance and the need for more concerted action to prevent, delay and control bacterial resistance against antibiotics is generally recognised. In addition to other studies in the literarure, the studies in this thesis show clearly that man and animals share a common pool of resistant bacteria and resistance genes and that resistant bacteria from food animals can reach humans either directly or via the food chain. Because antibiotic use in animals selects for bacterial resistance in the endogenous flora of these animals, it is logical to accept, as has been proven, that antibiotic use in animals contributes to certain resistance problems in human medicine. This makes control of antibiotic use in food animals not only of importance for maintaining the clinical efficacy of antibiotics in veterinary medicine, but also as a public health issue. Therefore a low prevallence and degree of antibiotic resistance in the faecal flora of food animals is to be considered as a safery and quality benchmark for food animals. This goal can only be achieved by lowering the need for therapeutic antibiotics in these animals and by stopping to use them for mere economic reasons as AMGP. These measures alone, however, will by no means solve resistance problems in human medicine, as the major cause of resistance in human pathogens is the (over) use of antibiotics in humans. It is fruitless, however to apportion blame. A more productive approach for all sectors involved is to agree upon strategies to prevent the loss of these important drugs from our thera- 
peutic armament. With the strict adherence to a vererinary antibiotic policy, agreed upon by consensus, and the phasing out of AMGP usage the veterinary and animal producrion secrors in The Netherlands have clearly shown to take their responsibility for public health seri- ously. Additional decontamination of animal carcasses after slaughrering might decrease the risk of transfer of bacterial resistance and of zoonotic infections like salmonellosis, from animals to humans even further. 


\title{
Samenvatting
}

\author{
"De roos heeft gauw gedaan, de doornen blijven staan." \\ Jacob Cats (1577-1660), staarsnan, dichter en moralist.
}

Antibiotica zijn de meest effectieve en veilige geneesmiddelen, die we kennen. Hun werkzaamheid dreigt echter af te nemen door de antimicrobiële resistentie, welke in toenemende mate bij pathogene bacteriën voorkomt.

In de inleiding wordt deze resistentie-problemariek besproken. De belangrijkste ongewenste bijwerking van antibiotica is dat zij niet alleen (potentieel) pathogene bacteriên doden of in hun groei remmen, maar iedere gevoelige bacterie. Dit heeft echter geen daling van het totaal aantal. bacteriër tot gevolg, omdat de gedode gevoelige bacteriën onmiddellijk vervangen worden door resistent geworden bacteriën en door ongevoelige soorten. Dit wordt selectie genoemd.

Bacteriën kunnen bovendien onderling relatief gemakkelijk genen, die coderen voor resistentie-eigenschappen, uirwisselen. Als gevolg van het jarenlange kwistig gebruik van antibiotica in de (dier)-geneeskunde, veeteelt en landbouw zijn de aantallen resistente bacteriën in de darmflora van mens en dier en in her millieu enorm toegenomen. Deze resistente commensale bacteriën vormen een reservoir van resistentie-genen voor (potentieel) pathogene bacteriën. Resistente bacteriën uit de darmflora worden bovendien uitgescheiden mer de faeces. Omdat tijdens het slachtproces vlees veelal besmet wordt met darmbacteriën van slachtdieren, kunnen mensen nier alleen door direct contact besmet worden met resistente bacteriën, afkomstig van slachtdieren, maar ook indirect via voedingsmiddelen van dierlijke oorsprong. Wanneer het pathogene bacteriën zoals salmonellae betreft, zal dit vaak een (voedsel) infectie veroorzaken. Echter in geval van andere niet-pathogene bacteriën uit de darmflora van dieren kunnen mensen ongemerkt door deze resistente bacterièn gekoloniseerd worden of kunnen deze bacteriën hun resistentie-genen aan bacteriën van de darmflora van de mens overdragen. Dit heet verspreiding van resistentie.

Ondanks het feit dat selectie en verspreiding van resistentie onvermijdelijk gevolgen zijn wan het gebruik van antibiotica, kunnen de gevolgen beperkt worden door de selectiedruk te verminderen door minder antibiotica te gebruiken (lees: antibiotica alleen te gebruiken indien noodzakelijk). Verspreiding kan men voorkomen én door vermindering van het antibioticum gebruik én door het werbeteren van de hygiène en sanitaire maatregelen. Bij producten van dierlijke oorsprong betekent dit decontaminatie van karkassen na het slachten, een goede hygiëne in slagerijen en keukens, en verhitting van het eindproduct voor consumptie.

In hoofdstuk I wordt het gebruik van antibiotica bij dieren besproken. Antibiotica worden aan nutsdieren niet alleen toegediend voor behandeling en preventie van bacterièle infecties op voorschrift van de dierenarts, mat ook continu door her veevoer gemengd als antimicrobiële groeibevorderant (AMGB) om de groei te bevorderen, de voederconversie te verbeteren en de mestproductie te verminderen. Ongeveer de helft van alle antibiotica (kg actieve stof) wordt in de EU en in de USA gebruikt voor dieren en meer dan $95 \%$ hiervan is bestend woor dieren die voedsel produceren woor menselijke consumptie, zogenaamde nutsdieren. De selectiedruk door antibioticagebruik bij nutsdieren is dus hoog. Dit veroorzaakt niet alleen resistentie bij bacteriën, die parhogeen zijn voor dieren, maar ook bij zoönotische bacteriën en bij bacteriën die behoren tot de normale darmflora van nutsdieren.

Omdar het nog niet duidelijk is in welke mate deze resistentie-selectie door antibioticagebruik bij dieren bijdraagt aan de resistentie-problematiek bij de mens, zijn de bestaande gegevens uit de literatuur over dir onderwerp samengevat en geèvalueerd. Klonale verspreiding van resistente bacteriën zoals Ecoli, Salmo- 
nella spp., Campylobacter spp. en enterokokken van nutsdieren naar mensen is bewezen en blijkt regelmatig voor te komen. Echter ook overdracht van resistentie-genen van faecale bacteriën van nutsdieren naar de darmflora van mensen en voor mensen pathogene bacreriën is aangetoond. De enig haalbare manier om dit risico woor de volksgezondheid te reduceren is om minder antibiotica aan nutsdieren te geven. Stoppen met het gebruiken van antibiotica alls AMGB om puur economische redenen zou het totale antibioticumgebruik bij dieren in éen keer mer 30\%-50\% verminderen.

In hoofdstuk II worden mogelijkheden besproken om het diergeneeskundig gebruik van antibiotica te verminderen zonder het welzijn van dieren te schaden. Een belangrijke stap in dit proces is het opstellen van een veterinair antibioticumbeleid of richtlijnen voor het zorgvuldig gebruik van antibiotica. Een antibioticumbeleid is erop gericht om her gebruik en voorschrijven van antibiotica door dierenartsen te optimaliseren door regels op te stellen betreffende indicaties voor antibioticagebruik. Een essenticel onderdeel is het opstellen van formularia: richtlijnen, waarin voor meer dan $90 \%$ van de indicaties in de veterinaire praktijk adviezen worden gegeven of, en zo ja, welk antibioticum bij voorkeur gebruikt moet worden. Bij de keuze dient men naast effectiviteit ook rekening te houden met de kans op resistentie-ontwikkeling mer het doel on dexe zoveel mogelijk te voorkomen. Het antal geadviseerde antibiorica is zoveel mogelijk beperkt en, indien voor een indicatie meerdere antibiotica geschikt zijn, wordt een volgorde aangegeven van middelen van eerste, tweede of derde keuze. Antibiotica, die gebruikt worden voor de behandeling van levensbedreigende infecties bij mensen en warvoor geen alternatieven (meer) bestaan, zijn in diergeneeskundige formularia altijd derde keuze middelen. Deze mogen alleen gebruikt worden als bacteriologisch onderzoek heeft uitgewezen dat de verwekker niet gevoelig is voor een eerste of tweede keuze antibioticum. Dergelijke praktische richtlijnen zijn niet alleen erg handig voor praktiserende dierenartsen, maar verhinderen ook dat her antibioticumbeleid verwatert en een dode letter wordt. Ook wordt daardoor voorkomen dat een antibioticumbeleid of richtlijnen voor zorgvuldig antibioticum gebruik alleen worden geformuleerd om politiek move- rende redenen en zo ontaarden in een opportunistische lippendienst. Op de noodzaak van een continue survelllance van resistentie in bacteriën geisoleerd uit zieke dieren en faecesmonsters van slachtdieren, en van het antibioticumgebruik bij dieren wordt gewezen, omdat dit essentiele woorwaarden zijn voor een goed antibioticumbeleid. Door de gegevens uit deze survelllance regelmatig te analyseren kan het effect wan de formularium-adviezen gemeten worden en kunnen, indien nodig, de adviezen aangepast worden. Bovendien worden hierdoor nieuwe resistentie-problemen tijdig onderkend, zodat interventie mogelijk is.

In de volgende hoofdstukken is de prevalentie en mate van resistentie van indicatorbacteriën in de faecale flora: E. coli en enterokokken, gebruikt om selectie en verspreiding van resistente bacteriën en resistentie-genen van nutsdieren naar de mens te onderzoeken. De resistentie-prevalentie tegen een bepaald antibioticum is het percentage monsters in een populatie, waarin E. coli of enterokokken, die resistent zijn tegen dat antibioticum, gevonden zijn. De mate van resistentie tegen een bepaald antibioticum in een faecesmonster is het percentage $E$. coli of enterokokken, dat resistent is tegen dat antibioticum.

In hoofdstuk III zijn de resultaten gepresenteerd van een onderzoek naar de prevalentie en mate van resistentie van indicatorbacteriën: Escherichia coli en enterokokken, in de faecale flora van slachtvarkens. De monsters waren verzameld aan de slachtijn op vijf Nederlandse abattoirs en in Zweden. In de Nederlandse monsters was de prevalentie en mate van resistentie van de onderzochte indicatorbacteriën tegen antibiotica, die als AMGB gebruikt worden of als geneesmiddel, hoog. Er bestonden significante verschillen tussen de monsters afkomstig van de verschillende slachthuizen. Deze verschillen konden echter niet verklaard worden omdat geen gegevens over her antibioticum gebruik in de verschillende populaties beschikbaar waren. In de Zwweedse monsters werd nauwelijks resistentie tegen de meeste $\mathrm{AMGB}$ gevonden en er werden geen vancomycine-resistente enterokokken (VRE) uit geïsoleerd Vanwege het Zweedse verbod sedert 1986 op het gebruik van AMGB in veevoeder was dit te verwachten. De lagere resistentie tegen therapeutisch gebruikte antibiotica in de Zweedse monsters toonde duidelijk aan dat een verbod op AMGB niet 
hoeft te leiden tot een toename van het veterinair gebruik van antibiotica. Bovendien bleek uit de verschillen tussen de Nederlandse en Zweedse monsters dat het bepalen van de prevalentie en mate van resistentie in faecesmonsters, verzameld op slachthuizen, een geschikte methode is om verschillen in antibioticumgebruik tussen populaties op te sporen.

In hoofdstuk IV is de prevalentie en mate van vancomycine-resistente enterokokken (VRE) bepaald in de faecale flora van kalkoenen en drie groepen mensen met een verschillende mate van intensiteit in het contact met kalkoenen: kalkoenhouders, kalkoenslachters en stadsbewoners. Bij kalkoenen, waarbij avoparcine als AMGB door het voer gemengd was, bleek de VRE-prevalenrie significant hoger $(62 \%)$ dan bij de dieren, die niet aan dat middel blootgesteld waren $(8 \%)$. Bij de kalkoenhouders werd geen verschil gevonden tussen avoparcine gebruikers $(37 \%)$ en nietgebruikers (42\%). De VRE-prevalentie in kalkoenslachters en stadsbewoners was respectievelijk $20 \%$ en $13 \%$. Genotypering met behulp van pulsed-field gel electroforese (PFGE) toonde aan dat de VRE-stammen, geïsoleerd uit mensen en kalkoenen, zeer heterogeen waren. In twee gevallen werd echter op dezelfde boerderij een genotypisch identieke $E$. faecium stam geïsoleerd uit de faeces van de veehouder en een van zijn kalkoenen. Bovendien bevatten beide genotypen $E$. faecium een identieke variant van het $V a n A-g e n$ cluster, dat nog niet eerder was aangetoond in VRE geisoleerd uit mensen. Tevens werd deze variant van het VanA-gen ook gevonden in een aantal andere genotypen van VRE geïsoleerd uit mensen en kalkoenen. Dit bewijst dat niet alleen klonale overdracht van VRE van kalkoen naar mens plaats vindt maar ook dat verspreiding van vancomycine resistentie-genen, afkomstig van kalkoenstammen, naar enterokokken in de darmflora van mensen voorkomt.

In hoofdstuk $\mathrm{V}$ is de prevalentie en mate van resistentie tegen antibiotica onderzocht van enterokokken in de faecale flora van twee kippenpopulaties: legkippen en vleeskuikens en drie groepen mensen: legkippenhouders, vleeskuikenhouders en kippenslachters. Bij legkippen worden geen $A B G M$ en relatief weinig antibiotica gebruikt; bij vleeskuikens daarentegen worden relatief veel antibiotica gebruikt. Zowel de prevalentie als de mate van resistentie tegen de onderzochte antibiotica waren bij de enterokokken afkomstig van wleeskuikens hoger dan bij die van legkippen. Ook bij de vleeskuikenhouders en kippenslachters was de resistente prevalentie van de meeste antibiotica hoger dan bij legkippenhouders. Er bestond een duidelijke correlatie tussen de resistentie-prevalenties voor de verschillende antibiotica bij vleeskuikens en bij vleeskuikenhouders en kippenslachters. Van ieder VRE positief faecesmonster werd een isolaav getypeerd met behulp van PFGE. De gevonden genotypen in alle groepen waren erg heterogeen. Echter op twee boerderijen werd zowel uir de ontlasting van de pluimveehouder als van een vleeskuiken een vancomycine-resistente $E$. birat geïsoleerd, beiden met hetzelfde PFGE patroon. Moleculaire analyse van de VanAgenen van deze stammen toonde aan dat deze ook identiek waren en dat het varianten van her oorspronkelijke VanA-genencluster betrof , die voornamelijk bij pluimvee gevonden worden. Deze VamA-varianten werden niet alleen in isolaten met hetzelfde PFGE genotype gevonden, maar ook in andere genotypen, geïsoleerd uit mensen en kippen. Dit wijst duidelijk op resistentie-overdracht van kippen naar mensen. Dir kan klonale verspreiding van resistente stammen zijn, maar het lijkt dat overdracht van transposons van kippen enterokokken naar enterokokken uit de faecale flora van de mens meer voorkomt.

In hoofdstuk VI zijn de prevalentie en mate van resistentie van $E$. coli in de faecale flora van de populaties uit de hoofdstukken IV en V bepaald. Van monsters, waarin ciprofloxacine-resistente $E$. coli waren ge.. vonden, werd bovendien een ciprofloxacine-resistente stam getypeerd mer behulp van PFGE. De prevalentie en mate van resistentie was significant hoger bij kalkoenen en vleeskuikens, beide populaties mer een relatief hoog antibioticum gebruik, dan bij legkippen. Ook bij kalkoen- en vleeskuikenhouders en pluimveeslachters was de resistentie hoger dan bij legkippenhouders. Bovendien werden dezelfde resistentie-patronen gevonden bij E. coli isolaten van kalkoenen, kalkoenhouders en -slachters en in die van vleeskuikens, vleeskuikenhouders en -slachters. Multiresistentie kwam veelvuldig voor bij isolaten afkomstig van kalkoenen, veeskuikens en kalkoen- en vleeskuikenhouders, maar werd niet gevonden bij legkippen(houders). De genotypen van de ciprofloxacine-resistente $E$. coli uit de acht 
populaties waren erg heterogeen. Echter op twee boerderijen werden identieke genotypen geisoleerd uit faeces van de kalkoenhouder en zijn kalkoenen en ook uit een vleeskuikenhouder en een vleeskuiken, maar deze waren afkomstig van verschillende bedrijven. Bovendien waren drie ciprofloxacine-resistente stammen geísoleerd uit kalkoenvlees met behulp van PFGE niet te onderscheiden van het isolaat uit de faeces van een kalkoenhouder in dit onderzoek. De resultaten van deze studie geven aan dat overdracht van resistente $E$. coli stammen van kippen naar mensen en uitwisseling van resistentie-plasmiden tussen kippen $E$ coli en $E$. coli-stammen in de darm van mensen regelmatig voorkome.

In hoofdstuk VII is onderzocht of naast vermindering van antibioricumgebruik er ook andere mogelijkheden zijn om een lage prevalentic en mate van resistentie in de faecale flora van varkens te bewerkstelligen. Uit de literatuur was bekend dat een antibioticum, flavophospholipol, dat gebruikt wordt als AMGB, in vitro en in vivo onder experimentele condities de antibioticumresistentie bij $E$. coli bacteriën vermindert. Om vast te stellen of dit effect onder praktijkomstandigheden ook optreedr, werden op een boerderij drie groepen varkens afgemest, waarbij gedurende de laatste 12 weken voor het slachten voer werd verstrekt met en zonder AMGB. Een groep kreeg voer zonder AMGB (negatieve controle), cen andere groep voer met 9 $\mathrm{mg} / \mathrm{kg}$ flavophospholipol (studiegroep) en bij de derde groep (positieve controle) was avoparcine $(15 \mathrm{mg} / \mathrm{kg}$ ) an het vour roegevoegd. De prevalentie en mate van resistentie tegen $A M G B$ en antibiotica, die regelmatig therapeutisch gebruikt worden, werd bepaald bij de enterokokken en $E$. colt in faecesmonsters, individueel verzameld aan het begin en aan het einde van de studie. Vlak voor het begin van de studie waren de varkens bovendien gekoloniseerd thet drie multiresistente $E$. coli stammen afkomstig van varkens door deze te mengen door her voer. Gedurende de studie nam de prevalentie en mate van resistentie van de $E$. coli van varkens in beide controlegroepen significant toe. Echter bij de warkens uit de flavophospholipol-groep bleef de prevalentie en mate van resistentie gelijk aan de waarden, gevonden in het begin van de studie. $\mathrm{Bij}$ het begin van de studie werden in de drie groepen geen VRE gevonden. Aan het einde van de studie was de
VRE prevalentie $44 \%$ en $41 \%$ in respectievelijk de negatieve controle- en flavophospholipol-groep, maar de mate van resistentie was in beide groepen erg laag, gemiddeld circa 1\%. Bij dieren, dic avoparcine kregen, was echrer $72 \%$ wan de varkens VRE drager en bij $57 \%$ wan de dieren was de meerderheid van alle enterokokken in de faecale flora vancomycine resistent. Geconcludeerd werd dat flavophospholipol de vermeerdering en verspreiding van multiresistente $E_{\text {. coli }}$ in de darmflora van varkens voorkomt en dat avoparcine duidelijk selecteert voor VRE. Indien men in een veldproef, waarbij een groot aantal varkensbedrijven betrokken is, hetzelfde effect vindt, dient men een toekomstig verbod op het gebruik van flavophospholipol als veevoederadditief kritisch te heroverwegen. In een risico-baten-analyse zou het voordeel van een vermindering van de prevalentie en mate van resistentie in de faecale $E$. coli flora van varkens door het gebruik van flavophospholipol groter geacht kunnen worden dan het nadeel van een mogelijke selectie van resistente $E$. faecalis stammen en eventuele overdracht van dergelijke stammen naar mensen.

In hoofdstuk VIII is het effect onderzocht van het verbod op het gebruik van avoparcine in veevoeders in Nederland. Daartoe werd de prevalentie en mate van resistentie van enterokokken gemeten in faecesmon sters van slachrvarkens, slachrkuikens en gezonde vrijwilligers tegen drie voor de geneeskunst belangrijke antibiotica, nauw verwant en kruisresistent met AMGB. De faecesmonsters waren verzameld op dezelfde slach thuizen in 1997, vlak voor her verbod op het gebruik van avoparcine, en anderhalf jaar later in 1999. De faecesmonsters van de vrijwilligers waren afkomstig uit dezelfde twee regio's De VRE prevalentie was in alle drie de populaties in 1999 significant lager dan in 1997. Bij vleeskuikens daalde de prevalentie van VRE van $80 \%$ naar $31 \%$, bij varkens van $34 \%$ naar $17 \%$ en bij mensen van $12 \%$ naar $6 \%$. De resistentie regen erythromycine was gelijk gebleven, maar ook de resistentie tegen quinupristine-dalfopristine was significant gedaald, ondanks het feit dat het verwante AMGB, virginiamycine, ten tijde van het onderzoek nog niet verboden was. Het bleek echrer dat in 1998 en 1999 virginiamycine in Nederland nauwelijks beschikbaar was varnwege productie- problemen bij de producent. Deze resultaten tonen duidelijk aan dat continue- 
ring van her verbod op avoparcine niet alleen zal leiden tot een verdere werlaging en waarschijnlijk eradicatie van VRE uit de faecale flora van slachtdieren, maar ook van mensen. Aangezien het vancomycine-gebruik in Nederland tussen 1996 en 2000 praktisch gelijk is gebleven, is de waargenomen daling van de VREprevalentie bij mensen ook een bewijs dat VRE dragerschap in de faecale flora van de gezonde Nederlandse bevolking veroorzaakt wordt door avoparcine-gebruik bij dieren. De daling van de quinuprisrine-dalfopristine-resistentie duidt aan dat in geval van een verbod van andere $A M G B$ een zelfde daling verwacht kan worden. Het is echter niet waarschijnlijk dat door het verbod op het gebruik van virginiamycine als AMGB deze resistentie wolledig zal verdwijnen, omdat kruisresistentie bestaat met andere therapeutisch veel bij mens en dier gebruikte antibiotica: de lincosamides en macrolides.

In de conclusies wordt gesteld dat 60 jaar kwistig gebruik van antibiotica, met als gevolg een vloedgolf van resistente (potentieel) pathogene bacteriën, heeft geleid tot een erosie van de klinische effectiviteit van antibiotica. Men dient zich echter te realiseren, dat de waargenomen resistentie in (voorwaardelijk) pathogene bacrerièn slechts het topje wan de resistentieijsberg is. Er is tegenwoordig in de darmflora van mens en dier een geweldig reservoir van resistentie genen, waaruit pathogene bacteriën naar believen kunnen putten. Thans bestaat nationaal en internationaal bezorgdheid over de resistentie-toename en ziet men de noodzaak in om gezamenlijk en wereldwijd maatregelen te nemen ter beheersing van resistentieontwikkeling in bacteriën bij mens en dier. Uit de literatuur en ook uit het in dit proefschrift beschreven onderzoek blijkt duidelijk dat bacteriën uit de darmflora van mens en dier wat resistentie genen betreft in dezelfde vijver wissen. Resistente commensale bacteriën van nutsdieren kumnen direct, maar ook indirect, via de voedselketen, mensen besmetten, koloniseren of resistentie aan darmbacteriën vam mensen en pathogene bacteriën overdragen. Daarom is het zorgvuldig gebruik van antibiotica bij nutsdieren niet alleen van belang om de resistentie-problematiek in de diergeneeskunde te beheersen, maar ook een volksgezondheidsbelang! Een lage prevalentie en mate van resistentie in de faecale flora wan nutsdieren moet daarom beschouwd worden als een veiligheidsgarantie en kwaliteitskenmerk binnen de integrale keten beheersing systemen, die de kwaliteit van producten van dierlijke oorsprong "van zaadje tot karbonaadje" pogen te waarborgen. Dit kan alleen bereikt worden door minder antibiotica te gebruiken. Daarvoor is het nier voldoende om alleen her gebruik van antibiotica op puur economische gronden als $A M G B$ te stoppen, maar dient de dierlijke productiesector ook andere maatregelen te nemen om minder afhankelijk te worden van het gebruik van antibiotica. Echter beperking van het gebruik van antibiotica bij dieren alleen, zal de resistenrie-problematiek in de medische sector niet oplossen. Het probleem in die sector wordt namelijk voornamelijk veroorzaakt door antibioricumgebruik door mensen. Het heeft echter geen zin om elkaar over en weer verwijten te maken en te beschuldigen. Een positievere benadering is samenwerking van alle betrokkenen om gezamenlijk strategieën te ontwerpen om het dreigende verlies wan antibiotica uit het ons ter beschikking staande arsenaal geneesmiddelen te voorkomen. De Nederlandse veehouders en dierenartsen hebben duidelijk getoond dat zij hun verantwoordelijkheid voor de volksgezondheid serieus nemen door het op korte termijn afschaffen van het gebruik wan $A M G B$ en zich te confirmeren aan het afgesproken veterinaire antibioticumbeleid. Het toestaan van decontaminatie van karkassen van dieren na her slachten kan her risico van overdracht van bacteriële resistentie en pathogene bacteriên van dier naar mens op korte termijn zonder problemen nog verder doen dalen. Voorlichting aan de vleesverwerkende sector en de consument over de noodzaak van koeling, hygiënisch werken en een goede verhitting van vleesproducten, voordar men deze consumeert, blijft echter belangrijk ter woorkoming van overdracht van pathogene en/of resistente bacteriën van dier naar mens via voedingsmiddelen van dierlijke oorsprong. 


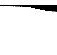




\section{Dankwoord}

Het is zover.

Dit proefschrift was nooit voltooid zonder de medewerking en vooral het stimulerende enthousiasme van vele anderen. Aangezien het onmogelijk is allen persoonlijk te noemen en bovendien dan het gevaar bestaat om iemand te vergeten, bedank ik hierbij iedereen, die direct of indirect aan de totsrandkoming van dit proefschrift heeft meegeholpen. Tevens bied ik mijn excuses aan als ik wel eens wat drammerig overkwam of mijn humeur niet optimaal leek.

Op de eerste plaats ben ik veel dank verschuldigd aan de veehouders en andere vrijwilligers die door het inleveren van faeces monsters dit onderzoek hebben mogelijk gemaakt. De directies van de coöperaties, integraties en slachterijen ben ik zeer erkentelijk voor hun welgemeende belangstelling en effectieve hulp. Zij zagen onmiddellijk het belang in dat resistentie onderzoek heeft voor hun voortdurend streven om een veilig product op de markt te brengen. Iedere keer weer wisten zij velen van hun toeleveranciers of leden te overtuigen om aan het onderzoek deel te nemen, ondanks het feit dat de resultaten volgens sommige korte termijn denkers niet altijd gunstig voor de sector uitpakten. Nooit heb ik tevergeefs een beroep gedaan op de dierenartsen en keurmeesters van de RVV om faeces monsters te verzamelen van slachtdieren. Mijn dank en ik hoop op een verdere samenwerking. Op de boerderij van de familie Mares doen wij al jaren onderzoek. Ik dank hen hartelijk voor hun interesse, hulp en begeleiding van de AIOs en stagiaires bij de verzorging van en omgang met vee, maar vooral ook voor de genoten gastvrijheid.

Tenslorte wil ik toch enige personen met name bedanken.

Verreweg de grootste bijdrage aan de totstandkoming van dit proefschrift heef mijn copromotor $\mathrm{Dr}$. E.E. Stobberingh gehad. Ellen, sedert wij na een bezoek aan het Praeventiefonds in Den Haag tijdens een aansluitende wandeling over het Scheveningse strand besloten om de door jou en mij ingediende projecten te combineren, is een effectieve samenwer- king ontstaan. Het gecombineerde onderzoek naar bacterièle resistentie in de darmflora bij gezonde mensen en bij dieren is vruchtbaar gebleken. Bovendien heb je me al die tijd bij de les gehouden en erroor gezorgd, dat ik geen kans meer had on te switchen, als een ander en naar mijn mening op dat moment interessanter onderwerp mijn aandacht trok. Ik dank je hiervoor hartelijk en ik hoop dat we nog lang mogen samenwerken. Dit soort onderzoek vereist een gedegen laboratorium ondersteuning. Dr. Nancy London, Ing. Math Hazen en Christel Driessen dank ik hartelijk voor her vele verzette werk, maar vooral voor jullie wolledige inzer, krirische kanttekeningen en waardevolle suggesties. De organisatie van het werk en de begeleiding en opleiding van de vele analisten en stagiaires was en is bij jullie in goede handen. Nogmaals bedankt.

De prettige samenwerking met en de collegiale hulp wan andere instituten heb ik zeer gewaardeerd. I want especially to acknowledge the help of Dr. Lars Jensen of rhe Danish Veterinary Laboratory in Copenhagen and Dr. Rob Willems of the RIVM in Bilthoven for typing the Vand gene clusters. Thank you both very much indeed. Peter Terporten dank ik voor de hulp, vaak tussen twee rookpauzes door, met het data management en voor de statistische analyse van de resultaten. Patricia Lucassen, Brigitte Stegen-Custers en Marlies Prein voor het ontcifferen van mijn manuscripten en het typen en hertypen van artikelen.

Mijn beide promotores, Prof. Dr. Catrien Bruggeman en Prof. Dr. Anton Pijpers, ben ik dank verschuldigd voor de psychologische ondersteuning en hun bereidheid als promotor op te treden. De leden van de leescommissie en met name de voorzitter Prof. Dr. Jos Smits voor het in een korte tijd lezen van het manuscript.

De medewerkers van de Dienst Centrale Proefdier Voorzieningen, bied ik mijn excuses aan voor mijn vaak geestelijke afwezigheid tijdens mijn anwezigheid de laatste maanden. Jullie hebben getoond zelf in staat te zijn om her CPV goed te laten funcrioneren. $\mathbb{k}$ ben 
daar trots op en ik dank jullie voor het begrip en de hulp, zodat ik tijd vrij kon maken voor de afronding van dit proefschrift. Hopelijk kan en mag ik me nu weer wat intensiever met de dagelijkse gang van zaken op het CPV gaan bezig houden.

Tot slot dank ik mijn hond Joffer en het paard Orlok, die ervoor zorgen, dat ik toch nog regelmatig in de buitenlucht verkeer. Fia en Gert zullen nu een ander onderwerp moeten verzinnen om mij op de kast te krijgen.

En, Valerie, nu gaan we samen bridgen; bedankt voor je geduld.

Allerheiligen, Maastricht, 1 november 2000 


\title{
Curriculum vitae
}

\author{
A.E.J.M. van den Bogaard
}

\section{4}

Geboren op 11 januari te Tilburg.

\section{2}

Diploma Gymnasium-B, Gymnasium "Katwijk de Breull" te Zeist.

$$
1962-1968
$$

Studie diergeneeskunde aan de Faculteit Diergeneeskunde van de Rijksuniversiteit Utrecht.

$$
1969-1970
$$

Praktiserend dierenarts te Tilburg.

$$
1970-1972
$$

Associate expert virologist. Proyecto de investigacion sobre la rabia paralytica (paralytische rabiës met de veermuis: Desmodus rotundus als reservoir), FAOUNDP, Mexico D.F., Mexico.

$$
1973-1974
$$

Expert epizooriologist Rinderpest eradication programme, FAO-UNDP, Kabul, Afghanistan.

$$
\text { Januari } 1975 \text { - september } 1975
$$

Seminar fur Tropenveterinärmedizin, Freie Universität Berlin. Diplomate in tropical veterinary medicine (DTVM)

$$
1975
$$

\section{September 1975 - juli 1976}

Postgraduate course in clinical microbiology: Diploma in bacteriology (DipBact(Lon)), London School of Hygiene and Tropical Medicine, University of London.

$$
1976
$$

Wetenschappelijk medewerker bij de Capaciteitsgroep Medische Microbiologie van de Faculteit der Geneeskunde te Maastricht.

\section{7}

Wetenschappelijk hoofdmedewerker bij de Capaciteitsgroep Medische Microbiologie en dierenartsmicrobioloog bij de dienst Centrale Proefdier Voorzieningen (CPV) van de Rijksuniversiteit Limburg

$$
1976-1986
$$

Geven van onderwijs aan de Faculteir der Geneeskunde te Mastricht in de Medische Microbiologie, blokcoordinator, jaarcoördinator van het derde en vierde studiejaar en lid van de examen commissie.

$$
1986 \text { - heden }
$$

Geven van post academisch onderwijs.

$$
\text { 1985-beden }
$$

Gelukkig gehuwd met Valerie Dekkers.

$$
\text { 1986- heden }
$$

Proefdierdeskundige van de Universiteit Mastricht. Hoofd dienst Centrale Proefdier Voomieningen. Universitair Hoofddocent Vakgroep Medische Microbiologie.

$$
1986-1990
$$

Lid bestuur Nederlandse Vereniging Vergunninghouders Dierproeven (NVVD).

$$
1990-1998
$$

Voorzitter van de afdeling Limburg van de Koninklijke Nederlandse Maatschappij voor Diergeneeskunde (KNMVD).

$$
1991-1996
$$

Voorzitrer Diergeneesmiddelen Advies Commissie (DAC) van de KNMvD.

$$
1991 \text { - heden }
$$

Lid van de Antibioticum Beleidscommissie en formularium-commissies van de KNMvD. 
1991

Registratie op uitnodiging als specialist veterinaire microbiologie.

\section{1-heden}

Secretaris van de Dier Experimenten Commissie (DEC) van de UM.

$$
1997 \text { - beden }
$$

Lid van de Werkgroep Resistentie Surveillance van de Stichting Werkgroep Antibiotica Beleid (SWAB).

Lid Commissie Antimicrobiele Groeibevorderaars van de Gezondlheidsraad.

\section{8}

Lid van het "Scientific Steering Committee on Antimicrobial Resistance" van de Europese Commissie, Directorate B - Scientific Health Opinions. Brussel.

$$
1999 \text { - beden }
$$

Lid van het "Committee for the Containment of Antimicrobial Resistance due to Antimicrobial Use in Animals intended for Food", WHO Consultation on Global Principles for the Containment of Antimicrobial
Resistance. Wereldgezondheidsorganisatie (WHO), Genève, Zwitserland.

$$
1997 \text { - heden }
$$

Participating partner in Europese samenwerkingswerbanden. FAIR5-CT97-3709: Epidemiology and ecology of enterococci, with special reference to antibiotic resistant strains in animalls, humans and the environment. FAIR973654: Antibiotic resistance in bacteria from animal origin.

Lid van de wetenschappelijke redactie van:

- Veterinary Microbiology

- The Veterinary Quarterly

- Nederlands Tijdschrift woor Diergeneeskunde

\section{Co-promotor:}

P.A.M. van Leeuwen. Ammonia generation in the gut and the influence of lactulose and neomycin. Proefschrift Maastricht, 1985.

N. London. Antibiotic resistance in the non-hospital environment. Proefschrift Maastricht, 1995.

R. Kuske - Nijsten. Antibiotic resistance in humans and pigs. Is there a relation? Proefschrift Maastricht, 1995. 


\section{List of publications}

Bijlenga, G., and Bogaard, A.E.J.M. van den. (1973). In wivo enhancement of rabies infection by diethylamino-erhyldextran. Arch. Gesamm. Virusforschung 42: 96-101.

Postmes, Th.J., M. Hukkelhoven, Bogaard, A.E.J.M. van den, Halders, S.G, and Coenegracht, J. (1980). Passage through the blood-brain barrier of thyrothropin-releasing hormone encapsulated in liposomes. f. Pharm. Phamacol. 32: 722-724.

Bogaard, A.E.J.M. van den, Weidema, W.F, and Hazen, M.J. (1981). A bacteriological evaluation of three methods of bowell prepararion for elective colorectal surgery. Antonie varn Leeuwenboek 47: 86-88.

Bogaard, A.E. I.M. van den, Boven, C.P.A. van, and Weidema, W.F. (1981). Whole gut irrigation with antibiotics recommended as preparation for colorectal surgery. Curr. Antibiotic Ther. 5: 6-7.

Bogaard, A.E.J.M. van den, Maes, J.H.J., and Simons, H.P. (1982). Behandeling met zilversulfadiazine-creme van chronische Psendomonas infecties van de uitwendige gehoorgang bij de hond. Tijdschr. Diengeneesk. 107: 224-228.

Hazen, M.J., and Bogaard, A.E.J.M. wan den. (1982). Anaeroben en gaschromatografie. Analyse 37: 355-358.

Bogaard, A.E., .M. van den. (1982). Ovario-hysterectiomie bij de hond 1. Tijdschr. Diengenesesk 107: 147-149 (correspondence).

Bogaard, A.E.J.M. van den. (1982). Ovario-hysterectomie bij de hond II. Tijdscbr. Diergenesk. 107: 191-192 (correspondence).

Bogaard, A.E.J.M. van den, and Hazen, M.J. (1983). The detection of obligate anaerobic bacteria in swine abscesses. A comparison between gas-liquid chromarography and bacteriological culturing methods. Veterinary Micrabiology 8: 389-396.

Walther, F.J., Bruggeman, C., Grauls, G., Stals, F., and Bogaard, A.E.J.M. van den. (1983). Symptomaric and asymptomatic rotavirus infections in hospitalised children. Acta Patdiatr. Scand. 72 : $659-663$.

Thijssen, H.H.W., Bogaard, A.E.J.M. van den, Wetzel, J.H., Maes, J.H.J. and Muller, A.P. (1983). Warfarin pharmacokinetics in the horse. Am. J. Vet Res. 44: 1192-1196.

Jongsma, F.H.M., Bogaard, A.E.J.M. van den, Gemer, M.J.C. van, and Hulsbergen-Henning, J.P. (1983). Is closure of open skin wounds in rats accelerated by Argon-laser exposure? Lasers in Surgery and Medicine 3: 75-80.
Hazen, M.J, and Bogaard, A. E.J.M. van den. (1983). Anatoben en gaschromatografie. Analyse 38:13-17.

Soeters, P.B. Leeuwen, P.A.M. wan, Janssen, M.A., Boer, J.E.G. de, Goossens, H.M., Eyl, H.A.M. van, Brombacher, P. Jonge, H. de, and Bogaard, A.E.J.M. vari den. (1984). Merabolic generation. of ammonia and amino acids in the intestinal wall and the inthence of neomycin and lactulose, pp. 147-154. Ln: Kleinberger, G., Ferenci, P., Riederer, P., Thaler, H. (eds.), Advances in Hepatic Encephaloparhy and Urea Cycle Diseases. Karger, S., Basel.

Leeuwen, P.A.M. van, Bogaard, A.E.J.M. wan den, Janssen, M.A., Boer, J,E.G. de, Eyk, H. van, and Soeters, P.B. (1984). Ammonia producrion and glutamine metabolism in the small and large intestine of the rat and the influence of lactulose and neomycin. $p$. 154-163. In: Kleinberger, G., Ferenci, P., Riedterer, P., Thaler, H. (eds.), Advances in hepatic encephalopathy and urea cycle diseases. Karger, S., Basel.

Bogaard, A.E.J.M. van den. (1984). Antibiotische profylaxe in de chirurgie van het kleine huisdier. Tijdschr. Diergenees. 109: $61.6-627$.

Thijssen, H.H.W., Baars, L.G.M., Hazen, M.J. and Bogaard, A.E.J.M. van den. (1984). The role of the intestinal microlora in the reductive metabolism of acenocoumarol in man. Btit. $\mathrm{f}$. Clin. Pharmac. 18: $247-249$.

Bogand. A.E.J.M. wan den. (1984). Inclusion ketraconjuncrivitis in sheep. A proposition of a new name and a comment on recent clinical trials. Vetermary Quarterly 6: 229 235 .

Bogaard, A.E.J.M. van den, Maes J.H.J, and Engels, W". (1984). Een nieuwe behandelingsmogelijkheid voor honden met chronische of recidiverende pyodermieèn. Tiydochr. Diergentesk. 109: $978-986$.

Bogaard, A.E.J.M. van den, Bohm, R.O.B., and Weidema, W.I., (1985). Antimikrobielle Prophylaxe in der Veteninătchirurgie. Der praktische Tieraret 4: $287-294$.

Bogaard, A.E.J.M. van den, and Weidema, W.F. (1985). Antimicrobial prophylaxis in canine sungery. J. Small Animal Practice: 26: 257-266.

Bogaard, A.E.M. van den, and Weidema, W.t. (1985). Antimicrobial prophylaxis in veterinary surgery. JAVMA 186 : 990-992. 
Bogand, A.E.M.M. wan den, Dam, E. van, and Weckers, F.H. (1985). Her gebruik van een koolzuurgas euthanasie apparaat voor ratten. Biotechniek $24: 34-38$.

Slangen F.M.A., Simons, M.P.s and Bogard, A.EJ.M. wan den. (1985). Een fruatie box voor schapen en geiten. Biotechnick 24: $22-24$

Bogaard, A.E.I.M. van den. (1985). Inclusion keratoconjunctivitis ("pink eye $e^{\text {"w }}$ in sheep. 1SVA-News Letter 7: 15-2\%.

Leeuwen, P.A.M. van, Keeman, J.N, Butzelaar, R.M.I.M., and Bogaard, A.E.M.M. van den. (1985). The correlation berween a positive galbladder culture and subsequent wound infection after billary surgery. A retrospecriwe study of 840 pathents. Neth. 7 . Surg. 37: 179-182.

Bogaand, A.E.JM. wan den, and Gool, F.J.J.E. (1985). Antibioprophylaxe en chimurgie veterinaire. Bull. Sor. Prat de France $69: 435-450$.

Bogaand, A. E.I.M. wan den, "Thifsen, H.W.W., and Hemker, H.C. (1985). De behandeling van podotrochleose met orale ancicoagulantia. Een bijstuirer gewenst. Tijdschr. Diergeneeste. 110: 585.600

Bogaard, A.E.J.M. van den. (1985). Het CAF van het koren scheiden. Tijotschr. Diengenesk. 110: 670-671 (letter).

Weidema, W.F., Bogaard, A.E.J.M. van den, Wesdorp, R.L.C., Boven, C.P.A. wan, and Greep, J.M. (1985). 24 Hour systemic antimicrobial prophylaxis widt gentamicin and metronidawole or metronidwole alone, in elective colorectal surgery after mechanical bowel preparation with mantitol and whole gut irrigation. Acta Chin Bug. 85: 349-353.

Bogatard, A.E.J.M. wan den, Hazen, M.J., and Boven, C.P.A. wan. (1986). Quantitative gaschromarographic analysis of volatile fatty acids in spent culture media and body huids. J. Clin. Mionobiol. 23: $523-530$

Bogarard, A.E.J.M. van den, Weidema, W.F., Boven, C.P.A. van, and Waaij, D. van de. (1986). Recolonisation and collonisation resistance of the large bowel after three methods of preoperative preparation of the gastrointestinal tract. J. Hyg. (Cambr) 97: $49-59$.

Herman, P.T.D. Hazen, M.J., and Bogard, A.E.J.M. van den. (1986). Gevoeligheidsbepaling van obligaat anaerobe bacteriën. I. Andyse 41:249-314.

Herman, P.T.D., Hazen, M. J, and Bogaard, A.E.J.M. van den. (1986). Gevoeligheidsbepaling van obligat anaerobe bacterien. II. Analyse 41: $311-314$.
Bogaard, A.E.M.M. van den, and Böhm, R.O.B. (1986). Silyersulfadiazine creme als Therapie bei chronischen Psodomonas Infektionen des äusseren Gehörganges des Hundes. Der pratktische Therdtat $11: 963-966$.

Leeuwen, P.A.M. van, Drukker, J, Kleyn, N.W. wan der, Bogaard, A.E.J.M. van der, and Soerers, P.B. (1986). Morphological effects of high dose neomycin sulphate on the small and large intestine. Acta Morphol. Neerl. Siand. 24: 223-234.

Bogaard, A.E.J.M. wan den, Smeets, F.A.M., Slangen, F.A.M., and Muytiens, A. (1986). Real time ultrasound pregnancy testing in ewes and estimation of fetal age. Europ. J. Obstet. Gynecol. Reporod. Biol. 20: 266-267.

Walther, F.J., Blanco, C.E., and Bogaard, A.E.J.M. van den. (1986). Combined high. frequency oscillatory and intermittent positive pressure ventilation in saline lavaged rabbirs. Europ. 1 . Obstet. Gynecol. Reprod. Biol. 20:259-261.

Bogaard, A.E.J.M. van den, and Hazen, M.J. (1987). "The derection of obligate anaerobic bacteria in udder secretions of dry cattle with mastitis during summer: A comparison berween gas-liquid chromatography and bacteriological culturing methods. Veterinary Microbiology 14: 173-182.

Bogaard, A.E.J.M. van den. (1987). A comparison of the agar dilintion merhod for susceptibility testing of obligate anacrobic bacteria and a new method: the spirall gradient agat dilution test. Antonie vaw Leewitwerwoek 53: 208-210.

Berlo, C.L.H.y Jonge, H.R. de, Bogaard, A.E.J.M. wan den, Eijk, H.M.H. var, Janssen, M.A., and Soeters, P.B. (1987). $\gamma$ Aminobutyric acid production in small and large intestine of normal and germ-free Wistar rats. Influence of food intalke and intestinal Hota. Gatroesterology 93: 472-479.

Veche, U, Wisselink, H.J, Sol, J., and Bogaard, A.E.I. M. van den. (1987). The bacteriological constitution of Dutch Summer Mastitis Cases, pp. 56-77. In: Thomas, G., Vecht, U., Nansen, P. (eds.). Summer mastitis: Current Topics in Veterinary Medicine and Animal Science vol. 45, Marrinus Nijhof Publishers, Dordrecht.

Bogaard, A.E.J.M. wan den, Veche, U., and Sol, J. (1987). Gaschromatographic analysis of summer masrit is secretions for the presumptive diagnosis of infections by obligate anaerobic bacteria, p. 63-67. In: Summer Mastitis. Current Topics in Veterinary Medicine and Animal Science vol. 45. Martinus Nijhof Publishers, Dordrecht.

Bruggeman, C.A., Bruning, J.H., Grauls, G., Bogard, A.E.J.M. van den, and Bosman, $\mathrm{F}$. (1987). Presence of cytomegalovirus in brown fat. Study in a rac model. Intervirology $27: 32-37$. 
Leeuwer, P.A.M. van, Bogaard, A.E.I.M. wan den, Hazen, M.J., Janssen, M.A.s and Soeters, P.B. (1988). The effect of intestinal flora modulation on ammonia production in the rat intestine. FEMS Microbiology Letters 49: 59-64.

Van Berlo, C.L.H., Bogaard, A.E.J.M. van den, Bost, M.C.F., and Soeters, P.B. (1988). A technique to study splanchric metabolism in the unrestrained conscious pig. Laboratom Animal Science 38 : $463-466$

Bogaard, A.E.J.M. van den. (1988). Antimicrobial prophylaxis in vererinary surgery. Ret. Portug. Clienc. Veter. 133: 377-389.

Bogaard, A.E.J.M. van den. (1988). Dierenartsen, let op uw saeck. Tijdshr. Diergenesk. 113:1261-1264 (correspondence).

Bogaard, A.E.J.M. van den. (1988). The importance of laboratory data for a rational ancimicrobial therapy in veterinary practice. Tajdschr. Diergeneesk. 113: 1135-1165.

Bogaard, A.E.J.M. van den. (1988). Een beschouwing over de zin en onzin van gevoeligheidsbepalingen voor de diergeneeskundige praktijk. Tijdschr. Diergeneesk 113: 921-932.

Bogaard, A.E.J.M. wan den, and Boven, C.P.A. van. (1988), Hoofdstuk 24: Infectiezielten: Bacteriën, pp. 903 - 936. In: Diagnose en Therapie (editors: Hulsman, H.A.M., Rahn, K.H, en Boven, C.P.A. van), Kooyker Scientific Publications B.V, Leiden.

Bogaard, A.E.J.M. van den, and Boven, C.P.A. valn. (1988). Hoofdstuk 25: Infecrieziekren: Spirocheren pp. 937 - 948. In: Diagnose en Therapie (edirors: Hulsman, H.A.M., Rahn, K.H. en Bowen, C.P.A. van), Kooyker Scientific Publications B.V., Leiden.

Bogaard, A.E.J.M. van den, and Boven, C.P.A. van. (1988). Hoofdstuk 28: Infectieziekten: Schimmels, pp. 995 - 1006 . In: Diagnose en Therapie (editors: Hulsman, H.A.M., Rahn, K. H. en Boven, C.P.A. van), Kooyker Scientific Publications B.W., Leiden.

Bogaard, A.E.J.M. van den. (1988). Comments on the use on antimicrobial agents for veterinary purposes. Tijalschr. Diergeneesk. 113: 1261-1264 (correspondence).

Bogaard, A.E.J.M. van den. (1989). Medicamenteuze haemostase 1. De behandeling van bloedingen en bloedingsneigingen in de diergeneeskundige praktijk. Tijdschr. Diergeneerk. 114: 136-145.

Bogaard, A.E.).M. van den. (1989). Medicamenteuze haemostase II. Systemische haemostarica, een kritische evaluatie. $T_{i j d}$ lshr. Diergeneesk 1.14: 145-149.

Berlo, C.L.H, van, Bogaard, A.E.J.M. van den, Heijden, M.A. van der, Eijk, H.M. van, Bost, M.C.F, and Soerers, P.B. (1989). Is increased ammonia liberation after bleeding in the digestive track the consequence of complere absence of isolewcine in haemoglobin? Heportalogy 10: 315-523.
Bogaard, A. E.J.M. van der. (1989). Bacteriology of bite wounds. Veterinaty Qwatterly 1149:985-995.

Bogaard, A.E.J.M., wan den, Hazen, M.J. and Maes, J.H. (1989). Rapid presumprive diagnosis of anacrobic infections in animals by gas-liquid chromatography, Am. J. Ver. Ra. 50: 1454-1459.

Bogaand, A.E.J.M. van den, and Nohimans, M.K.E. (1990). Lyme borreliosis in domestic animals; the siturtion in the Netherlands. Veterimary Quarterly 1150:565-585.

Parka, P., Bogaard, A.E.J.M. wan den, and Wesdorp, R.I.C. (1990). De behandeling van honde- en katwebeten. Ned Tijdebr. Genewsh 134: $995-998$.

Hazen, M.J, and Bogaard, A.E.M.M. van den. (1990). Commercielle idencificario systemen nor obligat anderobe bacteriën. Analye 45: 132-139.

Bogaard. A.E.J.M van den. (1990). Peritonitis in adult horses. Vetrimaly Recond 127:387-388 (leter).

Nohlmans, M.K.E., Boer, R de, Bogaard, A. E.J.M. van den, Blaaww A.A.M. and Boven C.P.A. van. (1990), Voorkomen wan Borrelia burgdorferi in Nodes ricinus in Nederland. Ned Thdshr. Geneested. 134: 1300-1303.

Boer, R. de, Nohlmans, M.K.E. and Bogaard, A.E.J.M. van den. (1990). Nederlandse reken als overbrengers van infecrieziekren. Ned. Tijdschr. Genceskd 134: 1295-1299.

Stals, F.S., Bogaand, A.E., M. van den, and Bragemath, C. (1990). Selective bowel decontamination and the incidence of bacteratemia in irradiated and cytomegalovirus infected tats. Microcology and Therapy $20.153-156$

Ericzon, B.G., Wijnen, R.M.H., Kubota, K., Bogaard, A. wan den, and Kootstra, G. (1991). Diabetes ind terion and pancreacic cransplancation in the cynomolgus monkey: nethodological considerarions. Transtam International 4: 103-109.

Bogard, A.E. J.M. wan den. (1991). De deskundige gok: afwegingen bij de keuze van antibiotica in de diergeneeskunde. Tijolschr. Diergeveesk. 116:860-863.

Postmes, Th. Bogard, A.E. J.M. van den, and Hazen, M. (1991). De bacteriostarische werking van natumhoning. Amalye 12: $240-243$

Bogaard, A.E.l.M. wan den. (1991). Good weterinary practices Tijdsch. Diergeneesk. 116:922-923 (correspondence).

Noldmans, M.K.E., Bugaard, A.E.J.M. van den, Blaaw, A.A.M., and Boven, C.P. van. (1991). Prewalence of lyme borthliosis in whe Neherlands. Ned. Tijolsckr. Geneeshd 135:2288-2292. 
Leunisen, H.D.M, Vos, M.A., Gorgels, A.P.M., Bogarar, A.E.J.M. van den, and Wellens, H.J. (1991). Het gebrulk wan de wakkere hond om mechanismen van hartitmestroonissen te bestuderen: beschrijwing van een diemodel. Biotechnele 30: 10-14.

Blaaw, I, Nohlmans, M.K.E., Bogaard, A.E. J.M. wan den, and Linden Sj. van der. (1992). Diagnostic rools in Lyme borreliosis: clinical history compared with scrology. J. Clin. Epidemiol. 4 : 1229-1236.

Bogaard, A.E.J.M. wan den, Hazen, M.J, and Kriele, C.P.M.A. (1992). Rationale for treatment of retained placenta in cows with neomycin and metronidazole. Veterinary Record. 130:349-350.

Faasen, A. wan, Hazen, M.), Brandx, P.A wan den, Bogaard, A.E.J.M. van den, Hermus, R.J.J., and Janknegt, R.A. (1993). Bile acid and $\mathrm{pH}$ walues in total feces and in faecal water from habirually omniworous and vegetarian subjects. Am. fo Clin. Nutr. 58: $917-922$

London, N., Nijsten, R., Bogaard, A.E.J.M. van den, and Stobberingh, E. (1993). Antibioric resistance of faecal entretobackeriacene isolated from healthy volunteers; a 15 week follow-up study. J. Antimicrab. Chemother. 32: 83-91.

Boev, R. de, and Bogard, A.E. .M. van den. (1993). Removal of atrached nymphs and adults of Ixodes ricinus (Acari: Ixodidae). I. Med. Entomol 30: 748-752.

Bogaard, A.E.J.M. van den. (1993). A veterinary antibiotic policy: a personal wiew on the perspectives in the Netherlands. Verewinary Microbiology $35: 303-312$

Nijisten, R. London, N., Bognard, A.E.J.M, wan den, and Stobberingh, E. (1993). Antibiotic resistance of enterobacteriaccac isolated from the faecal flora of fattening pigs. Vetwriary Quarerly 15: $152: 156$

Postmes, Th, Bogaard, A. wan den, and Haxen, M. (1993). Honey for wounds, ulcers, and skin grafe preservation. Lancet 341 : $756-757$ (letren).

Bogard, A.E.J.M. van den. (1993). Een veterinair antibioticumbeleid. Tyjdots. Diergeneesh 118:565-568.

Yin, M., Booster, M.H., Bogaard, A. E. J.M. van den, and Kootstra, G. (1994). A simple technique to harwest two kidneys from one donor rat for transplantation. Labowary Animals 25:387-390.

Kuiper, J.D., and Bogaard, A.E.J.M. wan den. (1994). Verdoser versie 2-1: Een database met doseringen en indicaries woot het diergeneeskundig gebruik van ancibiotica. ISBN 90-75195-01-X.

Hoenderken, R., Lambooy, B., Bogaard, A.E.J.M. van den, and Hillebrand, S.J.W. (1994). Tierschntzgerechte Gasbetaubung won Geflugel. Fleischwinch. 74: 497-500.
Faasen, A van, Bogaard, A.E.J.M. van den, Hazen, M.I., and Janknege, R.A. (1994). Effects of a calcium binder on the solubility of bille acids and fatry acids in the large intestine of the rat. Caver Letuers 81:77-80.

Stals, F.S., Bogaard, A.E.J.M. van den, and Bruggeman, C.A. (1.994). Prevention of bacteraemia by systemic ciprofloxacin treatment in rat cytomegallowirus-infected immunocompromised tats. $J$. Antimicrob. Chemother. 34: 101-110.

Bogaard, A.E.J.M. wan den, Breeuwsma, A.J., Julicher, C.H.M., Mostert, A. Nieuwenhuijs, J.H.M. Vaarkamp, H., Verhoef, J, and Vulto, A. (1994). Een vererinair antibioticumbeleid: aanbevelingen van een werkgroep. Tijdschr. Diergerseesk. 119: 160-183.

London, N., Nijsten, R., Mertens, P., Bogaard, A.E.J.M. wan den, and Stobberingh, $E_{\text {. }}$ (1994). Effects of antibiotic therapy on the antibiotic resistance of Faecal Escherichia coli of patients attending general practitioners. J. Antimicrob. Chemother. 34: 239-246.

Nijsten, R., London, N., Bogaard, A.E.J.M. van den, and Stobberingh, E. (1994). Resistance in faecal Escherichio coll isolated from pig farmers and abattoir workers. Epidem. Infect. 113:45-52

London, N., Nijsten, R., Bogaard, A.E.J.M. van den, and Stobberingh, F. (1994). Carriage of antibiotic-resistant Escherichia coli by healthy volunteers during a 15 week period. Infection 22: 187-192.

Nohlmans, M.K.E., Boer, R. de, Bogaard, A.E.M.M. wan den, and Boven, C.P.A. van. (1994). Evaluation of nine serological rests for diagnosis of lyme borreliosis. Europ. J. Clin. Microbiol. Infect. Du. 13: $394-400$.

Nohtmans, M.K.E., Boer, R, de, Bogaard, A.E.J.M. wan den, and Boven, C.P.A. wan. (1995). Genorypic and phenotypic analysis of Bormelin burgdofferi isolates from the Netherlands. I. Clin. Microbiol 33: 119-125.

Mckenna, P. , Clement, J., Dijck, D. van, Lauwerys, M., Carey, D., and Bogaard, A.E.J.M. van den. (1995). Canine Lyme disease in Belgium. Veterinary Record 136: 244-247.

Postmes, Th., Bogaand, A van den, and Hazen, M. (1995). The sterilization of honey with cobalt 60 gamma radiation. A study of honcy spiked with spores of Clostridium botulimum and Bacillus subtilis. Experimewria 51: 986-989.

Nijsten, R., London, N., Bogaard, A.E. van den, and Srobberingh, E. (1995). In-viwo transfer of resistance plasmids in rat, human or pig-derived intestinal flora using a rat model. J. Antimicrob. Chemother. 36: $975-985$.

Nijsten, R., London, N., Bogaard, A.E.J.M. wan den, and Stobberingh, $\mathbb{E}$. (1996). In-vitro transfer of antibiotic resistance 
between faecal Eschertichio colis strains isolated from pig farmers and pigs. J. Antimicrob. Chemorther, 37:1141-1154.

Faassen, A. wan, Bogaard, A.E. van der, Hazen, M. J., Geerlings, P., and Janknegr, R.A. (1996) Effects of Calcisorb on faecal bile acids and fatty acids in human wolunteers. Dig. Dis. Sit. 41: $2319-2325$.

Bogaard, van den AE.J.M. (1996). Endocarditis bij veulens, microbiologisch onderzoek essentieel voor stellen diagnose en woor adequate therapie. Tijdschr. Diergenesk. 121:626-627 (cortespondencel.

Have, G.A.M. ten, Bost, M.C.F., Suyk-Wierts, J.C.A.W., Bogaard, A.E.J.M. van den., and Deutz, N.E.P. (1996). Simultaneous measurement of metabolic flux in portally-drained viscera, liver, spleen, kidney and hindquarter in the conscious pig. Latboratory Asrmals 30: 347-358.

Kleinjans J.C., Moonen, E.I. Dallinga, J.W., Bogaard, A.E. wan den, and Schooten, F.J. (1996) Polycyclic aromatic hydrocarbons in whiskies. Lancet 348: 1731 (letter).

Heurn, van L.W.E., Bogaard, A.E.J.M. wan den, Rootstra, G., and Brink, P.R.G. (1996). Percutaneous dilatational versus conventional open tracheotomy in a growing animal: a study in goats. $J$. Pediatr. Surg. 31-11: 1512-1515.

Bogaard, van den A.E., and Stabberingh, E.E. (1996). Is it rime to ban all antibiotics as animal growth-promoting agents? Lancet 348: 619 (letrer).

Bogaand, van den A.E., and Srobberingh, E. E. (1996). It is wime to ban all antibiotics as animal growth-promoting agencs! Authors reply. Lancet 348: 1454 1455 (correspondence).

Overduin, L.M., and Bogaard, A.E.J.M.van den. (1997). Lyme borreliose bij de hond. Tijdschr. Diergeneesk 122: 7-9.

Overduin, L.M., and Bogard, A.E.J.M. wan den. (1997). Enige opmerkingen over Lyme borreliose bij de hond. Tijdschr. Diergenesste. 122:281 (correspondence).

Bogaard, A.E.J.M. wan den (1997). Antimicrobial resistance - relacion to human and animal exposure to antibiorics. I. Antimicrob. Chemother. 40: 453-454.

Bogaard, A.E.J.M. wan den, Mertens, P. London, N.H., and Srobberingh, E.E. (1997). High prevalence of colonisation with vancomycin- and pristinamycin-resistant enterooocci in healry humans and pigs in the Netherlands: is the addition of antibiotics to animal feeds to blame? J. Antimicrob. Chermother. 40: 454-456.

Bogaard, A.E. van den, Jenssen, L.B., and Stobberingh, E.E. (1997). Vancomycin-resistant enterococci in rurkeys and farmers. N. Eng. J. Med. 337: 1558-1559 (correspondence).
Tiel F.H. wan, and Bogard. A.E wan den. (1997). In-vitu suscep. ribility to LY333328 of wancomycin-resistant enterococi isolated from humans and animals. J. Amtiwicrob. Chemothes: $40: 733-746$.

Bogaard, A.E.J.M. van den (1997). Antibiorica: Gencesmiddelen of varkenswoer? Tijdshts. Diewgeweeskd. 122: 722-724.

Mijten, P., Bogaard. A.E.J.M. wan den, Hazen, M.I., and Kruif, A. de (1997). Bacterial contamination of feral fluids at the rime of cesarean section in the cow. Theriogenology 48: 513-521.

Kaarsemaker, Sj., Walenkamp, G.H.I.M., and Bogatard, A.E.J.M. van den. (1997). New model for chronic osteomyelicis wirh Suphylococus anrew in sheep. Clinical Orthopated 339:246-252.

Nijhuis, P., Bogaard, A.E.J.M. van den, Daemen, M. $y_{\text {, }}$ and Baeten, C.G. (1998). Perianal injection of polydimethylsiloxane (Bioplastique implants) paste in the treatment of soiling. Dis. Colon Rectum 41-5: 624-629.

Landman, A.J.M., Bogaand, A.E.J.M. wan den, Doornenbal, P., Tooten, P.C.J, Eibers, A.R.W., and Gruys, E. (1998). The role of various microbial agents in chicken amyloid arthropathy. Amyloid 5: $266-278$.

Jensen, L.B., Hammerum, A.M., and Bogaard, A.E. wan den. (1998). Occurrence of sati and togb gencs in streptogramin-resistant Enterococos factum isolates of animal and human origins in the Netherlands. Antimicrabial Agents and Chemotheraty 42: $3330-3331$.

Bogaand, A.E.J.M. van den. (1998). Streng in de leer of roomster dan de paus? Tijdschr. Diepreneesh. 123:206-207 (cotrespondence).

Piersma, F.E., Daemen, MA.R.C., Bogaard, A.E.M. vali den. and Butrman, W.A. (1999). Interference of pair control employing opioids in in who indrunological expeniments. Latbond tory Arimals 33:328-333.

Bogaard, A.E. van den, and Srobberingh, E.E. (1909). Antibionic usage in animals - Impact on bacterial resistance and public health. Drugs 58:589-607.

Bogaard, A.E. wan den, and E. E. Stobberingh. (1999). Contamination of animal feed by multiresistant enterococci. Lancet 354:163 (letter).

Stobberingh, E., Bogaard, A. E. van den London, N., Driessen, $C_{.}$ Top. I., and Willems $\mathbb{R}$ (1999). Enterococci with glycopeptide resistance in rurkeys, rurkey farmers, turkcy slaughterers, and (sub)urban residents in the Sourh of the Nerherlands: Evidence for transmission of vancomycin resistance from animals to humans? Antimicrob. Agetws Chemother. 43: 2215-2221.

Goossens, H.A.T, Nohlmans, M.K.E., and Bogaard, A.E. wan den. (1999). Epstein-Barr virus and cytomegalovirus infections cause 
false-positive resuls in lgM two-test protocol for early Lyme borreliosis. Infection 27: 231 .

Goossens, H.A.T., Bogaard, A.E. van den and Nohlmans, M.K.E. (1999). Evaluarion of fifteen commercially avalable serologicat tests for diagnosis of lyme bortellowis. Europ. J. Chrt Mirobiol Infect. Dis. 18:551-560.

Bogaard, A.E. wan den, and Stobberingh, E.E. (1999). Antibiotics in animal feeds and the emergence and disgemination of bacterial resistance in man, pp $51-60$ in Antibiotic therapy and control of antimicrobial resistance in hospirals. Andremont, A.s C. Brun-Buisson and J.E. McGowan Jr.(eds), Maurice Rapin Colloquia, Elsevier, Paris.

Haroche, J, Allignet, I., Aubert, S., Bogaard, A.E. wan den, and El-Solh, N. (2000). Sat $G$, conferring resistance to streptogramin $A$, is widely distributed in Enterococus factim straing bur not in staphylococci. Antimicrob. Agents Cbemother. 44: 190-191.

Stobberingh, E. E., and Bogaard, A.E. van den. (2000). Spread of antibiotic resilstance from food animals to man. Artat Veterinarita Suandinavica Suppl. 93:47.52.

Bogaard, A.E. van den, and Srobberingh, E.E. (2000). Epidemiology of resistance to antibiotics - Links between animals and humans. International Journal of Antimicrabial Agents 14:327-335.

Bogaard, A.E.J.M. van den, London, N., and Stobberingh, E.E. (2000). Antimicrobial resistance in pig faecal samples from the Nerherlands (five abartoirs) and Sweden. If Antwicrob. Chemother. $45: 663-671$.

Weil, E.H., Ruiz-Cerda, J.L., Bogaard, A.E. wan den, and Kerrebroeck, P.E van. (2000). Novel test lead designs for sacral nerve stimulation: improved fxarion in an animal model. $/ .4 \mathrm{r}$. 164: $551-555$

Bogaand, A.E van den, Bruinsma, N., and Stobberingh, EE. (2000). The effect of banning avoparcin on VRE carriage in the Netherlands. /. Antimicrob. Chemather. 45: 146-148.

Goossens, H.A.T., Bogaard, A.E van den, and Nohlmans, M.K.E. (2000). Reduced specificity of combined IgM and IgG enzyme immunoassay testing for Lyme borreliosis. Eurr. J. Clin. Mrorobiol. Infect. Dis. 19: $400-402$.

Willems, R. J. L., Top, J., van den Brak, N., van Belkum, A., Endez, H., Mevius, D., Srobberingh, E, Bogatard, A. van den, and Embden, J.D.A. van. (2000). Host specificity of vancomycinresiscant Enterococous faecium. Joumal of Infectious Diseases 182: $816-823$

Cormican, M., Collignon, P., and Bogaard, A.E. van den. (2000). The benefirs of "risk-benefit assessment". Lancet 1356: 1190 (letter).

Berends, B.R., Bogaard, A.E van den, Knapen, F. wan, Bergwerf, A. and Snijders J.M.A. (2001). Consumer risks of residues of tetracyclines in Dutch pork. Veterinary Quarterly (in press).

Berends, B.R., Bogaard, A.E van den, Knapen, $\mathbb{F}_{\text {, wan, and Snijders }}$ J.M.A. (2001). An appraisal of consumer risks of resistant bacteria on pork. Veterinary Quarterly (in press).

Goossens, H.A.T, Nohlmans, M.K.E., and Bogaard, A.E. van den. (2001) Serodiagnosis of Lyme borreliosis using derection of different immunoglobulin (sub)classes by enzyme linked immunosorbent assay and Western blotting Chnical Laboratory (in press).

Goossens, H.A.T, Bogaard, A.E. van den, and Nohlmans, M.K.E. (2001). Dogs as sencinels for human I yme borreliosis in the Nerherlands. Jouryal of Clinical Microbiology (accepted for publication). 